\title{
CONVERSÃO DO PROCESSO KRAFT EM SODA-DDA (SAL DI- SÓDICO DE 1,4-DIHIDRO-9,10-DIHIDROXI ANTRACENO) PARA MADEIRA DE EUCALIPTO
}

\section{FRANCIDES GOMES DA SILVA JÚNIOR \\ Engenheiro Florestal}

Orientador: Prof. Dr. Luiz Emesto George Barrichelo

Dissertação apresentada à Escola Superior de Agricultura "Luiz de Queiroz", da Universidade de São Paulo, para obtenção do título de Mestre em Ciências. Área de Concentração: Ciência e Tecnologia de Madeiras

PIRACICABA

Estado de São Paulo - Brasil

Julho - 1994 


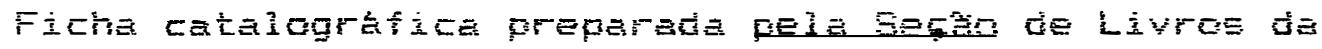

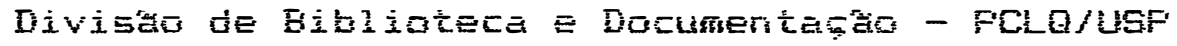

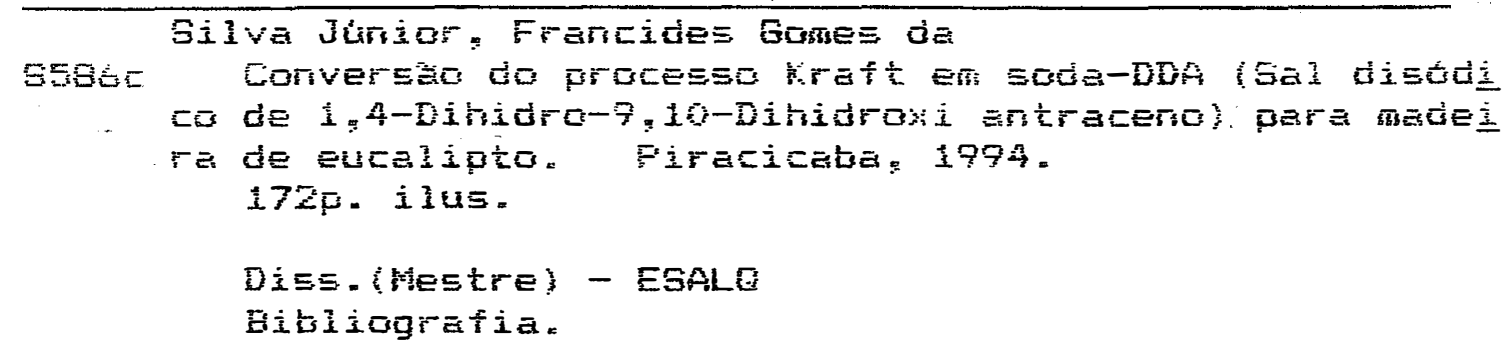

$\operatorname{CDS} \quad 675.12$ 


\title{
CONVERSÃO DO PROCESSO KRAFT EM SODA-DDA (SAL DI- SÓDICO DE 1,4-DIHIDRO-9,10-DIHIDROXI ANTRACENO) PARA MADEIRA DE EUCALIPTO
}

\author{
FRANCIDES GOMES DA SILVA JÚNIOR
}

Aprovada em: 13.09.1994

Comissão julgadora:

Prof. Dr. Luiz Ernesto George Barrichelo ESALQ/USP

Dr. Celso Edmundo Bochetti Foelkel Riocell S.A.

Dr. José Mangolini Neves CTCP/IPT

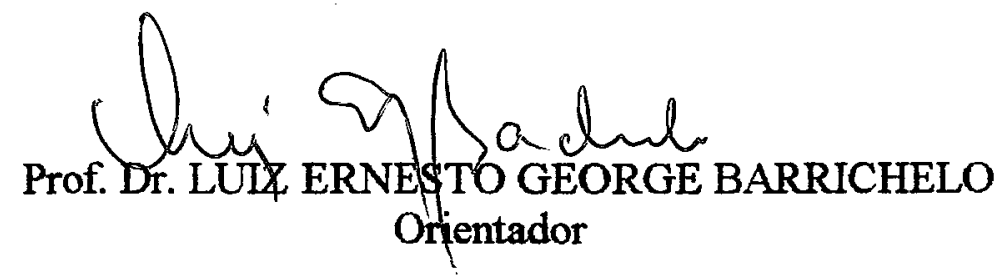


Aos meus pais, Francides e Yara, que com amor, dedicação e exemplos, mostraram-me o caminho ...

À minha esposa, Isabel, que tem me acompanhado incondicionalmente nesta caminhada ...

Ao meu irmão, Flávio, pelo carinho ...

À Divina Mãe, para que nossos passos sejam justos e retos ... 


\section{Agradecimentos}

Ao Professor Dr. Luiz Ernesto George Barrichelo, pela orientação, apoio, amizade e confiança.

Aos Professores Dr. Ivaldo Pontes Jankowsky e Dr. José Otávio Brito pelo apoio como coordenadores do Curso de Pós-graduação em Ciência e Tecnologia de Madeiras.

A Escola Superior de Agricultura "Luiz de Queiroz" e ao Departamento de Ciências Florestais pela oportunidade.

As empresas Mitsubishi Corporation do Brasil S. A. e Champion Papel e Celulose S. A pelo fornecimento do material.

A empresa CELPAV pelo apoio e auxilio na parte experimental.

A Fundação de Amparo à Pesquisa do Estado de São Paulo FAPESP - pelo suporte financeiro necessário a realização do trabalho.

A técnica Maria Regina Bush e aos estagiários do Setor de Química, Celulose e Energia pela colaboração recebida nas diversas fases do trabalho.

A secretária Beatriz Regina Duarte Novaes pelo apoio.

Aos colegas do Departamento de Ciências Florestais e a todos que direta ou indiretamente colaboraram para realização deste trabalho. 


\section{Sumário}

Lista de Tabelas

vii

Lista de Figuras

$\mathrm{xi}$

Resumo

xvii

Summary

xix

1. Introdução

01

2. Revisão Bibliográfica

2.1. O processo kraft de produção de celulose

2.2. Utilização de aditivos aos processos alcalinos de produção de celulose

2.3. Compostos quinônicos como aditivos para processos alcalinos de produção celulose

2.4. Utilização do sal di-sódico de 1,4-dihidro-9,10-dihidroxi antraceno em processos alcalinos de produção de celulose

2.5. Utilização de antraquinona em processos alcalinos de produção de celulose

3. Material e Métodos

3.1. Material

3.2. Métodos

3.2.1. Caracterização do material

3.2.1.1. Dimensões dos cavacos 
3.2.1.3. Determinação da composição quimica

3.2.1.4. Caracterização morfológica das fibras

3.2.2. Otimização de paràmetros de cozimentos

3.2.2.1. Cozimentos testemunhas

3.2.2.2. Determinação da dosagem ótima de DDA

3.2.2.3. Otimização do álcali ativo

3.2.2.4. Otimização do tempo à temperatura máxima de cozimento

3.2.2.5. Avaliação do efeito da sulfidez

3.2.3. Parâmetros determinados para cada cozimento

3.2.3.1. Determinação do fator $H$

3.2.3.2. Determinação de rendimento e número kappa

3.2.3.3. Refino da celulose

3.2.3.4. Formação de folhas

3.2.3.5. Ensaios físico-mecânicos

3.2.3.6. Alfa, beta e gama celulose

3.2.3.7. Teor de pentosanas

3.2.3.8. Teor de lignina residual 
3.2.3.10.Teor de sólidos do licor negro

3.2.3.11. Teor de matéria-orgânica do licor negro

3.2.3.12. Álcali ativo residual do licor negro

3.2.3.13. Viscosidade do licor negro

4.1. Caracterização do material

4.1.1. Dimensões dos cavacos

4.1.2. Densidade básica

4.1.3. Composição química básica

4.1.4. Dimensões de fibras

4.2. Cozimentos testemunhas

4.3. Determinação da dosagem ótima de DDA

4.4. Determinação da carga alcalina

4.5. Determinação do tempo à temperatura máxima 


\section{Lista de Tabelas}

Tabela 1. Resultados das análises de dimensões de cavacos de Eucalyptus grandis

Tabela 2. Composição química dos cavacos de $E$. grandis

Tabela 3. Valores médios das dimensões das fibras de $E$. grandis

Tabela 4. Rendimento bruto e depurado, teor de rejeitos dos cozimentos testemunhas para fator $\mathrm{H}$ de 677

Tabela 5. Número kappa, viscosidade, lignina residual e relações

Tabela 6. Teor de pentosanas e alfa, beta e gama celuloses

Tabela 7. Propriedades físicas e mecânicas da celulose do tratamento 1 - kraft convencional

Tabela 8. Propriedades físicas e mecânicas da celulose do tratamento 2 - soda-AQ

Tabela 9. Propriedades físicas e mecânicas da celulose do tratamento 3 - soda convencional

Tabela 10. Análises de licor negro dos tratamentos 1,2 e 3

Tabela 11. Rendimento bruto e depurado, teor rejeitos para fator $\mathrm{H}$ igual a 677

Tabela 12. Número kappa, viscosidade, lignina residual e relações

Tabela 13. Teor de pentosanas e alfa, beta e gama celuloses dos tratamentos 4 , 5,6 e 7 
Tabela 14. Propriedades físicas e mecânicas da celulose do tratamento 4 soda- $0,04 \%$ DDA

Tabela 15. Propriedades físicas e mecânicas da celulose do tratamento 5 soda- $0,06 \% \mathrm{DDA}$

Tabela 16. Propriedades físicas e mecànicas da celulose do tratamento 6 soda $-0,08 \% \mathrm{DDA}$

Tabela 17. Propriedades fisicas e mecânicas da celulose do tratamento 7 soda- $0,10 \% \mathrm{DDA}$

Tabela 18. Análise de licor negro dos tratamentos $4,5,6$ e 7

Tabela 19. Rendimento bruto e depurado, teor de rejeitos para fator $\mathrm{H}$ igual a 677

Tabela 20. Número kappa, viscosidade, lignina residual e relações

Tabela 21. Teor de pentosanas e alfa, beta e gama celuloses dos tratamentos $8,9,10$ e 11

Tabela 22. Propriedades físicas e mecànicas da celulose do tratamento 8 soda- $0,04 \%$ DDA - álcali ativo $12 \%$

Tabela 23. Propriedades físicas e mecânicas da celulose do tratamento 9 soda- $0,04 \%$ DDA - álcali ativo $13 \%$

Tabela 24. Propriedades físicas e mecânicas da celulose do tratamento 10 soda- $0,04 \% \mathrm{DDA}$ - álcali ativo $14 \%$ 
Tabela 25. Propriedades físicas e mecânicas da celulose do tratamento 1 soda- $0,04 \% \mathrm{DDA}$ - álcali ativo $15 \%$

Tabela 26. Análise de licor negro dos tratamentos $8,9,10$ e 11

Tabela 27. Rendimento bruto e depurado, teor de rejeitos e fator $\mathrm{H}$

Tabela 28. Número kappa, viscosidade, lignina residual e relações

Tabela 29. Teor de pentosanas e alfa, beta e gama celuloses dos tratamentos $12,13,14$ e 15

Tabela 30. Propriedades físicas e mecânicas da celulose do tratamento 12 soda- $0,04 \%$ DDA - álcali ativo $13 \%$ - fator H 215

Tabela 31. Propriedades físicas e mecânicas da celulose do tratamento 13 soda- $0,04 \%$ DDA - álcali ativo $13 \%$ - fator H 369

Tabela 32. Propriedades físicas e mecânicas da celulose do tratamento 14 soda- $0,04 \%$ DDA - álcali ativo $13 \%$ - fator H 522

Tabela 33. Propriedades físicas e mecânicas da celulose do tratamento 15 soda- $0,04 \%$ DDA - álcali ativo $12 \%$ - fator $\mathrm{H} 677$

Tabela 34. Análises de licor negro dos tratamentos $12,13,14$ e 15

Tabela 35. Rendimento bruto e depurado, teor de rejeitos para fator $\mathrm{H}$ igual a 522 
Tabela 36. Número kappa, viscosidade, lignina residual e relações

Tabela 37. Teor de pentosanas e alfa, beta e gama celuloses dos tratamentos $16,17,18,19,20$ e 21

Tabela 38. Propriedades físicas e mecânicas $\mathrm{da}$ celulose do tratamento 16 $0 \%$ de sulfidez

Tabela 39. Propriedades físicas e mecânicas da celulose do tratamento 17 $5 \%$ de sulfidez

Tabela 40. Propriedades físicas e mecânicas da celulose do tratamento 18 $10 \%$ de sulfidez

Tabela 41. Propriedades físicas e mecânicas da celulose do tratamento 19 . $15 \%$ de sulfidez

Tabela 42. Propriedades físicas e mecânicas da celulose do tratamento 20 $20 \%$ de sulfidez

Tabela 43. Propriedades fisicas e mecânicas da celulose do tratamento 21 $25 \%$ de sulfidez

Tabela 44. Análise do licor negro dos tratamentos $16,17,18,19,20 \mathrm{e}$ 21 


\section{Lista de Figuras}

Figura 1. Representação esquemática da quebra das ligações fenil-éter da lignina

Figura 2. Fórmula estrutural do DDA

Figura 3. Representação esquemática da forma de atuação do DDA em cozimentos alcalinos

Figura 4. Fórmula molecular da antraquinona

Figura 5. Representação esquemática da forma de atuação da antraquinona em cozimentos alcalinos

Figura 6. Distribuição de porcentagem em peso e porcentagem em peso acumulada para classes de comprimento de cavacos de Eucalyptus grandis

Figura 7. Distribuição de porcentagem em peso e porcentagem acumulada para classes de largura de cavacos de Eucalyptus grandis

Figura 8. Distribuição de porcentagem em peso e porcentagem em peso acumulada para classes de espessura de cavacos de Eucalyptus grandis

Figura 9. Número kappa, viscosidade e rendimento depurado das celuloses obtidas nos tratamentos 1,2 e 3 
Figura 10. Relação rendimento depurado / kappa e viscosidade/kappa

Figura 11. Grau de refino em função do número de revoluções (moinho PFI)

Figura 12. Espessura em função do grau de refino

Figura 13. Peso especifico aparente em função do grau de refino

Figura 14. Volume específico aparente em função do grau de refino

Figura 15. Índice de tração em função do grau de refino

Figura 16. Esticamento em função do grau de refino

Figura 17. Índice de estouro em função do grau de refino

Figura 18. Índice de rasgo em função do grau de refino

Figura 19. Resistência à passagem de ar em função do grau de refino

Figura 20. Teor de sólidos e álcali ativo residual dos tratamentos 1,2 e 3

Figura 21. Número kappa, viscosidade e rendimento depurado das celuloses em função da dosagem de DDA utilizada

Figura 22. Relação rendimento depurado / kappa e viscosidade/kappa em função da dosagem de DDA utilizada 
Figura 23. Grau de refino em função do número de revoluções (moinho $\mathrm{PFI})$

Figura 24. Espessura em função do grau de refino

Figura 25. Peso específico aparente em função do grau de refino

Figura 26. Volume específico aparente em função do grau de refino

Figura 27. Índice de tração em função do grau de refino

Figura 28. Esticamento em função do grau de refino

Figura 29. Índice de estouro em função do grau de refino

Figura 30. Índice de rasgo em função do grau de refino

Figura 31. Resistência à passagem de ar em função do grau de refino

Figura 32. Teor de sólidos e álcali ativo residual em função da dosagem de DDA empregada nos cozimentos

Figura 33. Número kappa, viscosidade e rendimento depurado das celuloses em função do álcali ativo

Figura 34. Relação rendimento depurado / kappa e viscosidade/kappa em função do álcali ativo 
Figura 35. Grau de refino em função do número de revoluções (moinho PFI)

Figura 36. Espessura em função do grau de refino

Figura 37. Peso específico aparente em função do grau de refino

Figura 38. Volume específico aparente em função do grau de refino

Figura 39. Índice de tração em função do grau de refino

Figura 40. Esticamento em função do grau de refino

Figura 41. Índice de estouro em função do grau de refino

Figura 42. Índice de rasgo em função do grau de refino

Figura 43. Resistência à passagem de ar em função do grau de refino

Figura 44. Teor de sólidos e álcali ativo residual em função do teor do álcali ativo

Figura 45. Número kappa, viscosidade e rendimento depurado das celuloses em função do fator $\mathrm{H}$

Figura 46. Relação rendimento depurado / kappa e viscosidade/kappa em função do fator $\mathrm{H}$

Figura 47. Grau de refino em função do número de revoluções (moinho PFI) 
Figura 48. Espessura em função do grau de refino

Figura 49. Peso especifico aparente em função do grau de refino

Figura 50. Volume especifico aparente em função do grau de refino

Figura 51. Índice de tração em função do grau de refino

Figura 52. Esticamento em função do grau de refino

Figura 53. İndice de estouro em função do grau de refino

Figura 54. Índice de rasgo em função do grau de refino

Figura 55. Resistência à passagem de ar em função do grau de refino

Figura 56. Teor de sólidos e álcali ativo residual em função do fator $\mathrm{H}$

Figura 57. Número kappa, viscosidade e rendimento depurado das celuloses em função do nível de sulfidez

Figura 58. Relação rendimento depurado / kappa e viscosidade/kappa em função do nivel de sulfidez

Figura 59. Grau de refino em função do número de revoluções (moinho PFI) 
Figura 60. Espessura em função do grau de refino

Figura 61. Peso específico aparente em função do grau de refino

Figura 62. Volume específico aparente em função do grau de refino

Figura 63. Índice de tração em função do grau de refino

Figura 64. Esticamento em função do grau de refino

Figura 65. Índice de estouro em função do grau de refino

Figura 66. Índice de rasgo em função do grau de refino

Figura 67. Resistência à passagem de ar em função do grau de refino

Figura 68. Teor de sólidos e álcali ativo residual em função do nível de sulfidez 


\title{
CONVERSÃO DO PROCESSO KRAFT EM SODA-DDA (SAL DI- SÓDICO DE 1,4-DIHIDRO-9,10-DIHIDROXI ANTRACENO) PARA MADEIRA DE EUCALIPTO
}

\author{
Autor: Francides Gomes da Silva Júnior \\ Orientador: Luiz Ernesto George Barrichelo
}

\section{Resumo}

Neste trabalho buscou-se converter o processo kraft de produção de celulose de Eucalyptus grandis em processo soda através da adição de 1,4-dihidro9,10-dihidroxi antraceno (DDA). Além da redução/eliminação da sulfidez, procurouse diminuir a carga alcalina e o consumo de energia sem prejudicar as características do processo e a qualidade da celulose.

Na etapa de otimização da dosagem de DDA pôde-se concluir que $0,04 \%$ de DDA é a dosagem que apresenta os melhores resultados tanto para o processo como para as características da celulose; com esta dosagem foi possível reduzir a carga alcalina de 14 para $13 \%$ (cerca de $7 \%$.).

Fixados os níveis de DDA e álcali ativo, obteve-se uma redução do fator $\mathrm{H}$ da ordem de $20 \%$ sem comprometer a qualidade da celulose e as características do processo.

$\mathrm{Na}$ última etapa do trabalho foi avaliado o efeito da sulfidez em cozimentos de Eucalyptus grandis com $0,04 \%$ de DDA, álcali ativo de $13 \%$ e fator $H$ de 522. Nesta etapa observou-se que a sulfidez apresenta efeitos benéficos, principalmente sobre a viscosidade; no entanto, o nivel de sulfidez ideal ficou entre 5 e $10 \%$. 
O DDA apresentou efeito bastante pronunciado em cozimentos soda e kraft de Eucalyptus grandis, permitindo reduzir a carga de reagentes (especialmente sulfeto de sódio) e consumo de energia sem afetar significativamente a qualidade da celulose ou os parâmetros do processo. A redução da sulfidez representa um grande avanço no sentido de reduzir os impactos ambientais provocados pelas fábricas de celulose kraft. 


\title{
CONVERSION OF THE KRAFT PROCESS IN SODA-DDA (DI-SODIUM SALT OF 1,4-DIHYDRO-9,10-DIHYDROXIANTHRACENE) FOR EUCALYPTUS
}

\author{
Author: Francides Gomes da Silva Júnior \\ Adviser: Prof. Dr. Luiz Ernesto George Barrichelo
}

\section{Summary}

In this research was investigated the possibility of convert the kraft pulping process of Eucalyptus grandis in soda process by the addition of disodium salt of 1,4-dihydro-9,10-dihydroxianthracene (DDA). Besides the reduction/elimination of sulfidity, was looked for the reduction of the alkalinity charge and energy consumption without prejudice the process characteristics and pulp quality.

In the stage of determination the best level of DDA was concluded that $0,04 \%$ of DDA was the level that showed the best results for the process characteristics and also for the pulp; with this level was possible to reduce alkaline charge from 14 to $13 \%$ (approximately $7 \%$ ).

After have fixed the levels of DDA and active alkaly, was reached a reduction in the $\mathrm{H}$ factor near to $20 \%$ without prejudice the pulp quality and process characteristics.

On the last stage of this research was evaluated the effect of sulfidity on Eucalyptyus grandis cookings with $0,04 \%$ of DDA, active alkaly of $13 \%$ and $\mathrm{H}$ factor of 522. On this stage was observed that sulfidity have a beneficial effect. specially for the pulp viscosity; however, ideal sulfidity level was between 5 and $10 \%$. 
DDA shows good effects in soda and kraft pulping process of Eucalypius grandis allowing the reduction of chemical charge (specially sulfidity) and energy consumption during cooking without damage the pulp quality or process characteristics. The sulfidity reduction represents a great advance in the reduction of the enviromental impacts caused by kraft pulp mills. 
CONVERSÃO DO PROCESSO KRAFT EM SODA-DDA (SAL DISÓDICO DE 1,4-DIHIDRO-9,10-DIHIDROXI ANTRACENO) PARA MADEIRA DE EUCALIPTO

\section{Introdução}

No cenário mundial, o Brasil se destaca como sendo o maior produtor mundial de celulose de eucalipto. Tal fato se deve basicamente ao desenvolvimento da tecnologia dos processos de produção, fazendo com que a celulose produzida a partir desta matéria-prima atingisse padrões internacionais de qualidade, e consequentemente conquistasse mercados até então fechados para a celulose de fibra curta de eucalipto.

A importância do Brasil, neste particular, deve se consolidar, uma vez que estão sendo implantadas novas unidades de produção e as unidades já existentes estão ampliando a sua capacidade de produção.

Paralelamente às expectativas de crescimento da produção nacional de celulose, tem aumentado o sentimento ecológico mundial no sentido de manter intactos e proteger o maior número possível de ecossistemas.

As fábricas de celulose são caracterizadas por causar grandes impactos ao meio ambiente, notadamente aos recursos hídricos e atmosféricos. Tal fato se deve basicamente à utilização de compostos alcalinos e compostos de enxofre no processo de produção, impedindo, muitas vezes, que estas 
indústrias sejam instaladas próximas a centros urbanos. Estes fatores, associados aos aspectos econômicos, tem levado as indústrias e instituições ligadas ao setor a realizarem pesquisas no sentido de minimizar o impacto ao meio ambiente e permitir o aumento da produtividade industrial, contribuindo assim para uma economia de recursos naturais.

Dentro deste panorama, uma linha de pesquisa que tem apresentado grandes potencialidades é a de uso de aditivos químicos que aumentem a eficiência das reações de polpação.

Os aditivos que tem apresentado maior eficiência são os compostos quinônicos, e entre eles merece destaque a antraquinona, já utilizada em vários países, tais como Japão, Finlândia, Estados Unidos, Espanha, Brasil, entre outros. A antraquinona apresenta como grande inconveniente a sua baixa solubilidade no licor de cozimento, fazendo-se necessário o desenvolvimento de sistemas que permitam uma distribuição uniforme deste aditivo no digestor, uma vez que desta uniformidade dependerá a eficiência da antraquinona.

Um outro composto que também apresenta grande potencialidade como aditivo ao processo de polpação é o sal di-sódico de 1,4-dihidro-9,10dihidroxi antraceno (DDA), que se apresenta na forma líquida e é solúvel no licor de cozimento, facilitando sobremaneira a sua distribuição nos digestores. Este composto tem sido amplamente utilizado em escala industrial no Japão.

Desde a descoberta da influência benéfica que os compostos quinônicos apresentam sobre as reações de polpação, vários estudos tem sido realizados em laboratórios do mundo inteiro, visando entender e quantificar o efeito dos compostos quinônicos sobre o processo de produção de celulose. Tais 
estudos, em alguns paises, já saíram da fase laboratorial para serem utilizados em escala industrial.

O uso de compostos quinônicos tem se mostrado bastante eficiente no aumento do rendimento dos processos industriais de produção de celulose, na redução do consumo de reagentes químicos, principalmente os compostos de enxofre e na economia de energia.

A utilização de compostos quinônicos nas indústrias brasileiras certamente trará beneficios de ordem econômica e ambiental, uma vez que a utilização de tais compostos possibilitam a redução significativa da utilização de reagentes quimicos e consequentemente a descarga de seus resíduos no meio ambiente.

Dentro deste enfoque faz-se necessário que sejam conduzidos estudos mais detalhados sobre a utilização de compostos quinônicos (antraquinona e DDA), aplicados à realidade brasileira. Este trabalho tem por objetivo converter o processo kraft de produção de celulose de Eucalyptus grandis em processo Soda-DDA. Com isto, além da redução/eliminação da sulfidez, procurar-se-á diminuir a carga alcalina e o consumo de energia com aumento do rendimento do processo, sem contudo reduzir a qualidade da polpa produzida. Desta forma, espera-se fornecer subsídios para uma alteração gradual do processo produtivo atualmente empregado pela maioria das empresas produtoras de celulose no Brasil. 


\section{Revisão Bibliográfica}

\subsection{O processo kraft de produção de celulose}

O processo kraft de produção de celulose se originou do processo soda pela introdução de sulfeto de sódio com o objetivo de diminuir a carga alcalina e melhorar as características da celulose. Entretanto, a formação de compostos de enxofre, característicos do processo kraft, causa poluição odorífica, impossibilitando sua utilização em algumas indústrias, principalmente as localizadas em perimetros urbanos e suas proximidades (GOMIDE et al., 1987).

O processo kraft apresenta várias vantagens sobre outros processos de polpação como alta qualidade da polpa, eficiência de recuperação de reagentes químicos e de energia e a possibilidade de utilizar praticamente todos os tipos de madeira. Entretanto, apesar dessas características, seus baixos rendimentos, juntamente com fatores econômicos e ambientais têm constituído grandes desafios para o desenvolvimento de processos mais vantajosos ou para a modificação do atual processo. O simples aumento de 3 - 5\% no rendimento constituiria substancial melhoria econòmica do atual processo kraft (GOMIDE, 1980).

Uma desvantagem do processo kraft consiste na ineficiente utilização do álcali. Apenas cerca de $30 \%$ do álcali empregado no processo são utilizados na degradação e solubilização da lignina, sendo o restante consumido na 
solubilização de polissacarídeos e neutralização dos ácidos orgânicos formados. $O$ uso ineficiente do álcali resulta na necessidade de utilização de elevada carga alcalina no digestor, o que, por sua vez, requer grande capacidade dos equipamentos de recuperação, aumentando, assim, significativamente o custo total do capital investido (GOMIDE, 1980).

O processo kraft tem como uma de suas principais caracteristicas a alta qualidade da celulose obtida. Esta qualidade é avaliada basicamente pelo teor de lignina residual (número kappa); grau de degradação dos carboidratos (viscosidade) e propriedades físico-mecânicas. No entanto, estas características podem ser alteradas de acordo com algumas variáveis do processo produtivo tais como: carga alcalina, tempo e temperatura de cozimento, entre outros.

O álcali efetivo utilizado em cozimentos alcalinos apresenta efeito sobre a composição de carboidratos na polpa celulósica. $O$ aumento do álcali efetivo leva à redução do teor de $\alpha$ e $\delta$-celuloses e a um aumento do teor de $\beta$ celulose em licores soda e kraft sem diferença significativa entre os dois processos. Este aumento no teor de $\beta$-celulose reflete a degradação de carboidratos de cadeia longa e tem como consequência a redução da resistência à tração expressa através do zero-span (EACHUS, 1983).

No processo kraft cerca de $20 \%$ dos polissacarídeos da madeira são perdidos. Esta perda é especialmente alta para glucomanana (a qual está presente na madeira na forma de galactoglucomananas) bem como para celulose. A degradação dos polissacarídeos da madeira inicia-se pela redução dos grupos terminais das cadeias (despolimerização terminal primária). Novos grupos redutores são gerados após hidrólise alcalina das cadeias de polissacarídeos e inicia-se então a despolimerização terminal secundária. Estas reações de 
degradação acontecem principalmente durante o período de aquecimento do digestor. A degradação dos polissacarídeos leva a formação de uma mistura complexa de ácidos não voláteis bem como ácido acético e ácido fórmico (SJÖSTRÖM, 1977).

As perdas de celulose devidas às reações de despolimerização terminais (cerca de 65 monômeros) podem ser consideradas pequenas tendo em vista o alto grau de polimerização (8000 - 10000) da celulose nativa; no entanto a hidrólise das ligações glucosídicas resulta no fracionamento das cadeias de polissacarídeos, exercendo desta forma, forte influência sobre o grau de polimerização dos carboidratos. Deve-se ressaltar que as reações de hidrólise das ligações glucosídicas ocorrem principalmente nas temperaturas máximas de cozimento, ou seja, 160 a $180^{\circ} \mathrm{C}$ (GOMIDE, 1979).

Em estudos sobre a viscosidade de polpas alcalinas de madeira KUBES et al. (1984) observaram que agentes aceleradores de deslignificação como a antraquinona e o sulfeto de sódio não tem efeito sobre a viscosidade da polpa quando os demais parâmetros do processo (álcali efetivo, tempo e temperatura de cozimento) são mantidos constantes. Os autores observaram que a viscosidade é determinada por 3 parâmetros: álcali efetivo, tempo e temperatura de cozimento, sendo o primeiro o mais importante. Com este trabalho os autores concluiram que a viscosidade é altamente dependente da carga alcalina e não da espécie de madeira.

Em todos os processos químicos de produção de celulose para papel, as variáveis tempo e temperatura de deslignificação são da máxima importância, pois afetam diretamente a taxa de remoção de lignina e a qualidade do produto final (MARQUES et al., 1979). 
Conforme afirmado anteriormente o tempo e a temperatura de cozimento são duas variáveis de fundamental importância no processo kraft. Estas variáveis se relacionam de forma inversa, ou seja, quanto maior a temperatura, menor o tempo de cozimento, e vice-versa. Na tentativa de se relacionar tempo e temperatura de cozimento em uma única variável, foi desenvolvido o fator $\mathrm{H}$

Segundo BUGAJER et al. (1979), o fator $\mathrm{H}$ é uma variável que relaciona o tempo e a temperatura de cozimento, foi desenvolvido por VROOM em 1957 e desde então tem sido utilizado pelas indústrias de produção de celulose. O seu valor representa a área sob a curva obtida pela velocidade relativa de reação de deslignificação em função do tempo e para o cálculo do fator $\mathrm{H}$, utilizam-se valores de velocidades relativas obtidas para Picea sp, pois o valor da energia de ativação para a reação de deslignificação, que é utilizada no cálculo da velocidade relativa, foi obtida em experimentos com Picea sp.

Leon (1977) e Pacini (1979) citados por BUGAJER et al. (1979) indicaram em seus trabalhos que o limite de deslignificação para Eucalyptus saligna de 6 anos é atingido com um fator $\mathrm{H}$ de aproximadamente 700 .

Em estudos realizados para verificar a influência da taxa de aquecimento em cozimentos com mesmo fator $\mathrm{H}$ sobre a qualidade da polpa celulósica, BUGAJER et al. (1979), concluíram que para cozimentos com Eucalyptus saligna com 6 anos, intervalo de temperatura máxima compreendido entre 160 e $170^{\circ} \mathrm{C}$ e fator $\mathrm{H}$ de 600 , o rendimento depurado diminui acentuadamente, cerca de 5\%, com o aumento da temperatura máxima, ou seja, o teor de rejeitos aumenta. O número kappa aumenta cerca de 2 pontos com o aumento da temperatura máxima; estes resultados podem ser explicados pelo fato de que nos cozimentos realizados a $170^{\circ} \mathrm{C}$ o tempo não foi suficiente para que 
houvesse penetração e difusão do licor de cozimento nos cavacos e para que as reações de deslignificação ocorressem até o mesmo grau que nos cozimentos a $160^{\circ} \mathrm{C}$, mais prolongados.

MARQUES et al. (1979) em seus experimentos, concluiram que celuloses kraft branqueáveis de eucalipto podem ser obtidas com maiores rendimentos depurados e maiores resistências à tração e arrebentamento, quando a deslignificação for conduzida a temperaturas baixas $\left(160^{\circ} \mathrm{C}\right)$, por mais longo tempo à temperatura máxima de cozimento.

No processo kraft, fundamentalmente destrutivo, a separação da celulose é conseguida pela dissolução da lignina e das hemiceluloses, resultando em uma perda total de aproximadamente $50 \%$ de matéria orgânica que forma o licor negro em conjunto com os reagentes químicos utilizados no processo (REDKO \& SILVA, 1979).

Embora de uma importância inquestionável, pois quase metade do vapor das modernas fábricas de celulose kraft e mais de $95 \%$ do álcali empregado são recuperados do licor negro, este é relativamente pouco conhecido no que diz respeito as suas características (ZVINAKEVICIUS et al., 1979)

Segundo REDKO \& SILVA (1979) o licor negro é um sistema pouco conhecido e a identificação de seus componentes é caracterizada por dificuldades analíticas.

Dentre as características do licor negro destaca-se a viscosidade por ser um fator importante no cálculo de tubulações, seleção de bombas, estimativa de coeficientes de transferência de calor e influi, inclusive, no custo de energia para bombeamento de licores. Altas viscosidades favorecem também problemas de incrustações nos evaporadores com reflexos na economia energética do sistema, 
além de, em alguns casos, impedir a utilização de sistemas indiretos de evaporação até concentrações superiores a 60-65\% de sólidos (ASSUMPÇÃO et al., 1983). Segundo este autor a viscosidade do licor negro depende do teor de sólidos, da natureza dos componentes dissolvidos e da temperatura.

O licor negro oriundo do processo de produção de celulose kraft é concentrado e queimado para recuperação de reagentes químicos e energia. No caso do licor negro de eucalipto a concentração é prejudicada pela elevada viscosidade do licor, muito superior à ocorrente durante a concentração do licor negro de pinus (REDKO \& SILVA, 1979).

Os problemas causados pelo aumento da viscosidade começam a aparecer a partir de $30 \%$ de teor de sólidos no licor e como este deve ser concentrado de $12 \%$ até no mínimo $55 \%$ de teor de sólidos para a queima, grande parte do sistema de evaporação está sujeita a depósitos e a bloqueamento, com a consequente perda de rendimento energético, causando atrasos no processo para limpeza e manutenção (REDKO \& SILVA, 1979).

Em suas pesquisas com licor negro kraft de Eucalyptus spp., ASSUMPÇÃO et al. (1983) observaram que a quantidade de álcali ativo residual variou de 3,0 a 6,0\% sobre sólidos secos.

O processo kraft apresenta como uma de suas características emissões aéreas poluentes, que incluem tanto gases mal-cheirosos como material particulado. As principais contribuições para o odor típico do processo são os gases de enxofre reduzido (TRS), como: sulfeto de hidrogênio $\left(\mathrm{H}_{2} \mathrm{~S}\right)$, metil mercaptana $\left(\mathrm{CH}_{3} \mathrm{SH}\right)$, dimetil sulfeto $\left(\mathrm{CH}_{3} \mathrm{SCH}_{3}\right)$ e dimetil dissulfeto $\left(\mathrm{CH}_{3} \mathrm{SSCH}_{3}\right)$. Além desses, colaboram as emissões de óxidos de enxofre $\left(\mathrm{SO}_{\mathrm{x}}\right)$ e óxidos de nitrogênio $\left(\mathrm{NO}_{\mathrm{x}}\right)$. As emissões de particulados constituem-se de 
sulfato e carbonato de sódio ou cálcio, em sua maior parte. Tanto o $\mathrm{H}_{2} \mathrm{~S}$ como os sulfetos orgânicos são extremamente odorosos e detectáveis pela sensibilidade olfativa em concentrações de ppb. Assim o odor é o principal problema ambiental de fábricas de celulose (FOELKEL et al., 1983).

A formação de compostos mal-cheirosos é proporcional à quantidade de grupos metoxilas. Nas madeiras de coníferas há uma predominância de unidades guaiacil, enquanto que nas madeiras de folhosas, há uma predominância de unidades siringil. Deste modo, em uma folhosa haverá relativamente mais grupos metoxílicos do que em uma conífera; logo, no processo de polpação kraft, forma-se maior quantidade de compostos odorificos com folhosas do que com coníferas (D'ALMEIDA, 1985).

A mudança de mentalidade com relação aos aspectos ambientais, especialmente nos que dizem respeito a legislação sobre emissões aéreas, tem aumentado o interesse por processos de polpação que não utilizam compostos de enxofre (EVANS et al., 1983).

A melhor maneira de se eliminar os gases mal cheirosos é eliminar completamente do processo de produção de papel, os compostos à base de enxofre (KAWASAKI KASEI CHEMICAL, 1979).

O processo soda poderia ser um bom substituto para o processo kraft se o grau de deslignificação, o rendimento e a qualidade da polpa alcançassem os níveis da polpa kraft (BARBADILLO \& POTTI, 1982).

Segundo GOMIDE \& OLIVEIRA (1980), devido à ação da antraquinona, o processo soda- $A Q$, em condições otimizadas de cozimento, poderá vir a constituir alternativa viável para os problemas de poluição atmosférica do 
processo kraft, uma vez que as fábricas de celulose têm sofrido crescentes pressões relacionadas com os aspectos de poluição ambiental.

O processo soda-AQ tem recebido grande ênfase nos últimos anos, uma vez que representa solução fundamental para os problemas odoríficos do processo kraft (GOMIDE, 1980).

Para Worster (1979), citado por GOMIDE (1980), as principais características de um "processo ideal de polpação":

- ser livre de sulfetos inorgânicos capazes de formar compostos odoríficos de enxofre;

- não utilizar ácidos ou bases fortes, que causariam degradação dos carboidratos e, consequentemente, baixos rendimentos;

- ser capaz de solubilizar grande parte da lignina ou modificá-la quimicamente, de tal modo que a lignina transformada possa contribuir para as características desejáveis da polpa, e ao mesmo tempo, causar apenas pequena perda de celulose e hemiceluloses;

- não utilizar cozimentos de multiestágios nem condições de pressão, de temperatura e de tempo mais altas que as empregadas nos processos atuais;

- utilizar um eficiente sistema de recuperação, mais simples que o do kraft, sem, entretanto, criar condições perigosas para a segurança;

- não causar poluição ao meio ambiente.

Modificaçães do processo kraft, ou um novo processo, só poderão realmente desafiar a atual superioridade desse processo se proporcionarem redução do custo de capital, eliminação de compostos de enxofre, bons rendimentos, polpa de alta qualidade e, finalmente, compatibilidade com os atuais 
equipamentos e operações de tal modo que a conversão possa ser realizada com um mínimo de modificações industriais (GOMIDE, 1980).

\subsection{Utilização de aditivos aos processos alcalinos de produção de celulose}

Segundo GOMIDE et al. (1987) o uso de aditivos que aumentem a eficiência das reações de polpação, possibilitando a diminuição da carga alcalina, sem causar poluição odorifica é uma alternativa que apresenta potencial técnico.

Geraimente, os reagentes considerados eficazes para a melhoria do rendimento kraft, como o boridreto de sódio e a hidrazina, não são comercialmente aconselháveis em razão de seu alto custo. Os polissulfetos e bissulfetos são também eficazes na melhoria do rendimento e poderiam ser comercialmente utilizados graças a seus baixos custos, mas não são aconselháveis pois agravam a poluição ambiental (GOMIDE, 1980).

Nas temperaturas altas de cozimentos alcalinos utilizando-se boridreto de sódio ocorre uma reação lateral de decomposição:

$$
\mathrm{NaBH}_{4}+2 \mathrm{NAOH}+\mathrm{H}_{2} \mathrm{O} \rightarrow \mathrm{Na}_{3} \mathrm{BO}_{3}+4 \mathrm{H}_{2}
$$

Com isso há uma perda de boridreto que é um produto caro, há formação de hidrogênio, que eleva a pressão do digestor e se constitui em perigo pois é explosivo (FOELKEL, 1978).

Segundo FOELKEL et al. (1980) o boridreto de sódio $\left(\mathrm{NaBH}_{4}\right)$ no cozimento kraft de Eucalyptus urophylla levou a um ganho de rendimento acima de $2 \%$ base madeira . 
Uma das maiores dificuldades em desenvolver aditivos aos processos de polpação é que muitos compostos de interesse não são estáveis nas condições de polpação (WRIGHT \& FULLERTON, 1984).

NOMURA (1974) pesquisou 26 diferentes compostos com características potenciais para utilização como aditivo na polpação kraft. A escolha do aditivo mais eficaz foi baseada em dois critérios: potencial redox do aditivo e aditivo com estrutura eneciiol. Nessa pesquisa foi verificado que a hidroxiantraquinona, a diidroxiantraquinona, a tetraidroxiantraquinona e o diidroxiantraceno, com potenciais redox inferiores ao da antraquinona, apresentaram ligeira superioridade sobre a antraquinona na deslignificação e no rendimento e os mesmos resultados na resistência das polpas.

HOLTON (1978) estudou cerca de 300 compostos como aditivos a processos de polpação e de uma forma geral, o autor concluiu que os compostos quinônicos se constituem em aditivos bastante efetivos em cozimentos alcalinos. Segundo o autor, as benzoquinonas produzem efeito negativo e as naftoquinonas se revelam eficientes porém menos que as antraquinonas.

Bach \& Fiehn (1972) citados por BARBADILLO \& POTTI (1982) verificaram que a adição de pequenas quantidades (menos de 1-2\%, base madeira) de antraquinona monossulfato de sódio (AMS) em cozimentos soda e kraft de Pinus resultavam em aumento do rendimento, decréscimo do teor de rejeitos e melhoria de deslignificação, sem causar nenhum efeito adverso sobre as propriedades de resistência das polpas. Foi verificado que a AMS não apenas protegia os polissacarídeos contra as reações de degradação alcalina, como também reagia com a lignina, causando deslignificação mais intensa e mais rápida. Entretanto o AMS apresenta alguns inconvenientes, tais como o seu 
elevado custo, o que torna proibitivo seu uso em escala industrial e ainda a introdução de uma certa quantidade de enxofre no sistema produtivo, com o que não se evitaria os problemas de odor.

WHRIGHT \& FULLERTON (1984) estudaram complexos orgânometálicos como possíveis catalisadores de processos de polpação alcalina e concluíram que o complexo metálico de mesotetra(p-sulfofenil) porfirina, CoTSPP, na polpação de Pinus radiata promove a deslignificação porém com menor eficiência que a antraquinona.

Em suas pesquisas CUERVO (1983) conciui que o aditivo ideal deve ser solúvel no licor de cozimento para favorecer sua adição ao processo e atuar fundamentalmente sobre a lignina nas primeiras etapas do processo de polpação.

2.3. Compostos quinônicos como aditivos para processos alcalinos de produção de celulose

Os processos alcalinos de cozimento representam um conjunto de reações de redução-oxidação segundo Nikitn (1974) e Chupka (1974) citados por BARBADILLO \& POTTI (1982). Como consequência, pode-se concluir que a velocidade de deslignificação depende do poder redutor do licor de cozimento, supondo-se que há álcali suficiente para completar a degradação final da lignina em fragmentos solúveis. $O$ poder redutor que controla a velocidade de deslignificação pode ser conseguido mediante a adição, em quantidade conveniente, de agentes redutores (BARBADILLO \& POTTI, 1982). 
$\mathrm{Na}$ classe dos compostos quinônicos, as antraquinonas se destacam pelo seu potencial para utilização como aditivos em cozimentos alcalinos.

Segundo estudos conduzidos pela KAWASAKI KASEI CHEMICALS (1979), a utilização de compostos quinônicos em processos alcalinos de produção de celulose levam a uma aceleração da taxa de deslignificação e de estabilização de carboidratos, e estes dois fatores tem os seguintes efeitos benéficos:

- redução da temperatura de cozimento, aumento da vida útil dos digestores e economia de energia;

- redução do tempo de cozimento, economia de energia e aumento de produtividade;

- diminuição do número kappa, melhoria no processo de branqueamento e economia de energia no refino;

- redução do álcali ativo, dos custos com reagentes e madeira;

- diminuição da sulfidez e redução da poluição ambiental;

- aumento do rendimento e redução de custos com madeira;

- menor degradação de polissacarideos e aumento das resistências da celulose.

O aumento da taxa de deslignificação em cozimentos com compostos quinônicos é explicado pelo aumento da taxa de ruptura das ligações fenil-éter da lignina, formando moléculas de baixo peso molecular, solúveis no licor de cozimento (KAWASAKI KASEI CHEMICALS, 1979). 
Segundo OBST et al. (1979) é amplamente aceito que a reação de maior contribuição na deslignificação alcalina é a quebra da ligação éter $\beta-4$ entre unidades de fenil-propano.
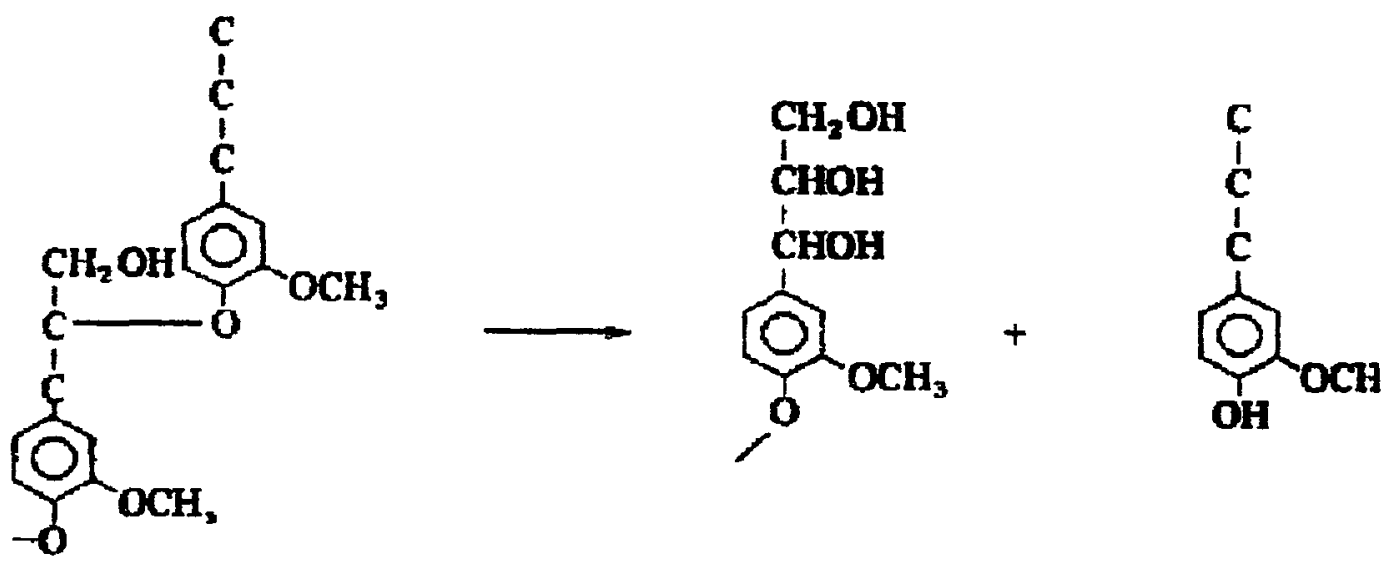

Figura 1. Representação esquemática da quebra das ligações feniléter da lignina

No que diz respeito a estabilização dos carboidratos, em presença de quinonas, grupos terminais da celulose e hemiceluloses são oxidados a ácido carboxilico, estabilizando-se assim as moléculas (KAWASAKI KASEI CHEMICALS, 1979). 
2.4. Utilização do sal di-sódico de 1,4-dihidro-9,10dihidroxi antraceno em processos alcalinos de produção de celulose

O sal di-sódico de 1,4-dihidro-9,10-dihidroxi antraceno (DDA) é um composto quinônico usado como aditivo químico do processo de cozimento. Apesar de sua utilização comercial em larga escala no Japão na produção de celulose de Eucalyptus e outras espécies de folhosas, poucos estudos tem sido realizados com este aditivo (BIERMANN \& DUTTA, 1989). Este composto foi patenteado como aditivo em processos de polpação em 1976 (KAWASAKI KASEI CHEMICALS LTD, 1986).

O DDA, também chamado de "antraquinona solúvel" apresenta-se na forma líquida, o que facilita sua uniformização nos digestores (BIERMANN \& DUTTA, 1989). Suas principais caracteristicas são (KAWASAKI KASEI CHEMICAL, 1986):

- solúvel no licor de cozimento;

- temperatura de ebulição: $103^{\circ} \mathrm{C}$;

- pressão de vapor (mm de Hg): aproximadamente 760 à temperatura de ebulição;

- solubilidade em água: aproximadamente $410 \mathrm{~g} / 1$ à $20^{\circ} \mathrm{C}$;

- peso específico: $1,15 \sim 1,20$

- aparência: líquido de coloração avermelhada cristalina

- odor: sem odor característico

- Dose letal 50: $1000 \mathrm{mg} / \mathrm{kg}$. 
A fórmula estrutural do DDA é apresentada a seguir.

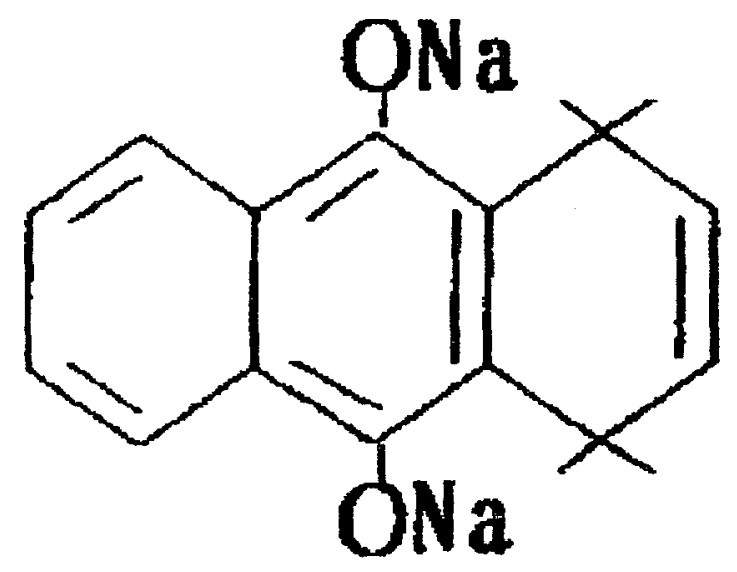

Figura 2. Fórmula estrutural do DDA

NOMURA (1974) afirma que a fäbrica japonesa Kushiro, desde 1975, utiliza o sal di-sódico de 1,4-dihidro-9,10-dihidroxi antraceno (DDA), como aditivo, na produção de polpa kraft para papelão (1700t/dia) e de polpa branqueada (200t/dia). Para a produção do DDA, essa fábrica utiliza a reação de Diels Alder, entre a naftoquinona e butadieno.

NAKANO et al. (1979) estudou o mecanismo de reação do DDA no processo de cozimento de guaiacil-glicerol- $\beta$-guaiacil-éter, usado como substância modelo para lignina e conclui que este reagente atua como catalisador redox.

Os efeitos positivos do sal di-sódico de 1,4-dihidro-9,10-dihidroxi antraceno são mais pronunciados em cozimentos com baixa sulfidez. Desta forma pode-se concluir que este composto pode apresentar beneficios substanciais ao processo soda de polpação (BIERMANN \& DUTTA, 1989). 


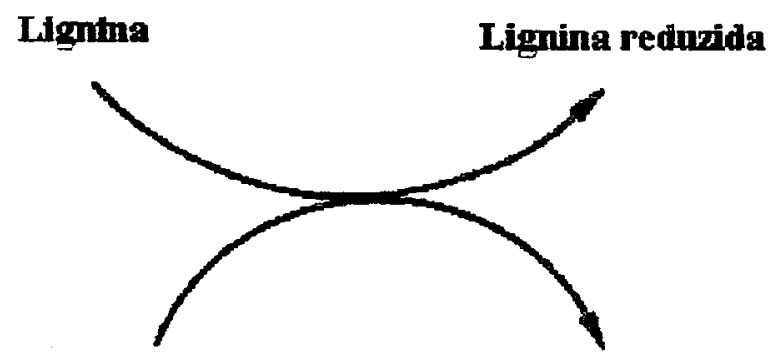

DDA

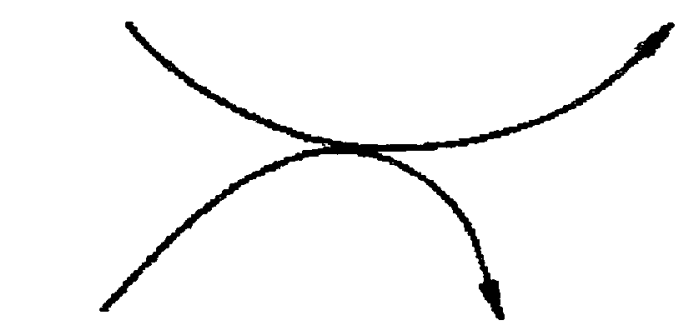

Lignina

Lignina redazida
$\mathrm{H}_{2} \mathrm{AQ}$

AQ

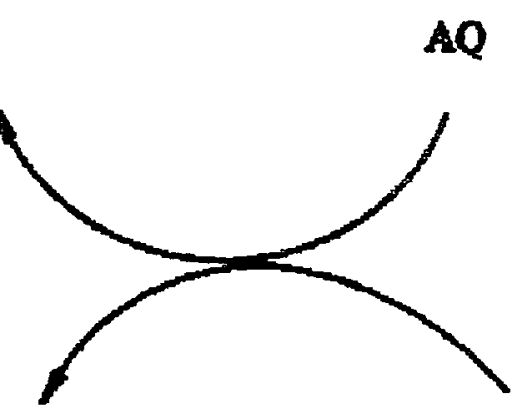

Oxidação dos grupos terminais da celulose

Celulose

Figura 3. Representação esquemática da forma de atuação do DDA em cozimentos alcalinos

Estudos realizados por BIERMANN \& DUTTA (1989), mostram que, para a madeira de "Douglas-fir" (Pseudotsuga menziesii), o sal di-sódico de 1,4-dihidro-9,10-dihidroxi antraceno, em todas as concentrações estudadas, apresenta maior eficácia do que a antraquinona, no que diz respeito à redução do número kappa. Os autores concluem ainda que o sal di-sódico de 1,4-dihidro9,10-dihidroxi antraceno apresenta efeito acentuado sobre o rendimento do processo de produção de celulose, superior, inclusive, ao efeito da antraquinona; o uso deste composto aumenta o rendimento em 1-2\% quando comparado com a antraquinona e 3-4\% quando comparado ao processo kraft convencional. Estes 
autores, afirmam ainda, que a maioria dos efeitos benéficos do DDA são alcançados em concentrações de $0,1 \%$ do produto em relação ao peso seco de madeira.

Estudos realizados pela KAWASAKI KASEI CHEMICALS LTD. (1986) mostram que o emprego do DDA promove uma redução do álcali ativo, diminuição da temperatura e do período de cozimento, aumento do rendimento do processo, diminuição do número kappa e redução da carga de compostos de enxofre.

Segundo NOMURA (1974), o sal di-sódico de 1,4-dihidro-9,10dihidroxi antraceno apresenta as seguintes vantagens sobre a antraquinona: potencial redox inferior, resultando em melhores redimentos, melhor taxa de cozimento e superior qualidade da polpa, mesmo com a utilização de pequena quantidade; maior solubilidade no licor de cozimento, sendo portanto mais fácil de ser utilizado nas instalações industriais existentes. A antraquinona é produzida, principalmente por meio de um processo de oxidação do antraceno, que permanecé parcialmente não oxidado; embora ocorra em quantidades despreziveis, ainda assim o antraceno remanescente não é desejável, por ser considerado substância com caracteristicas cancerigenas.

Conforme apresentado anteriormente o DDA atua nos processos alcalinos de produção de celulose de forma bastante semelhante à antraquinona. Por esta razão, e associando-se ao fato de ser escassa a bibliografia a cerca do DDA como aditivo de polpação, procedeu-se neste trabalho a uma revisão bibliográfica complementar a cerca da antraquinona. 


\subsection{Utilização de antraquinona em processos alcalinos de produção de celulose}

A antraquinona é uma substância orgânica de peso molecular 208,23, com coloração amarela, cristalina com agulhas rombiformes, temperatura de fusão de $286^{\circ} \mathrm{C}$, temperatura de ebulição de $379,8^{\circ} \mathrm{C}(760 \mathrm{~mm} \mathrm{Hg})$ e densidade de $1,438 \mathrm{~g} / \mathrm{cm}^{3}$. Sua fórmula molecular é $\mathrm{C}_{14} \mathrm{H}_{8} \mathrm{O}_{2}$ (PENALBER, 1983).

A descoberta do uso da antraquinona como aditivo ao processo soda ou kraft de produção de celulose abriu novas oportunidades tecnológicas (LIEBERGOTT \& VAN LIEROP, 1981).

A possibilidade de redução da carga poluente típica do processo kraft de produção de celulose é um grande incentivo para a pesquisa de processos de polpação soda-antraquinona de madeira de folhosas (MACLEOD \& CYR, 1983).

Como resultado de um número sempre crescente de estudos, a antraquinona é hoje considerada o primeiro aditivo realmente eficaz e de valor prático tanto no aspecto industrial como comercial, para polpação alcalina (GOMIDE, 1980).

Por ter seu uso em indústrias de celulose patenteado, a utilização de antraquinona como catalisador de processos alcalinos de polpação implica no pagamento de direitos de patente no valor de aproximadamente US\$0,33/ $\mathrm{kg}$ de antraquinona consumidos (HOLTON, 1978). 


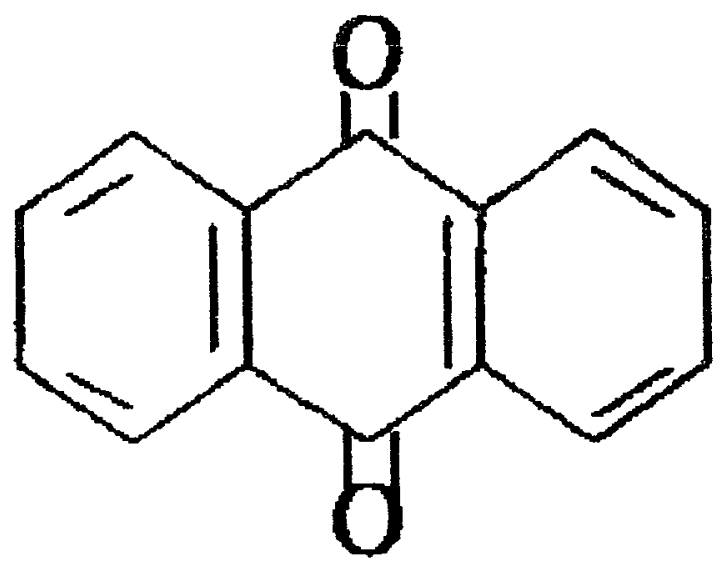

Figura 4. Fórmula molecular da antraquinona

Em suas pesquisas FALK et al. (1984) observaram que na polpação soda-AQ há uma distribuição irregular da antraquinona nos estágios iniciais do cozimento, se depositando principalmente na região superficial dos cavacos enquanto o álcali penetra no mesmo. Ainda segundo este autores, com o aumento do tempo de cozimento e da temperatura, a concentração de antraquinona na região superficial dos cavacos diminui marcadamente. Este fato pode ser devido ao fenômeno de redução da antraquinona para antrahidroquinona, a qual é solúvel em meio alcalino. Esta diferença de penetração de antraquinona e carga alcalina no cavaco na face inicial do cozimento implica em um cozimento soda-AQ superficial dos cavacos enquanto que a parte central dos mesmos é submetida a um cozimento soda convencional.

Quando a temperatura de cozimento atinge $90-100^{\circ} \mathrm{C}$, ocorre rápida redução e dissolução da antraquinona, causada pela sua reação com os carboidratos da madeira (GOMIDE, 1980). 
CUERVO (1983) avaliando o comportamento da antraquinona como aditivo em cozimentos alcalinos, enfatiza que os dois mais importantes mecanismos de ação da antraquinona são:

1 - estabilização das cadeias de celulose mediante a oxidação terminal hemiacetal à ácido aldônico.

2 - aumento da velocidade de deslignificação com adição de antraquinona. Existem pelo menos três interpretações diferentes, porém todas três coincidem com $\mathrm{o}$ ataque do derivado quinônico à ligação $\beta-0,4$ éter do modelo de lignina, conduzindo a formação de guaiacol e 2-metoxi-4-viniifenol.

Em suas pesquisas DIMMEL et al. (1985) afirmam que um dos possíveis mecanismos de deslignificação da madeira é através de reações de transferência de elétrons e a antraquinona provavelmente atua desta forma.

Em linhas gerais, é aceito o princípio básico de que a antraquinona funciona como um catalisador redox, transferindo elétrons dos carboidratos da madeira para as estruturas intermediárias da degradação da lignina, o que resuita em maior rendimento e menor número kappa (GOMIDE, 1980). 
celulose (grupo terminal redutor)

-CHO

celulose $(-\mathrm{COOH})$

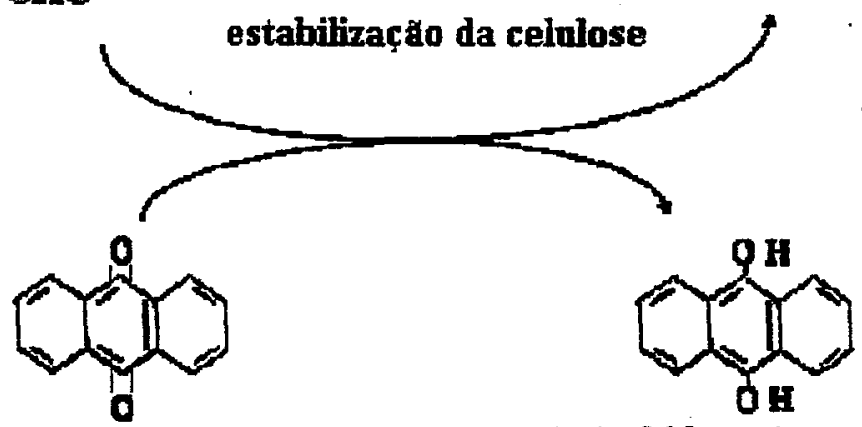

Antraquinona ( $\mathrm{AQ}$ )

Antrahidroquinona (AHQ)

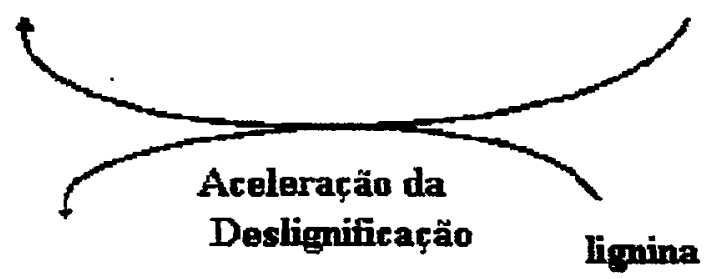

lignina de baixo peso molecular

Figura 5. Representação esquemática da forma de atuação da antraquinona em cozimentos alcalinos

Em pesquisas realizadas com cozimentos soda-AQ de cavacos de Eucalyptus spp., GOMIDE et al. (1987) constataram que a ação da antraquinona foi mais pronunciada nos cozimentos realizados com álcali ativo mais baixo, o que pode ser explicado pela alta concentração de íons $\mathrm{OH}^{-}$nas cargas mais altas de álcali ativo, mascarando a ação da antraquinona.

Em cozimentos kraft NELSON \& IRVINE (1992) afirmam que a presença de íons HS- em grande quantidade no licor de cozimento é mais eficaz na deslignificação da madeira do que pequenas quantidades de antraquinona empregada em cozimentos soda-AQ. 
Segundo HOLTON (1978) existe uma relação inversa entre quantidade de antraquinona e sulfidez, ou seja, os efeitos da antraquinona são mais perceptiveis em cozimentos com baixa sulfidez.

VAN ALLEN et al. (1981) em pesquisa realizada com madeira de Picea glauca afirma que o efeito da adição de pequenas quantidades antraquinona como aditivo para produção de celulose é mais pronunciado em processos sem enxofre.

PARTHASARATHY et al. (1983) afirmam que para produção de celulose kraft a partir da mistura de cavacos de $E$. tereticornis e $P$. roxburghii (70:30), a adição de $0,05 \%$ de antraquinona permite a utilização de uma sulfidez de $10 \%$, uma redução de $29 \%$ no fator $\mathrm{H}$ e de 5,4 unidades no número kappa sem que haja redução no rendimento, quando comparado com um cozimento kraft tradicional (sulfidez de $25 \%$, fator $\mathrm{H}$ de 1050 ).

Blain (1978) citado por GOMIDE (1980) estudou a eficiência da antraquinona na polpação alcalina de madeira de folhosas, em niveis de sulfidez que variaram de 0 a $25 \%$. Os resuitados indicaram que em qualquer sulfidez, dentro desse limite, a presença de antraquinona proporcionou benefícios significativos, em termos de taxas mais altas de polpação, menores exigências de álcali, maiores rendimentos e viscosidades das polpas mais elevadas.

Em cozimentos soda-AQ de Quercus nigra, a adição de $0,05 \%$ de antraquinona reduz a quantidade de rejeitos para cerca de $1 \%$ (GHOSH et al., 1977).

NELSON \& IRVINE (1992) afirmam que a taxa de deslignificação em cozimentos soda-AQ pode ser aumentada com a adição de doses maiores de 
antraquinona, mas o rendimento e a resistência ao rasgo serão aumentados em uma escala bem menor.

Segundo HOLTON (1978) a quantidade de antraquinona a ser utilizada em um determinado processo depende do objetivo da aplicação, da madeira empregada no processo e dos efeitos desejados. No entanto, com o uso de pequenas doses de antraquinona o beneficio econômico é maior em folhosas do que em coniferas.

Em cozimentos soda de Eucalyptus spp. a substituição de parte da carga alcalina por antraquinona resuitou em significativa elevação da viscosidade da polpa ceiulósica ( $52 \%$ ), quando a carga alcalina de $21,8 \%$, foi substituída por $17 \%$ com a adição de $0,105 \%$ de antraquinona. Esses resultados demonstram a ação protetora da antraquinona nos carboidratos, tanto pela menor carga alcalina requerida para o cozimento, como pela ação direta sobre os grupos terminais redutores dos carboidratos, minimizando as reações de despolimerização terminal (GOMIDE et al., 1987).

Segundo Basta \& Samueison (1978) citados por BARBADILLO \& POTTI (1982) a influência da antraquinona sobre o grau de polimerização da celulose é pequena quando comparada com sua influência na deslignificação.

HALDAR \& BHATTACHARYA (1987) em pesquisas com produção de celulose de madeiras da Índia, verificaram o efeito benéfico da antraquinona sobre o rendimento e sobre a deslignificação. Este aumento no rendimento deve-se basicamente a estabilização dos carboidratos em oposição a degradação progressiva, na forma de reação de "descascamento".

A antraquinona causa a oxidação do grupo terminal redutor dos carboidratos, estabilizando-os em relação às reações de despolimerização terminal 
(reação de descascamento). Essa estabilização resulta em proteção dos carboidratos contra reações de degradação e solubilização e, consequentemente, num aumento de rendimento. A ação da antraquinona sobre a lignina é explicada pela aceleração da reação de hidrólise das ligações $\beta$-éter, ocasionando a formação de fragmentos de lignina de menor peso molecular, o que resulta numa intensificação da taxa de deslignificação (GOMIDE, 1980).

Em suas pesquisas GHOSH et al. (1977) observaram que o aumento da temperatura de cozimento $\left(160-170^{\circ} \mathrm{C}\right.$ ) com cargas alcalinas baixas ( $10 \%$ base madeira) leva a uma redução do rendimento em cerca de 5\% independentemente da carga de antraquinona empregada. Os autores observam que este efeito é menor em cozimentos soda-AQ com cargas alcalinas altas (13\% base madeira) e de antraquinona elevadas $(0,1 \%$ ou mais $)$.

O branqueamento das polpas, segundo Lachennal et al. (1979) citado por GOMIDE (1980) reduz as diferenças entre as características mecânicas das polpas kraft e soda- $A Q$, que apresentam, depois do branqueamento, as mesmas qualidades.

GHOSH et al. (1977) observaram que o tratamento da celulose soda-AQ de Quercus nigra com oxigênio assegura uma alta seletividade na remoção de lignina (número kappa aproximadamente 10) com aumento de rendimento na ordem de 4 - $5 \%$.

VIRKOLA (1981) em suas pesquisas mostra que o uso da antraquinona permite um aumento de produtividade sem contudo aumentar a produção de licor negro; este fator se reveste de grande importância quando se considera que o sistema de recuperação do licor negro representa um ponto de estrangulamento à diversas indústrias de celulose. 
No processo de polpação alcalina com o uso de antraquinona como catalisador, observa-se um importante problema, o qual corresponde a perda deste catalisador durante a polpação. Segundo LANDUCCI \& RALPH (1984) esta perda é especialmente séria no processo kraft-AQ onde o controle das variáveis de processo, como a carga de antraquinona, é essencial para o balanço técnico e econômico do processo. Estes autores observaram que, após o cozimento, 50-60\% da antraquinona está ligada quimicamente à resíduos de lignina; $15 \%$ foi convertido em derivados solúveis de antraquinona tais como o antraceno e dihidroantraceno, isolados do licor negro de cozimentos soda-AQ; $5-10 \%$ da carga de antraquinona é perdida na polpa e não é extraível por solventes orgânicos; no máximo cerca de $20 \%$ da carga de antraquinona é recuperada intacta.

No processo soda-AQ, a antraquinona é removida do sistema de forma irreversível devido a reações com carboidratos e com a lignina. Em suas pesquisas com cozimentos soda-AQ de madeira de coniferas EACHUS (1983) afirma que ao final de 70 minutos de cozimento, existiam no sistema de cozimentos apenas $30 \%$ da quantidade original de antraquinona.

Em suas pesquisas, Currah (1979) citado por GOMIDE (1980) determinou o teor residual de antraquinona em polpas, papéis e licores residuais e obteve os seguintes resultados médios:

- polpa não lavada: 100 a $1000 \mathrm{ppm}$

- polpa lavada: 0,5 a $80 \mathrm{ppm}$

- papelão: 5 - 30 ppm

- polpa branqueada: menos de 0,1 a 5 ppm

- papéis brancos: não detectada 
- licor residual: 10 - $100 \mathrm{ppm}$

Para a realidade da América do Norte, simples cálculos mostram que o uso da antraquinona com o objetivo de reduzir o consumo de matéria-prima (madeira, reagentes e energia) não é economicamente atraente. No entanto a possibilidade de se utilizar antraquinona na redução do nível de estrangulamento de alguns pontos na unidade de produção tem despertado interesse (BLAIN \& HOLTON, 1983). Segundo estes autores, os principais gargalos das indústrias de produção de celulose são:

- caldeira de recuperação - alta carga de sólidos orgânicos

- digestor - alimentação e ciclo de cozimento

- recuperação - forno de cal

Ainda segundo BLAIN \& HOLTON (1983) os problemas descritos acima podem ser resolvidos através da aquisição de novos equipamentos, o que requer grandes investimentos e tempo; no entanto o emprego da antraquinona pode aumentar a capacidade destes pontos com um mínimo investimento de capital ou perda de tempo.

A adição de antraquinona ao processo soda para produção de celulose de Eucalyptus spp resultou em maior facilidade de refino, em uma diminuição de $3,3 \%$ no álcali ativo do cozimento, correspondendo a $15,1 \%$ de economia de soda, e considerável melhoria das resistências da celulose, possibilitando melhoria de qualidade do papel, e provavelmente, uma maior velocidade da máquina de papel e menor frequência de "quebra" do papel na máquina formadora (GOMIDE et al. 1987). 
DIAS (1979) em suas pesquisas, concluiu que a adição de antraquinona em cozimentos kraft produz celulose com maior facilidade de refino. Este autor observou que enquanto as propriedades da polpa não são afetadas consideravelmente pela adição de antraquinona, há uma economia de energia no refino de cerca de $40 \%$ com relação a polpa kraft convencional.

A resistência ao rasgo da polpa soda de Eucalyptus urophylla, expressa pelo índice de rasgo, apresentou um aumento da ordem de $32 \%$ com a adição de $0,05 \%$ de antraquinona, ultrapassando a do processo kraft; a resistência ao arrebentamento apresentou notável acréscimo da ordem de $60 \%$; no entanto, no processo kraft, o acréscimo correpondente foi da ordem de $6 \%$. A resistência à tração, expressa pelo comprimento de auto-ruptura foi a que apresentou os menores efeitos benéficos da adição de antraquinona, cerca de $3 \%$ para o processo soda e 1\% para o kraft (GOMIDE \& OLIVEIRA, 1980).

Em suas pesquisas EACHUS (1983) conclui que, para um mesmo número kappa, a celulose soda- $\mathrm{AQ}$ apresenta resistências mecânicas inferiores a polpa kraft.

A presença de antraquinona em cozimentos soda aumentou os teores de $\alpha$ e $\delta$-celuloses indicando a estabilização de glucose e de glucomanana (Lowendahl \& Samueison, 1978 citados por EACHUS, 1983).

Em seus estudos, BIERMANN \& DUTTA (1989) concluem que a antraquinona apresenta efeitos positivos sobre o rendimento do processo de produção de celulose.

Zanella et al. (1979) citados por GOMIDE (1980) realizaram estudos sobre a toxidez e tratabilidade dos efluentes soda, soda- $A Q$, kraft e kraft$A Q$. Os efluentes soda e kraft, com e sem antraquinona, foram tratados em escala 
laboratorial, com lama ativada, não tendo sido detectadas diferenças causadas pela antraquinona na tratabilidade ou nas características dos efluentes. Teste de toxidez dos efluentes, realizados com a utilização de pequenos peixes (Pimephales promelas) e de crustáceos (Daphnia magna) indicaram que a presença de antraquinona não causa diferença na toxidez dos efluentes soda e kraft.

O uso da antraquinona, nos Estados Unidos, está regulamentado pelo Food and Drugs Administration (FDA) que estabelece a dosagem máxima de 0,1\% (CUERVO, 1983).

HALDAR \& BHATTACHARYA (1987) concluem que para um mesmo tempo de polpação, o uso da antraquinona implica em uma maior remoção de lignina quando comparado ao processo kraft convencional.

Em suas pesquisas, LIEBERGOTT \& VAN LIEROP (1981), concluem que o processo de produção de celulose com antraquinona não afeta as características de branqueamento de celulose de folhosas.

HOLTON (1981) acredita que a antraquinona não é um produto cancerígeno nem mutagênco. 


\section{Material e Métodos}

\subsection{Material}

Na realização deste trabalho foram utilizados cavacos obtidos a partir de árvores de Eucalyptus grandis com 7 anos de idade cedidos pela Champion Papel e Celulose (Mogi-Guaçú - SP) .

\subsection{Métodos}

\subsubsection{Caracterização do material}

\subsubsection{Dimensões dos cavacos}

Para determinação das dimensões dos cavacos (comprimento, largura e espessura) foram preparadas 3 amostras de cavacos com 250 gramas. Os cavacos foram medidos e separadus em classes com amplitude de $1 \mathrm{~mm}$ para comprimento e largura e $0,5 \mathrm{~mm}$ para espessura.

Os cavacos, após terem sido medidos e classificados, foram colocados em estufa a $105 \pm 3^{\circ} \mathrm{C}$ até atingirem peso constante. Com base no peso seco total e no peso seco de cada classe, determinou-se a porcentagem em peso de cada classe de cavacos na amostra analisada. 
Os resultados destas análises são apresentados em histograma de distribuição de frequència absoluta e relativa.

\subsubsection{Densidade básica}

A densidade básica foi determinada através do método do máximo teor de umidade (FOELKEL, BRASIL \& BARRICHELO, 1975), tomando-se 5 amostras de aproximadamente $20 \mathrm{~g}$ de cavacos cada.

Os resultados de densidade básica são apresentados como sendo a média aritmética das 5 amostras.

\subsubsection{Determinação da composição química}

Dos cavacos foram retirados pequenos fragmentos até integralizar $50 \mathrm{~g}$. Estes fragmentos foram moídos em moinho Wiley para obtenção de material classificado em peneira de com malha de $0,4 \mathrm{~mm}$ (40 mesh) conforme a metodologia utilizada nos laboratórios do Setor de Química, Celulose e Energia (SQCE) do Departamento de Ciências Florestais da ESALQ/USP (apêndice I).

Para o material em estudo foi determinado o teor de extrativos totais, e o teor de lignina. O teor de holocelulose foi determinado por diferença. 


\subsubsection{Caracterização morfológica de fibras}

Dos cavacos foram retirados cerca de 50 fragmentos para maceração pelo processo nítrico-acético, o qual se constitui em submeter o material a ser dissociado a um tratamento com solução de ácido acético, ácido nítrico e água $(5: 2: 1)$ aquecida em banho-maria a $100^{\circ} \mathrm{C}$ por um período de tempo suficiente para que as fibras sejam individualizadas. Após o término do tratamento, lava-se o material em água destilada.

Com o material dissociado foram montadas 10 lâminas. De cada lâmina, foram medidos o comprimento, a largura e o diâmetro do lume e a espessura de 10 fibras. Os resultados são apresentados como sendo a média aritmética das 100 medições efetuadas para cada dimensão medida.

\subsubsection{Otimização de parâmetros de cozimentos}

Na otimização dos principais parâmetros de cozimento, este trabalho foi divido em etapas, onde em cada uma determinou-se o nível ótimo de um respectivo parâmetro.

Para realização dos cozimentos utilizou-se uma autoclave rotativa com capacidade para 20 litros com 8 cápsulas de tela de aço inoxidável com capacidade para $200 \mathrm{~g}$ de cavacos absolutamente secos, integralizando um total de $1600 \mathrm{~g}$ de cavacos absolutamente secos por cozimento. 
Para cada tratamento foram realizados 2 cozimentos e após cada cozimento foram retirados aleatoriamente 2 cápsulas para análise da celulose obtida.

Ao final de cada cozimento foi coletada uma amostra do licor negro para análise.

\subsubsection{Cozimentos testemunhas}

Para efeito de comparação foram realizados cozimentos sob as seguintes condições:

\section{Coximento kraft}

álcali ativo: $14 \%\left(\right.$ como $\left.\mathrm{Na}_{2} \mathrm{O}\right)$

sulfidez: $25 \%$

relação licor/madeira: $4 / 1(1 / \mathrm{kg})$

temperatura máxima: $170^{\circ} \mathrm{C}$

tempo até temperatura máxima: 60 minutos

tempo à temperatura máxima: 30 minutos 


\section{Cozimento Soda-AQ}

álcali ativo: $14 \%\left(\right.$ como $\mathrm{Na}_{2} \mathrm{O}$ )

antraquinona: $0,08 \%$

relação licor/madeira: $4 / 1(1 / \mathrm{kg})$

temperatura máxima: $170^{\circ} \mathrm{C}$

tempo até temperatura máxima: 60 minutos

tempo à temperatura máxima: 30 minutos

\section{Cozimento Soda}

álcali ativo: $14 \%$ (como $\mathrm{Na}_{2} \mathrm{O}$ )

relação licor $/$ madeira: $4 / 1(1 / \mathrm{kg})$

temperatura máxima: $170^{\circ} \mathrm{C}$

tempo até temperatura máxima: 60 minutos

tempo à temperatura máxima: 30 minutos 


\subsubsection{Determinação da dosagem ótima de DDA}

Para determinação da dosagem ótima de DDA, para cavacos de Eucalyptus grandis foram reaiizados cozimentos sob as seguintes condições:

álcali ativo: $14 \%\left(\right.$ como $\left.\mathrm{Na}_{2} \mathrm{O}\right)$

dosagem de DDA: $0,04-0,06-0,08-0,10 \%$ ( base princípio ativo)

relação licor/madeira: $4 / 1(1 / \mathrm{kg})$

temperatura máxima: $170^{\circ} \mathrm{C}$

tempo até temperatura máxima: 60 minutos

tempo à temperatura máxima: 30 minutos

\subsubsection{Otimização do álcali ativo}

Para determinação do nivel de álcali ativo ótimo foram realizados cozimentos sob as seguintes condições:

álcali ativo: 12 - $13-14-15 \%\left(\right.$ como $\left.\mathrm{Na}_{2} \mathrm{O}\right)$

dosagem de DDA: determinado na etapa 3.2.2.2.

relação licor/madeira: $4 / 1(1 / \mathrm{kg})$

temperatura máxima: $170^{\circ} \mathrm{C}$

tempo até temperatura máxima: 60 minutos

tempo à temperatura máxima: 30 minutos

Obs.: para determinação da melhor dosagem de DDA foram considerados o rendimento depurado, número kappa e viscosidade da celulose. 


\subsubsection{Otimização do tempo à temperatura máxima de cozimento}

Para determinação tempo ótimo à temperatura máxima de cozimento foram realizados cozimentos sob as seguintes condições:

álcali ativo: determinado na etapa 3.2.2.3.

dosagem de DDA: determinado na etapa 3.2.2.2.

relação licor/madeira: $4 / 1(1 / \mathrm{kg})$

temperatura máxima: $170^{\circ} \mathrm{C}$

tempo até temperatura máxima: 60 minutos

tempo à temperatura máxima: $0,10,20$ e 30 minutos

Obs.: para determinação do melhor nível de álcali ativo foram considerados o rendimento depurado, o número kappa e a viscosidade

\subsubsection{Avaliação do efeito da sulfidez}

Para determinação do efeito da sulfidez em cozimentos soda-DDA foram realizados cozimentos sob as seguintes condições:

álcali ativo: determinado na etapa 3.2.2.3.

sulfidez: $0,5,10,15,20$ e $25 \%$

dosagem de DDA: determinado na etapa 3.2.2.2.

relação licor/madeira: $4 / 1(1 / \mathrm{kg})$

temperatura máxima: $170^{\circ} \mathrm{C}$

tempo até temperatura máxima: 60 minutos 
tempo à temperatura máxima: determinado na etapa 3.2.2.3.

Obs.: para determinação do melhor tempo a temperatura máxima de cozimento, foram considerados o rendimento depurado, o número kappa e a viscosidade das celuloses obtidas.

\subsubsection{Parâmetros determinados para cada cozimento}

\subsubsection{Determinação do fator $H$}

$\mathrm{O}$ fator $\mathrm{H}$ dos cozimentos realizados foi calculado pela regra de Simpson.

\subsubsection{Determinação de rendimento e número kappa}

Para cada amostra de celulose foi determinado o peso absolutamente seco (a. s.) de celulose produzida. A relação percentual entre peso a. s. de celulose e peso a. s. de madeira utilizada forneceu o rendimento bruto de cada amostra.

Após a determinação do rendimento bruto, as amostras de celulose de Eucalyptus grandis foram depuradas em depurador laboratorial com fenda de $0,2 \mathrm{~mm}$. Os rejeitos foram secos em estufa para se obter o peso absolutamente seco. A relação percentual entre o peso a. .s. de rejeitos e peso a. $s$. de madeira forneceu o teor de rejeitos. O rendimento depurado foi obtido pela diferença entre o rendimento bruto e o teor de rejeitos. 
O número kappa foi determinado para cada amostra de celulose de acordo com a norma TAPPI T236.

Foi determinado também a relação rendimento depurado/kappa.

\subsubsection{Refino da celulose}

As amostras de celulose foram refinadas em moinho PFI em 4 níveis de refino $(0,2000,4000$ e 6000 revoluções) de acordo com a norma TAPPI T248.

\subsubsection{Formação de folhas}

Para cada nível de refino de cada cozimento foram formadas $\mathbf{8}$ folhas com gramatura de aproximadamente $63 \mathrm{~g} / \mathrm{cm}^{2}$ em formador de folhas e secador tipo KOETHEN-RAPID.

\subsubsection{Ensaios físico-mecânicos}

Os ensaios físico-mecânicos foram realizados de acordo com a norma TAPPI T220.

As propriedades físico-mecânicas foram determinadas para as amostras de celulose de acordo com o nível de refino. 
Foram determinadas as seguintes propriedades:

- grau de refino ( $\left.{ }^{\circ} \mathrm{SR}\right)$

- gramatura $\left(\mathrm{g} / \mathrm{m}^{2}\right)$

- espessura (mm)

- peso específico aparente $\left(\mathrm{g} / \mathrm{cm}^{3}\right)$

- volume especifico aparente $\left(\mathrm{cm}^{3} / \mathrm{g}\right)$

- resistência ao ar $\left(\mathrm{seg} / 100 \mathrm{~cm}^{3}\right)$

- índice de rasgo $\left(\mathrm{mN} \cdot \mathrm{m}^{2} / \mathrm{g}\right)$

- índice de estouro $\left(\mathrm{kPa} . \mathrm{m}^{2} / \mathrm{g}\right)$

- índice de tração ( $\mathrm{Nm} / \mathrm{g})$

- esticamento (\%)

\subsubsection{Alfa, beta e gama celulose}

Para cada amostra de celulose foi determinado os teores de alfa, beta e gama celulose de acordo com a norma TAPPI T203.

\subsubsection{Teor de pentosanas}

Para cada amostra de celulose foi determinado o teor de pentosanas de acordo com a norma TAPPI T223. 


\subsubsection{Teor de lignina residual}

Para cada amostra de ceiulose foi determinado o teor de lignina residual de acordo com metodologia corrente no SQCE/ESALQ/USP. (Apêndice II).

\subsubsection{Viscosidade}

Para cada amostra de celulose foi determinado a viscosidade de acordo com a norma TAPPI TM206.

Com os valores de viscosidade e numero kappa determinou-se a relação viscosidade/kappa para cada tratamento.

\subsubsection{Teor de sólidos do licor negro}

O teor de sólidos do licor negro de cada cozimento foi determinado de acordo com a norma TAPPI T650.

\subsubsection{Teor de matéria-orgânica do licor negro}

O teor de matéria-orgânica do licor negro de cada cozimento foi determinado de acordo com a norma TAPPI T625. 


\subsubsection{2. Álcali ativo residual do licor negro}

O álcali ativo residual do licor negro de cada cozimento foi determinado de acordo com a norma TAPPI T625.

\subsubsection{Viscosidade do licor negro}

A viscosidade do licor negro foi determinada em viscosímetro à temperatura de $20^{\circ} \mathrm{C}$. 


\section{Resultados}

\subsection{Caracterização do material}

\subsubsection{Dimensões dos cavacos}

Os cavacos de Eucalyptus grandis ( 7 anos) foram analisados com respeito a suas dimensões, sendo os resultados apresentados na tabela 2 .

Tabela 1. Resultados das análises de dimensões de cavacos de Eucalyptus grandis.

\begin{tabular}{|c|c|c|c|}
\hline & Otrownonto & (mon & stossmo \\
\hline Mmero de obse oracoes & 1450 & 1323 & 1325 \\
\hline 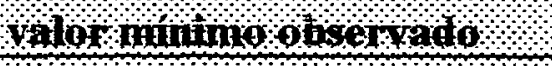 & 7,09 & 4,00 & 1,02 \\
\hline 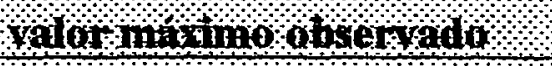 & 30,09 & 31,97 & 5,53 \\
\hline modnantmetha & 15,76 & 10,16 & 2,19 \\
\hline $16+10,101,10$ & 3,40 & 4,17 & 0,67 \\
\hline 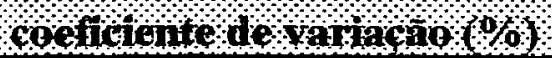 & 21,56 & 41,06 & 30.44 \\
\hline
\end{tabular}

Nas figuras 6,7 e 8 são apresentadas as distribuições de porcentagem em peso e porcentagem acumulada para comprimento, largura e espessura de cavacos 


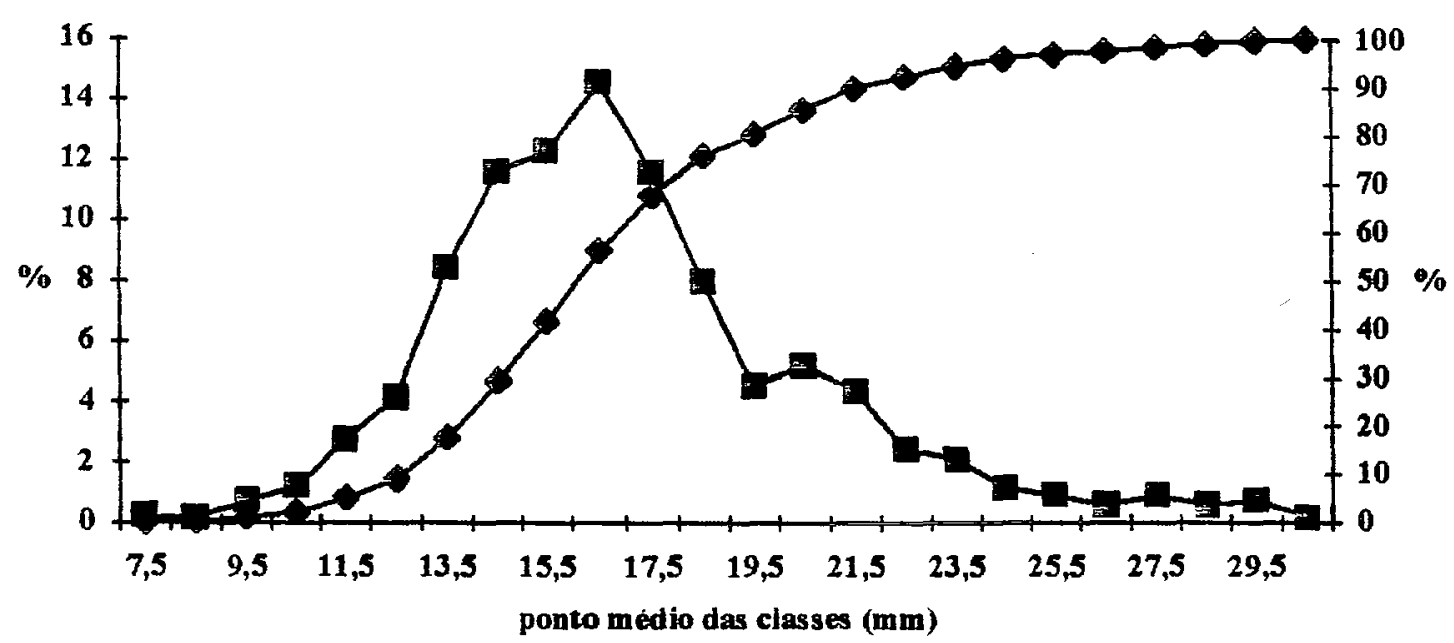

Figura 6. Distribuição de porcentagem em peso e porcentagem em peso acumulada para classes de comprimento de cavacos de Eucalyptus grandis.

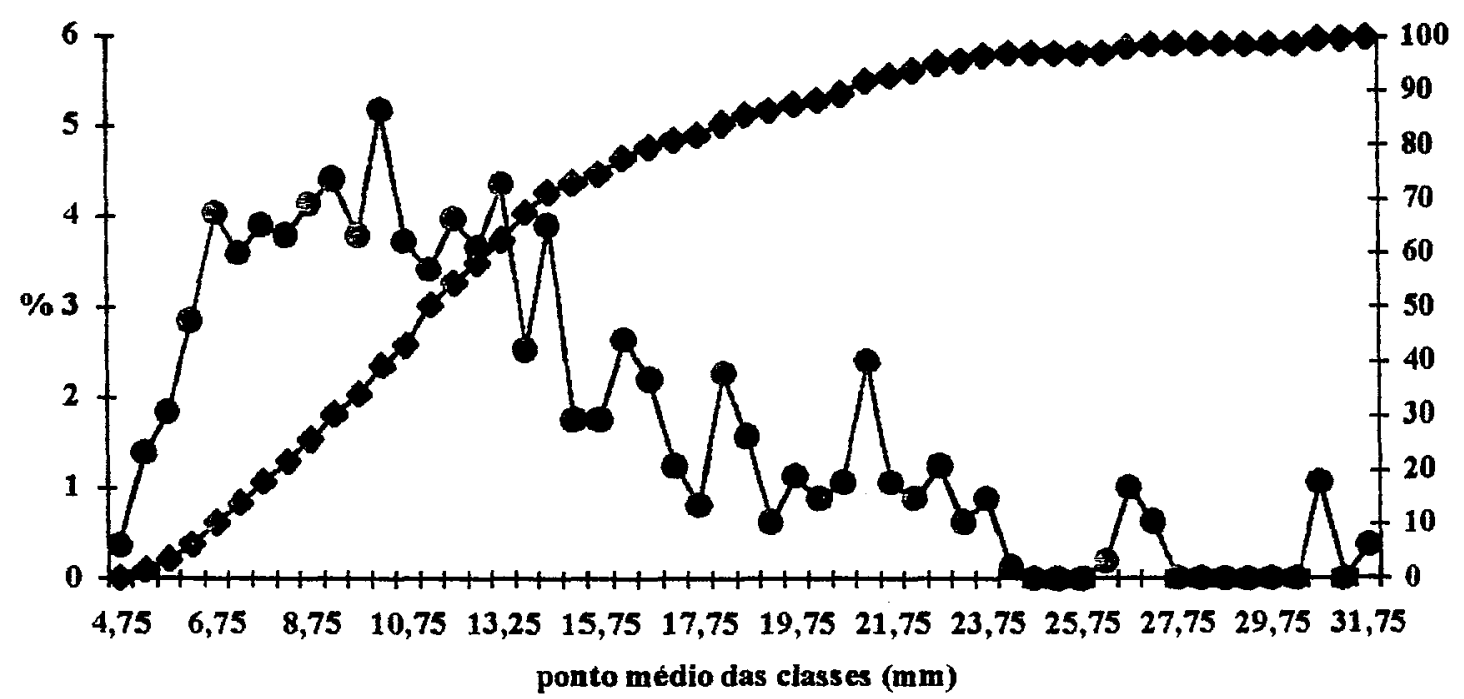

$\rightarrow$ - porcentagem $\quad-$ porcentagem acumulada

Figura 7. Distribuição de porcentagem em peso e porcentagem em peso acumulada para classes de largura de cavacos de Eucalyptus grandis. 


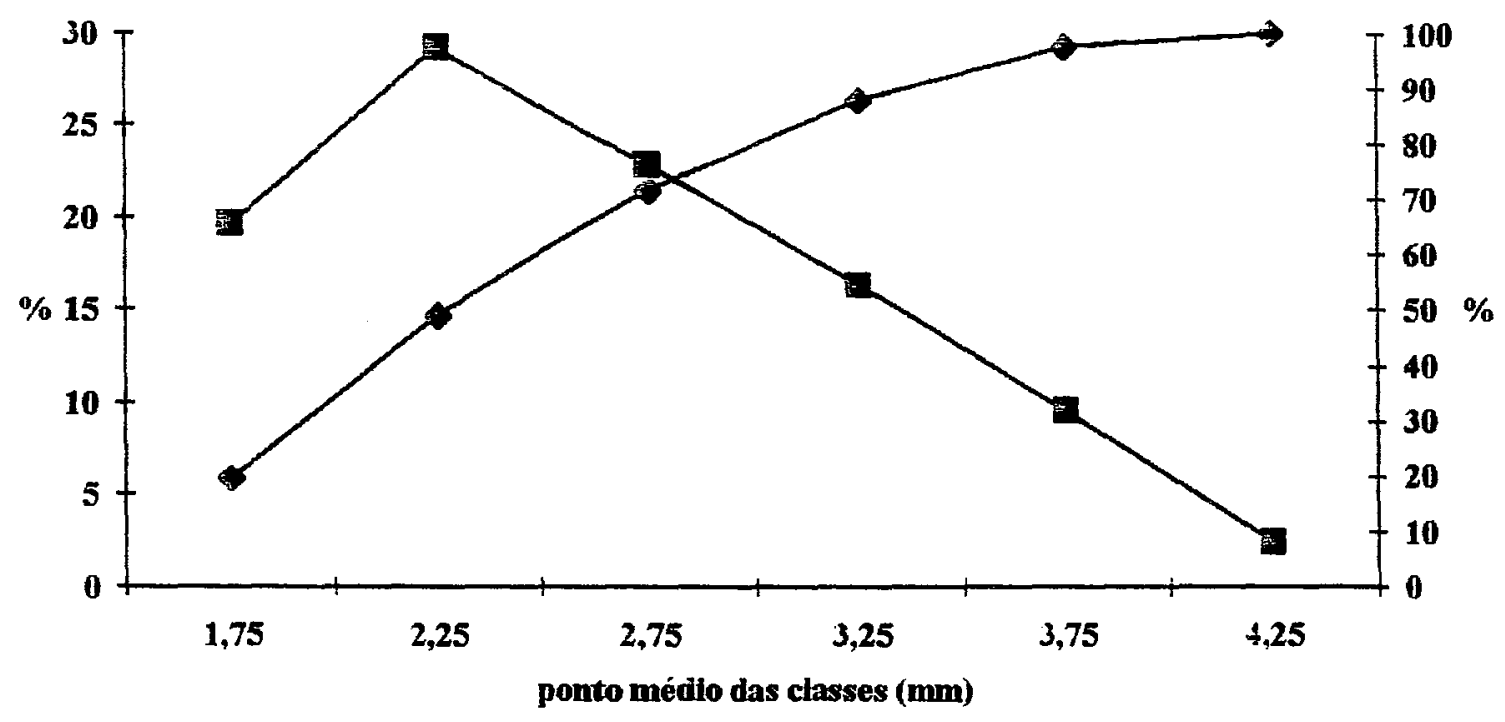

$\rightarrow$ - porcentagem $\longrightarrow$ porcentagem acumulada

Figura 8. Distribuição de porcentagem em peso e porcentagem em peso acumulada para classes de espessura de cavacos de Eucalyptus grandis.

\subsubsection{Densidade básica}

A densidade média para os cavacos de $E$. grandis foi de $\mathbf{0 , 4 3 4}$ $\mathbf{g} / \mathbf{c m}^{3}$ sendo o desvio-padrão e o coeficiente de variação respectivamente 0,0124 $\mathrm{g} / \mathrm{cm}^{3}$ e $2,85 \%$. 


\subsubsection{Composição química básica}

Os resultados das anảilises de composição química, ou seja, teor de holocelulose, lignina e extrativos totais, dos cavacos de $E$. grandis encontram-se na tabela 2.

Tabela 2. Composição quimica dos cavacos de E. grandis.

\begin{tabular}{|c|c|c|c|}
\hline Wulletro & neda & 6sopodro & rofforte \\
\hline 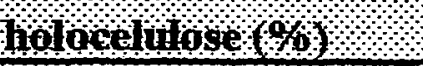 & 70,8 & 1,75 & 2,47 \\
\hline 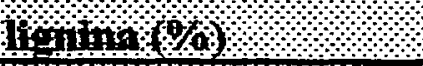 & 24,8 & 1,86 & 7,50 \\
\hline oftantros totals $(0,0)$ & 4,4 & 0,11 & 2,55 \\
\hline
\end{tabular}

\subsubsection{Dimensões de fibras}

Na tabela 3 são apresentados os resultados da análises de dimensões de fibras de $E$. grandis e suas relações, realizadas em material dissociado montado em lâminas. 
Tabela 3. Valores médios das dimensões das fibras de $E$. grandis e relações.

\begin{tabular}{|c|c|c|c|}
\hline parnetro & medta & dontopha & 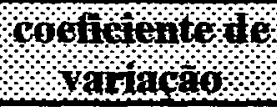 \\
\hline cont phlnentown & 1,11 & 0,23 & 20,94 \\
\hline Annano & 20,52 & 3,52 & 17,13 \\
\hline 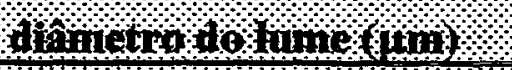 & 10,26 & 2,64 & 25,72 \\
\hline 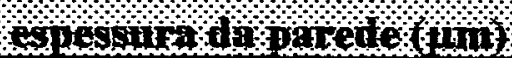 & 5,13 & 0,99 & 17,28 \\
\hline
\end{tabular}

\subsection{Coximentos testemunhas}

Foram realizados cozimentos testemunhas, sendo os tratamentos assim designados:

- tratamento 1 - kraft convencional

- tratamento 2 - soda-antraquinona com $0,08 \%$ (base madeira) de antraquinona

- tratamento 3 - soda convencional

Na tabela 4 , são apresentados os valores de rendimento bruto e depurado, teor de rejeitos e fator $\mathrm{H}$ das celuloses obtidas nos tratamentos descritos anteriormente. 
Tabela 4. Rendimento bruto e depurado, teor de rejeitos dos cozimentos testemunhas para fator $\mathrm{H}$ de 677 .

\begin{tabular}{|c|c|c|c|c|}
\hline \multicolumn{2}{|c|}{ truntento } & \multirow{2}{*}{ 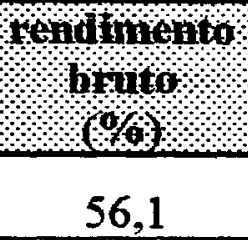 } & \multirow{2}{*}{ 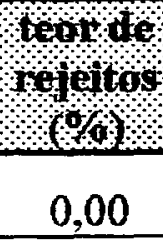 } & \multirow{2}{*}{$\begin{array}{c}\text { ond } \\
1,0,1010 \\
56,1\end{array}$} \\
\hline 1 & $\mathrm{~m}$ & & & \\
\hline & $\mathbf{s}$ & 0,53 & 0,00 & 0,54 \\
\hline & $\mathrm{CV}(\%)$ & 0,94 & - & 0,97 \\
\hline \multirow[t]{3}{*}{4} & $\mathrm{~m}$ & 55,5 & 0,06 & 55,5 \\
\hline & $\mathbf{s}$ & 0,11 & 0,04 & 0,07 \\
\hline & $\mathrm{CV}(\%)$ & 0,19 & 66,33 & 0,12 \\
\hline \multirow[t]{3}{*}{8} & $\mathbf{m}$ & 58,5 & 0,1 & 58,4 \\
\hline & $\mathbf{s}$ & 0,61 & 0,04 & 0,64 \\
\hline & $\mathrm{CV}(\%)$ & 1,05 & 35,36 & 1,10 \\
\hline
\end{tabular}

m - média

s - desvio-padrão

CV - coeficiente de variação tratamento 1 - kraft convencional tratamento 2 - soda-AQ tratamento 3 - soda convencional

$\mathrm{Na}$ tabela 5 são apresentados os resultados das análises quimicas das celuloses obtidas nos tratamentos anteriores bem como algumas relações 
Tabela 5. Número kappa, viscosidade, lignina residual e relações.

\begin{tabular}{|c|c|c|c|c|c|c|}
\hline \multicolumn{2}{|c|}{ Tronerto } & \multirow{2}{*}{$\begin{array}{c}\text { numuro } \\
19,3 \\
\end{array}$} & \multirow{2}{*}{ 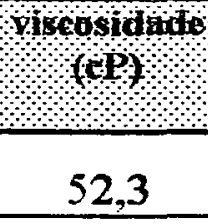 } & \multirow{2}{*}{$\frac{1 \text { esindian }}{1,0}$} & \multirow{2}{*}{$\begin{array}{c}r+p_{p} \\
2,90\end{array}$} & \multirow{2}{*}{ 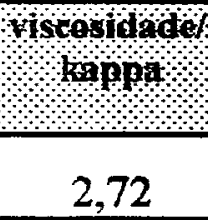 } \\
\hline 1 & m & & & & & \\
\hline & \% & 0,13 & 0,76 & 0,02 & 0,04 & 0,10 \\
\hline & $8 \times(0)$ & 0.67 & 6,19 & 2,27 & 1.21 & 3,83 \\
\hline \multirow[t]{3}{*}{2} & $\mathrm{~m}$ & 21,9 & 28.9 & 1,1 & 2,54 & 1,32 \\
\hline & 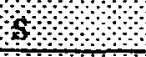 & 0.58 & 0,50 & 0,01 & 0,07 & 0,06 \\
\hline & 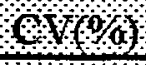 & 2,64 & 3,79 & 0,91 & 2,73 & 4,35 \\
\hline \multirow[t]{3}{*}{3} & आ1 & 48,7 & 30,3 & 1,7 & 1,20 & 0,62 \\
\hline & 8 & 0,59 & 0,60 & 0,02 & 0,01 & 0,07 \\
\hline & $\theta(\alpha)$ & 1,21 & 4,45 & 0,97 & 1,07 & 10,59 \\
\hline
\end{tabular}

m - média

s - desvio-padrão

$\mathrm{CV}$ - coeficiente de variação tratamento 1 - kraft convencional tratamento 2 - soda- $\mathrm{AQ}$

tratamento 3 - soda convencional

$\mathrm{Na}$ tabela 6 são apresentados os resultados das análises de pentosanas e alfa, beta e gama celuloses. 
Tabela 6. Teor de pentosanas e alfa, beta e gama celuloses.

\begin{tabular}{|c|c|c|c|c|c|}
\hline \multicolumn{2}{|c|}{ tratakutho } & pentosanas & I 1 - & $0,10,01010$ se & bonato 1 hlowo \\
\hline \multirow[t]{3}{*}{ i } & $\mathrm{m}$ & 12,3 & 87,5 & 6,9 & 5,6 \\
\hline & 8 & 0,76 & 0,47 & 0,85 & 0,93 \\
\hline & 00 & 6,19 & 0,54 & 12,32 & 16,61 \\
\hline \multirow[t]{3}{*}{2} & $1 \mathrm{~m}$ & 13,06 & 84,7 & 5,0 & 10,3 \\
\hline & $\mathrm{s}$ & 0,50 & 0,09 & 0,28 & 0,28 \\
\hline & $0(0)$ & 3,79 & 0,11 & 5,60 & 2,72 \\
\hline \multirow[t]{3}{*}{3} & m & 13,57 & 86,5 & 7,9 & 5,6 \\
\hline & 3 & 0,60 & 0,44 & 0,93 & 0,91 \\
\hline & 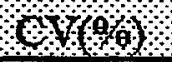 & 4,45 & 0,51 & 11,77 & 16,25 \\
\hline
\end{tabular}

m - média

s - desvio-padrão

$\mathrm{CV}$ - coeficiente de variação tratamento 1 - kraft convencional tratamento 2 - soda-AQ tratamento 3 - sodi convencional

Na figura 9 estão representados os resultados de rendimento depurado, número kappa e viscosidade das celuloses obtidas nos tratamentos $1,2 \mathrm{e}$ 3. Na figura 10 encontram-se as relações rendimento depurado/número kappa e viscosidade/kappa para os tratamentos considerados. 


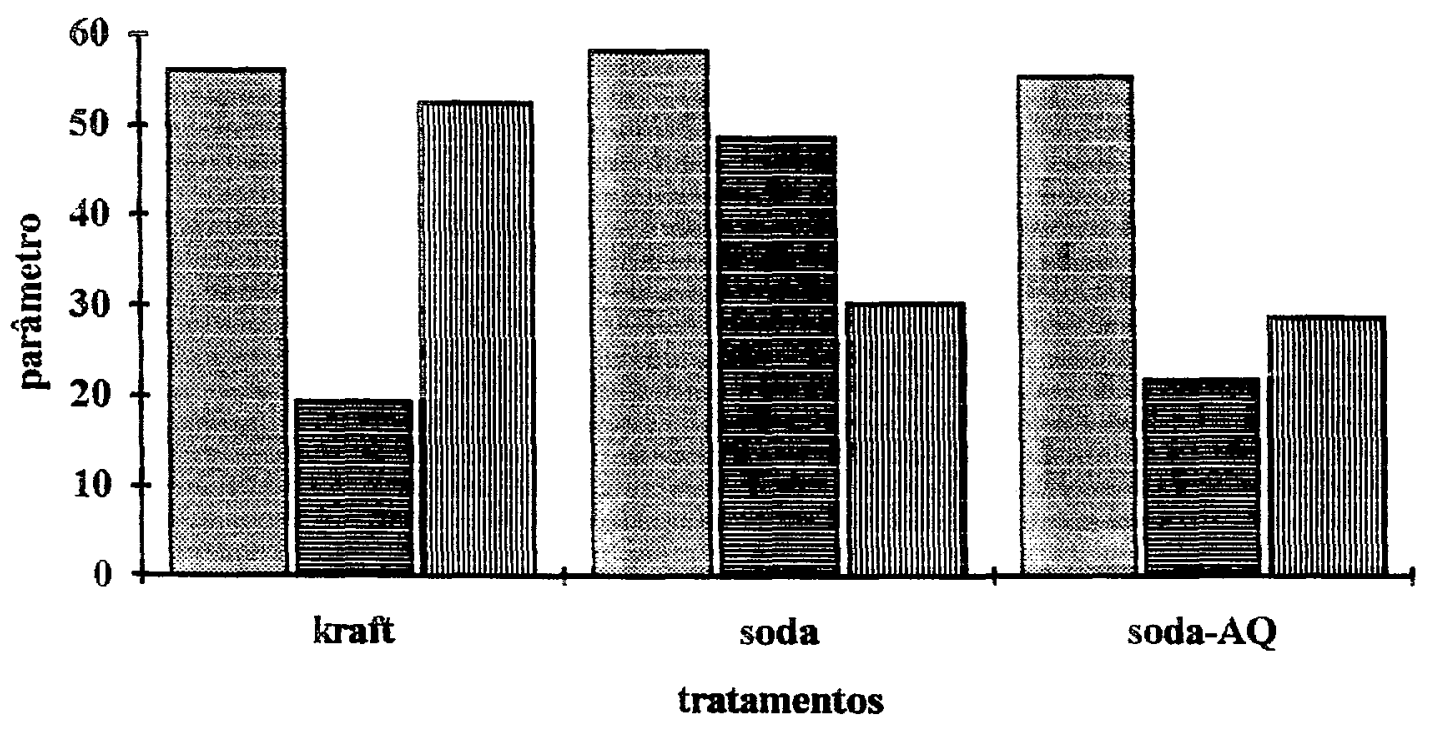

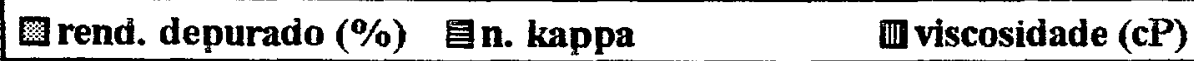

Figura 9. Número kappa, viscosidade e rendimento depurado das celuloses obtidas nos tratamentos 1, 2 e 3 .

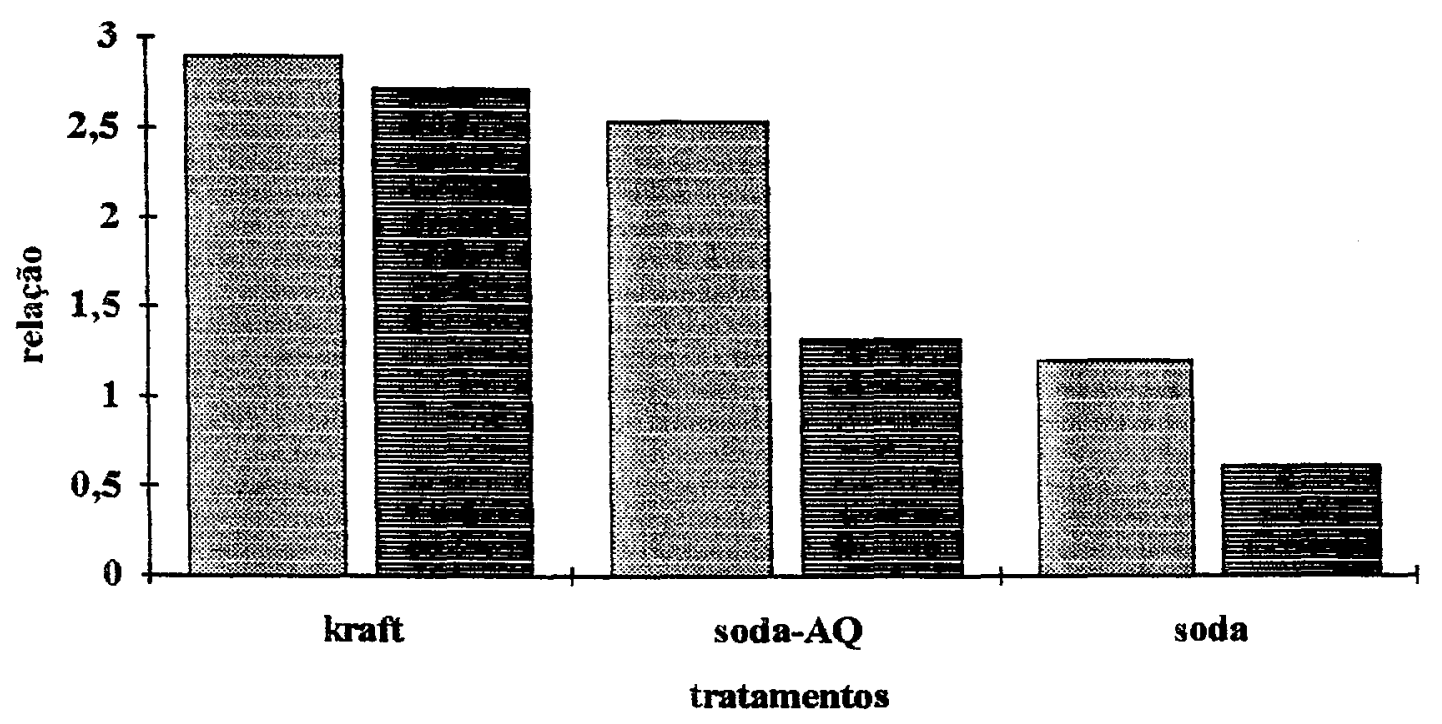

rend. depurado/kappa 目 viscosidade/kappa

Figura 10. Relação rendimento

depurado/kappa

e viscosidade/kappa. 
Nas tabelas 7, 8 e 9 são apresentados os resuitados dos testes físicos e mecànicos realizados com as celuloses dos tratamentos 1,2 e 3 .

Tabela 7. Propriedades físicas e mecânicas da celulose do tratamento 1 - kraft convencional.

\begin{tabular}{|c|c|c|c|c|}
\hline $10 \times 0$ nedes & 9 & 2000 & 000 & 6000 \\
\hline manderathor $\sigma \$ \mathrm{~W}$ & 16.7 & 23,3 & 32.0 & 42,0 \\
\hline$\mu_{1,1, w_{1}}\left(f_{1}\right)$ & 62,6 & 64,7 & 63.9 & 63,9 \\
\hline espescuna (nn) & 0,141 & 0,132 & 0,123 & 0,112 \\
\hline 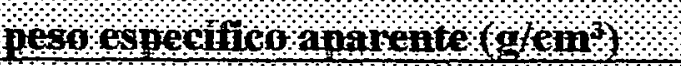 & 0,445 & 0.492 & 0,519 & 0,573 \\
\hline 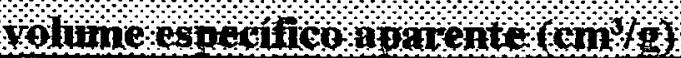 & 2,248 & 2,034 & 1,925 & 1,746 \\
\hline 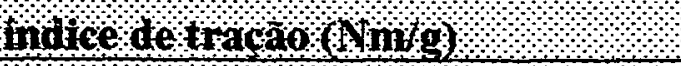 & 21,4 & 36,0 & 65,8 & 75,9 \\
\hline 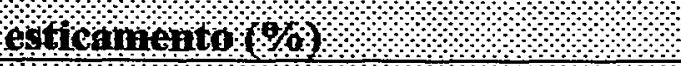 & 1,4 & 3,6 & 3,9 & 5.4 \\
\hline 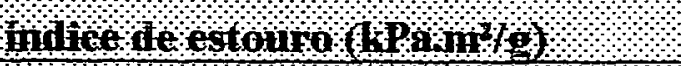 & 1,2 & 3,3 & 4,6 & 4,9 \\
\hline 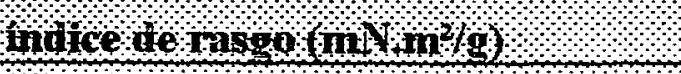 & 9.0 & 10.7 & 15,5 & 13,8 \\
\hline 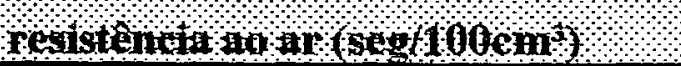 & 1.2 & 2.9 & 9.5 & 32,0 \\
\hline
\end{tabular}


Tabela 8. Propriedades físicas e mecânicas da celulose do tratamento 2 - soda-AQ.

\begin{tabular}{|c|c|c|c|c|}
\hline notheops & 0 & 2000 & eq⿴囗十 & 6000 \\
\hline 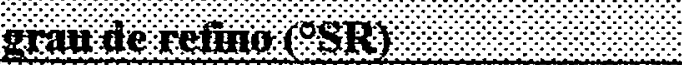 & 18 & 24 & 32,3 & 45,3 \\
\hline Omanura $(\mathrm{m} / \mathrm{m})$ & 64,4 & 65,3 & 64,5 & 63,8 \\
\hline espesunnom) & 0,149 & 0,132 & 0,123 & 0,115 \\
\hline 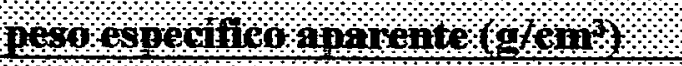 & 0,433 & 0,496 & 0,526 & 0,556 \\
\hline 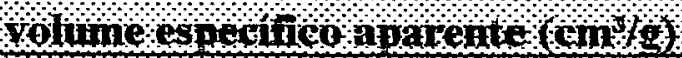 & 2,312 & 2,018 & 1,902 & 1,799 \\
\hline 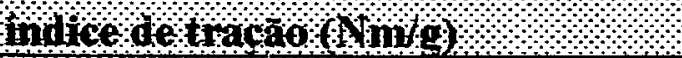 & 33.4 & 53,3 & 70,2 & 75,6 \\
\hline ostonanonto $(\%, \alpha)$ & 1,3 & 2,8 & 3,9 & 4,3 \\
\hline 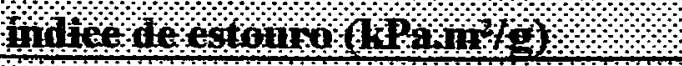 & 1,0 & 2,9 & 4,5 & 5,1 \\
\hline 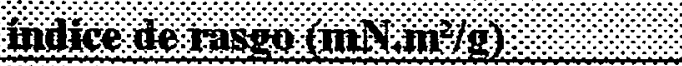 & 6,1 & 11,5 & 14,6 & 12,7 \\
\hline 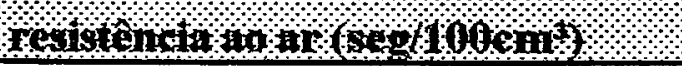 & 1,4 & 3,1 & 9,3 & 31,6 \\
\hline
\end{tabular}


Tabela 9. Propriedades físicas e mecànicas da celulose do tratamento 3 - soda convencional.

\begin{tabular}{|c|c|c|c|c|}
\hline $10 \times 0100$ & 0 & 2000 & 3000 & 6000 \\
\hline 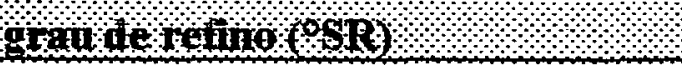 & 16,5 & 22,7 & 30,7 & 38,9 \\
\hline 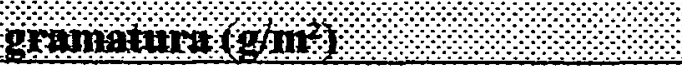 & 62,1 & 61,8 & 61,1 & 62.3 \\
\hline (pposinn $(\min )$ & 0,154 & 0,140 & 0,125 & 0,123 \\
\hline 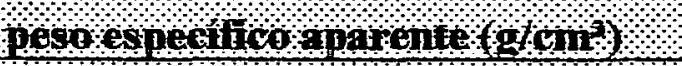 & 0,403 & 0,442 & 0,489 & 0,508 \\
\hline 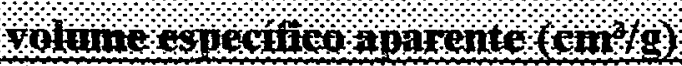 & 2,480 & 2.260 & 2,046 & 1,968 \\
\hline 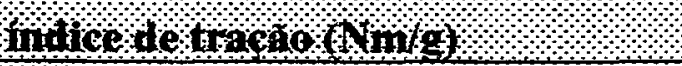 & 10,0 & 33,0 & 41,7 & 46,7 \\
\hline 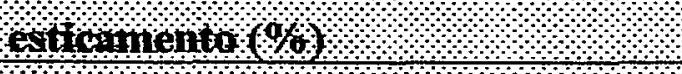 & 0,0 & 3,0 & 4,1 & 5,0 \\
\hline 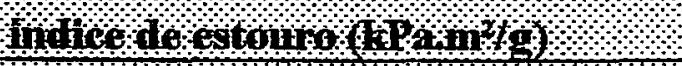 & 0,9 & 2,1 & 4,1 & 4,3 \\
\hline 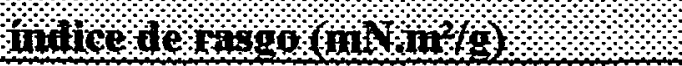 & 4,9 & 9,9 & 11,1 & 12,8 \\
\hline 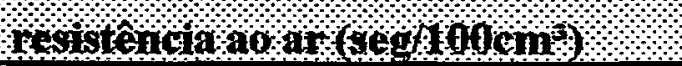 & 0,6 & 1,3 & 4,2 & 10,2 \\
\hline
\end{tabular}

Para efeito de comparação as caracteristicas físico-mecànicas das celuloses dos tratamentos 1,2 e 3 foram plotadas nos gráficos à seguir. 


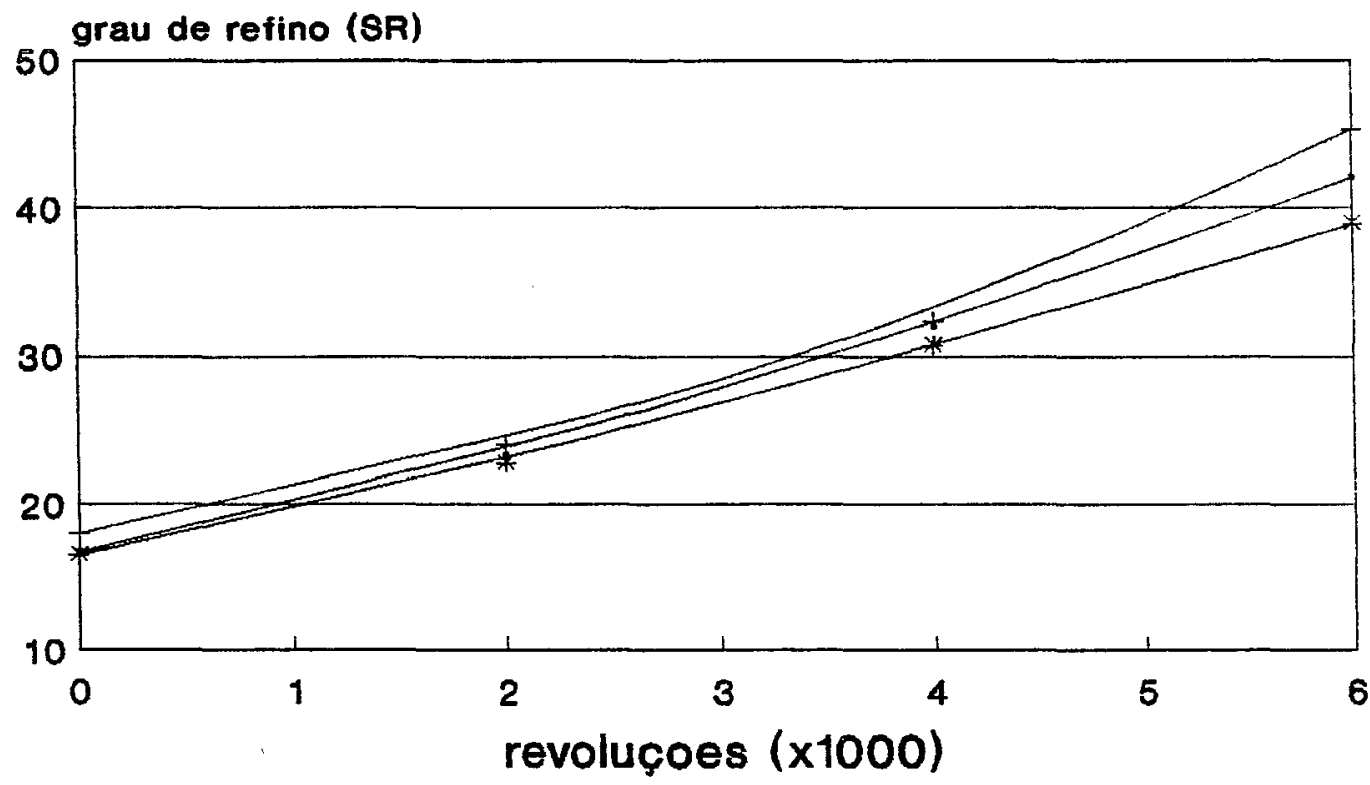

- kraft + soda-AQ * soda

Figura 11. Grau de refino em função do número de revoluções (moinho PFI).

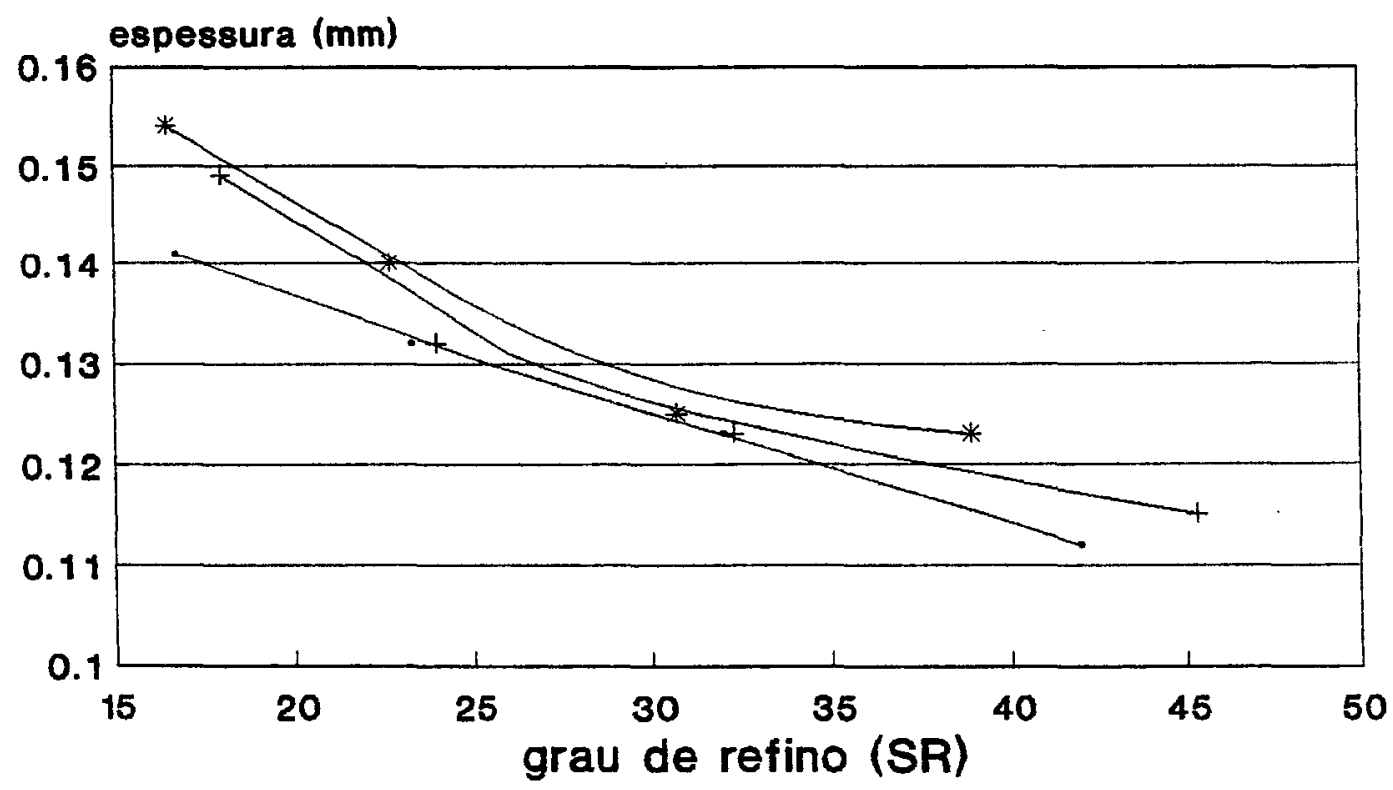

- kraft $\longrightarrow$ soda-AQ * soda

Figura 12. Espessura em função do grau de refino. 


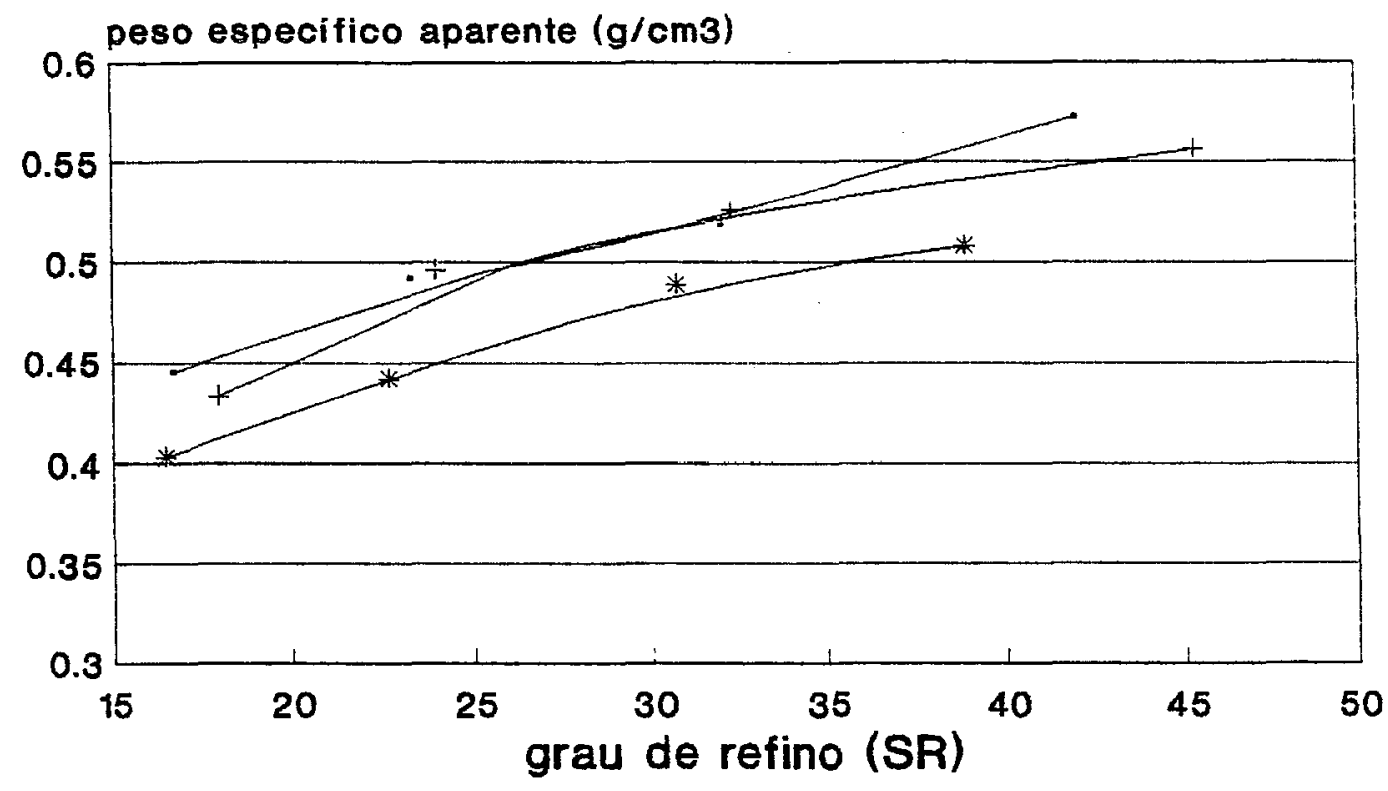

- kraft $\rightarrow$ soda-AQ - soda

Figura 13. Peso específico aparente em função do grau de refino.

volume especifico aparente $(\mathrm{cm} 3 / \mathrm{g})$

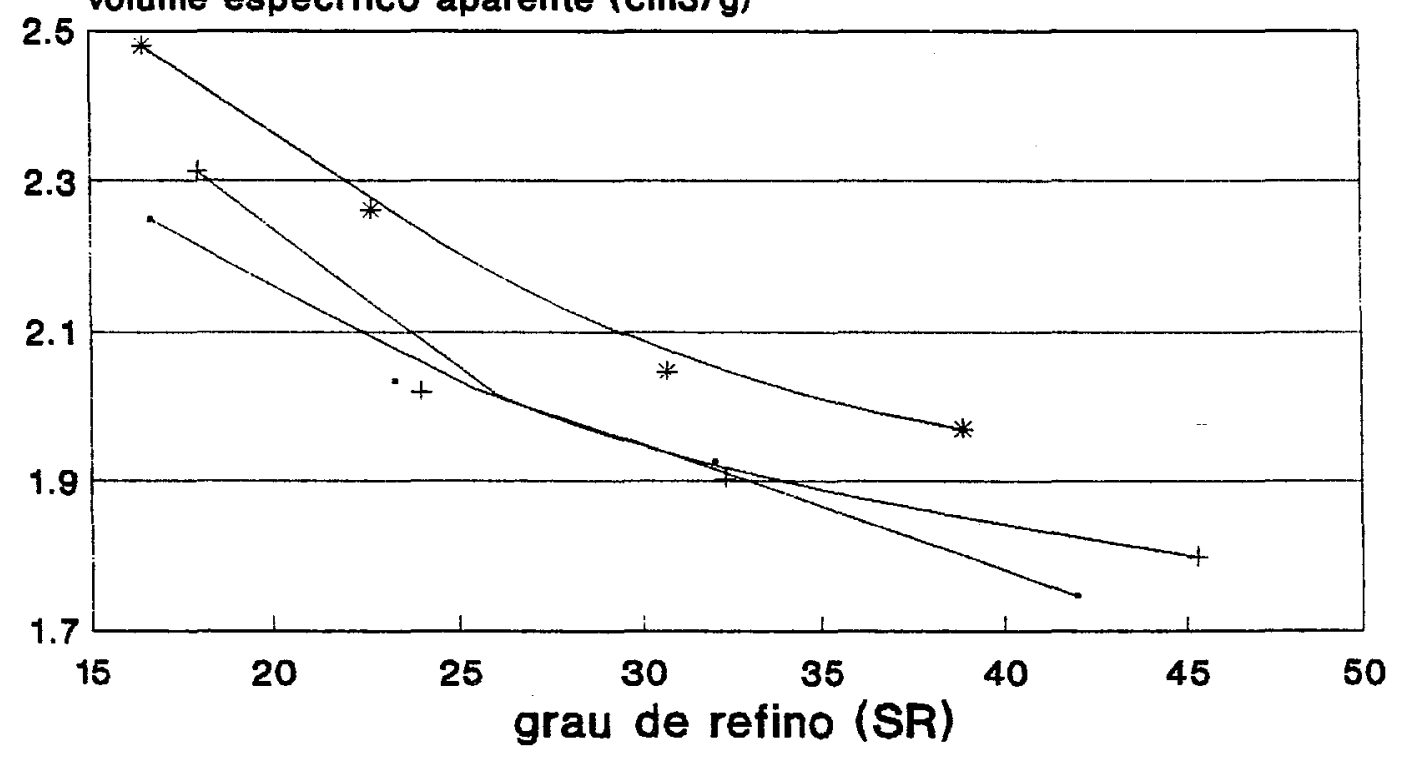

- kraft + soda-AQ $\rightarrow$ soda

Figura 14. Volume específico aparente em função do grau de refino. 


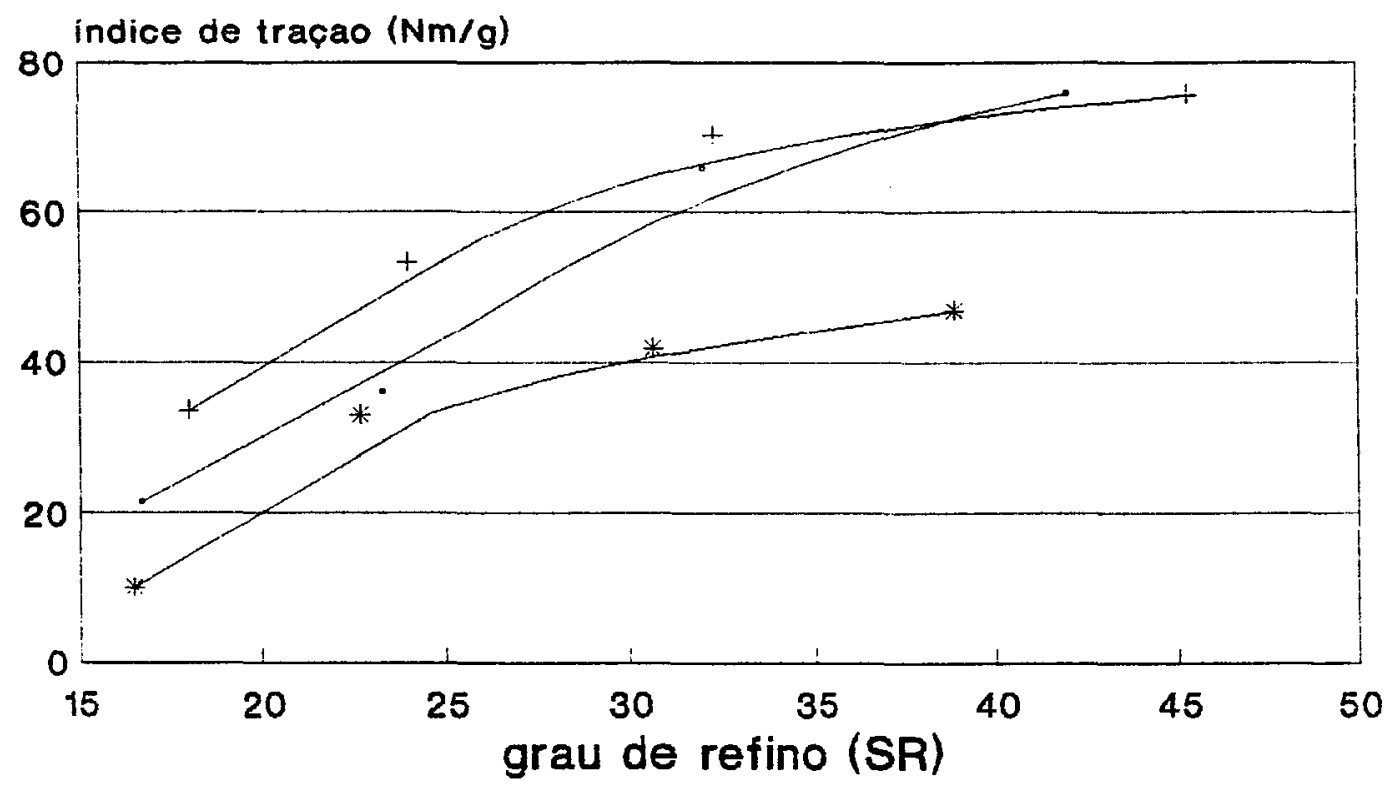

- kraft + soda-AQ * soda

Figura 15. Índice de tração em função do grau de refino.

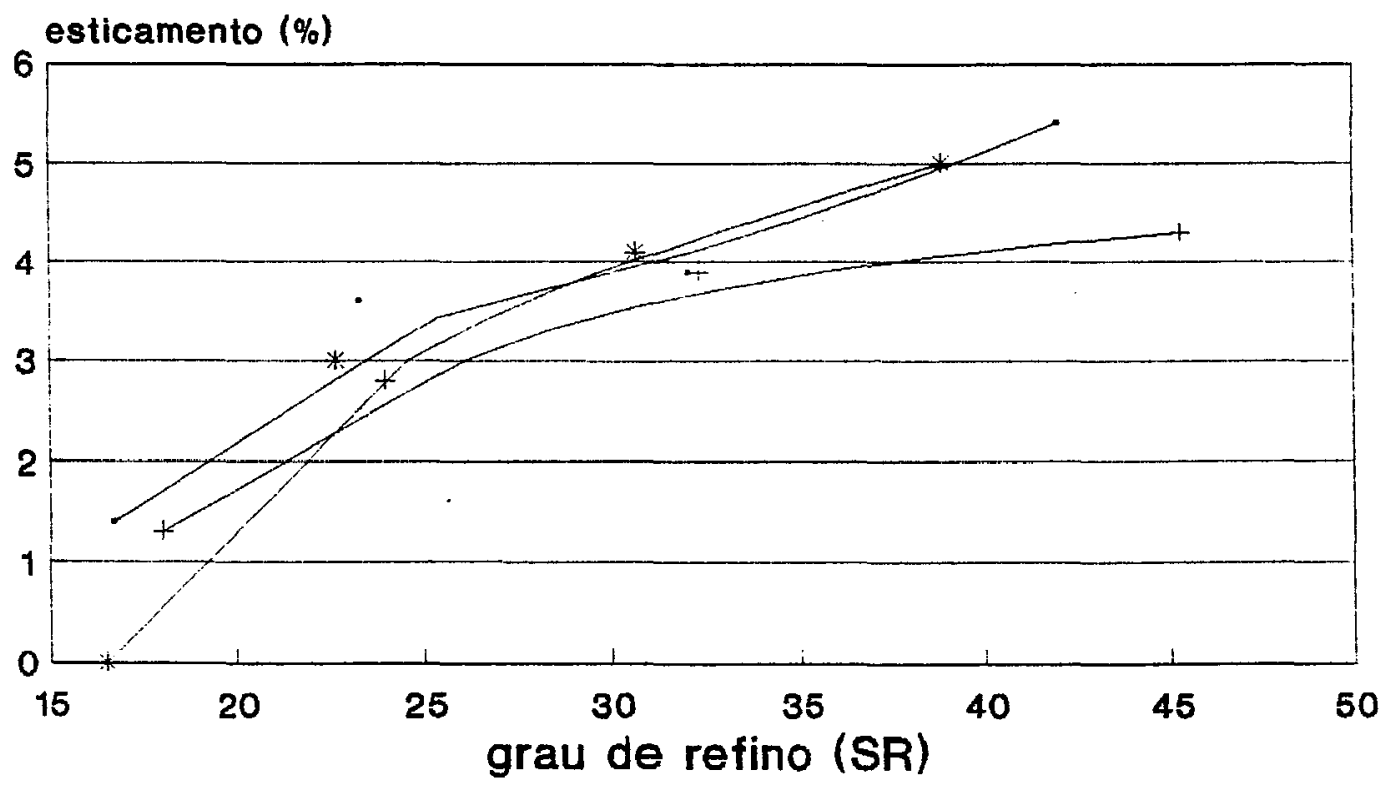

- kraft $\longrightarrow$ soda-AQ * soda

Figura 16. Esticamento em função do grau de refino. 


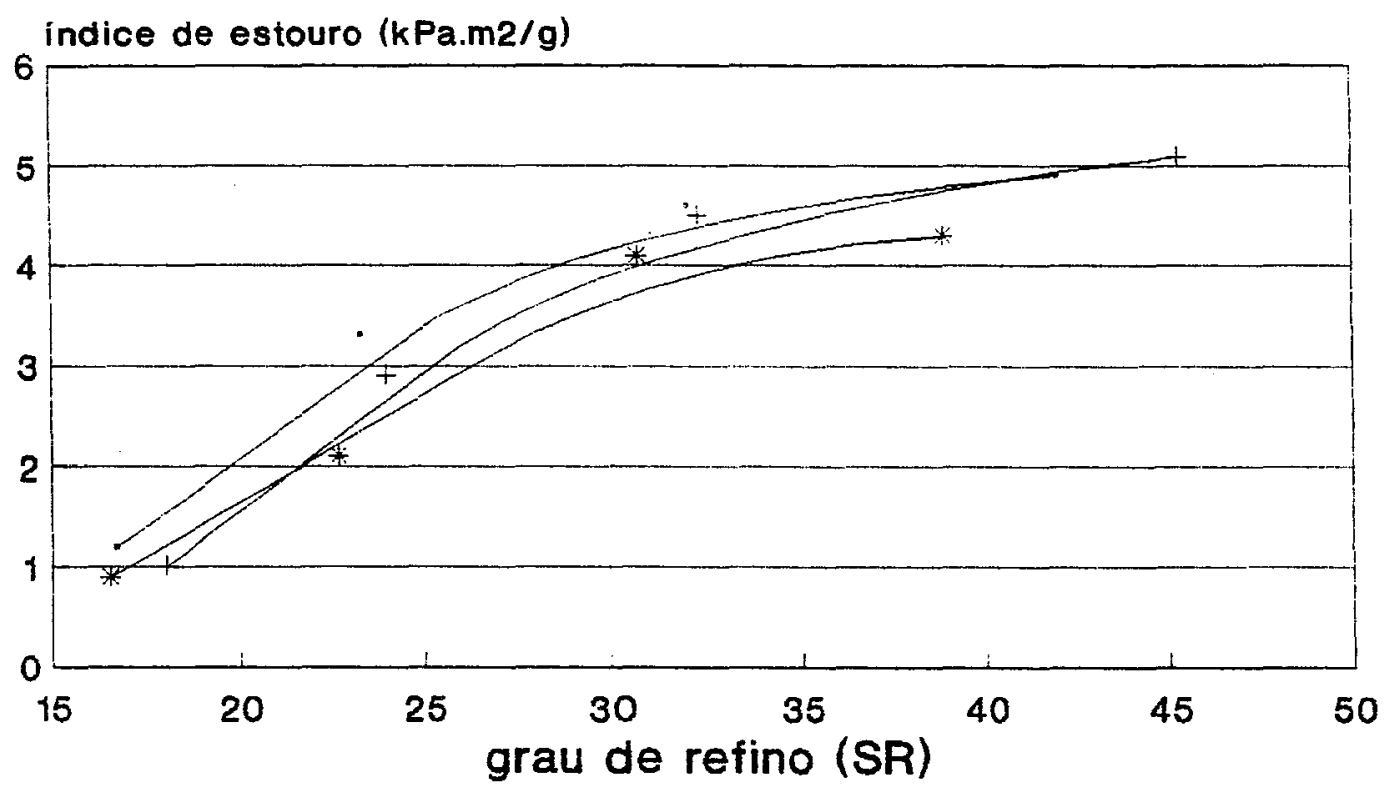

- kraft $\longrightarrow$ soda-AQ * soda

Figura 17. Índice de estouro em função do grau de refino.

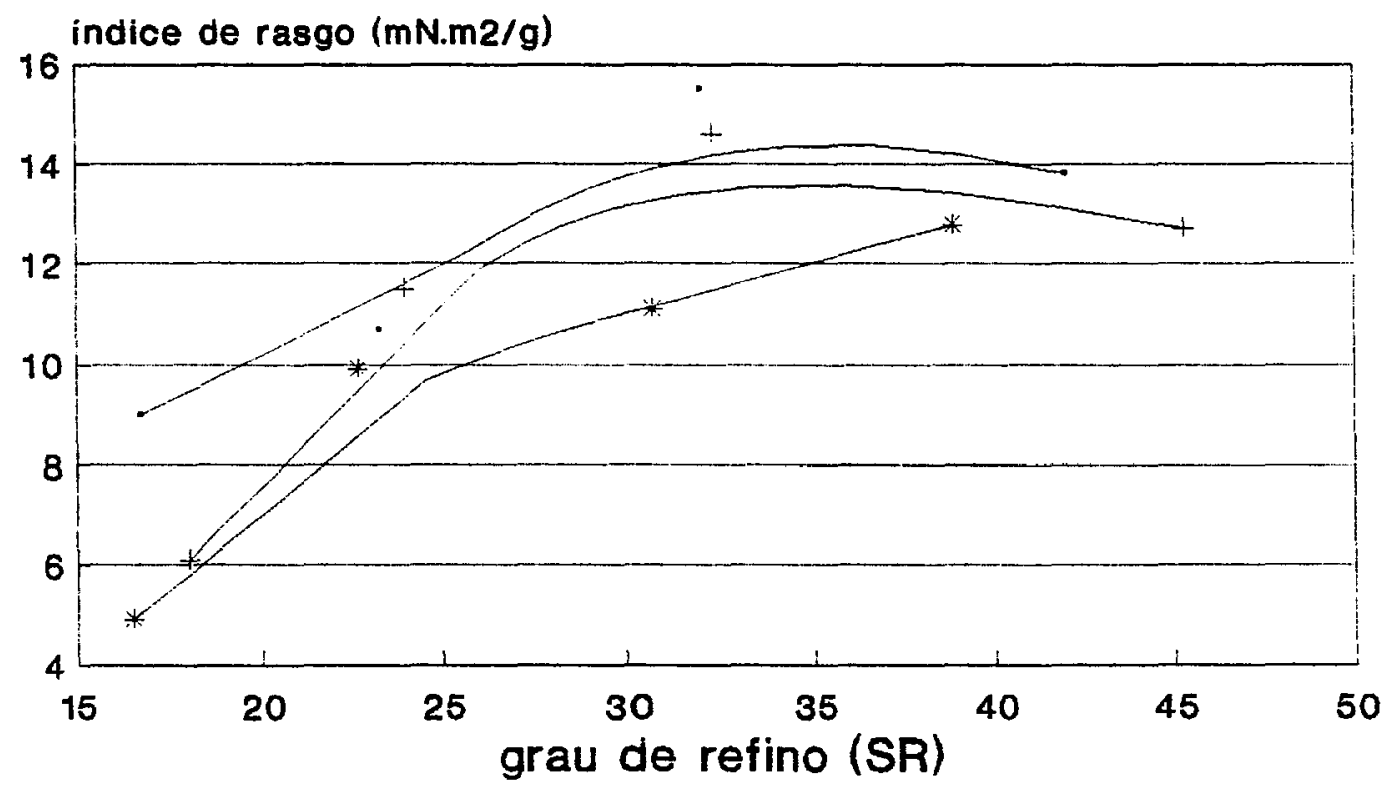

- kraft $\longrightarrow$ soda-AQ $\rightarrow$ soda

Figura 18. Índice de rasgo em função do grau de refino. 


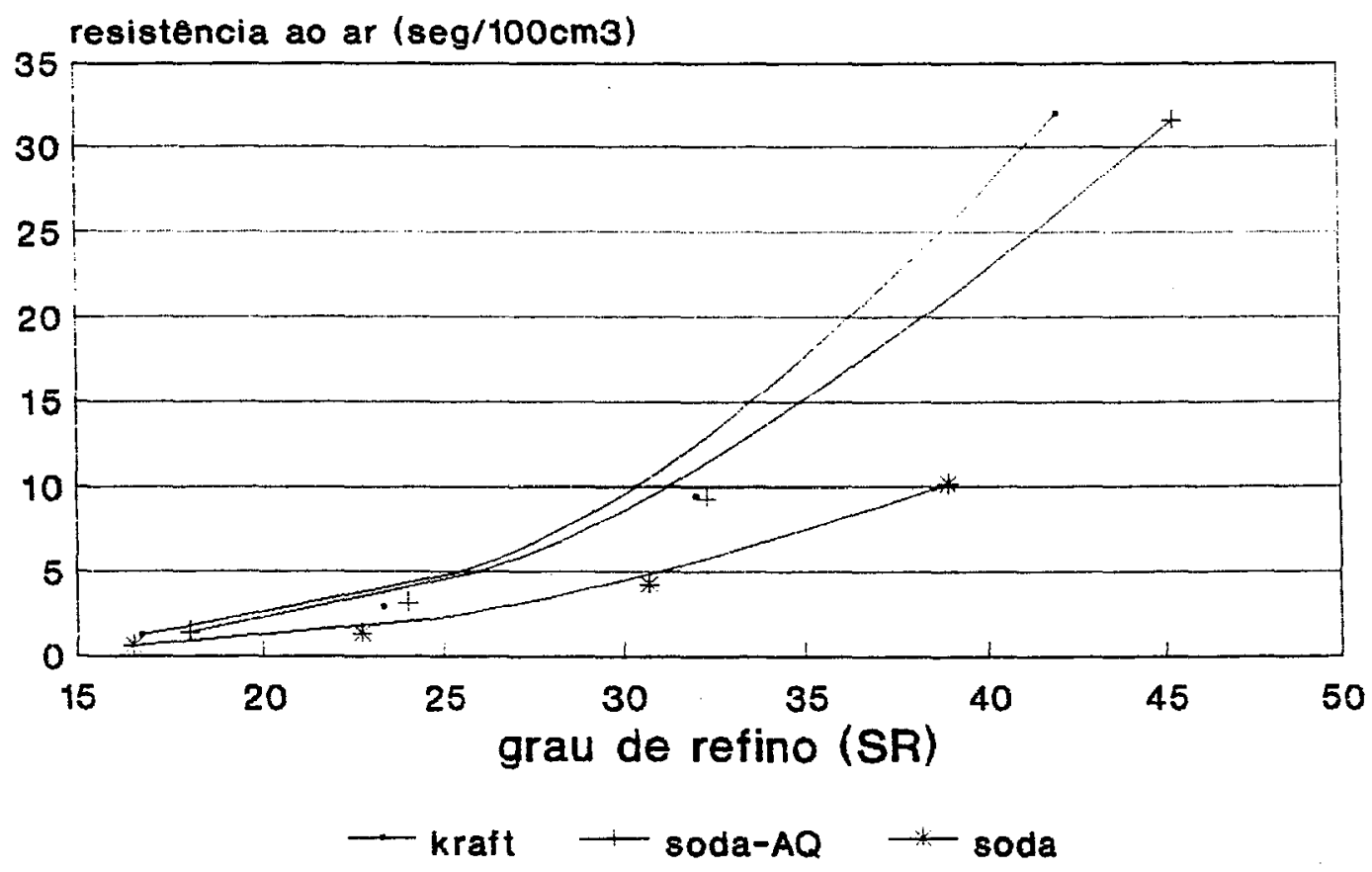

Figura 19. Resistência à passagem de ar em função do grau de refino. 
Na tabela 10 são apresentados os resultados das análises de licor negro.

Tabela 10. Análises de licor negro dos tratamentos 1,2 e 3 .

\begin{tabular}{|c|c|c|c|c|c|c|c|}
\hline tatnonto & 91 & (andols & owtols & no & hotopto & resdud & \\
\hline 1 & 12,55 & 1,06 & 14,47 & 66,08 & 33,92 & 3,9 & 2,6 \\
\hline 2 & 12,67 & 1,05 & 12,02 & 61,89 & 38,11 & 3,6 & 2,5 \\
\hline 3 & 12,81 & 1,05 & 12,01 & 62,84 & 37,16 & 5,2 & 2,3 \\
\hline
\end{tabular}

média de 2 determinações tratamento 1 - kraft convencional tratamento 2 - soda-AQ tratamento 3 - soda convencional

Na figura 20, foram plotados os resultados das análises de teor de sólidos e álcali ativo residual no licor negro dos tratamentos 1, 2 e 3 . 


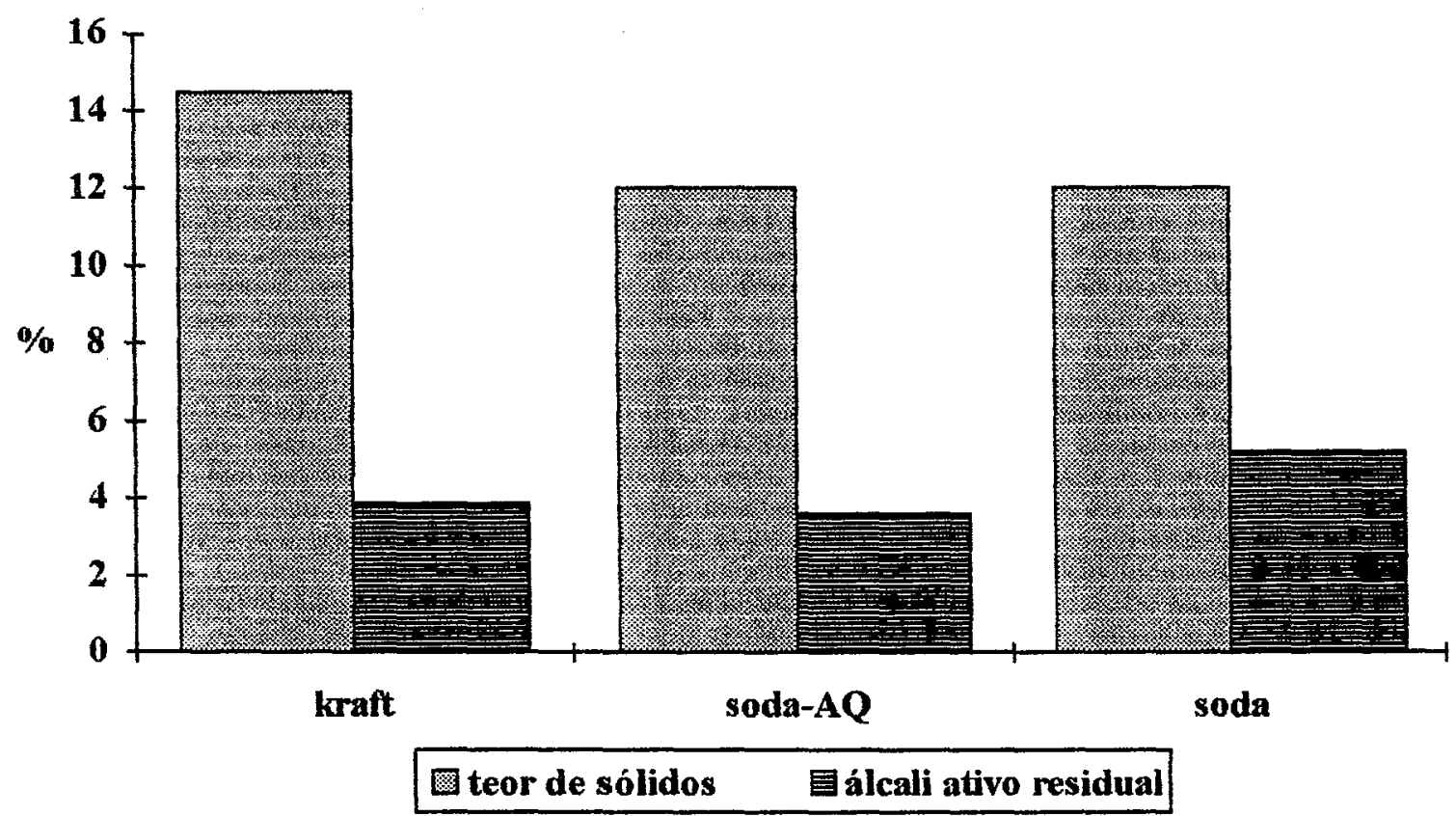

Figura 20. Teor de sólidos e álcali ativo residual dos tratamentos 1, 2 e 3.

\subsection{Determinação da dosagem ótima de DDA}

Foram realizados cozimentos com diferentes dosagens de DDA, sendo os tratamentos assim designados:

- tratamento 4 - soda-DDA com 0,04\% de DDA

- tratamento 5 - soda-DDA com 0,06\% de DDA

- tratamento 6 - soda-DDA com 0,08\% de DDA

- tratamento 7 - soda-DDA com $0,10 \%$ de DDA 
Na tabela 11, são apresentados os valores de rendimento bruto e depurado, teor de rejeitos e fator $\mathrm{H}$ das celuloses obtidas nos tratamentos 4, 5,6 e 7 .

Tabela 11. Rendimento bruto e depurado, teor de rejeitos para fator $\mathrm{H}$ igual a 677.

\begin{tabular}{|c|c|c|c|c|}
\hline \multicolumn{2}{|c|}{ trantorto } & \multirow{2}{*}{ 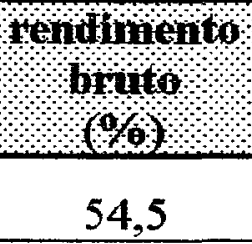 } & \multirow{2}{*}{ 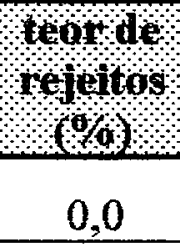 } & \multirow{2}{*}{ 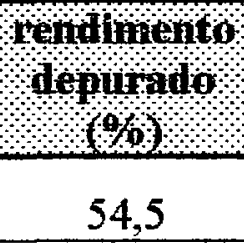 } \\
\hline 4 & $\mathbf{m}$ & & & \\
\hline & $\mathbf{s}$ & 0,51 & 0,00 & 0,51 \\
\hline & $\mathrm{CV}(\%)$ & 0,93 & $-\cdots$ & 0,93 \\
\hline \multirow[t]{3}{*}{4} & $\mathrm{~m}$ & 57,9 & 0,0 & 57,9 \\
\hline & $\mathbf{s}$ & 1,19 & 0,00 & 1,19 \\
\hline & $\mathrm{CV}(\%)$ & 2,05 & -- & 2,05 \\
\hline \multirow[t]{3}{*}{6} & $\mathbf{m}$ & 56,5 & 0,0 & 56,5 \\
\hline & $\mathbf{s}$ & 0,52 & 0,00 & 0,52 \\
\hline & $\mathrm{CV}(\%)$ & 0,92 & - & 0,92 \\
\hline \multirow[t]{3}{*}{3} & $\mathrm{~m}$ & 56,1 & 0,0 & 56,1 \\
\hline & $s$ & 0,18 & 0,00 & 0,18 \\
\hline & $\mathrm{CV}(\%)$ & 0,32 & --- & 0,32 \\
\hline
\end{tabular}

m - média

s - desvio-padrão

$\mathrm{CV}$ - coeficiente de variação tratamento 4 - soda- $0,04 \%$ DDA tratamento 5 - soda- $0,06 \%$ DDA tratamento 6 - soda- $0,08 \%$ DDA tratamento 7 - soda- $0,10 \%$ DDA 
Na tabela 12 são apresentados os resultados das análises químicas das celuloses obtidas nos tratamentos $4,5,6$ e 7 bem como algumas relações.

Tabela 12. Número kappa, viscosidade, lignina residual e relações.

\begin{tabular}{|c|c|c|c|c|c|c|}
\hline \multicolumn{2}{|c|}{ totanonto } & noppo & Prefold & 19 & rónpopto & 'rop \\
\hline \multirow[t]{3}{*}{4} & $\mathrm{~m}$ & 19,6 & 28,7 & 1,1 & 2,79 & 1,47 \\
\hline & $\mathrm{s}$ & 0,83 & 1,33 & 0,02 & 0,13 & 0,05 \\
\hline & $(v o d)$ & 4,23 & 4,65 & 2,19 & 4,68 & 3,29 \\
\hline \multirow[t]{3}{*}{5} & $\mathrm{~m}$ & 21,0 & 25,1 & 1,3 & 2,80 & 1,20 \\
\hline & $\mathrm{s}$ & 0,75 & 2,81 & 0,04 & 0,09 & 0,16 \\
\hline & $0 x(d)$ & 3,57 & 11,17 & 3,23 & 3,40 & 13,18 \\
\hline \multirow[t]{3}{*}{6} & 1 & 18,3 & 31,8 & 1,2 & 3,12 & 1,77 \\
\hline & 8 & 2,11 & 1,83 & 0,10 & 0,32 & 0,27 \\
\hline & 00 & 11,55 & 5.75 & 8,46 & 10,24 & 15,48 \\
\hline \multirow[t]{3}{*}{1} & $\mathrm{n}$ & 16,3 & 29,0 & 1,0 & 3,45 & 1,78 \\
\hline & 3 & 0,78 & 2,80 & 0,03 & 0,15 & 0,09 \\
\hline & 00 & 4,77 & 9,63 & 3,02 & 4,46 & 5,28 \\
\hline
\end{tabular}

m - média

s - desvio-padrão

$\mathrm{CV}$ - coeficiente de variação tratamento 4 - soda- $0,04 \%$ DDA tratamento 5 - soda-0,06\% DDA tratamento 6 - soda- $0,08 \%$ DDA tratamento 7 - soda- $0,10 \%$ DDA 
Na figura 21 estão representados os resultados de rendimento depurado, número kappa e viscosidade das celuloses obtidas nos tratamentos 3,4 , 5,6 e 7 .

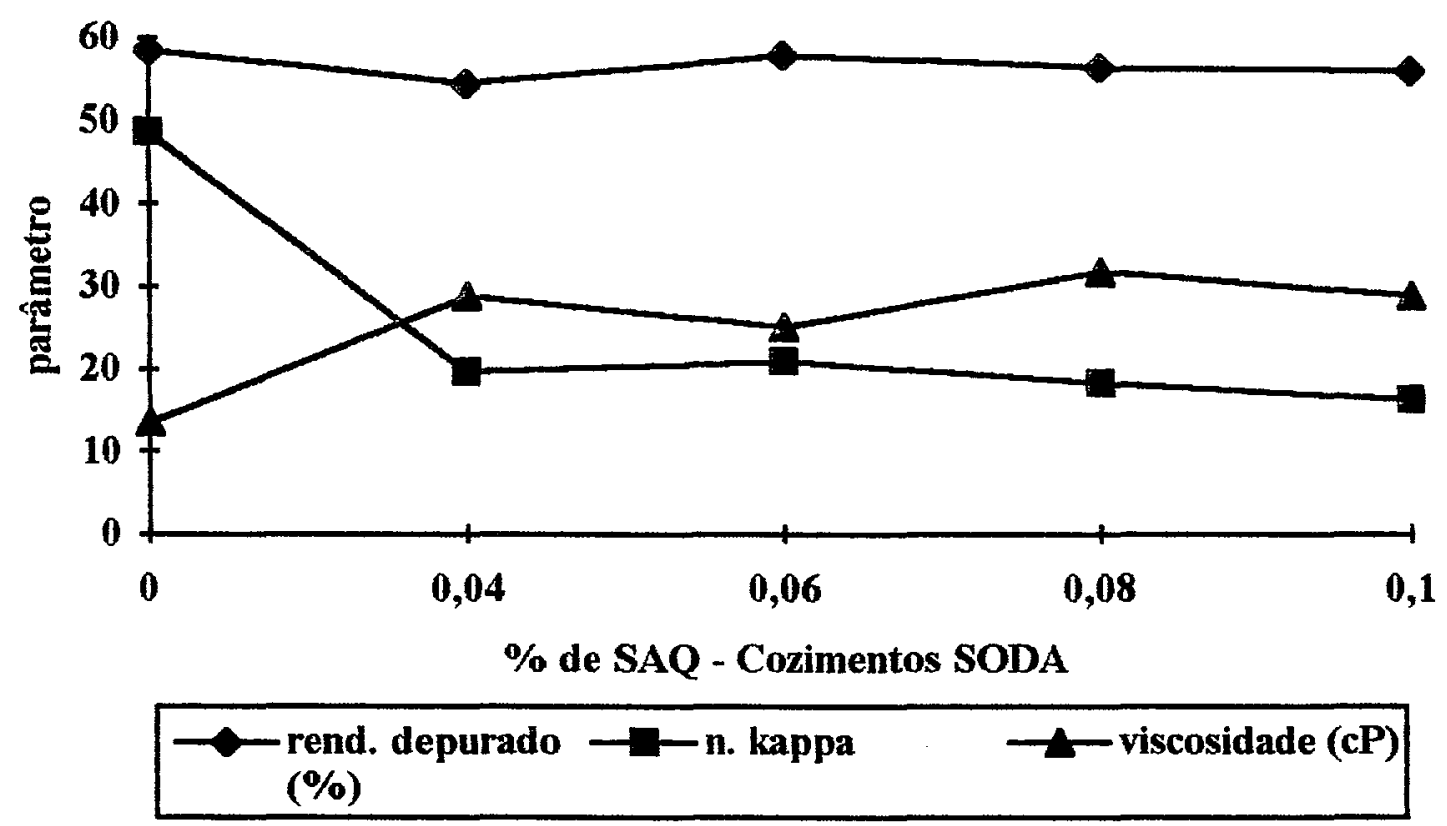

Figura 21. Número kappa, viscosidade e rendimento depurado das celuloses em função da dosagem de DDA utilizada. 
$\mathrm{Na}$ figura 22 são apresentadas a relação rendimento depurado/ kappa e viscosidade/kappa em função da dosagem de DDA empregada nos cozimentos

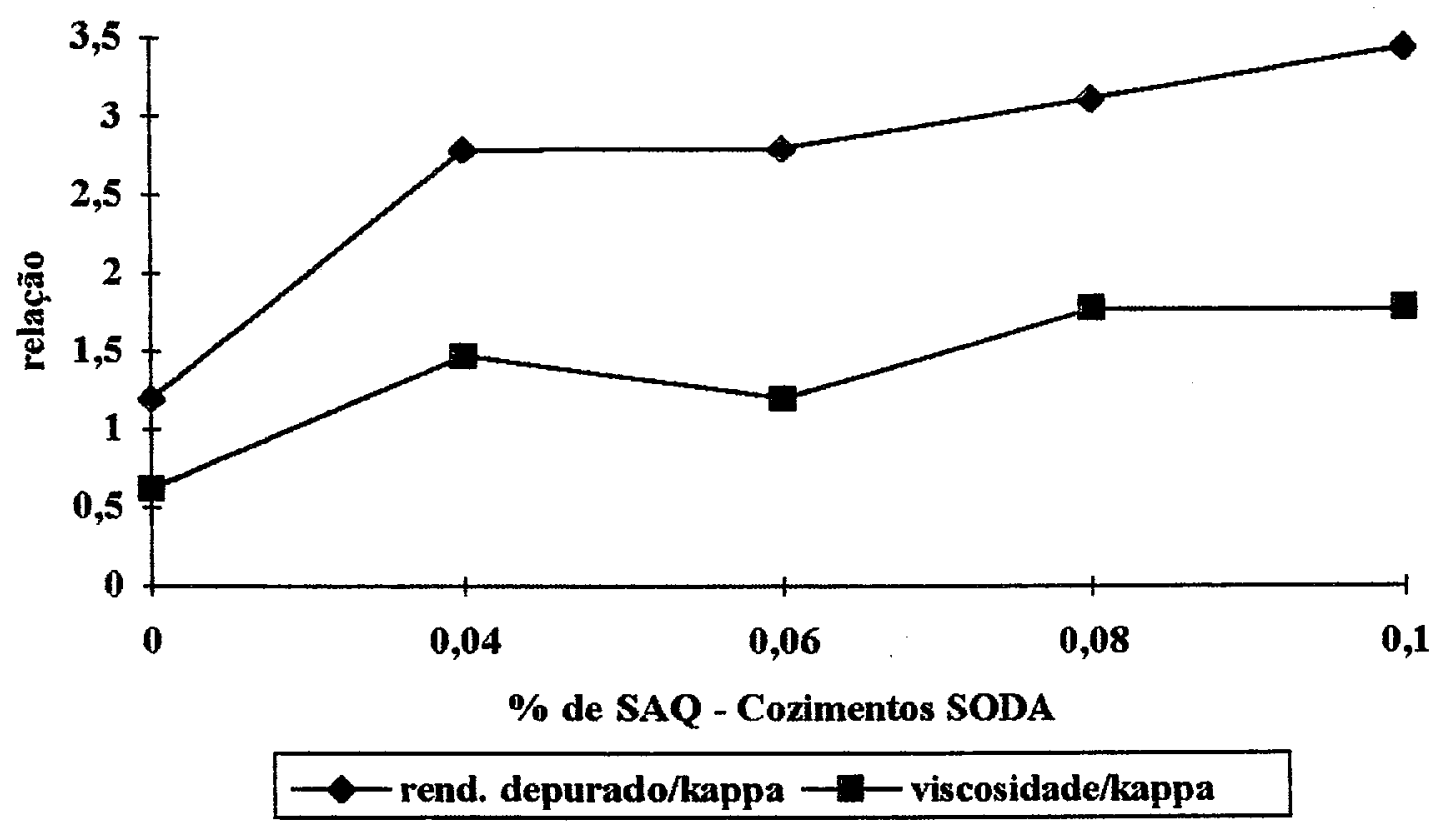

Figura 22. Relação rendimento depurado/kappa e viscosidade/kappa em função da dosagem de DDA utilizada.

Na tabela 13 são apresentados os resultados das análises de teor de pentosanas e alfa, beta e gama celulose dos tratamentos $4,5,6$ e 7 . 
Tabela 13. Teor de pentosanas e alfa, beta e gama celuloses dos tratamentos 4, 5, 6, 7 .

\begin{tabular}{|l}
\hline \\
\hline
\end{tabular}

$\mathrm{m}$ - média

s - desvio-padrão

CV - coeficiente de variação tratamento 4 - soda- $0,04 \%$ DDA tratamento 5 - soda- $0,06 \%$ DDA tratamento 6 - soda- $0,08 \%$ DDA tratamento 7 - soda-0,10\% DDA 
Nas tabelas 14, 15, 16 e 17 são apresentados os resultados dos testes físicos e mecânicos realizados com as celuloses dos tratamentos $4,5,6$ e 7 .

Tabela 14. Propriedades físicas e mecânicas da celulose do tratamento 4 - soda-0,04\%DDA.

\begin{tabular}{|c|c|c|c|c|}
\hline 1renolucoes & 9 & 2000 & now & 6000 \\
\hline gnauderenno (os S) & 18,3 & 22,0 & 30,7 & 41,0 \\
\hline mann ha $(\mathrm{gm})$ & 60,9 & 58,1 & 57,6 & 61,6 \\
\hline espessula $(1 \mathrm{n})$ & 0,142 & 0,122 & 0,117 & 0,115 \\
\hline 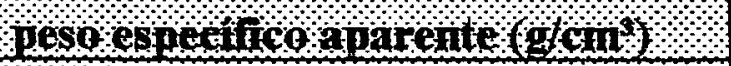 & 0,429 & 0.477 & 0,502 & 0,528 \\
\hline 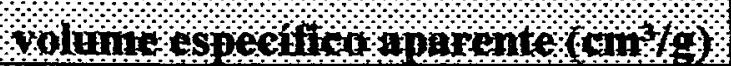 & 2,330 & 2,095 & 1.990 & 1.893 \\
\hline 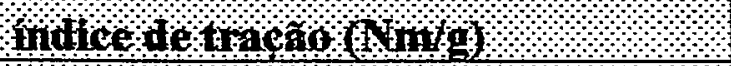 & 37,8 & 58,0 & 59,3 & 67,8 \\
\hline 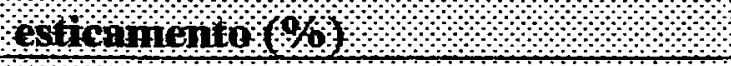 & 1,4 & 2,9 & 3,6 & 4,2 \\
\hline 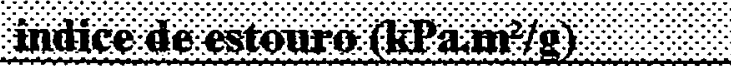 & 1,3 & 3.1 & 4,1 & 4,6 \\
\hline 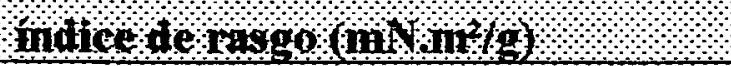 & 7,2 & 11,6 & 13,3 & 13,1 \\
\hline 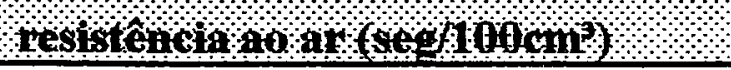 & 1,3 & 2.8 & 7,1 & 19,8 \\
\hline
\end{tabular}


Tabela 15. Propriedades físicas e mecânicas da celulose do tratamento 5 - soda- $0,06 \%$ DDA.

\begin{tabular}{|c|c|c|c|c|}
\hline rotolucos & 0 & 2000 & 4000 & 6000 \\
\hline 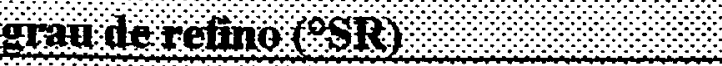 & 17,0 & 23,0 & 30,7 & 39,7 \\
\hline Homaturn $(\mathrm{q}, \mathrm{n})$ & 59,7 & 58,5 & 59,2 & 59,8 \\
\hline 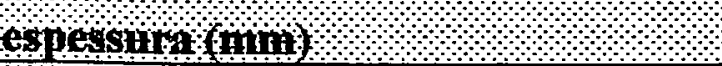 & 0,147 & 0,120 & 0,109 & 0,107 \\
\hline 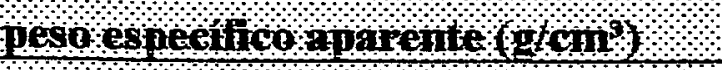 & 0,407 & 0,489 & 0,543 & 0,548 \\
\hline 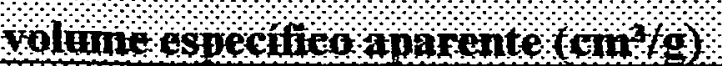 & 2,454 & 2.043 & 1,842 & 1,826 \\
\hline 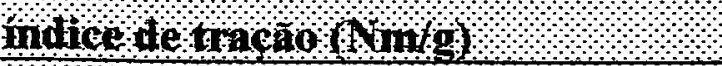 & 31,0 & 59,7 & 69.3 & 78.1 \\
\hline eston 10100 & 2,5 & 2,8 & 3,4 & 4,3 \\
\hline 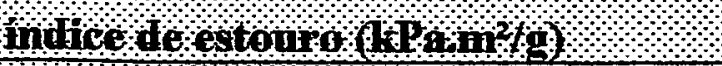 & 1,2 & 3,1 & 4,5 & 5,0 \\
\hline 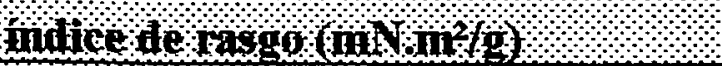 & 7,5 & 12,0 & 13,3 & 12,4 \\
\hline 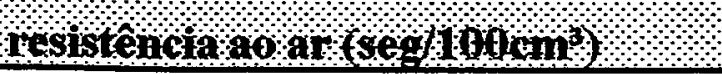 & 1,1 & 3,4 & 14,2 & 35,8 \\
\hline
\end{tabular}


Tabela 16. Propriedades físicas e mecânicas da celulose do tratamento 6 - soda- $0,08 \%$ DDA.

\begin{tabular}{|c|c|c|c|c|}
\hline $1000 \mathrm{hrogs}$ & 0 & 2000 & 4000 & 6000 \\
\hline 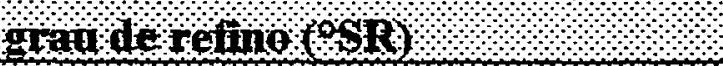 & 16,3 & 22,0 & 29,7 & 40,7 \\
\hline 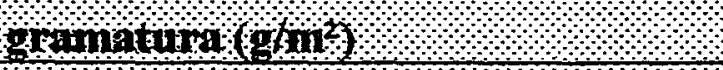 & 59,8 & 58,1 & 59,7 & 58,2 \\
\hline 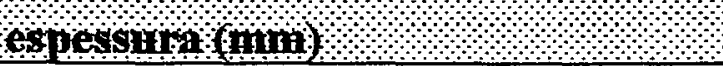 & 0,141 & 0,120 & 0,113 & 0,105 \\
\hline 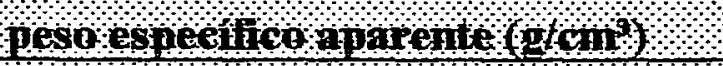 & 0,424 & 0,485 & 0,529 & 0,553 \\
\hline 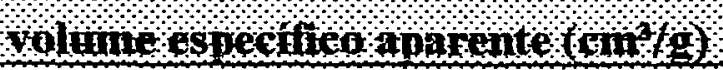 & 2,360 & 2.061 & 1,889 & 1.809 \\
\hline 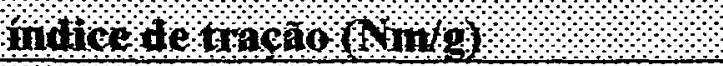 & 35,2 & 58,6 & 72,1 & 76.2 \\
\hline 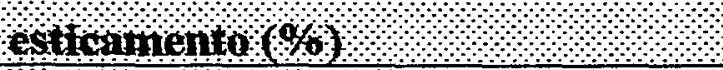 & 1,1 & 2,6 & 3,8 & 4,2 \\
\hline 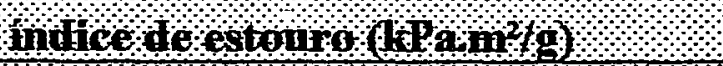 & 1,1 & 3,3 & 4,5 & 5,0 \\
\hline 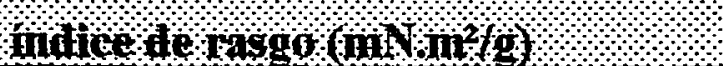 & 7,7 & 12,2 & 14,7 & 13,5 \\
\hline 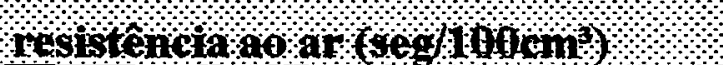 & 1,9 & 3,4 & 11,4 & 37,7 \\
\hline
\end{tabular}


Tabela 17. Propriedades físicas e mecânicas da celulose do tratamento 7 - soda-0,10\%DDA.

\begin{tabular}{|c|c|c|c|c|}
\hline revoluores & 0 & 2000 & 4000 & 6000 \\
\hline 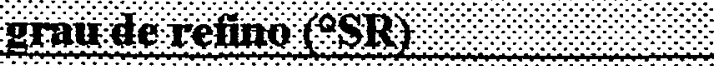 & 18,0 & 23,0 & 29,3 & 41,3 \\
\hline 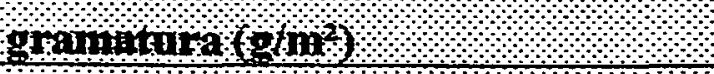 & 61,9 & 60,9 & 60,7 & 62,5 \\
\hline 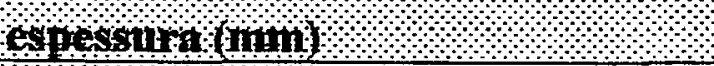 & 0.150 & 0,125 & 0,119 & 0,116 \\
\hline 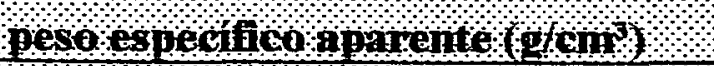 & 0,413 & 0,489 & 0,511 & 0,539 \\
\hline 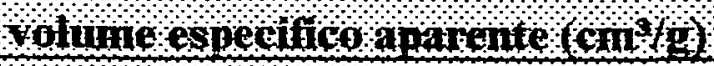 & 2,423 & 2.046 & 1,957 & 1,856 \\
\hline 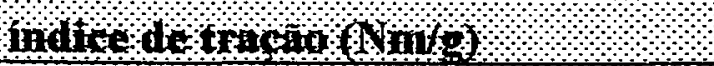 & 33,4 & 56,6 & 63.7 & 69,0 \\
\hline estankento $(0)$ & 1,3 & 2,4 & 3,6 & 4,3 \\
\hline 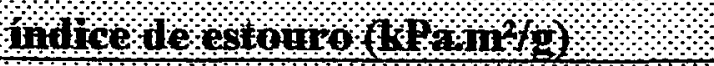 & 1,2 & 3,3 & 4,0 & 4,9 \\
\hline 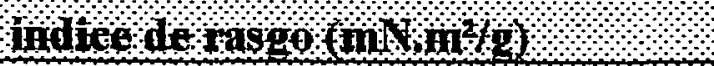 & 7,7 & 9,9 & 11,8 & 12,6 \\
\hline 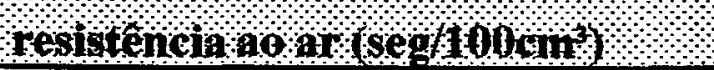 & 1,1 & 3,2 & 7,8 & 23,2 \\
\hline
\end{tabular}



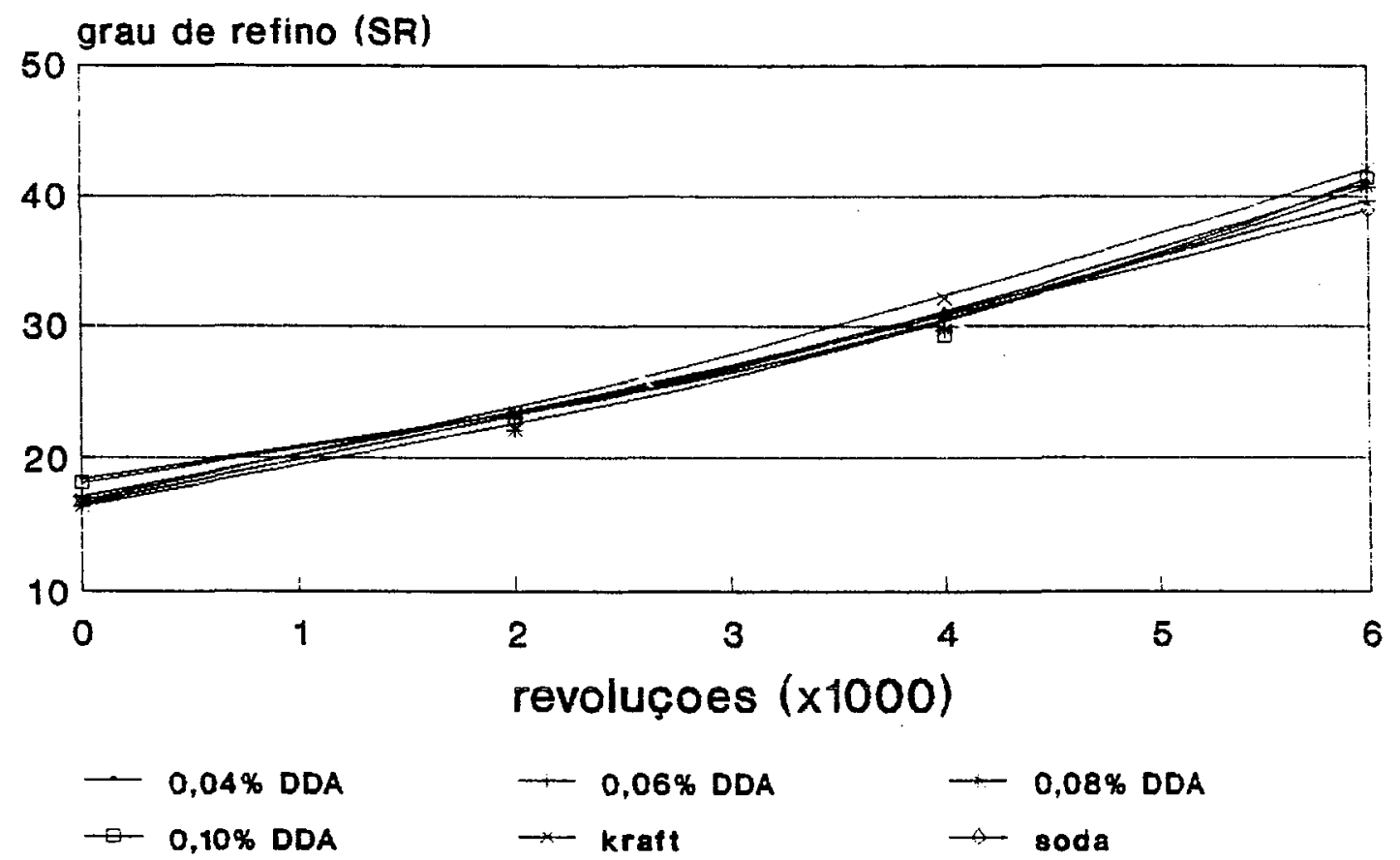

Figura 23. Grau de refino em função do número de revoluções (moinho PFI).

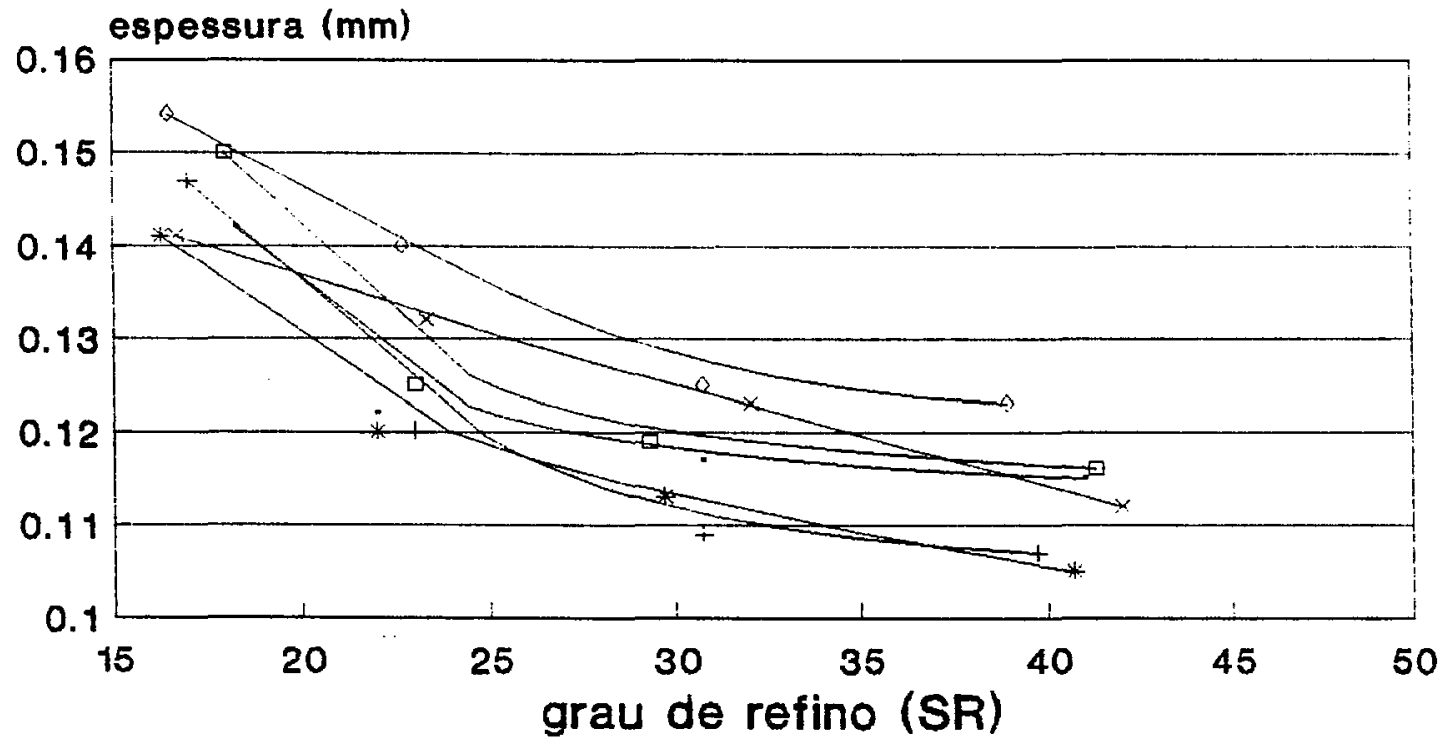
- $0,04 \%$ DDA
$-0,06 \%$ DDA
* $0,08 \%$ DDA
$=0,10 \% \mathrm{DDA}$
$\longrightarrow$ kraft
$\rightarrow$ soda

Figura 24. Espessura em função do grau de refino. 


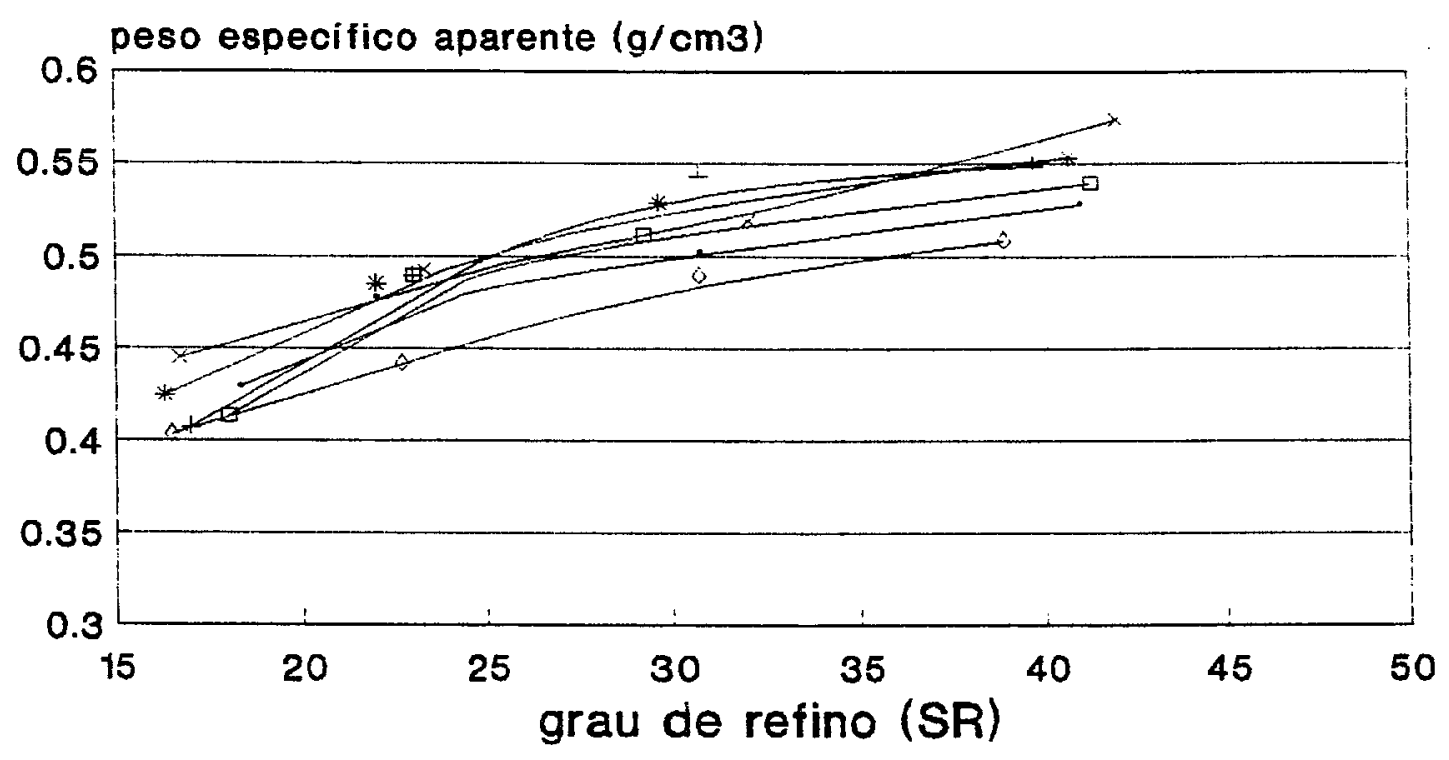

$\begin{array}{lll}-0,04 \% \text { DDA } & +0,06 \% \text { DDA } & * 0,08 \% \text { DDA } \\ -0,10 \% \text { DDA } & * \text { kratt } & -80 d a\end{array}$

Figura 25. Peso especifico aparente em função do grau de refino.

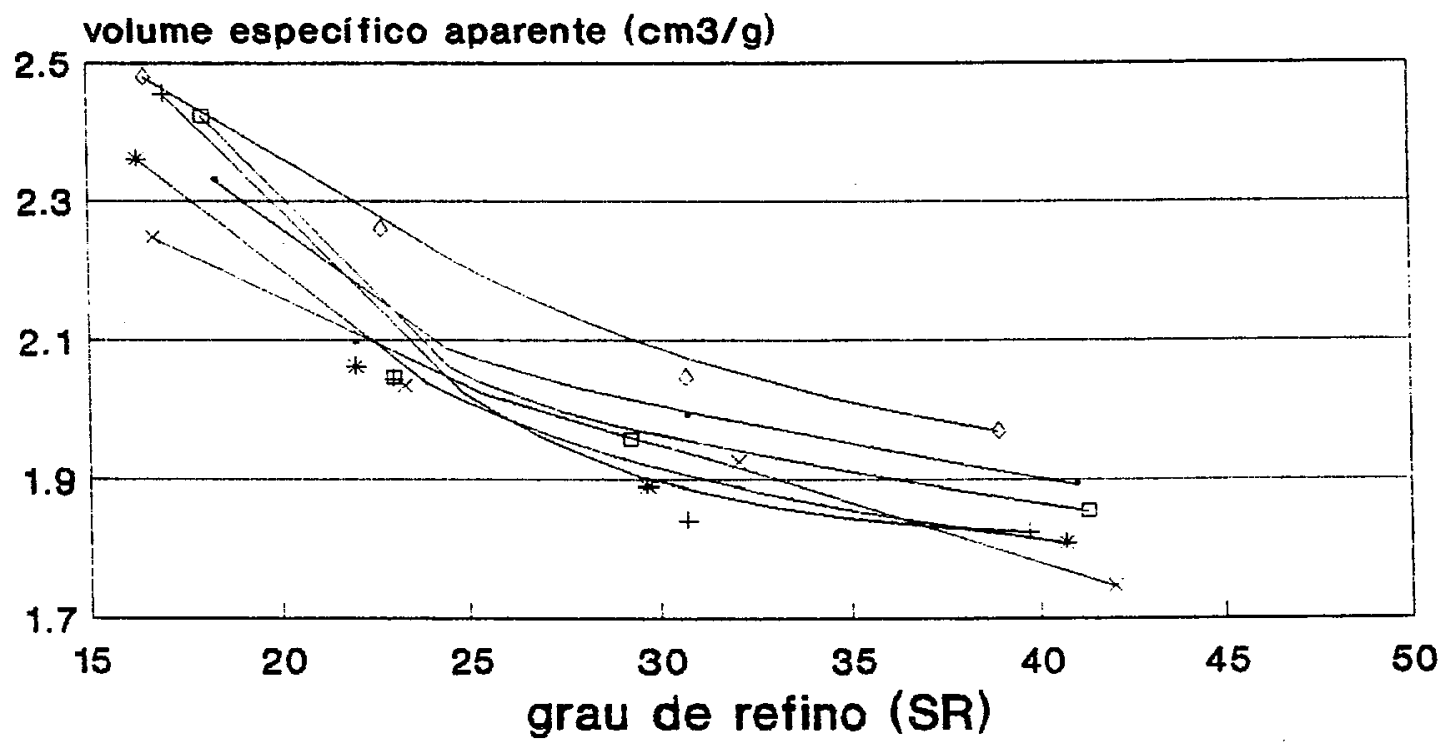

$\begin{array}{lll}=0,04 \% \mathrm{DDA} & +0,06 \% \mathrm{DDA} & -0,08 \% \mathrm{DDA} \\ =0,10 \% \mathrm{DDA} & - \text { kraft } & - \text { soda }\end{array}$

Figura 26. Volume especifico aparente em função do grau de refino. 


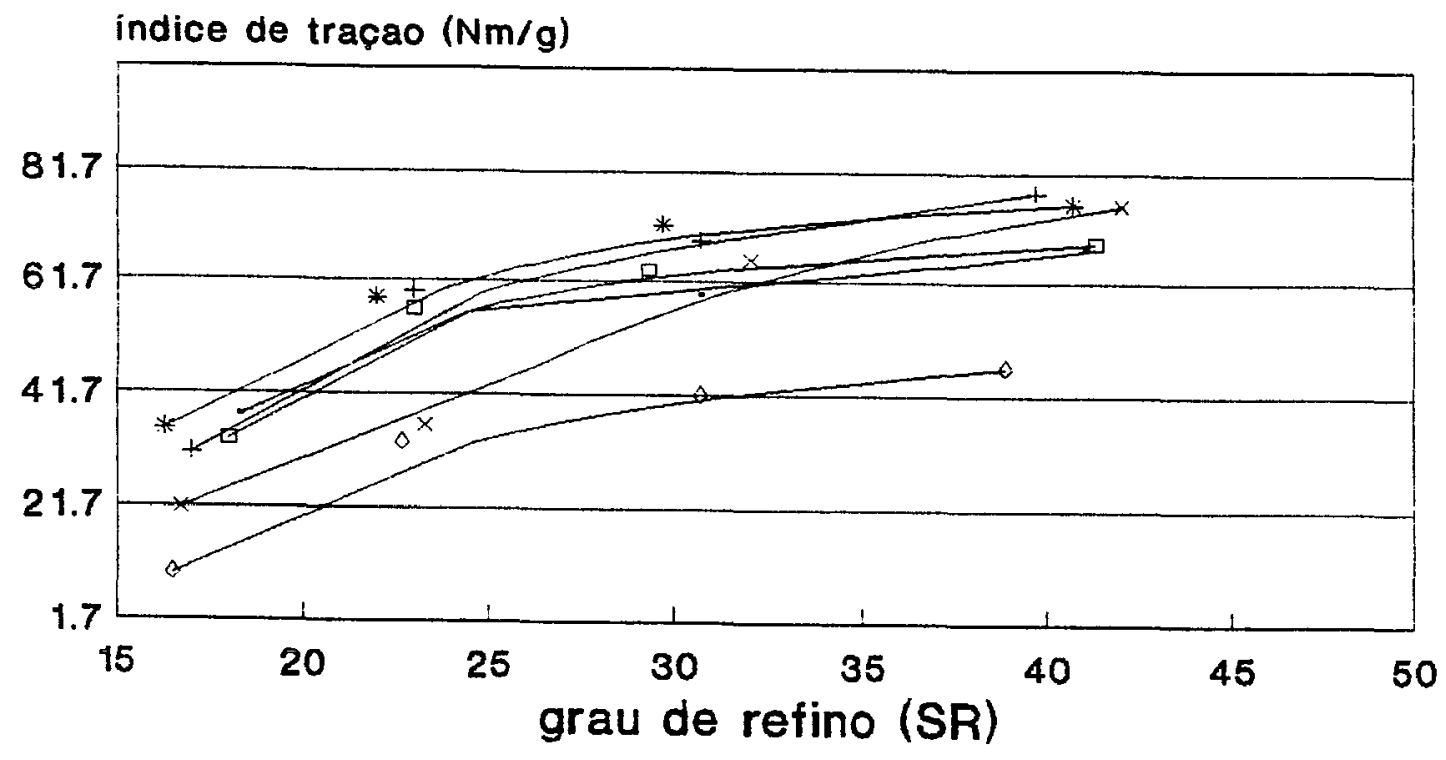

$\begin{array}{lll}-0,04 \% \text { DDA } & \rightarrow 0,06 \% \text { DDA } & * 0,08 \% \text { DDA } \\ \rightarrow 0,10 \% \text { DDA } & \rightarrow \text { kraft } & - \text { soda }\end{array}$

Figura 27. Índice de tração em função do grau de refino.

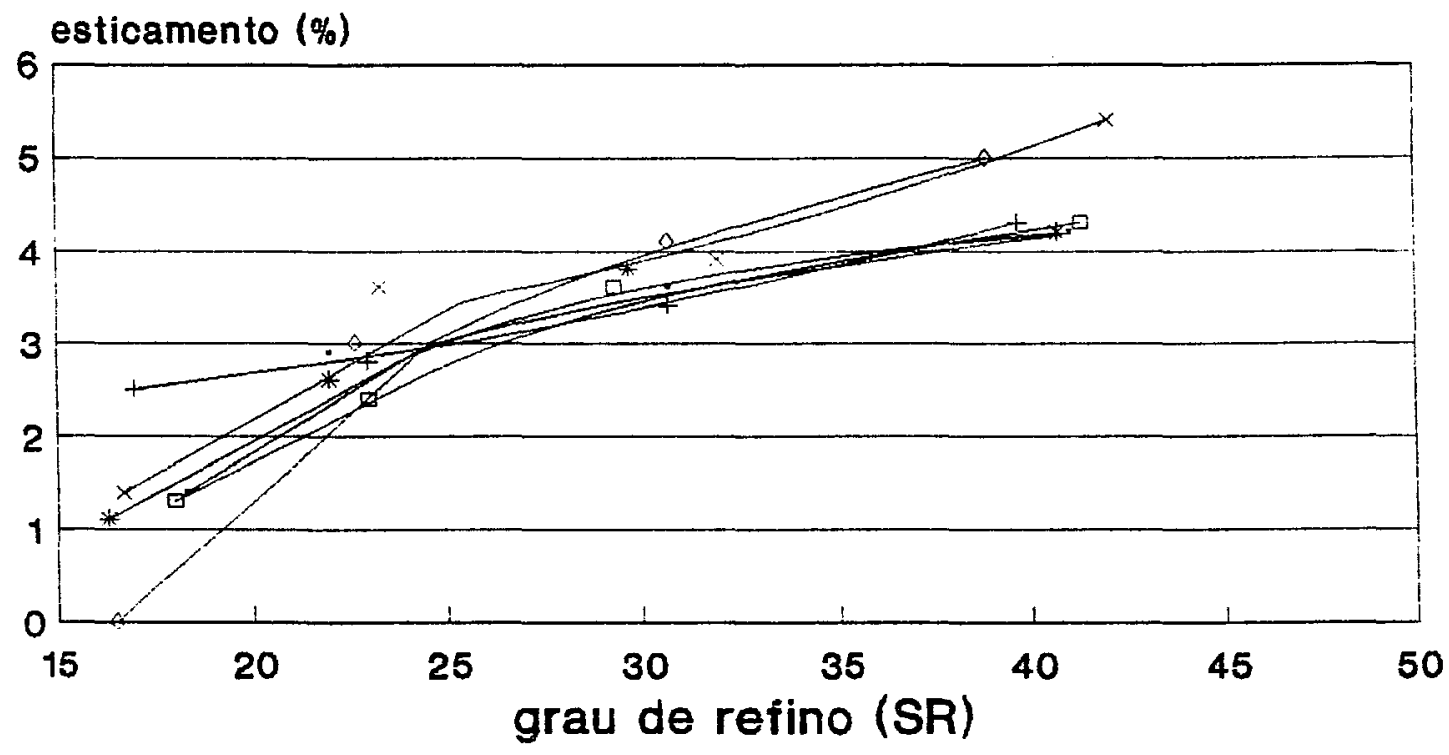
- $0,04 \%$ DDA
$+0,06 \%$ DDA
* $\quad 0,08 \%$ DDA
$\square \quad 0,10 \%$ DDA
$\multimap$ kraft
스 soda

Figura 28. Esticamento em função do grau de refino. 


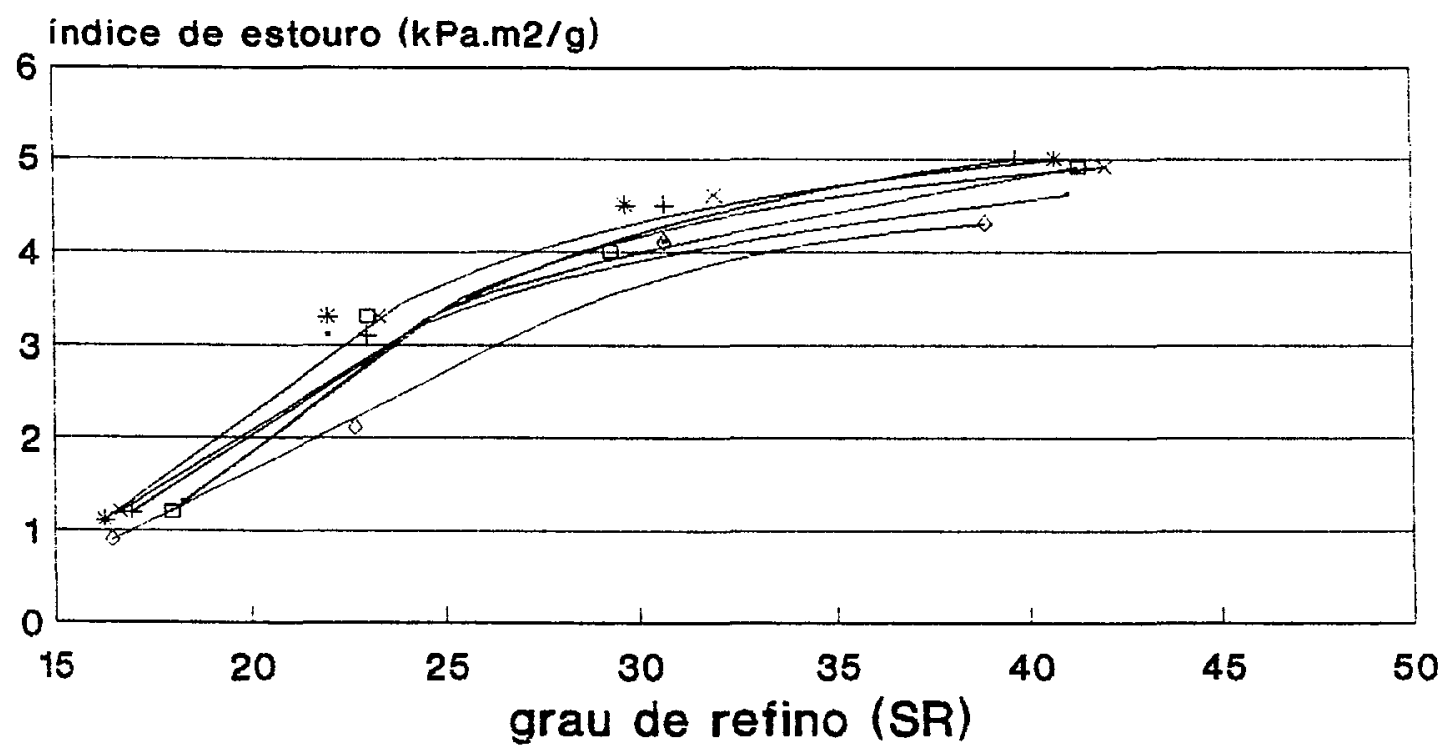

$\begin{array}{lll}-0,04 \% \mathrm{DDA} & +0,06 \% \mathrm{DDA} & * 0,08 \% \mathrm{DDA} \\ =0,10 \% \mathrm{DDA} & - \text { kraft } & - \text { soda }\end{array}$

Figura 29. Índice de estouro em função do grau de refino.

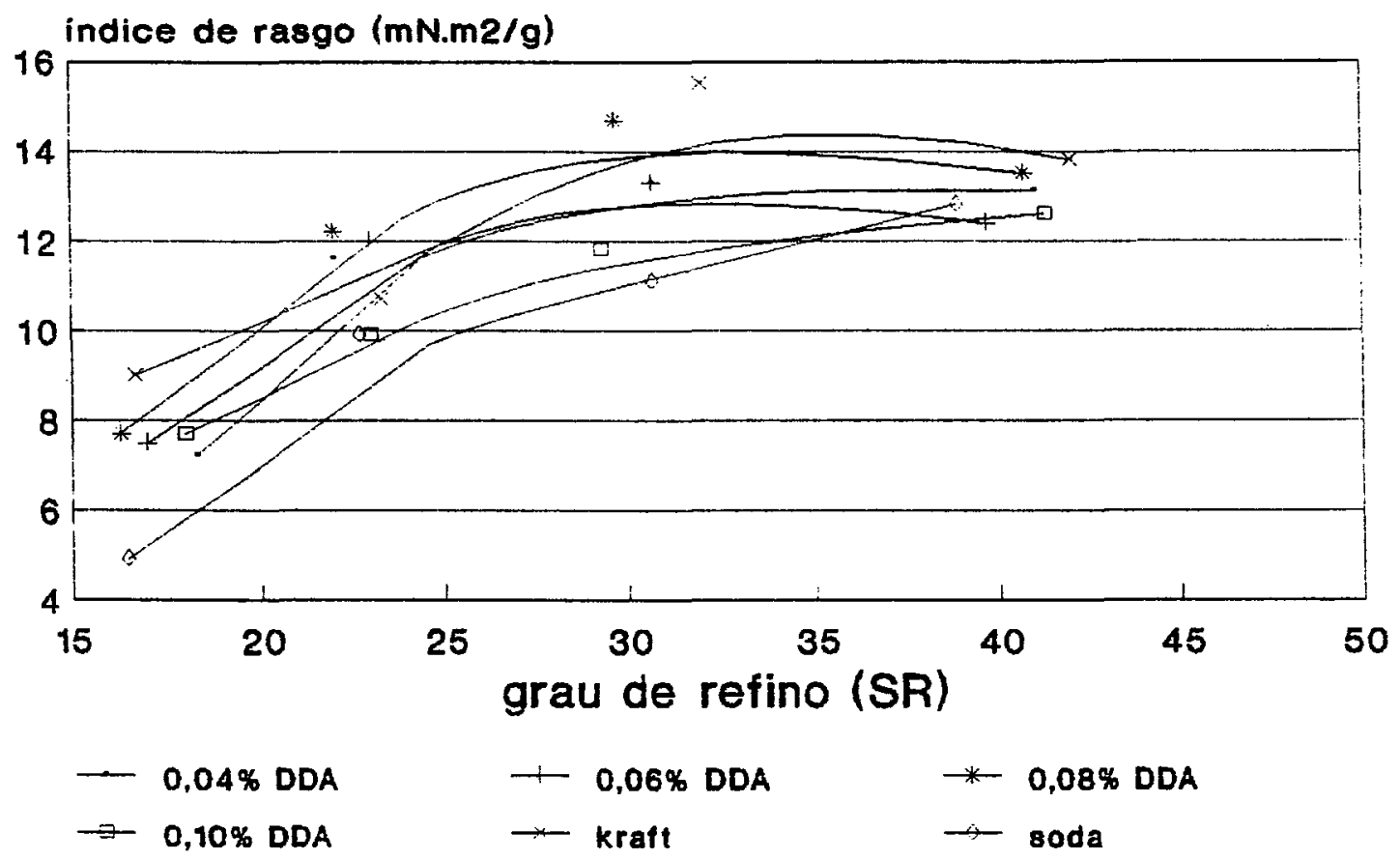

Figura 30. Índice de rasgo em função do grau de refino. 


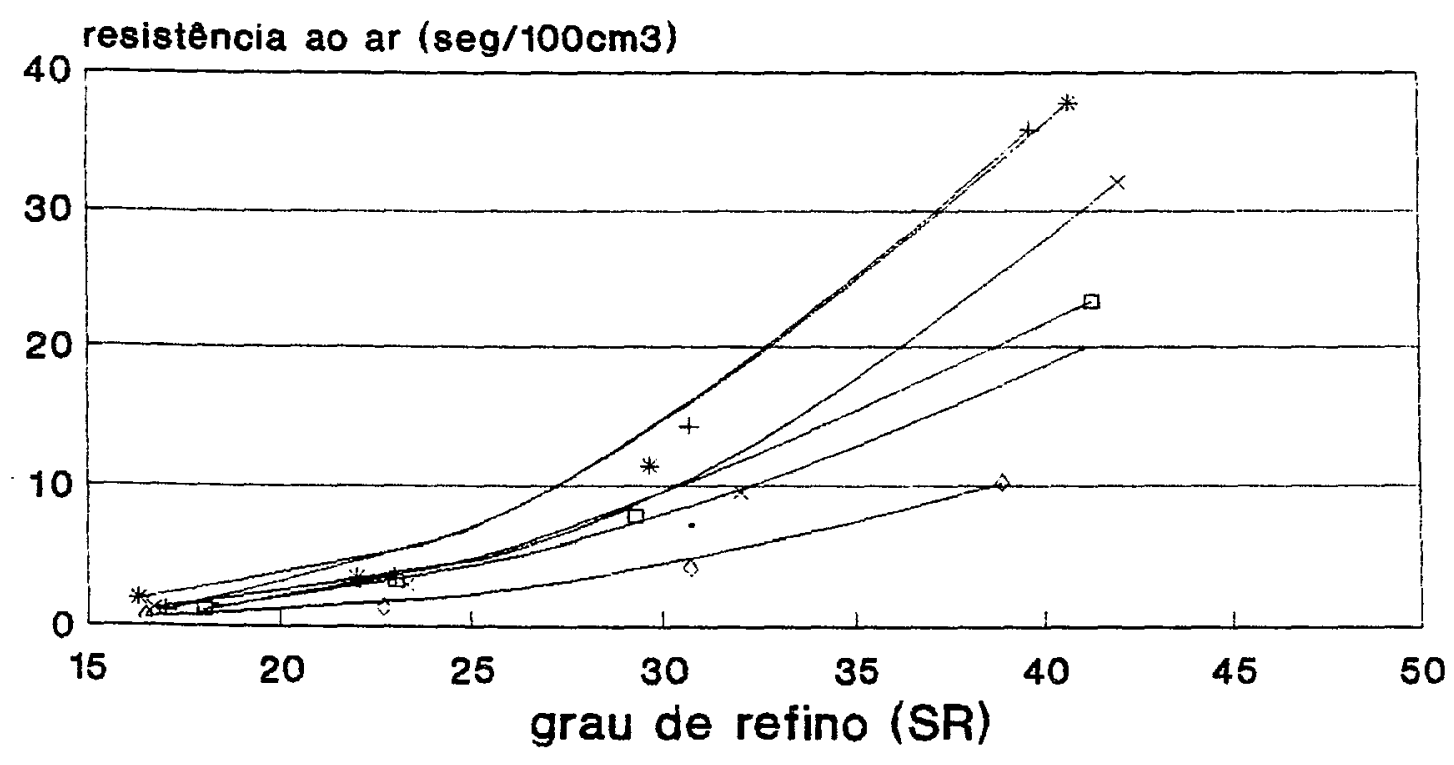

$\begin{array}{lll}-0,04 \% \text { DDA } & \rightarrow 0,06 \% \text { DDA } & -0,08 \% \text { DDA } \\ \rightarrow 0,10 \% \text { DDA } & \rightarrow \text { kraft } & - \text { soda }\end{array}$

Figura 31. Resistência à passagem de ar em função do grau de refino. 
Na tabela 18 são apresentados os resultados das análises de licor negro.

Tabela 18. Análises de licor negro dos tratamentos 4, 5, 6 e 7.

\begin{tabular}{|c|c|c|c|c|c|c|c|}
\hline fruphtpto & $\mathrm{pH}$ & fonsto & pofto & nthtorto & nopto & $1+1014 \%$ & 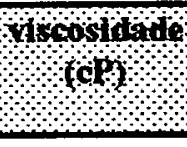 \\
\hline 4 & 12,77 & 1,06 & 14.52 & 61,63 & 38,37 & 6,0 & 3,0 \\
\hline 3 & 12,61 & 1.06 & 14.39 & 61.72 & 38,28 & 6,6 & 2.8 \\
\hline 6 & 12,55 & 1,07 & 14,26 & 62,56 & 37,44 & 6,5 & 2,7 \\
\hline 3 & 12,58 & 1.06 & 15,82 & 65,59 & 34,41 & 6,6 & 2,8 \\
\hline
\end{tabular}

média de 2 determinações tratamento 4 - soda- $0,04 \%$ DDA tratamento 5 - soda- $0,06 \%$ DDA tratamento 6 - soda- $0,08 \%$ DDA tratamento 7 - soda-0,10\% DDA

$\mathrm{Na}$ figura 32 foram plotados os resultados das análises de teor de sólidos e álcali ativo residual no licor negro dos tratamentos 4, 5, 6 e 7 . 


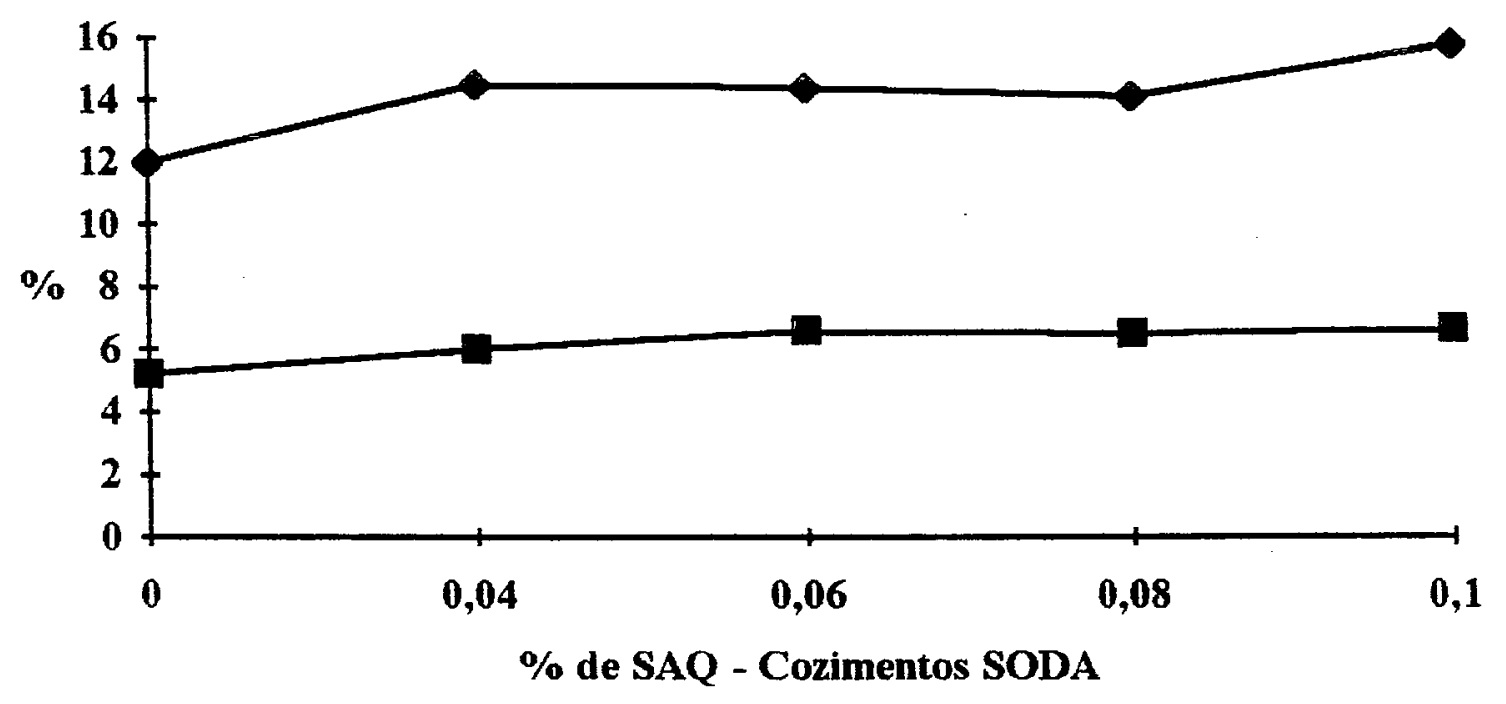

$\rightarrow$ teor de sólidos $\rightarrow$ álcali ativo residual

Figura 32. Teor de sólidos e álcali ativo residual em função do teor de DDA empregado nos cozimentos.

\subsection{Determinação da carga alcalina}

Foram realizados cozimentos com diferentes níveis de álcali ativo, sendo os tratamentos assim designados:

- tratamento 8 - soda-0,04DDA com $12 \%$ de álcali ativo

- tratamento 9 - soda-0,04DDA com 13\% de álcali ativo

- tratamento 10 - soda-0,04DDA com 14\% de álcali ativo

- tratamento 11 - soda-0.04DDA com 15\% de álcali ativo 
Na tabela 19, são apresentados os valores de rendimento bruto e depurado, teor de rejeitos e fator $\mathrm{H}$ das celuloses obtidas nos tratamentos descritos anteriormente.

Tabela 19. Rendimento bruto e depurado, teor de rejeitos para fator $\mathrm{H}$ igual a 677.

\begin{tabular}{ll}
\hline r \\
\hline
\end{tabular}

$\mathrm{m}$ - média

s - desvio-padrão

$\mathrm{CV}$ - coeficiente de variação tratamento 8 - soda- $0,04 \%$ DDA - álcali ativo $12 \%$ tratamento 9 - soda-0,04\% DDA - álcali ativo 13\% tratamento 10 - soda- $0,04 \% \mathrm{DDA}$ - álcali ativo $14 \%$ tratamento 11 - soda-0,04\% DDA - álcali ativo $15 \%$ 
$\mathrm{Na}$ tabela 20 são apresentados os resultados das anảlises quimicas das celuloses obtidas nos tratamentos $8,9,10$ e 11 bem como algumas relações

Tabela 20. Número kappa, viscosidade, lignina residual e relações.

\begin{tabular}{|c|c|c|c|c|c|c|}
\hline \multicolumn{2}{|c|}{ ratupuento } & nappa & צrsplots & resunus & ropopts & 1roplour \\
\hline \multirow[t]{3}{*}{8} & $\mathrm{~m}$ & 36,0 & 11,3 & 1,6 & 1,61 & 0,31 \\
\hline & 3 & 0,92 & 1,10 & 0,03 & 0,11 & 0,01 \\
\hline & $0 \quad 10$ & 2,55 & 9,78 & 1,79 & 6,83 & 3,23 \\
\hline \multirow[t]{3}{*}{9} & $\mathrm{~m}$ & 25,7 & 16,7 & 1,2 & 2,26 & 0,65 \\
\hline & 1 & 0,18 & 1,82 & 0,03 & 0,05 & 0,03 \\
\hline & $\mathrm{do}$ & 0.70 & 10,89 & 1.98 & 2.21 & 4,62 \\
\hline \multirow[t]{3}{*}{10} & 1 & 19,6 & 28,7 & 1,1 & 2,79 & 1,47 \\
\hline & 3 & 0.83 & 1,33 & 0,02 & 0,13 & 0,05 \\
\hline & $0 \%$ & 4,23 & 4,65 & 2.19 & 4,68 & 3,29 \\
\hline \multirow[t]{3}{*}{11} & n & 20,6 & 26,5 & 1,1 & 2,70 & 1,30 \\
\hline & 3 & 0,36 & 2,07 & 0,02 & 0,11 & 0,11 \\
\hline & $\alpha(10)$ & 1,77 & 7,82 & 2,07 & 4,25 & 8,41 \\
\hline
\end{tabular}

m - média

$s$ - desvio-padrão

CV - coeficiente de variação tratamento 8 - soda-0,04\% DDA - álcali ativo $12 \%$ tratamento 9 - soda-0,04\% DDA - álcali ativo $13 \%$ tratamento 10 - soda-0,04\%DDA - álcali ativo $14 \%$ tratamento 11 - soda-0,04\% DDA - álcali ativo $15 \%$ 
$\mathrm{Na}$ figura 33 estão representados os resultados de rendimento depurado, número kappa e viscosidade das celuloses obtidas nos tratamentos 8,9 , 10 e 11 .

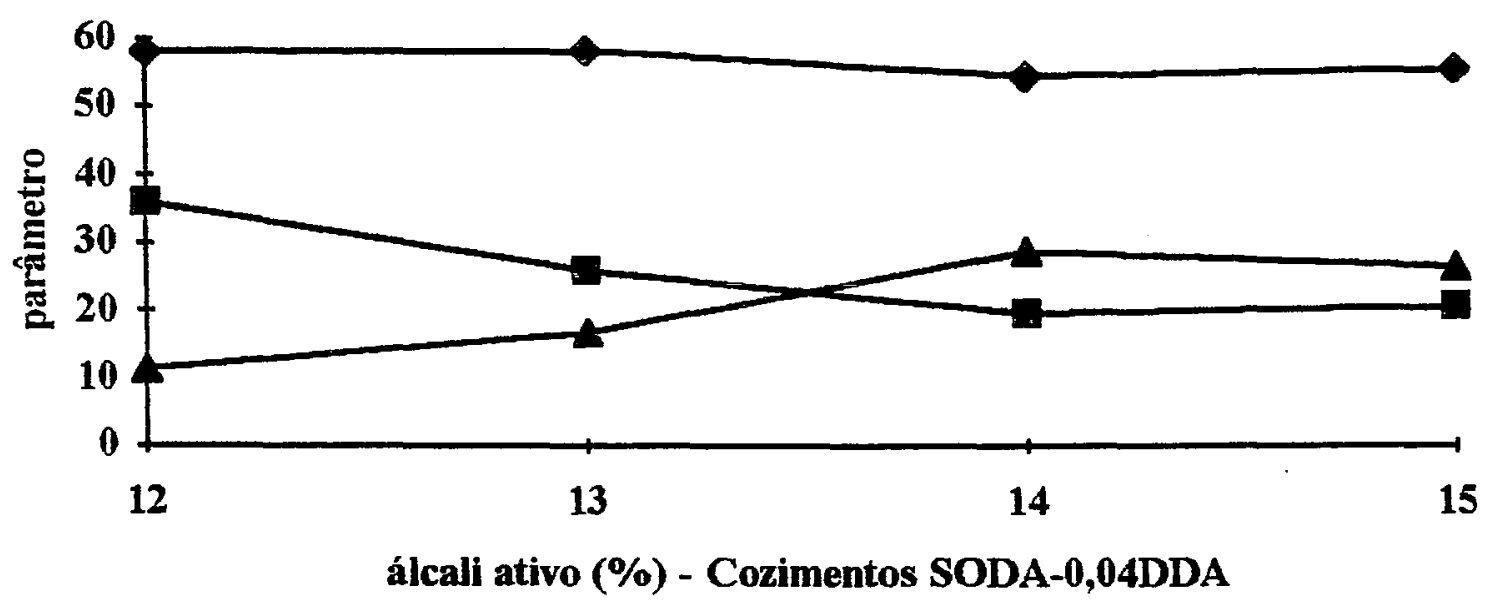

Figura 33. Número kappa, viscosidade e rendimento depurado das celuloses em função do álcali ativo. 
$\mathrm{Na}$ figura 34 são apresentados a relação rendimento depurado/número kappa e viscosidade/kappa em função do álcali ativo empregado nos cozimentos.

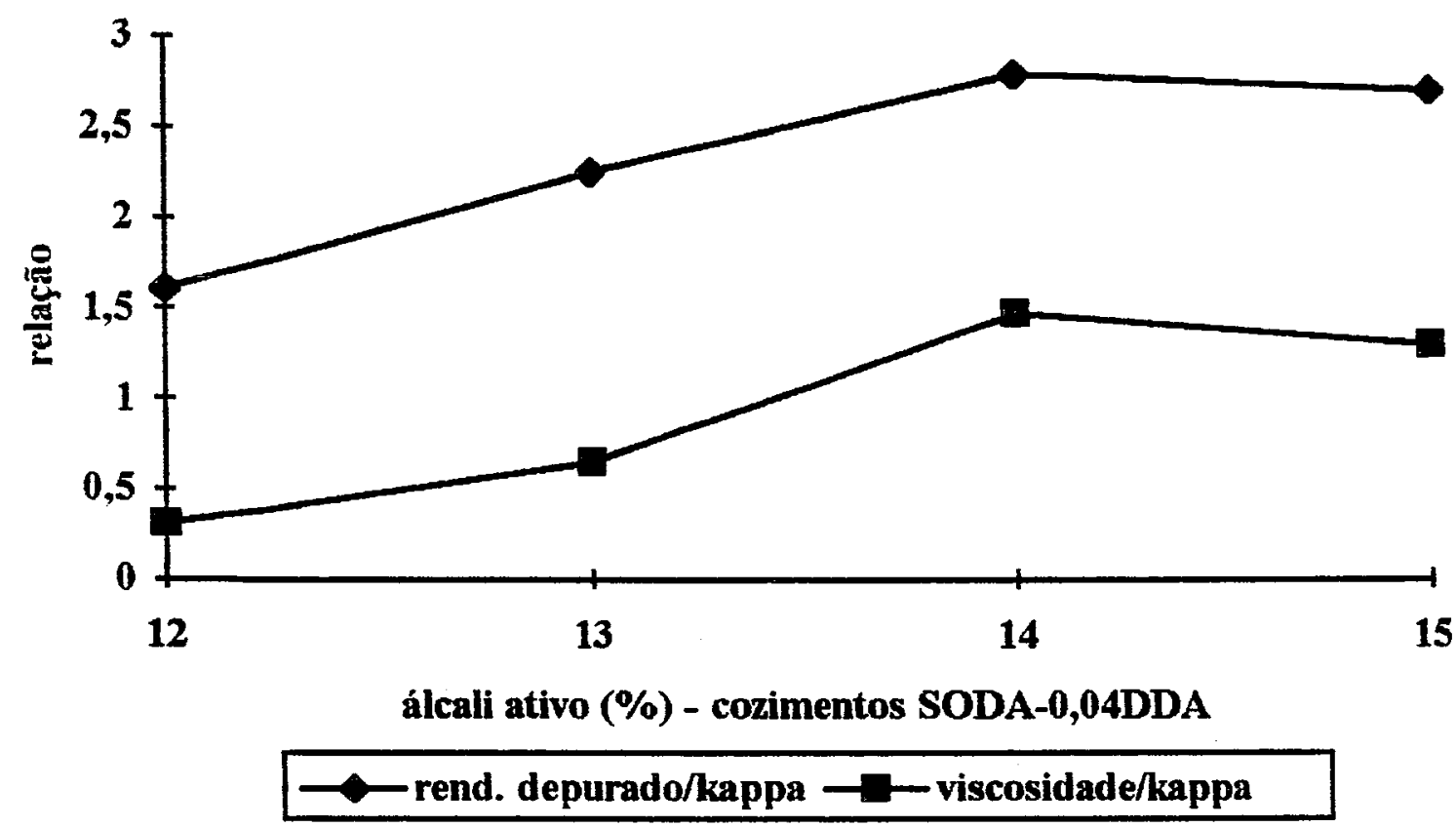

Figura 34. Relação rendimento depurado/número kappa e viscosidade/kappa em função do álcali ativo.

Na tabela 21 são apresentados os resultados das análises de teor de pentosanas e alfa, beta e gama celulose dos tratamentos $8,9,10$ e 11 . 
Tabela 21. Teor de pentosanas e alfa, beta e gama celuloses dos tratamentos $8,9,10$ e 11 .

\begin{tabular}{|l|c|c|c|c|}
\hline ron, \\
\hline
\end{tabular}

m - média

s - desvio-padrão

CV - coeficiente de variação tratamento 8 - soda-0,04\% DDA - álcali ativo $12 \%$ tratamento 9 - soda-0,04\% DDA - álcali ativo $13 \%$ tratamento 10 - soda-0,04\%DDA - álcali ativo $14 \%$ tratamento 11 - soda- $0,04 \%$ DDA - álcali ativo $15 \%$ 
Nas tabelas 22, 23, 24 e 25 são apresentados os resultados dos testes físicos e mecânicos realizados com as celuloses dos tratamentos $8.9,10 \mathrm{e}$ 11.

Tabela 22. Propriedades físicas e mecânicas da celulose do tratamento 8 - soda-0,04\%DDA - álcali ativo $12 \%$.

\begin{tabular}{|c|c|c|c|c|}
\hline Aevolluens & 0 & 2000 & 1000 & 6000 \\
\hline (nanlenefno (os 1$)$ & 15,3 & 21,3 & 28,9 & 45,0 \\
\hline 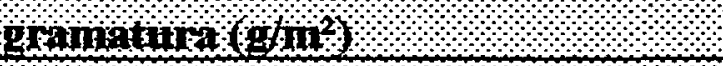 & 61,7 & 56,0 & 58,0 & 58,7 \\
\hline espessunta (mpl) & 0,148 & 0,124 & 0,115 & 0,111 \\
\hline 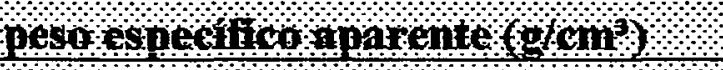 & 0,416 & 0,450 & 0,506 & 0,529 \\
\hline 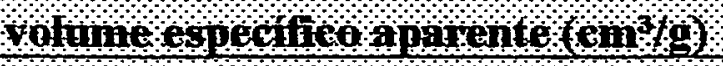 & 2,402 & 2,220 & 1,976 & 1,890 \\
\hline 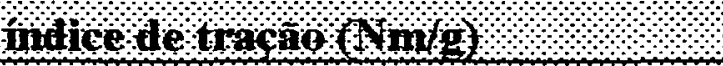 & 26,8 & 56,3 & 66,7 & 72,3 \\
\hline 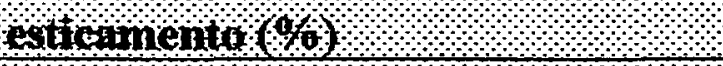 & 1,4 & 2,8 & 3,7 & 4,7 \\
\hline 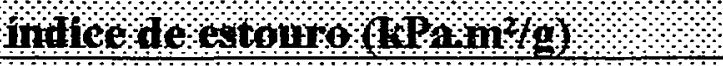 & 1,0 & 2,9 & 4,1 & 5,1 \\
\hline 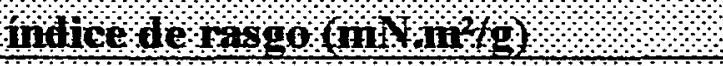 & 6,1 & 12,4 & 12,3 & 11.9 \\
\hline 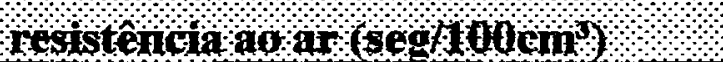 & 0,9 & 1,6 & 8,9 & 26,1 \\
\hline
\end{tabular}


Tabela 23. Propriedades físicas e mecânicas da celulose do tratamento 9 - soda-0,04\%DDA - álcali ativo $13 \%$.

\begin{tabular}{|c|c|c|c|c|}
\hline 10,011000 & 0 & 2000 & 1001 & 6000 \\
\hline 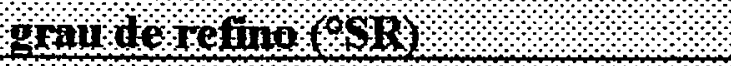 & 15,3 & 19,0 & 29,0 & 39,0 \\
\hline gmantur $(\mathrm{g}, \mathrm{m})$ & 59,6 & 52,6 & 57,7 & 54,6 \\
\hline enpessunt $($ nu & 0,149 & 0,121 & 0,118 & 0,107 \\
\hline 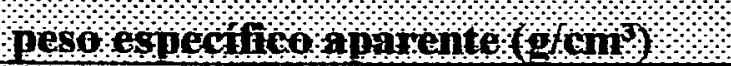 & 0,400 & 0.436 & 0,489 & 0,510 \\
\hline 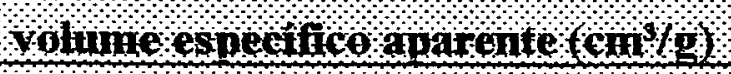 & 2,497 & 2.292 & 2.046 & 1.961 \\
\hline 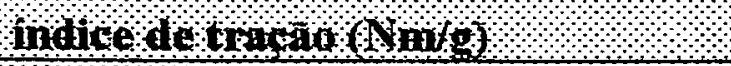 & 28.4 & 51,7 & 63,8 & 73,8 \\
\hline 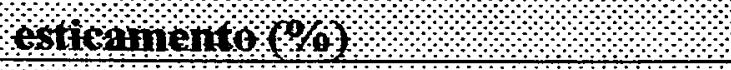 & 1,2 & 2,4 & 3,3 & 4,1 \\
\hline 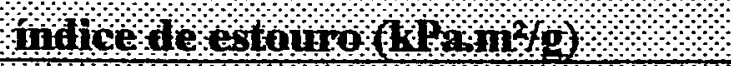 & 0,9 & 2,3 & 3,8 & 4.6 \\
\hline 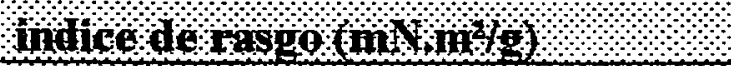 & 6,4 & 9,5 & 15,0 & 12,9 \\
\hline 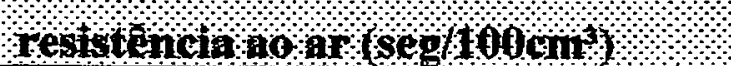 & 0,7 & 1,2 & 5,0 & 17,1 \\
\hline
\end{tabular}


Tabela 24. Propriedades físicas e mecànicas da celulose do tratamento 10 - soda-0.04\%DDA - álcali ativo $14 \%$.

\begin{tabular}{|c|c|c|c|c|}
\hline revolucoes & 0 & 2000 & 4000 & 6000 \\
\hline 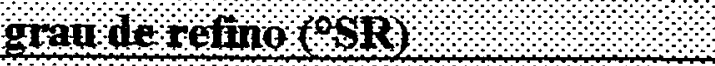 & 18,3 & 22,0 & 30,7 & 41,0 \\
\hline gramatura $(\mathrm{m})$, & 60,9 & 58,1 & 57,6 & 61,6 \\
\hline espessutal (nh) & 0,142 & 0,122 & 0,117 & 0,115 \\
\hline 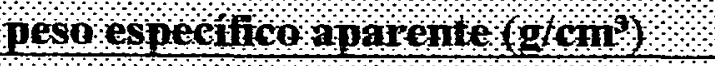 & 0,429 & 0.477 & 0.502 & 0,528 \\
\hline Yolnme especifieo a parente $(\mathrm{em} / \mathrm{o})$ & 2,330 & 2.095 & 1,990 & 1.893 \\
\hline 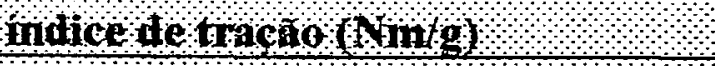 & 37,8 & 50,0 & 59,3 & 67.8 \\
\hline estotant to $(\alpha)$ & 1,4 & 2,9 & 3,6 & 4.2 \\
\hline 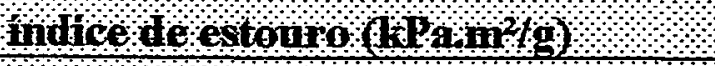 & 1,3 & 3,1 & 4,1 & 4,6 \\
\hline 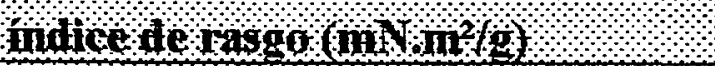 & 7,2 & 11,6 & 13,3 & 13,1 \\
\hline 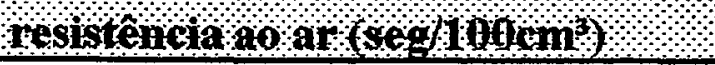 & 1,3 & 2,8 & 7,1 & 19,8 \\
\hline
\end{tabular}


Tabela 25. Propriedades físicas e mecânicas da celulose do tratamento 11 - soda-0,04\%DDA - álcali ativo $15 \%$.

\begin{tabular}{|c|c|c|c|c|}
\hline xenoluosos & 0 & 2000 & $\mathbf{4 0 0 0}$ & 6000 \\
\hline malueneflno $(9, \mathrm{~s})$ & 18,0 & 22,0 & 30,7 & 40,0 \\
\hline$g \mathrm{an}_{\mathrm{n}} \mathrm{t}, \mathrm{r},\left(\mathrm{w} / \mathrm{m}^{2}\right)$ & 58,9 & 56,5 & 58.2 & 58.0 \\
\hline espesphan (nul) & 0,150 & 0,123 & 0,115 & 0,110 \\
\hline 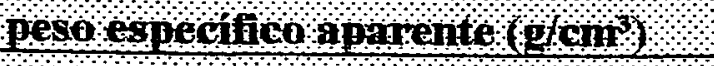 & 0,392 & 0,458 & 0,505 & 0,528 \\
\hline 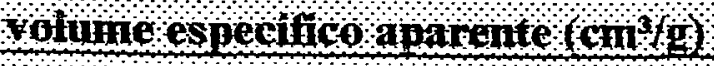 & 2.552 & 2.183 & 1.981 & 1.893 \\
\hline 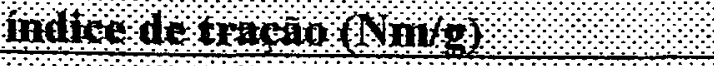 & 29,7 & 55,2 & 68,4 & 73.0 \\
\hline ostatant to $(\%)$ & 1,4 & 3,1 & 3.5 & 4.1 \\
\hline 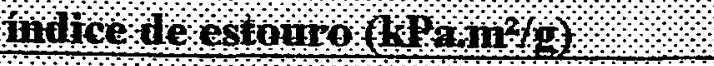 & 1,0 & 2,8 & 3.9 & 4,7 \\
\hline 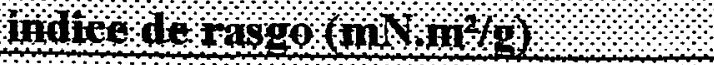 & 5,5 & 9,4 & 11,7 & 11,3 \\
\hline 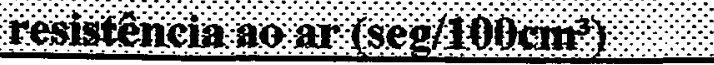 & 0,8 & 2,1 & 7,7 & 17,6 \\
\hline
\end{tabular}




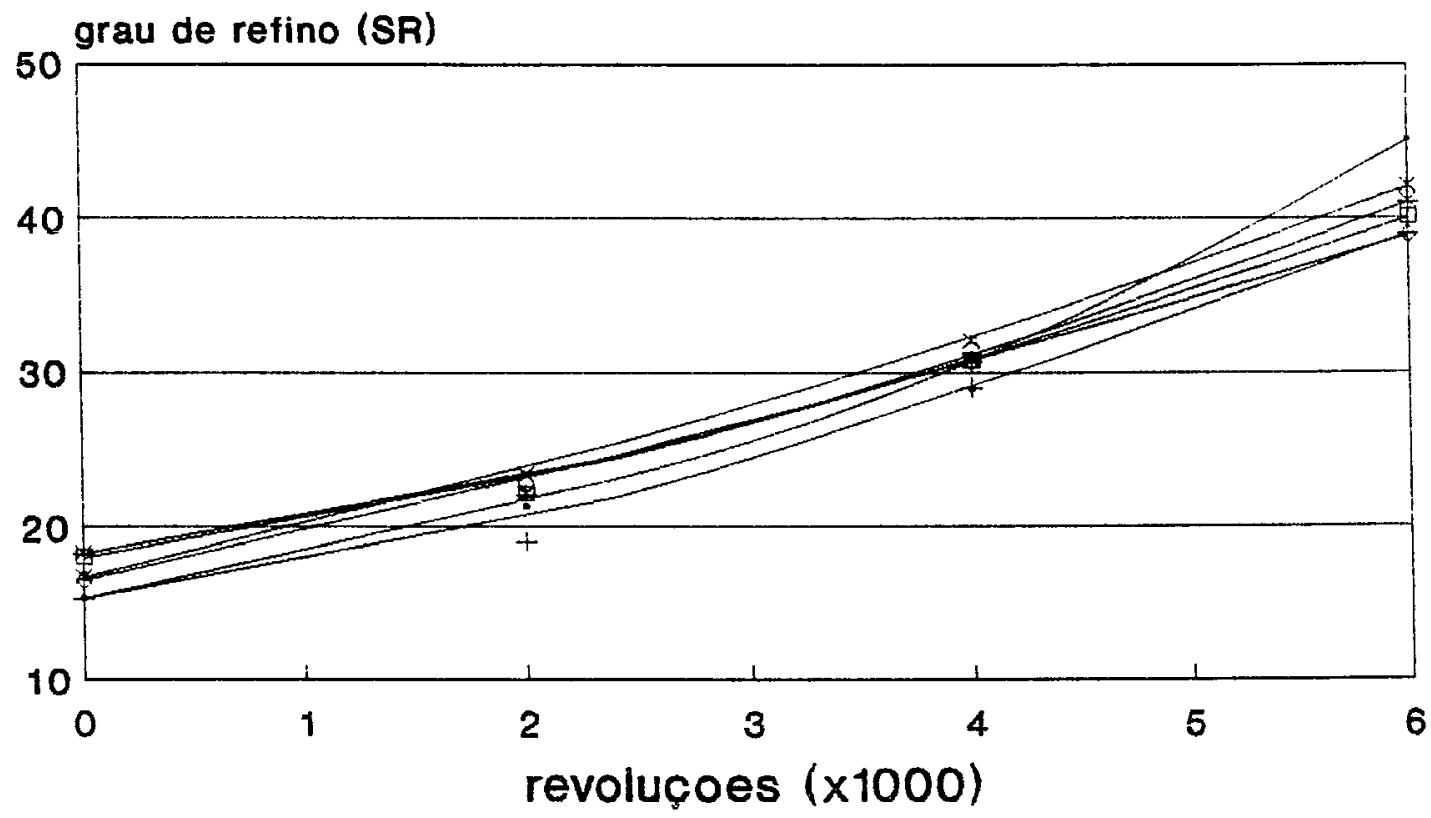

$-12 \%+13 \%+14 \% \rightarrow-\square \%$ kraft $\rightarrow$ ooda

Figura 35. Grau de refino em função do número de revoluções (moinho PFI).

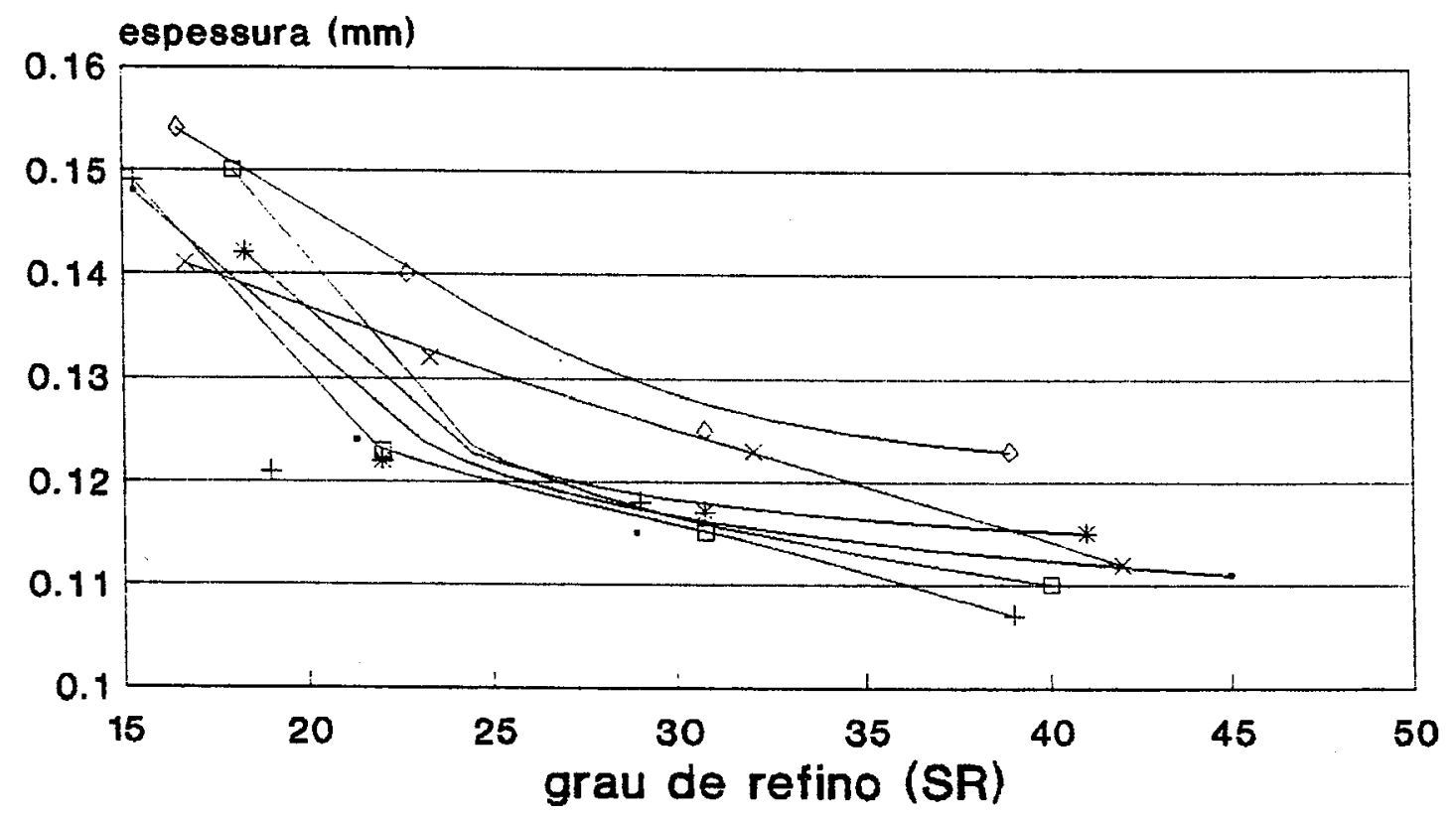

$-12 \%+13 \% \rightarrow 14 \% \rightarrow 15 \% \rightarrow$ kraft $\rightarrow$ soda

Figura 36. Espessura em função do grau de refino. 


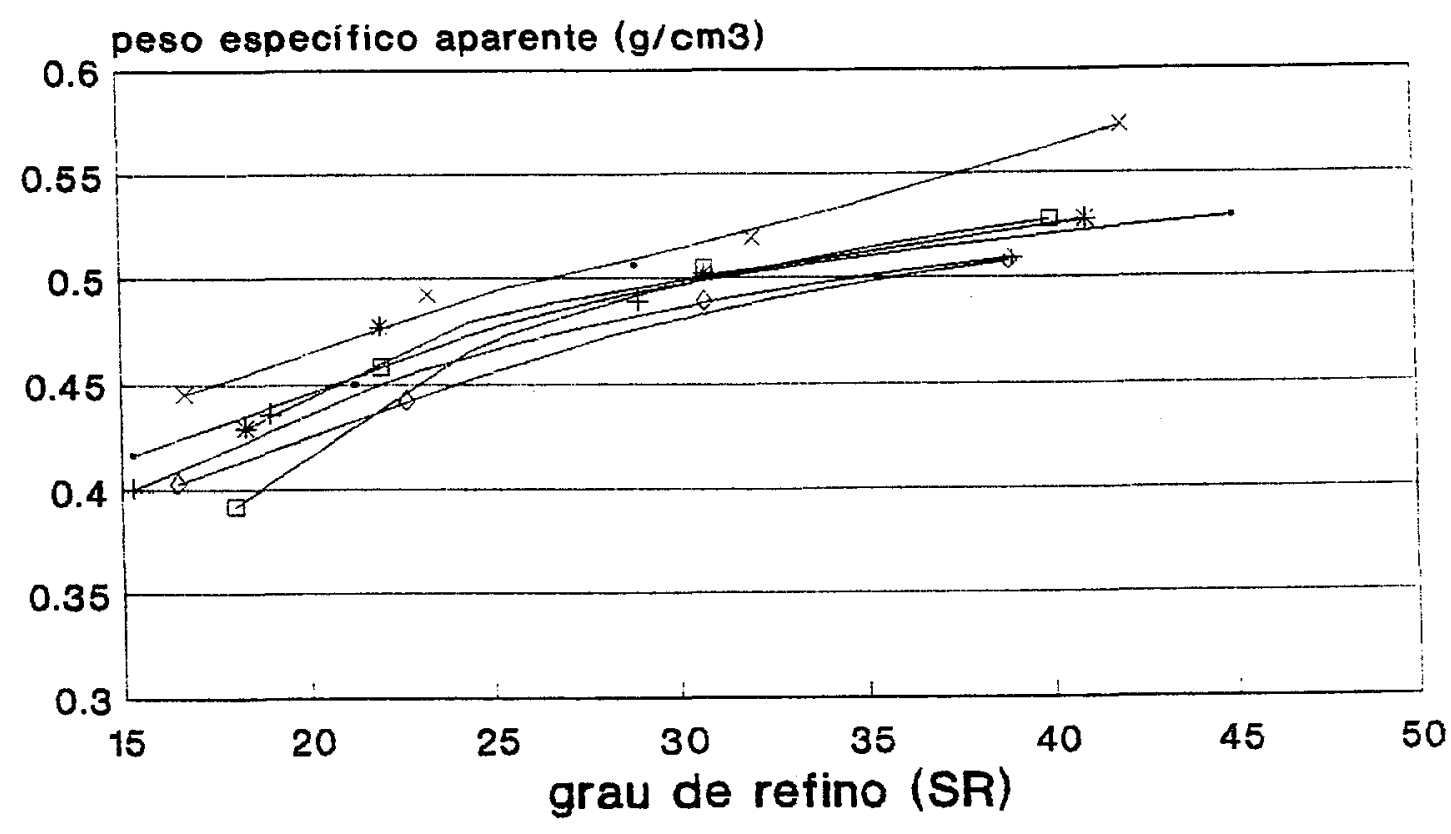

$-12 \%+13 \% \rightarrow 14 \% \rightarrow 15 \% \rightarrow$ kraft $\rightarrow 80 d a$

Figura 37. Peso específico aparente em função do grau de refino.

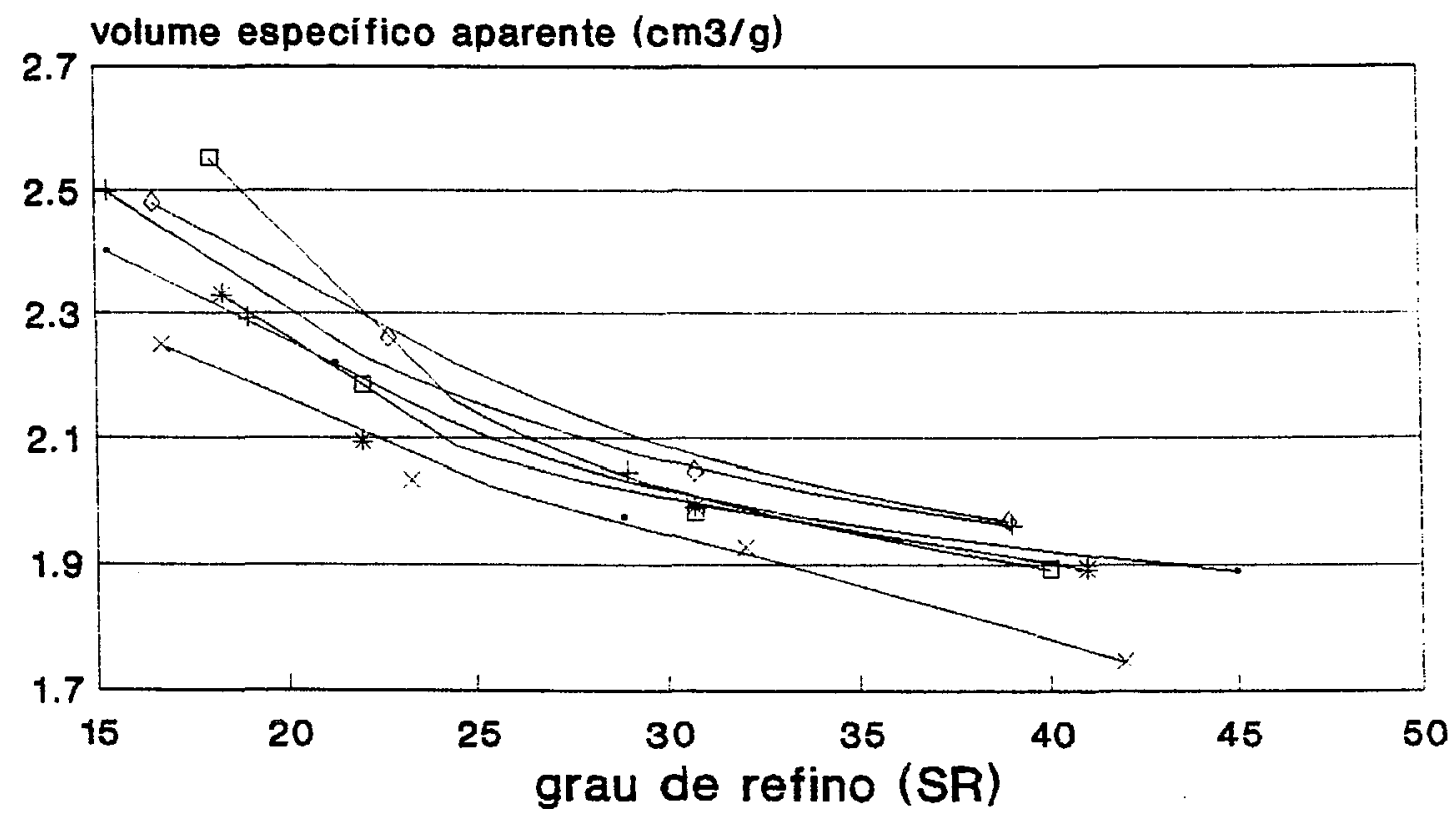

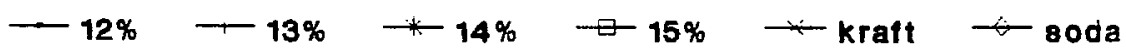

Figura 38. Volume específico aparente em função do grau de refino. 


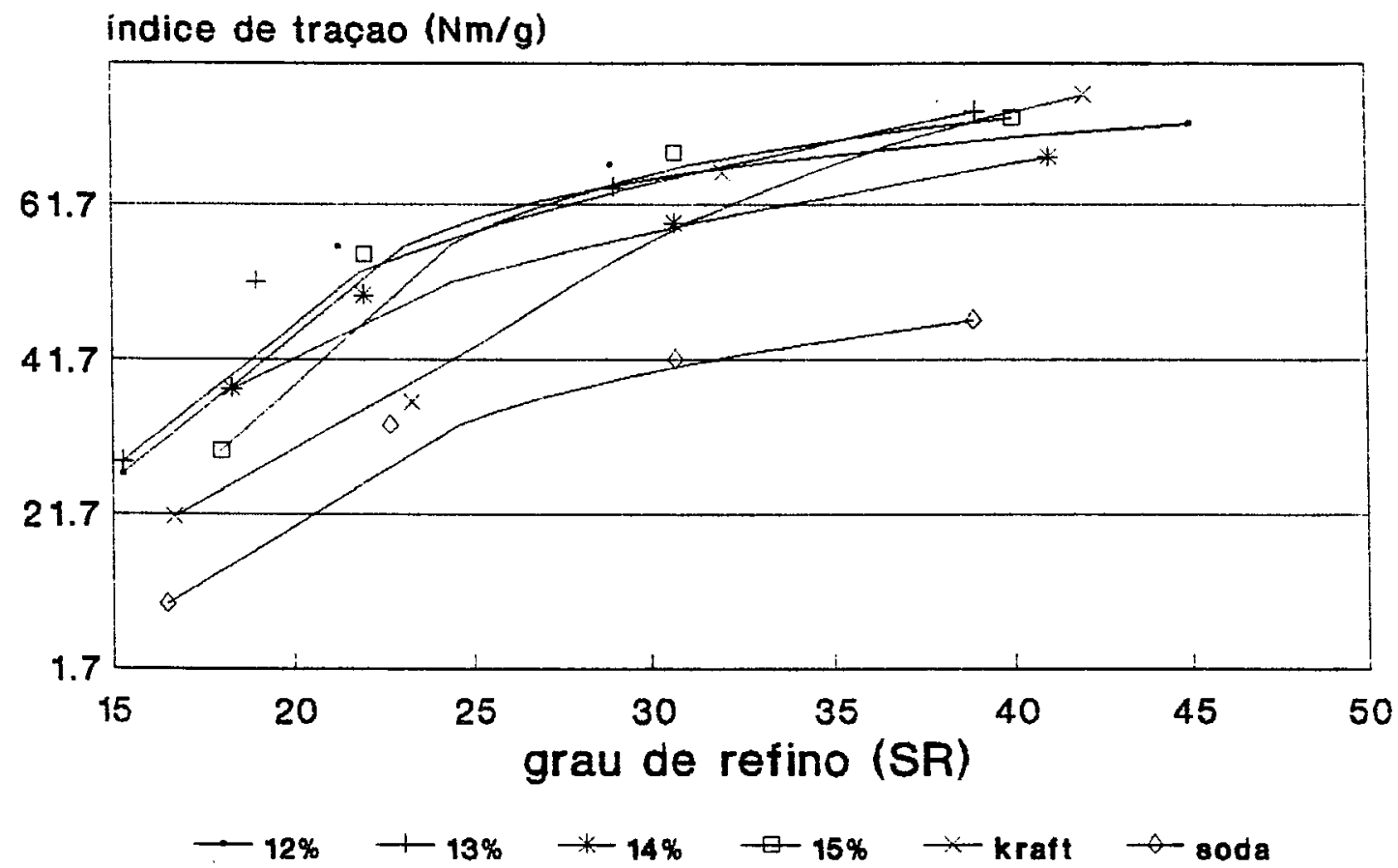

Figura 39. Índice de tração em função do grau de refino.

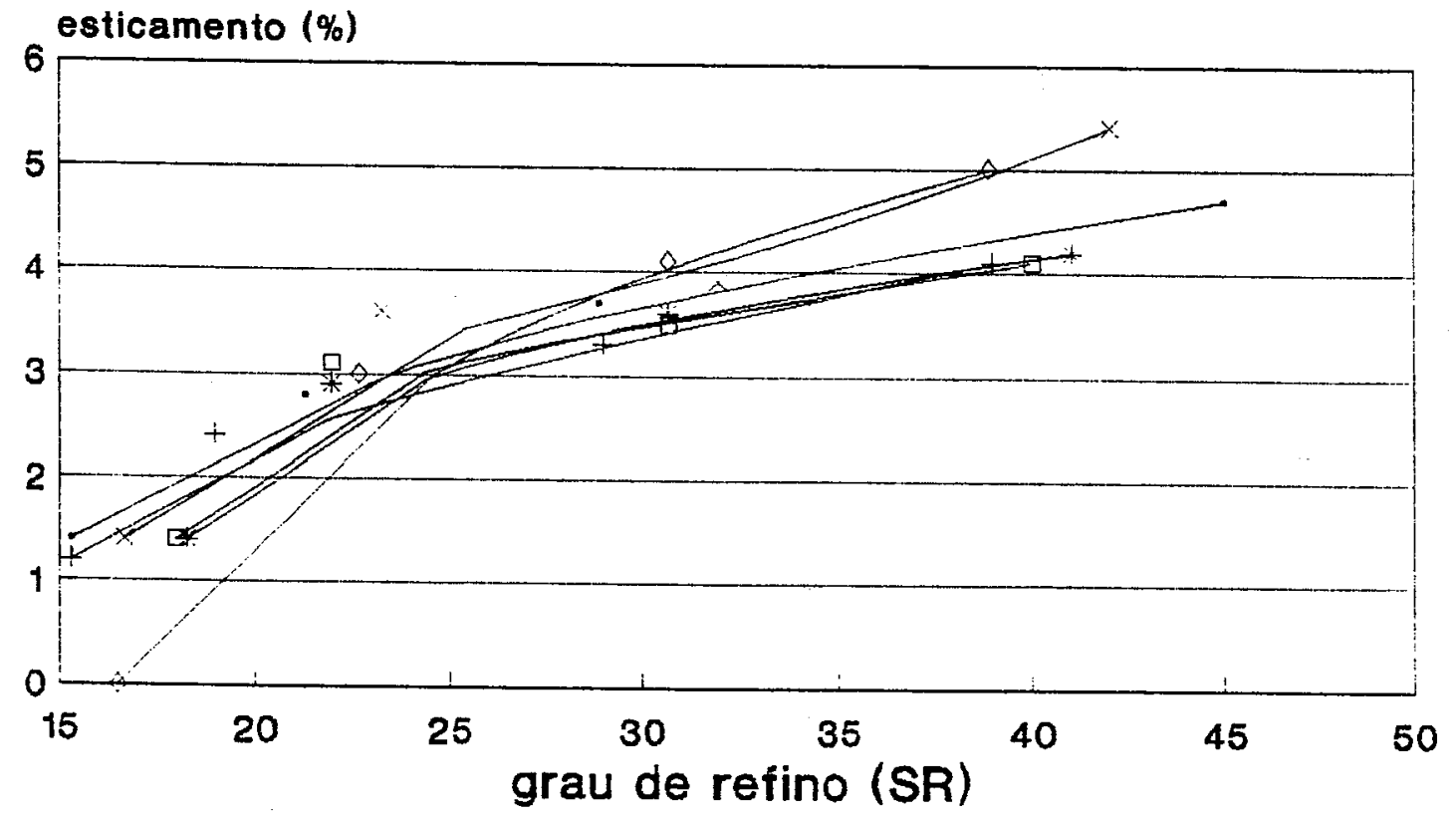

$-12 \% \longrightarrow 13 \% \rightarrow 14 \% \rightarrow 15 \% \rightarrow$ kraft $\rightarrow$ soda

Figura 40. Esticamento em função do grau de refino. 


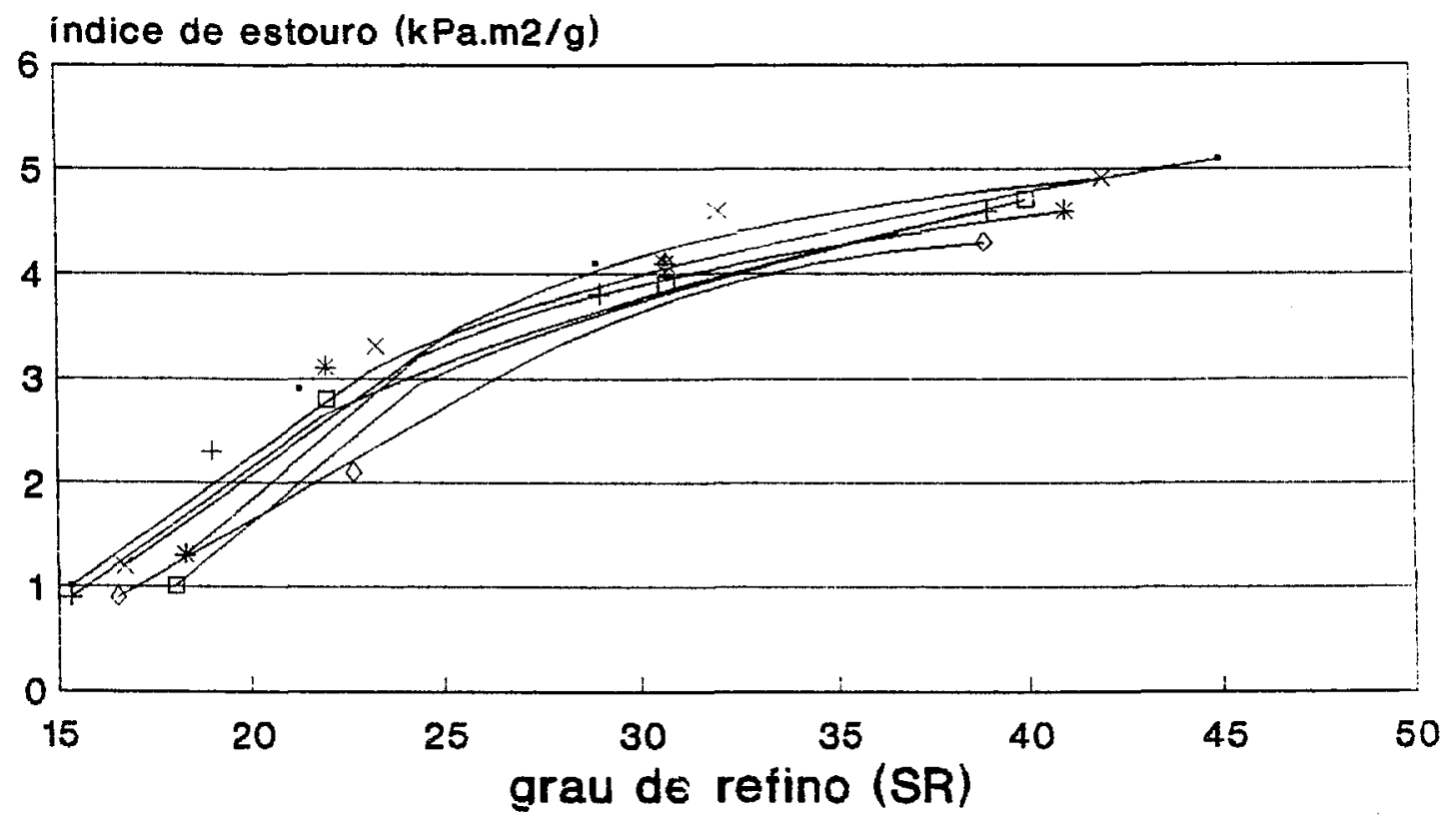

$\longrightarrow 12 \% \div 13 \% \rightarrow-* 14 \% \div 15 \% \rightarrow$ kraft $\rightarrow$ soda

Figura 41. Índice de estouro em função do grau de refino.

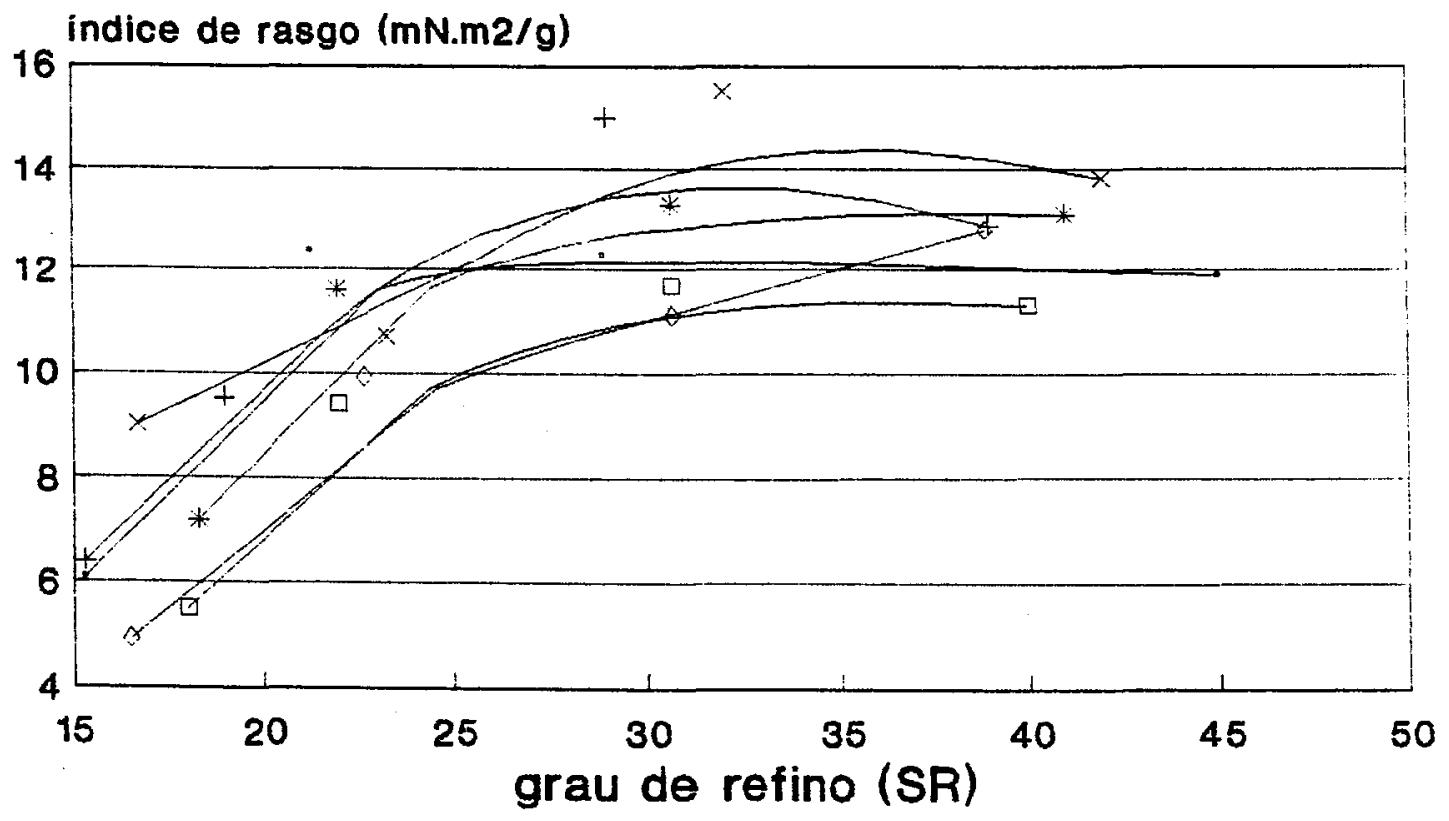

$-12 \% \rightarrow 13 \% \rightarrow 14 \% \quad-15 \% \multimap$ kratt $\rightarrow$ soda

Figura 42. Índice de rasgo em função do grau de refino. 


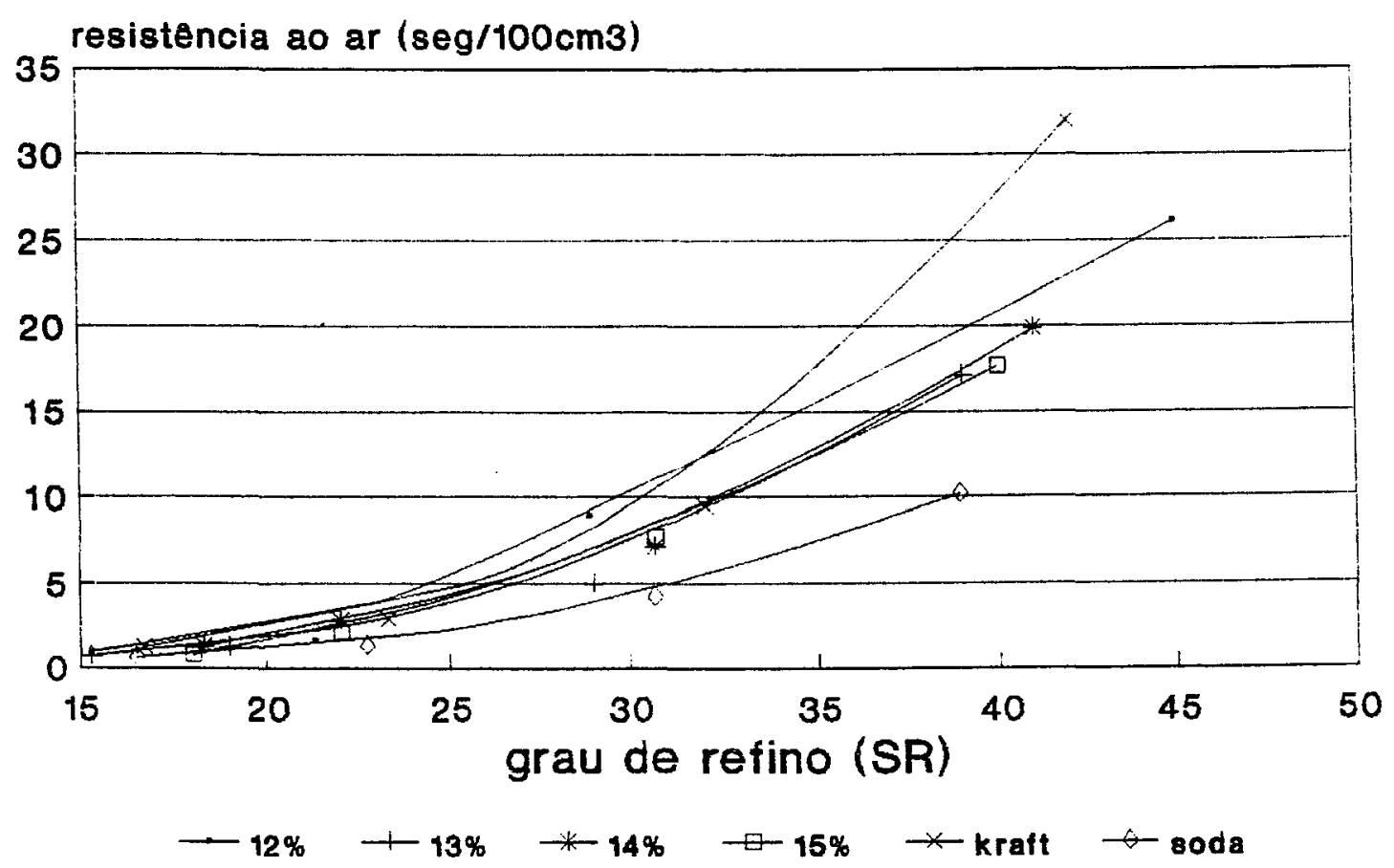

Figura 43. Resistência à passagem de ar em função do grau de refino. 
$\mathrm{Na}$ tabela 26 são apresentados os resultados das análises de licor negro.

Tabela 26. Análises de licor negro dos tratamentos $8,9,10$ e 11 .

\begin{tabular}{|c|c|c|c|c|c|c|c|}
\hline trutuneto & $\mathrm{mit}$ & rento & tortof & ortata & $\begin{array}{l}\text { butrat } \\
\text { potgants }\end{array}$ & resifual $\alpha$ & rotide \\
\hline 8 & 12,17 & 1.06 & 14,26 & 69,71 & 30.29 & 2.1 & 2.7 \\
\hline 9 & 12,34 & 1.06 & 14,52 & 68,05 & 31.95 & 3.5 & 2.8 \\
\hline 10 & 12,77 & 1,06 & 13,52 & 61,63 & 38,37 & 6,0 & 3,0 \\
\hline 11 & 12,56 & 1,06 & 15,38 & 64,82 & 35,18 & 5,8 & 3.1 \\
\hline
\end{tabular}

média de 2 determinações

tratamento 8 - soda- $0,04 \%$ DDA - álcali ativo $12 \%$ tratamento 9 - soda-0,04\% DDA - álcali ativo $13 \%$ tratamento 10 - soda- $0,04 \%$ DDA - álcali ativo $14 \%$ tratamento 11 - soda- $0,04 \%$ DDA - álcali ativo $15 \%$

$\mathrm{Na}$ figura 44, foram plotados os resultados das análises de teor de sólidos e álcali ativo residual no licor negro dos tratamentos $8,9,10$ e 11 . 


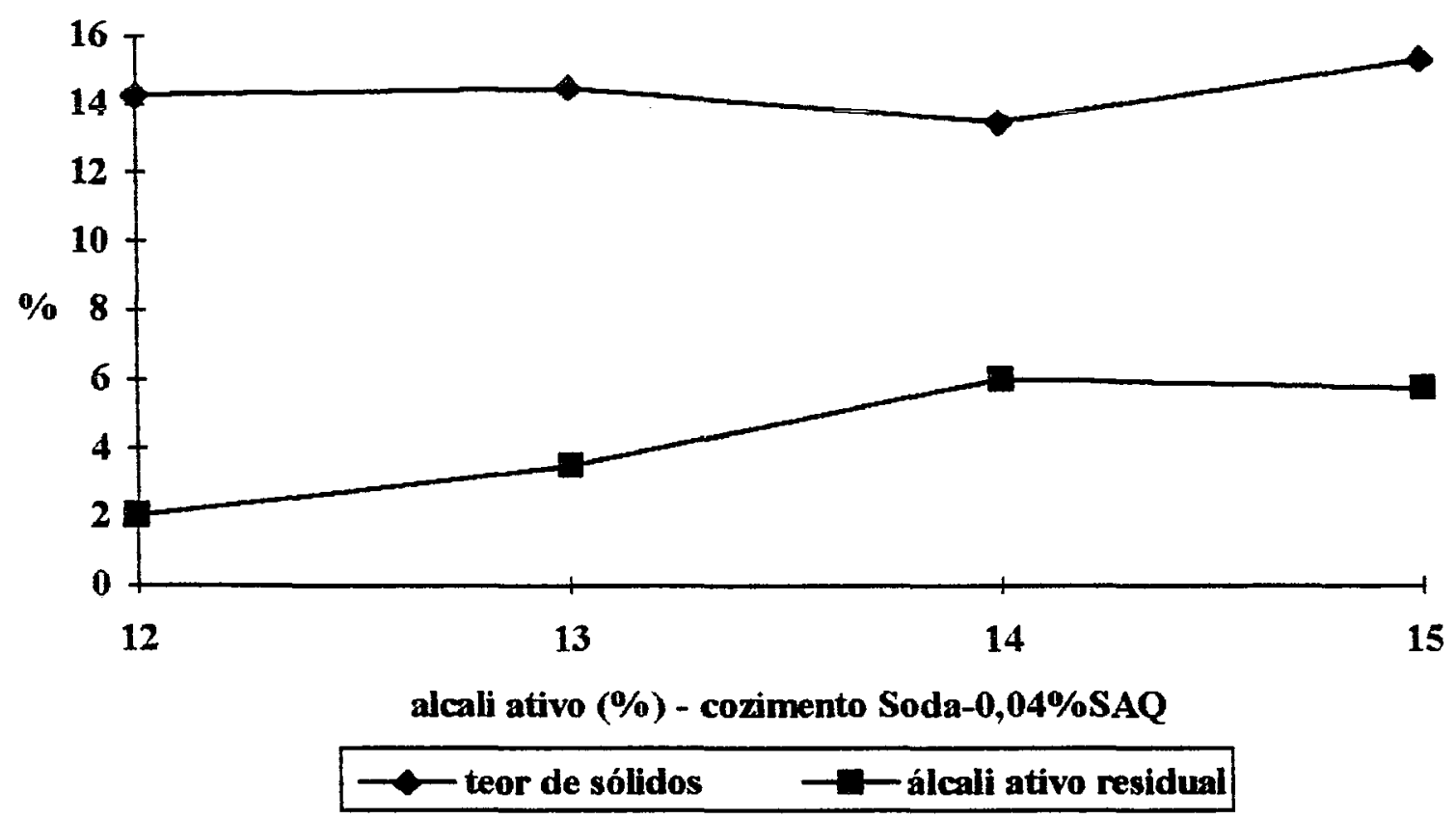

Figura 44. Teor de sólidos e álcali ativo residual em função do álcali ativo.

\subsection{Determinação do tempo à temperatura máxima}

Foram realizados cozimentos com diferentes tempos à temperatura máxima, sendo os tratamentos assim designados:

- tratamento 12 - soda-0,04DDA - 13\% de álcali ativo fator $H=215$

- tratamento 13 - soda-0,04DDA - 13\% de álcali ativo fator $\mathrm{H}=369$

- tratamento 14 - soda-0,04DDA - 13\% de álcali ativo fator $\mathbf{H}=\mathbf{5 2 2}$

- tratamento 15 - soda-0,04DDA $=13 \%$ de álcali ativo fator $H=677$ 
Na tabela 27, são apresentados os valores de rendimento bruto e depurado, teor de rejeitos e fator $\mathrm{H}$ das celuloses obtidas nos tratamentos descritos anteriormente.

Tabela 27. Rendimento bruto e depurado, teor de rejeitos e fator $\mathrm{H}$.

\begin{tabular}{|c|c|c|c|c|c|}
\hline \multicolumn{2}{|c|}{ tratruento } & topththto & से & tenthphto & fatort \\
\hline \multirow[t]{3}{*}{12} & $\mathrm{~m}$ & 64.6 & 16,1 & 48.5 & 215 \\
\hline & 8 & 0,93 & 5,35 & 4,89 & \\
\hline & 0,0 & 1,45 & 33.23 & 10,08 & \\
\hline \multirow[t]{3}{*}{1} & 19 & 60,6 & 4,29 & 56,4 & 369 \\
\hline & 3 & 0,26 & 1,69 & 1,56 & \\
\hline & 00 & 0,43 & 40.20 & 2,77 & \\
\hline \multirow[t]{3}{*}{14} & $\mathrm{~m}$ & 59,4 & 0,31 & 59,0 & 522 \\
\hline & 3 & 1,13 & 0.10 & 1,15 & \\
\hline & 00 & 1,91 & 32,74 & 1,95 & \\
\hline \multirow[t]{3}{*}{15} & $\mathrm{az}$ & 54,3 & 0,00 & 54,5 & 677 \\
\hline & 3 & 0,46 & $\ldots$ & 0.46 & \\
\hline & 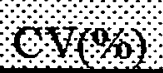 & 0.85 & - & 0,85 & \\
\hline
\end{tabular}

m - média

s - desvio-padrão

$\mathrm{CV}$ - coeficiente de variação tratamento 12 - soda-0,04\% DDA - álcali ativo $12 \%$ tratamento 13 - soda-0,04\% DDA - álcali ativo $13 \%$ tratamento 14 - soda-0.04\% DDA - álcali ativo $14 \%$ tratamento 15 - soda $0,04 \%$ DDA - álcali ativo $15 \%$ 
Na tabela 28 são apresentados os resultados das análises quimicas das celuloses obtidas nos tratamentos anteriores bem como algumas relações

Tabela 28. Número kappa, viscosidade, lignina residual e relações.

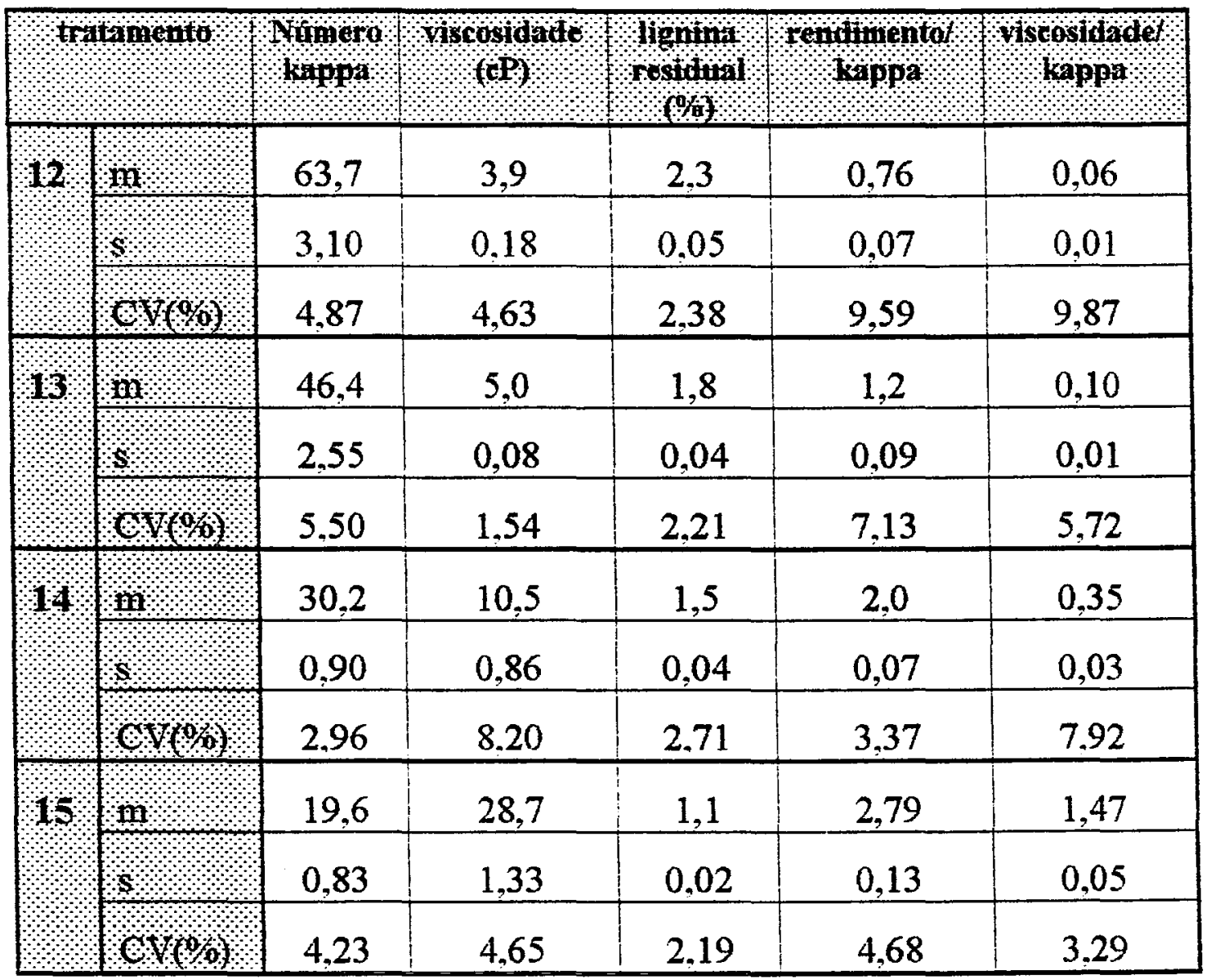

m - média

s - desvio-padrão

$\mathrm{CV}$ - coeficiente de variação tratamento 12 - soda- $0,04 \%$ DDA - álcali ativo $13 \%$ fator $\mathrm{H} 215$

tratamento 13 - soda-0,04\% DDA - álcali ativo 13\% fator $\mathrm{H} 369$

tratamento 14 - soda-0,04\% DDA - álcali ativo $13 \%$ fator $\mathrm{H} 522$

tratamento 15 - soda-0,04\% DDA - álcali ativo 14\% fator $\mathrm{H} 677$ 
$\mathrm{Na}$ figura 45 estão representados os resultados de rendimento depurado, número kappa e viscosidade das celuloses obtidas nos tratamentos 12 . 13,14 e 15 .

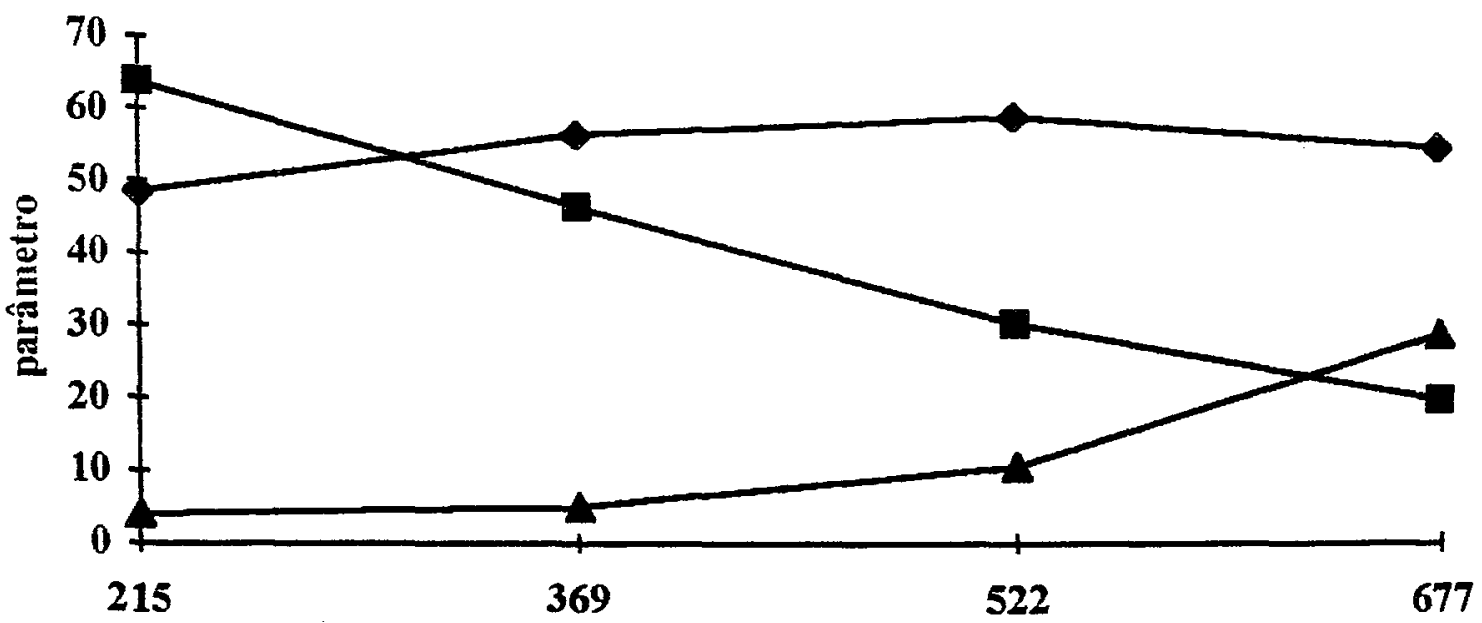

fator H - Cozimentos SODA-0,04DDA - álcali ativo 13\%

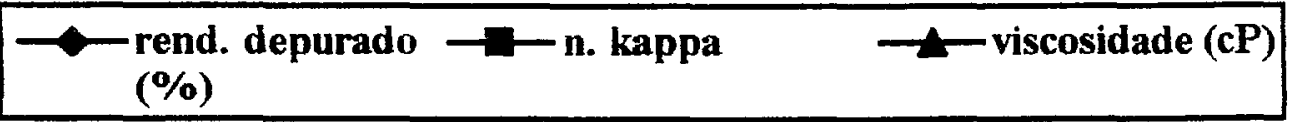

Figura 45. Número kappa, viscosidade e rendimento depurado das celuloses em função do fator $\mathrm{H}$. 
Na figura 46 são apresentados a relação rendimento depurado/ kappa e viscosidade/kappa em função do fator $\mathrm{H}$.

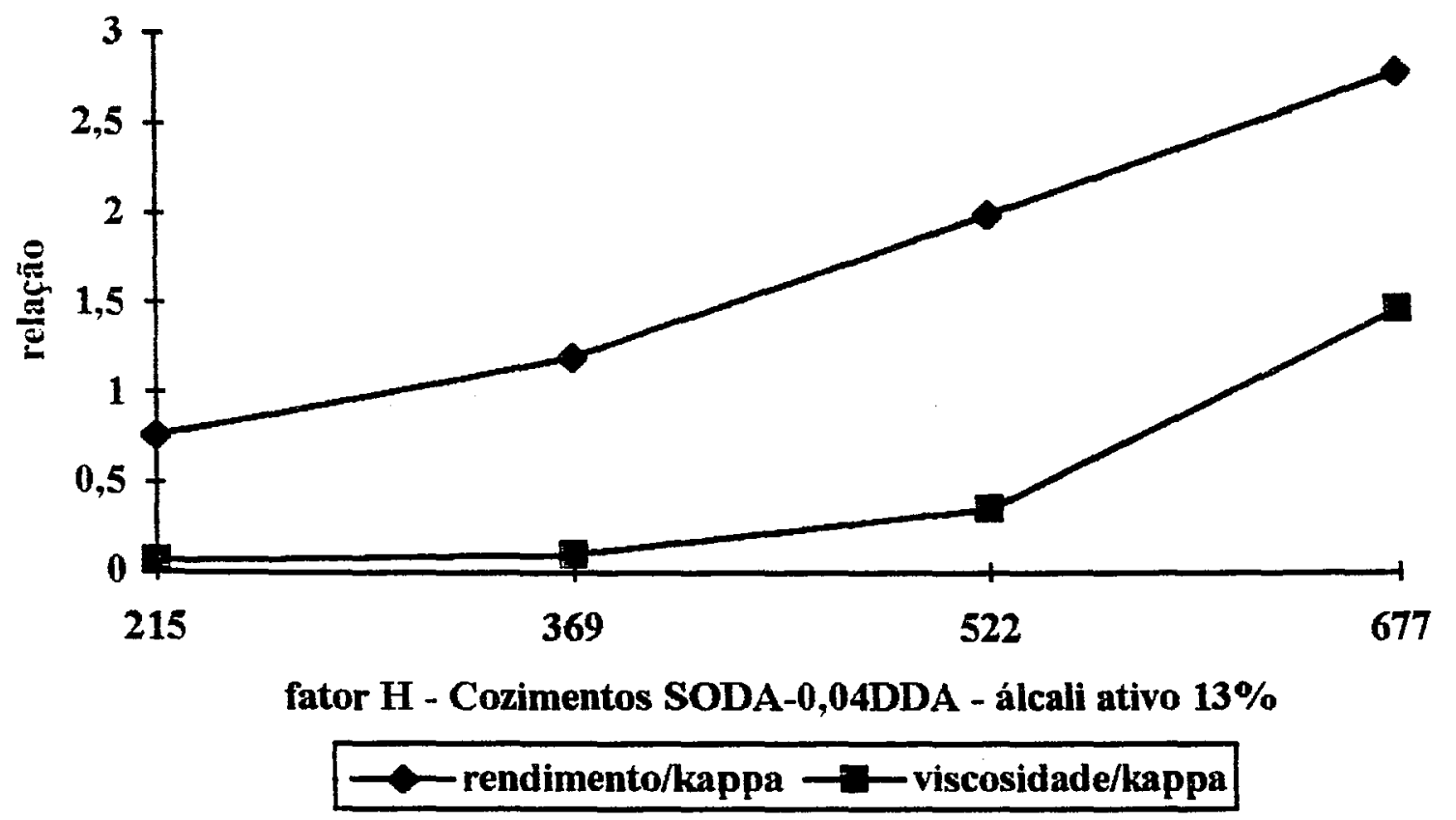

Figura 46. Relação rendimento depurado/número kappa e viscosidade/número kappa em função do fator $\mathrm{H}$ 
$\mathrm{Na}$ tabela 29 são apresentados os resultados das análises de teor de pentosanas e alfa, beta e gama celulose dos tratamentos $12,13,14$ e 15 .

Tabela 29. Teor de pentosanas e alfa, beta e gama celuloses dos tratamentos $12,13,14$ e 15 .

\begin{tabular}{|c|c|c|c|c|c|}
\hline \multicolumn{2}{|c|}{ म } & o 10 os & 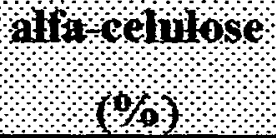 & lut & ofmar \\
\hline \multirow[t]{3}{*}{12} & $\mathrm{~m}$ & 13,8 & 85,5 & 4,5 & 10,0 \\
\hline & 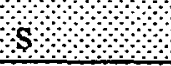 & 0,28 & 3,32 & 0.82 & 0,56 \\
\hline & 00 & 2,01 & 3,88 & 18.2 & 5,61 \\
\hline \multirow[t]{3}{*}{13} & $\mathrm{~m}$ & 13,8 & 84,9 & 4,0 & 11,1 \\
\hline & 3 & 0,55 & 0,50 & 0,45 & 0,64 \\
\hline & $0(0)$ & 3,98 & 0,59 & 11,25 & 5,76 \\
\hline \multirow[t]{3}{*}{14} & $\mathrm{~m}$ & 13,8 & 86,0 & 4,0 & 10,0 \\
\hline & $\mathrm{s}$ & 0,44 & 0,17 & 0,46 & 0,51 \\
\hline & $\mathrm{Ne}$ & 3.16 & 0.19 & 11.50 & 5.04 \\
\hline \multirow[t]{3}{*}{15} & 1 & 14.2 & 87,9 & 8.3 & 3.8 \\
\hline & 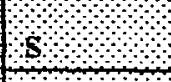 & 0.44 & 0.35 & 0.40 & 0,48 \\
\hline & (n $(\%)$ & 3,06 & 0.40 & 4,82 & 12,76 \\
\hline
\end{tabular}

m - média

s - desvio-padrão

$\mathrm{CV}$ - coeficiente de variação tratamento 12 - soda-0,04\% DDA - álcali ativo 13\% fator $\mathrm{H} 215$

tratamento 13 - soda-0,04\% DDA - álcali ativo $13 \%$ fator $\mathrm{H} 369$

tratamento 14 - soda-0,04\%DDA - álcali ativo $13 \%$ fator $\mathrm{H} 522$

tratamento 15 - soda-0,04\% DDA - álcali ativo $13 \%$ fator $\mathrm{H} 677$ 
Nas tabelas 30, 31, 32 e 33 são apresentados os resultados dos testes físicos e mecânicos realizados com as celuloses do tratamento $12,13,14 \mathrm{e}$ 15 .

Tabela 30. Propriedades fisicas e mecânicas da celulose do tratamento 12 - soda- $0,04 \%$ DDA - álcali ativo $13 \%$ fator $\mathrm{H} 215$.

\begin{tabular}{|c|c|c|c|c|}
\hline revoloo, & $\theta$ & 2000 & 4000 & 6000 \\
\hline 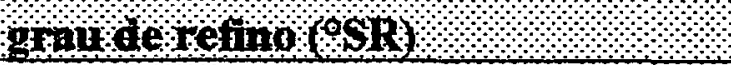 & 16,0 & 19,0 & 26,0 & 37,3 \\
\hline 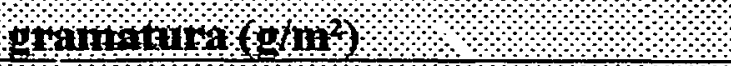 & 63,2 & 58,1 & 56,1 & 61,5 \\
\hline enposulan (n 1$)$ & 0,159 & 0,133 & 0.120 & 0,118 \\
\hline 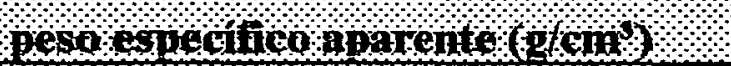 & 0,397 & 0,435 & 0,475 & 0.514 \\
\hline 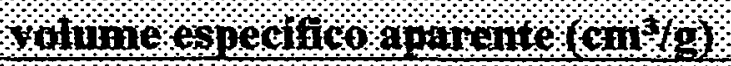 & 2,521 & 2.298 & 2,105 & 1.944 \\
\hline 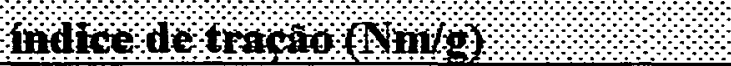 & 28,7 & 51,5 & 64,4 & 68.7 \\
\hline estonnento $(\%)$ & 1,2 & 2,5 & 3,3 & 3,9 \\
\hline 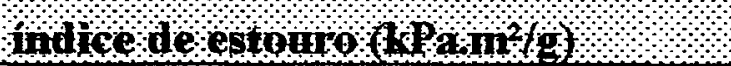 & 0,9 & 2,5 & 3,4 & 4,2 \\
\hline 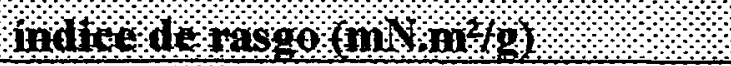 & 5,0 & 9,0 & 10,5 & 11,3 \\
\hline 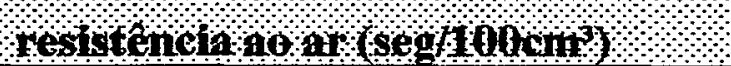 & 0,6 & 1,4 & 4,7 & 16,3 \\
\hline
\end{tabular}


Tabela 31. Propriedades físicas e mecânicas da celulose do tratamento 13 - soda-0,04\%DDA - alcali ativo $13 \%$ fator H 369.

\begin{tabular}{|c|c|c|c|c|}
\hline rewollowos & 0 & 2000 & 8000 & 6000 \\
\hline nanderanolos & 15,7 & 20,3 & 27,0 & 36,0 \\
\hline gramaturn $(1,1)$ & 61,3 & 62,0 & 58.2 & 60,7 \\
\hline espessuran (1, & 0,156 & 0,136 & 0.120 & 0,116 \\
\hline 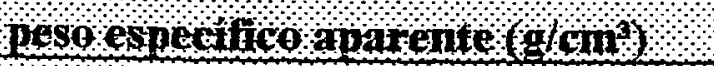 & 0,393 & 0.456 & 0,483 & 0.525 \\
\hline 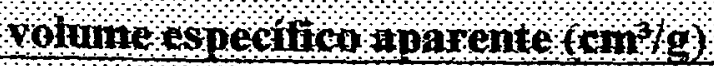 & 2.547 & 2,192 & 2.069 & 1.904 \\
\hline 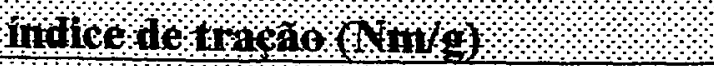 & 30,8 & 56,8 & 67,8 & 70,7 \\
\hline estand ${ }_{1}, 0 \%$ & 1.2 & 2.8 & 3,3 & 4.0 \\
\hline 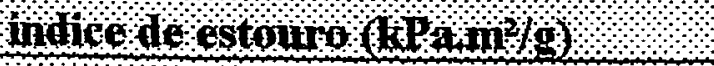 & 0,9 & 2.8 & 3,8 & 4,8 \\
\hline 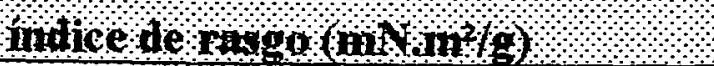 & 4,4 & 11,0 & 11,9 & 12,9 \\
\hline 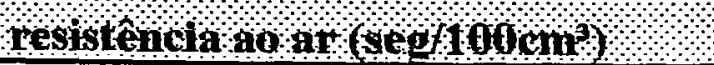 & 0.8 & 1,8 & 4,7 & 17,9 \\
\hline
\end{tabular}


Tabela 32. Propriedades físicas e mecànicas da celulose do tratamento 14 - soda- $0,04 \% \mathrm{DDA}$ - álcali ativo $13 \%$ fator $\mathrm{H} 522$.

\begin{tabular}{|c|c|c|c|c|}
\hline Hownowes & 0 & 2000 & 4000 & 6000 \\
\hline manderefno $\sigma$, & 18,3 & 21,0 & 30,0 & 41,7 \\
\hline I & 62,5 & 55,1 & 58,9 & 56.0 \\
\hline ep pessun (1n, & 0.150 & 0,120 & 0,114 & 0.108 \\
\hline 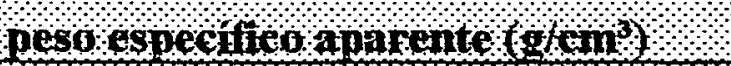 & 0,417 & 0.458 & 0.516 & 0.520 \\
\hline 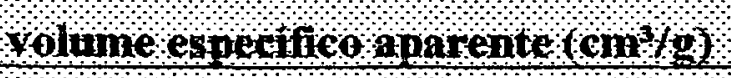 & 2.395 & 2.182 & 1,938 & 1,922 \\
\hline 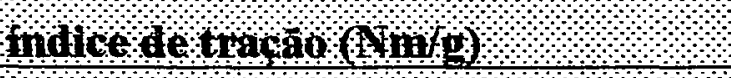 & 33,2 & 59,0 & 74,7 & 74,1 \\
\hline estleanento, $0, \%$ & 1,2 & 2,9 & 3.9 & 4,1 \\
\hline 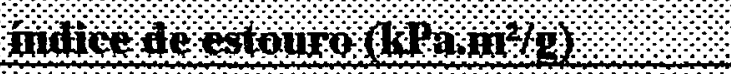 & 1,1 & 3,0 & 4,3 & 5,2 \\
\hline 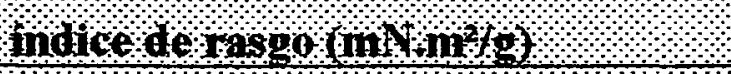 & 5,4 & 10,5 & 11,5 & 12,1 \\
\hline 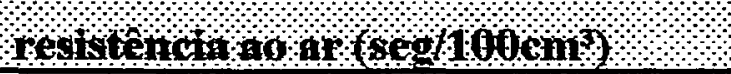 & 1,0 & 1,9 & 12,5 & 23,5 \\
\hline
\end{tabular}


Tabela 33. Propriedades físicas e mecânicas da celulose do tratamento 15 - soda-0,04\%DDA - álcali ativo 13\% fator $\mathrm{H} 677$.

\begin{tabular}{|c|c|c|c|c|}
\hline Mononoes & 0 & 2000 & 400 & 6000 \\
\hline snaderetmo $(0, \mathrm{k})$ & 15,3 & 19,0 & 29,0 & 39,0 \\
\hline thanturan $\left(\mathrm{g}_{\mathrm{n}}\right)$ & 59,6 & 52,6 & 57,7 & 54,6 \\
\hline espesph $(\mathrm{mhl}$ & 0,149 & 0,121 & 0,118 & 0,107 \\
\hline 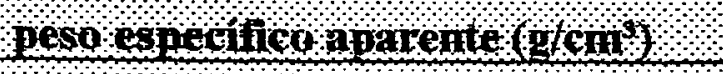 & 0,400 & 0.436 & 0,489 & 0,510 \\
\hline 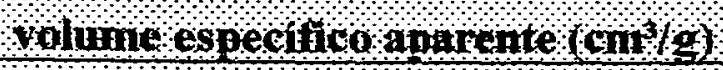 & 2,497 & 2.292 & 2.046 & 1,961 \\
\hline 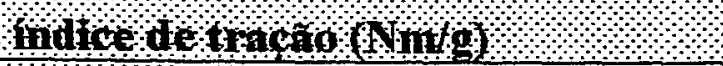 & 28,4 & 51,7 & 63,8 & 73,8 \\
\hline esfonnenton $(\alpha)$ & 1,2 & 2,4 & 3,3 & 4,1 \\
\hline 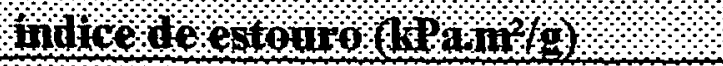 & 0,9 & 2,3 & 3,8 & 4,6 \\
\hline 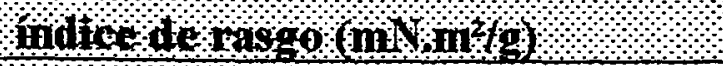 & 6,4 & 9,5 & 15,0 & 12,9 \\
\hline 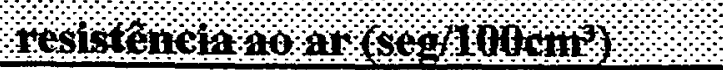 & 0.7 & 1,2 & 5,0 & 17,1 \\
\hline
\end{tabular}




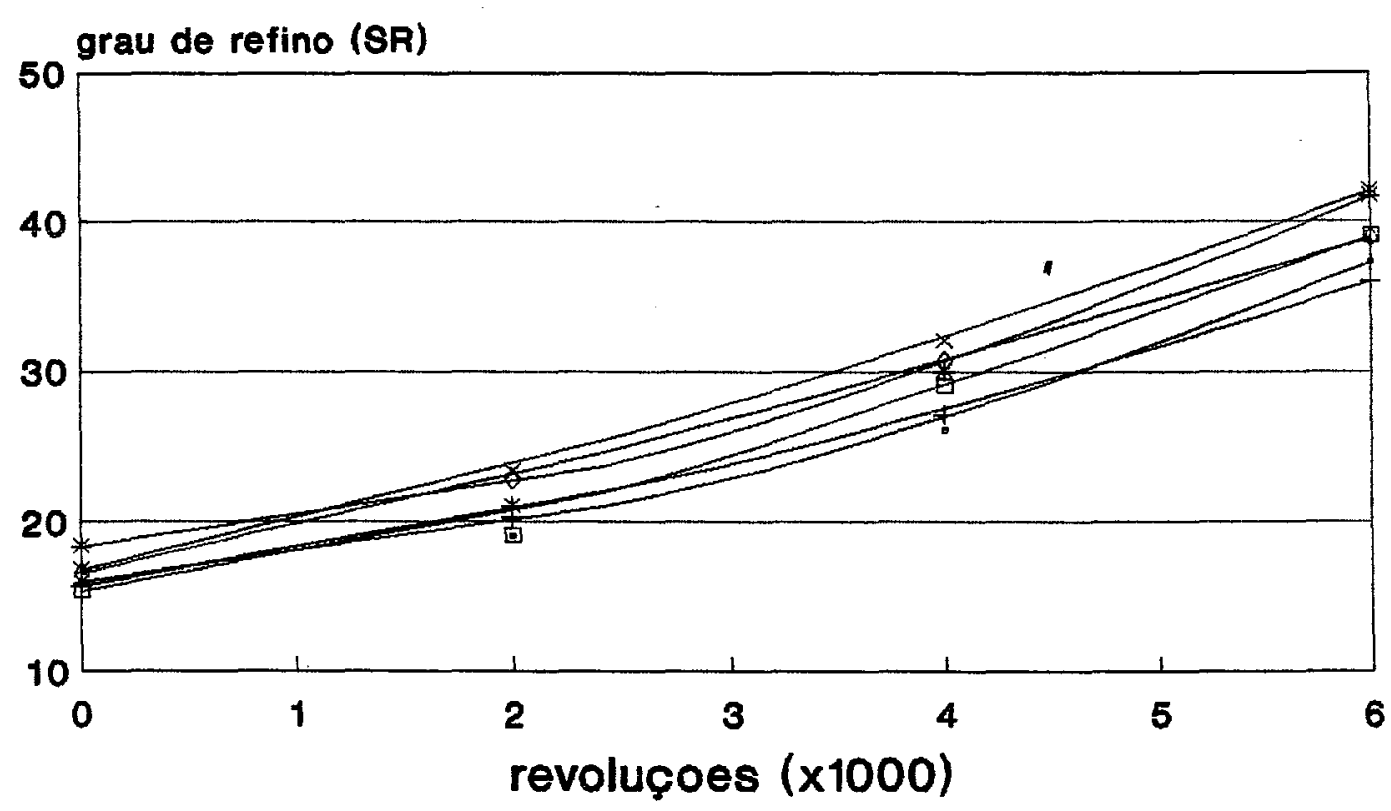

$\rightarrow 215+369 \rightarrow 522 \rightarrow 677 \multimap$ kraft $\multimap$ soda

Figura 47. Grau de refino em função do número de revoluções (moinho PFI).

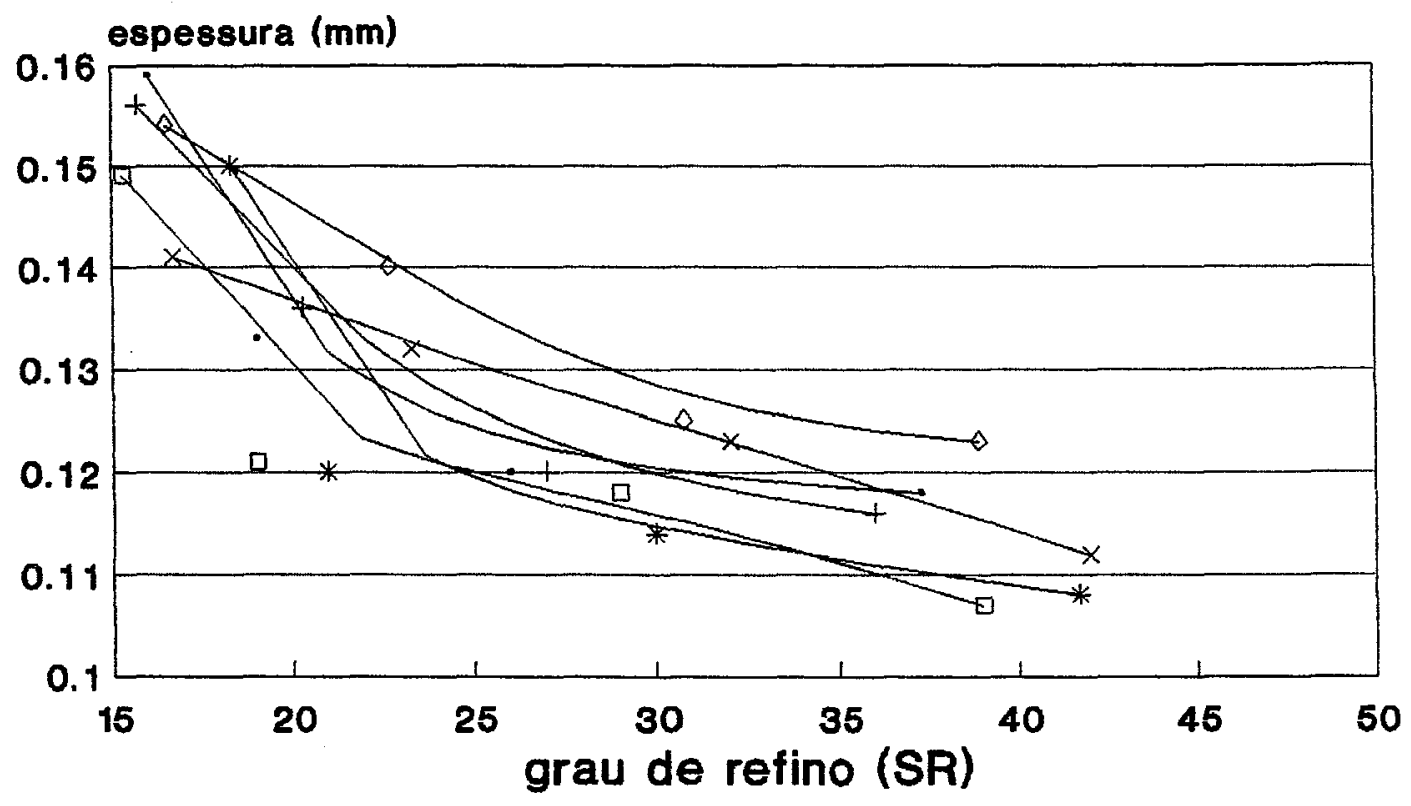

$-215+369 \rightarrow 522 \rightarrow 677 \rightarrow$ kraft $\rightarrow$ 8oda

Figura 48. Espessura em função do grau de refino. 


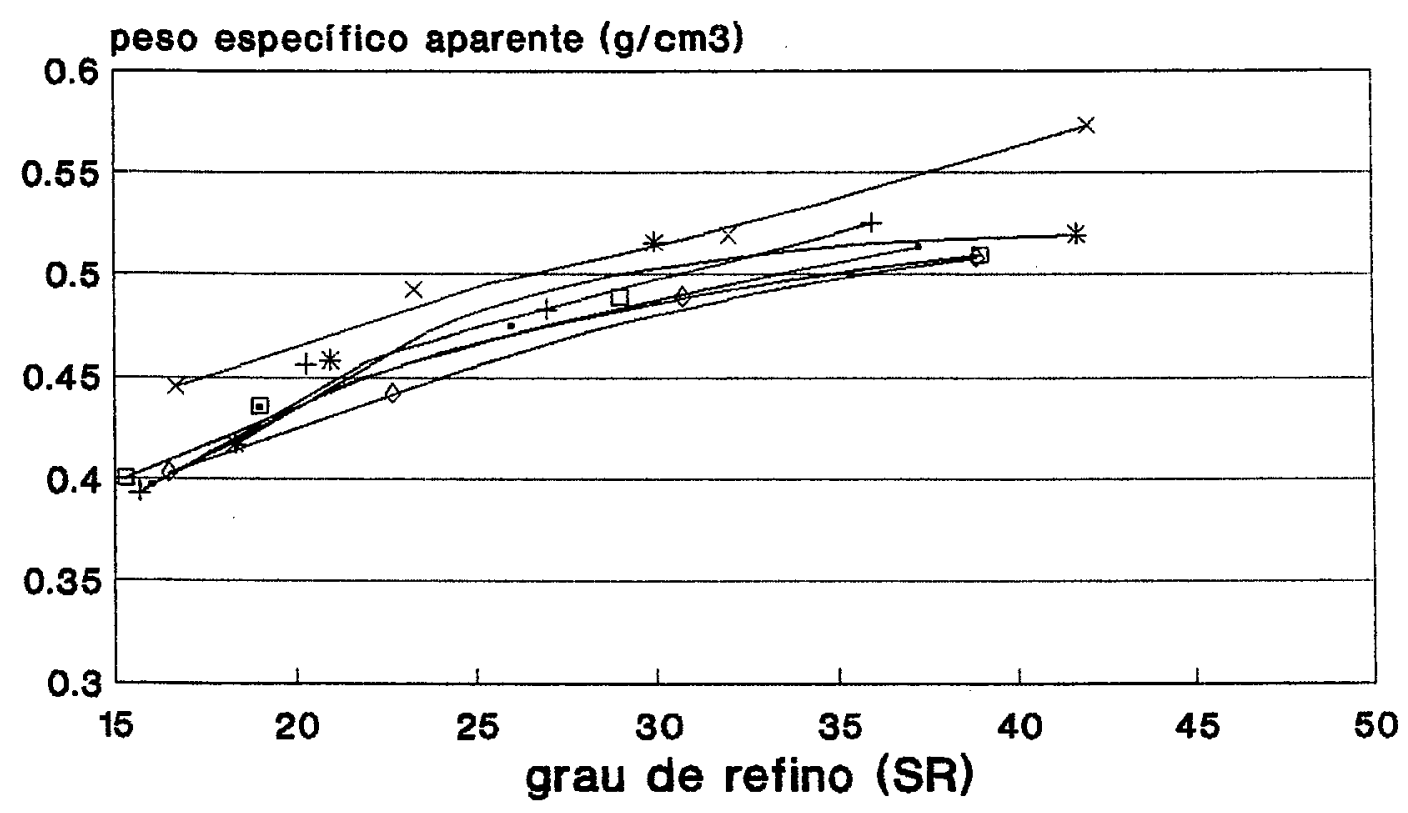

$\rightarrow 215+369 \rightarrow 522 \rightarrow 677 \rightarrow$ kraft $\rightarrow$ ooda

Figura 49. Peso específico aparente em função do grau de refino.

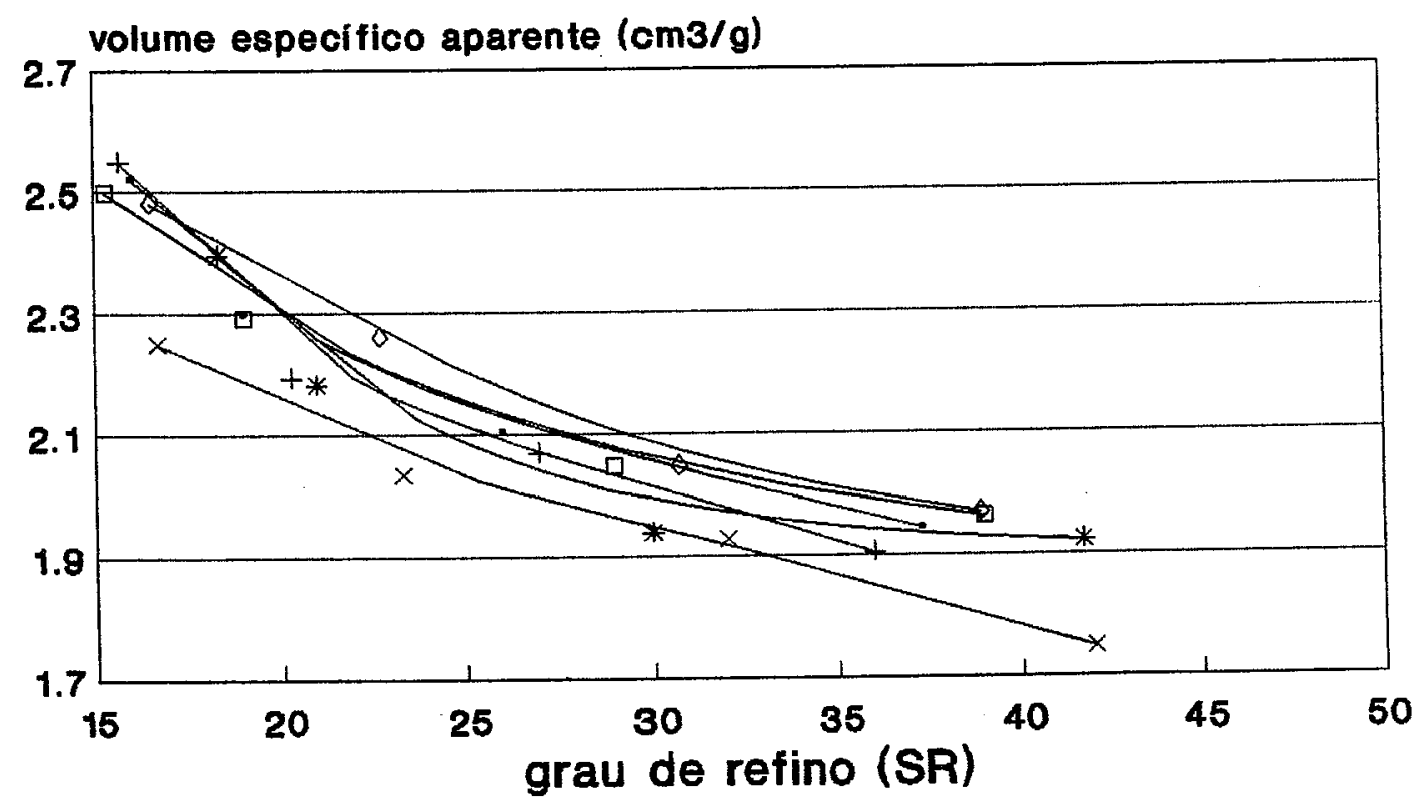

$-215+369+522 \rightarrow 677 \rightarrow$ kraft $\rightarrow$ ooda

Figura 50. Volume específico aparente em função do grau de refino. 


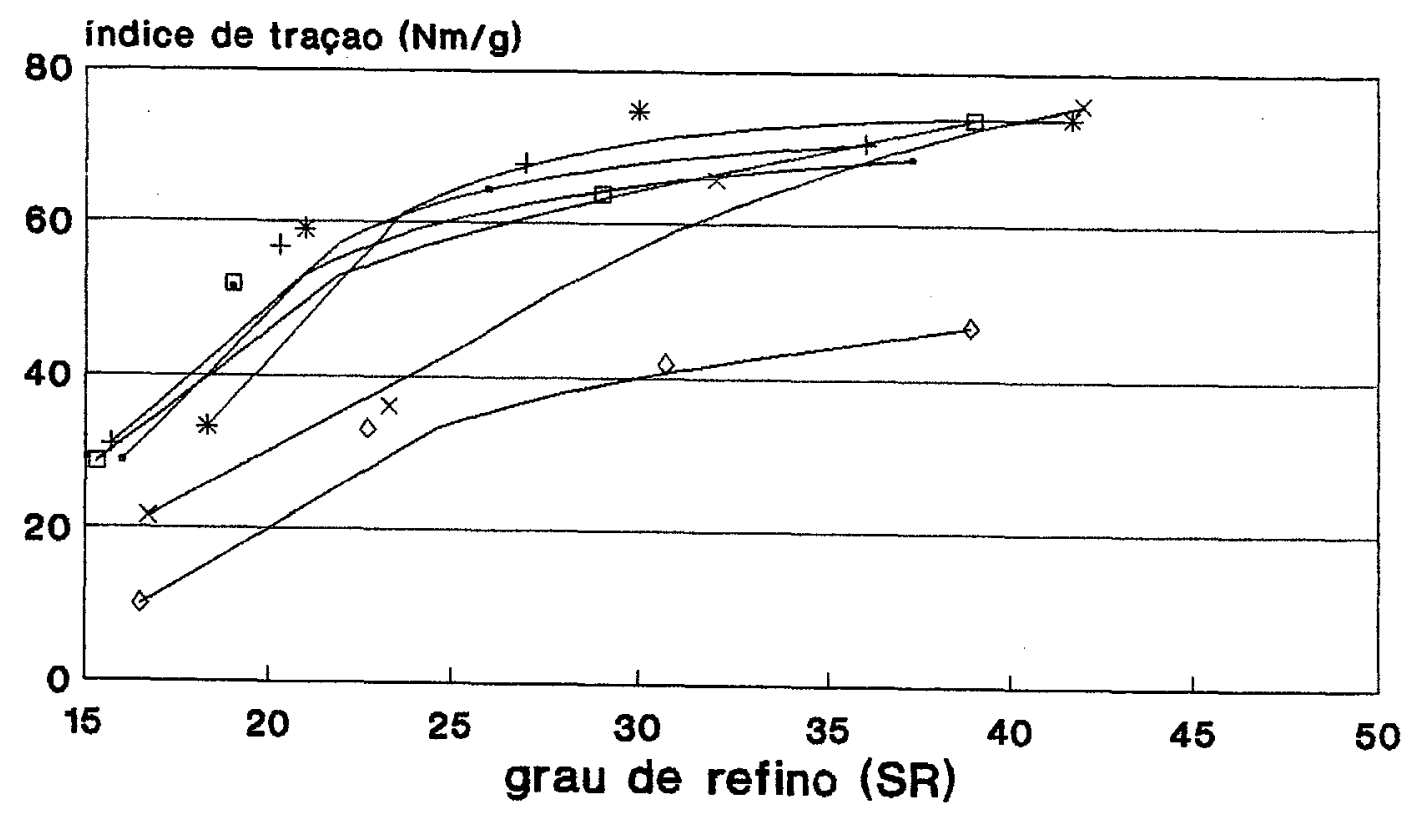

$-215+369 \rightarrow 522 \rightarrow 677 \rightarrow$ kraft $\rightarrow$ soda

Figura 51. Índice de tração em função do grau de refino.

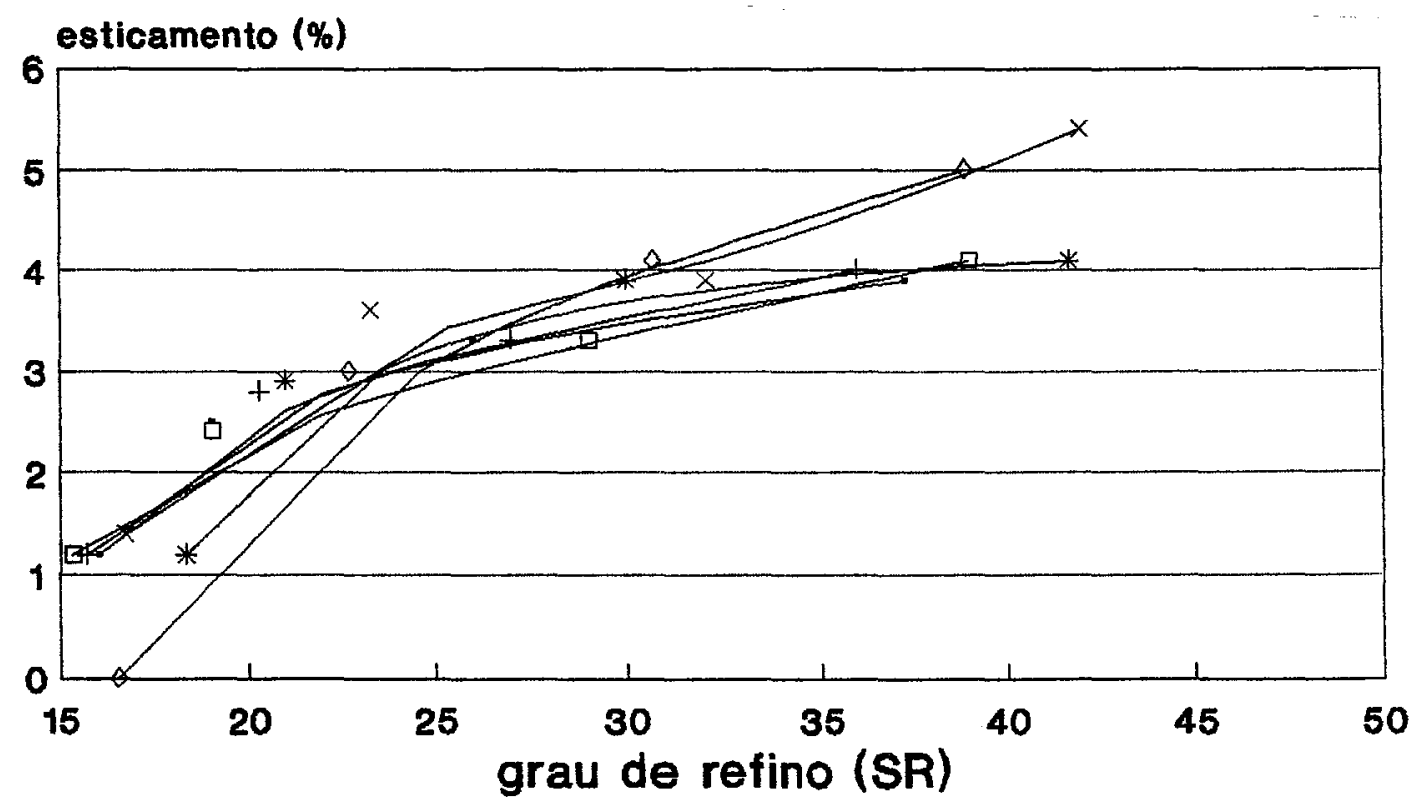

$215 \rightarrow 369 \rightarrow 522 \rightarrow 677 \rightarrow$ kraft $\rightarrow$ soda

Figura 52. Esticamento em função do grau de refino. 


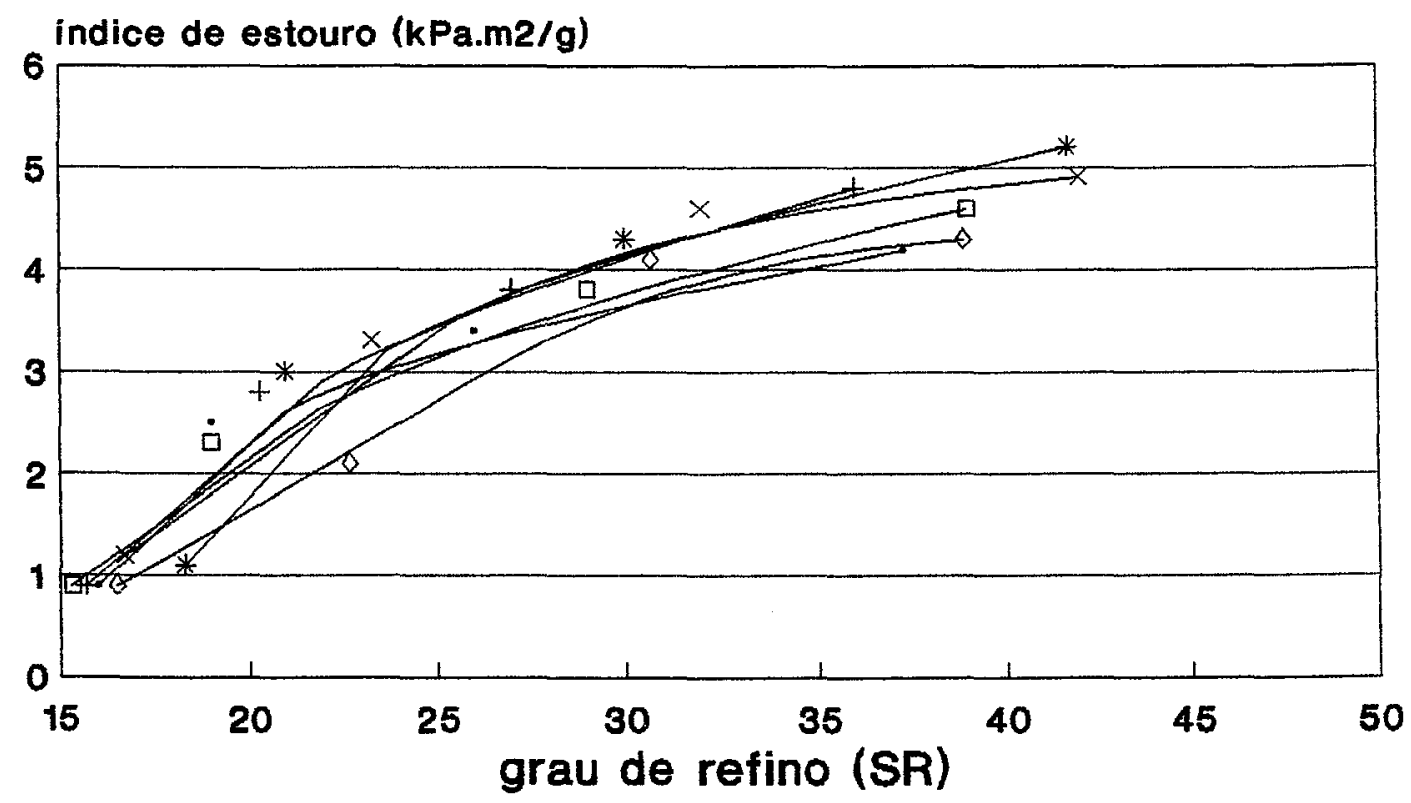

$\leftarrow 215 \leftarrow 369 \rightarrow 522 \rightarrow 677 \rightarrow$ kraft $\leftarrow$ soda

Figura 53. Índice de estouro em função do grau de refino.

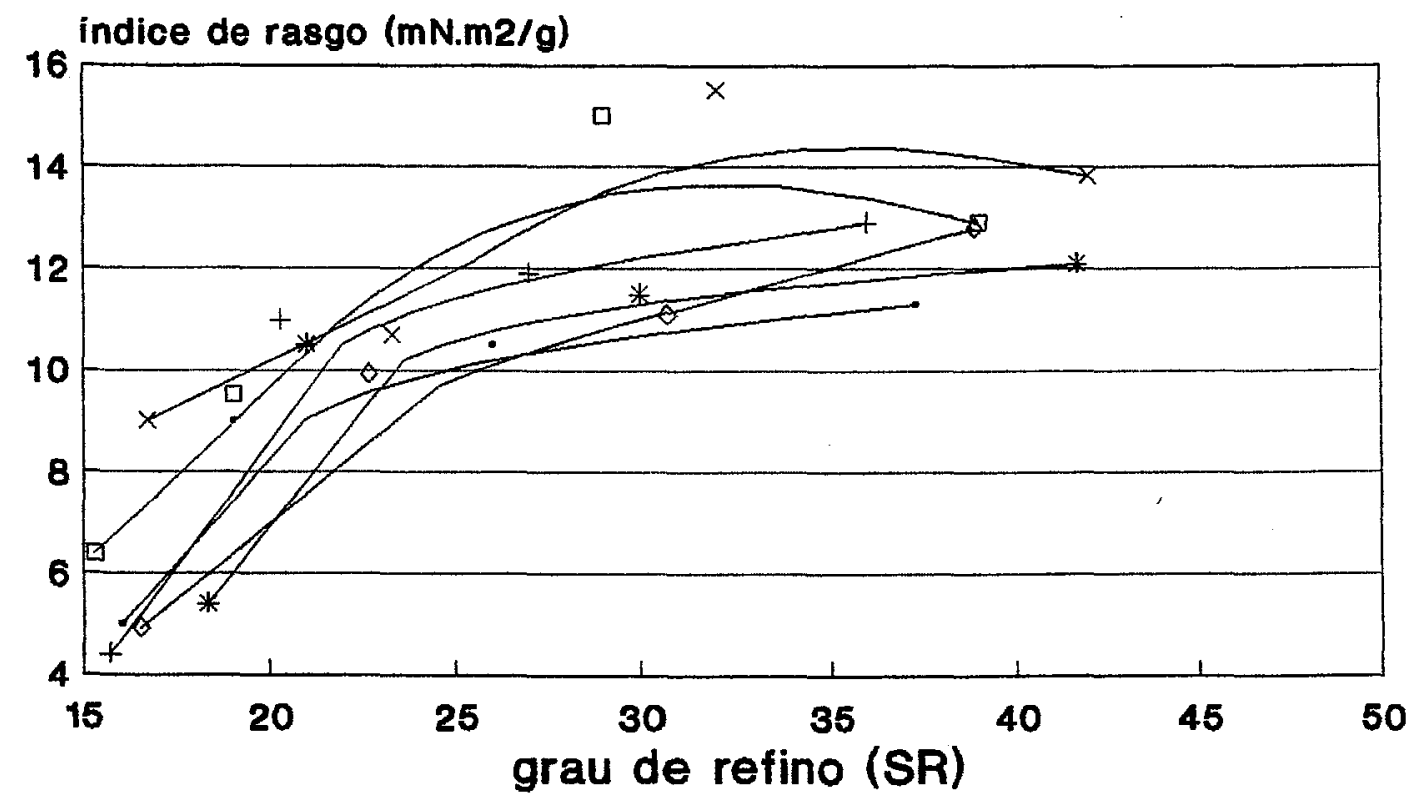

$\rightarrow 215+369 \rightarrow 522 \rightarrow 677 \rightarrow$ kraft $\rightarrow$ ooda

Figura 54. Índice de rasgo em função do grau de refino. 


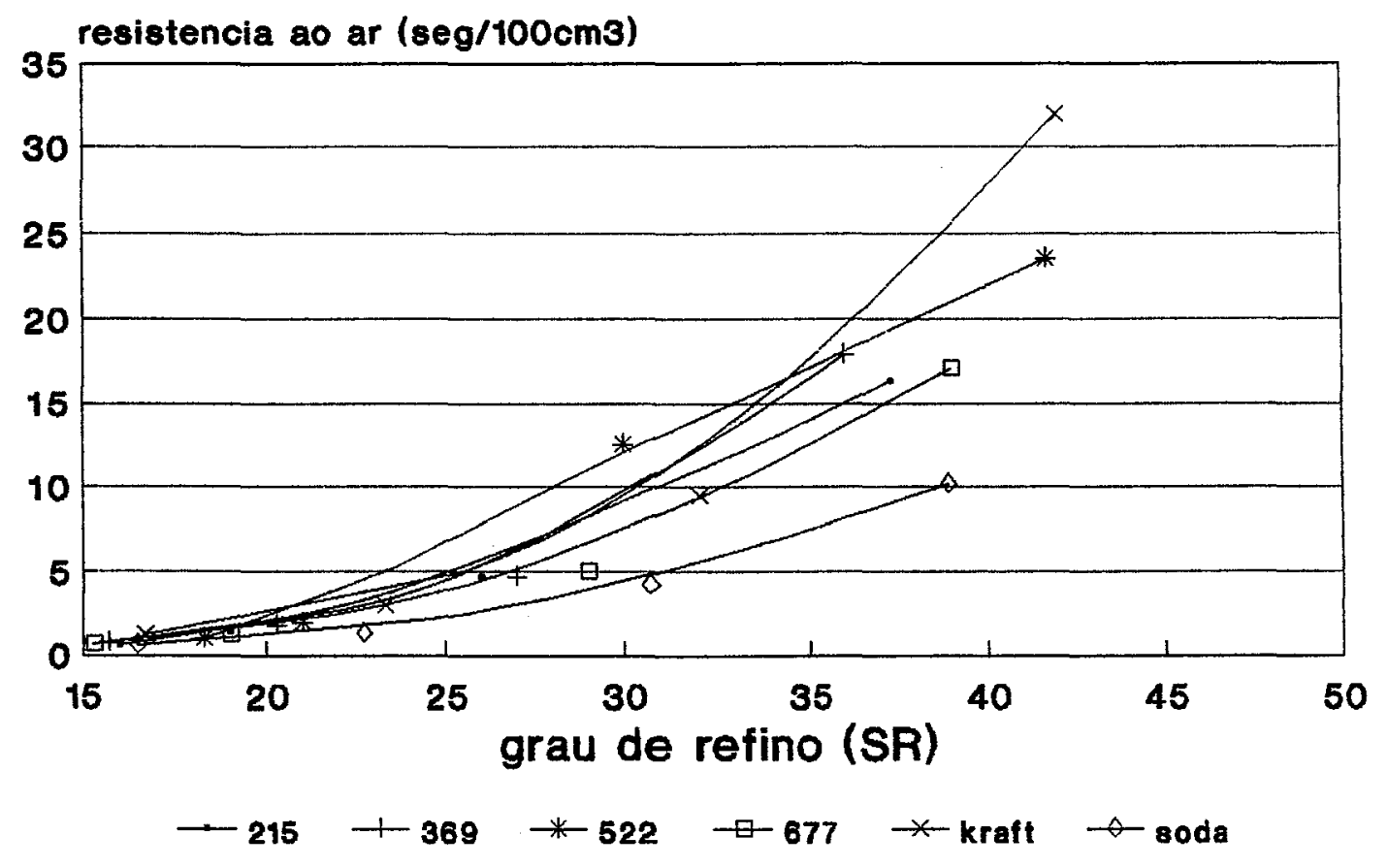

Figura 55. Resistência à passagem de ar em função do grau de refino. 
Na tabela 34 são apresentados os resultados das análises de licor negro.

Tabela 34. Análises de licor negro dos tratamentos $12,13,14$ e 15.

\begin{tabular}{|c|c|c|c|c|c|c|c|}
\hline tratanento & $\mathrm{nu}$ & denth & rotw & orghto & borkant & मी & votoldo \\
\hline $12 \mathrm{~m}$ & 12,36 & 1.04 & 10.42 & 52,30 & 47,70 & 10,7 & 2,1 \\
\hline $13 \mathrm{~m}$ & 12.09 & 1.05 & 12.57 & 60.98 & 39.025 & 7.9 & 2.5 \\
\hline $14 \mathrm{n}$ & 12,34 & 1,06 & 14,52 & 68,05 & 31,95 & 3,5 & 2,8 \\
\hline $1 \mathrm{sm}$ & 12,45 & 1,06 & 14.60 & 60,02 & 39.98 & 4,4 & 2.61 \\
\hline
\end{tabular}

m - média

s - desvio-padrão

CV - coeficiente de variação tratamento 12 - soda-0,04\% DDA - álcali ativo $12 \%$ fator $\mathrm{H} 215$ tratamento 13 - soda-0,04\% DDA - álcali ativo $13 \%$ fator $\mathrm{H} 369$ tratamento 14 - soda-0,04\%DDA - álcali ativo $14 \%$ fator $\mathrm{H} 522$ tratamento 15 - soda-0,04\% DDA - álcali ativo $15 \%$ fator $\mathrm{H} 677$

$\mathrm{Na}$ figura 56 , foram plotados os resultados das análises de teor de sólidos e álcali ativo residual no licor negro dos tratamentos $12,13,14$ e 15 . 


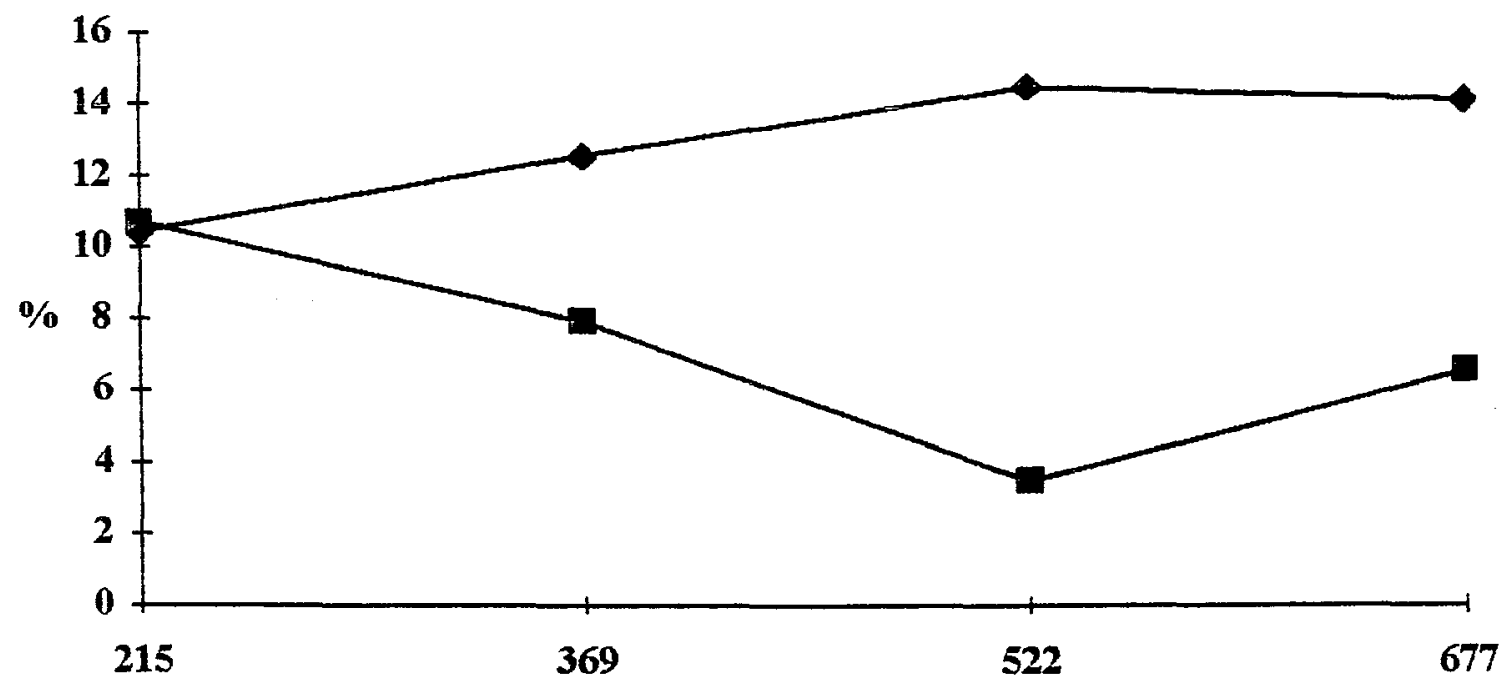

fator H - Cozimento SODA-0,04DDA - álcali ativo 13\%

- teor de sólidos $\rightarrow$ álcali ativo residual

Figura 56. Teor de sólidos e álcali ativo residual em função do fator $\mathrm{H}$. 


\subsection{Determinacão da sulfidez}

Foram realizados cozimentos com $0,04 \%$ de DDA, álcali ativo de $13 \%$, fator $\mathrm{H}$ de 522 e diferentes níveis de sulfidez, sendo os tratamentos assim designados:

- tratamento $16-0 \%$ de sulfidez

- tratamento 17 - $5 \%$ de sulfidez

- tratamento $18-10 \%$ de sulfidez

- tratamento 19 - $15 \%$ de sulfidez

- tratamento $20-20 \%$ de sulfidez

- tratamento $21-21 \%$ de sulfidez

Na tabela 35 , são apresentados os valores de rendimento bruto e depurado, teor de rejeitos e fator $\mathrm{H}$ das celuloses obtidas nos tratamentos descritos anteriormente. 
Tabela 35. Rendimento bruto e depurado, teor de rejeitos para fator $\mathrm{H}$ igual a 522.

\begin{tabular}{|c|c|c|c|c|}
\hline \multicolumn{2}{|c|}{ ththntento } & \multirow{2}{*}{$\begin{array}{c}\text { tentmonto } \\
\text { bnto } \\
59,4\end{array}$} & \multirow{2}{*}{$\begin{array}{c}\text { rodedtos } \\
0,01 \\
0,31\end{array}$} & \multirow{2}{*}{$\begin{array}{c}\text { tentmento } \\
10,0,0) \\
59,0\end{array}$} \\
\hline 16 & n & & & \\
\hline & 1 & 1,13 & 0,10 & 1,15 \\
\hline & $\mathrm{C}^{2}(\mathrm{p})$ & 1,91 & 32,74 & 1,95 \\
\hline \multirow[t]{3}{*}{17} & n? & 57,7 & 0,20 & 57,5 \\
\hline & 3 & 0,46 & 0,11 & 0,46 \\
\hline & 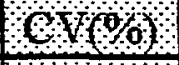 & 0.81 & 52,52 & 0.81 \\
\hline \multirow[t]{3}{*}{18} & $\mathrm{n}$ & 57,3 & 0.22 & 57,1 \\
\hline & 8 & 0,37 & 0,12 & 0,41 \\
\hline & 010 & 0,64 & 55,48 & 0,71 \\
\hline \multirow[t]{3}{*}{19} & $\mathrm{ma}$ & 58,2 & 0,25 & 58,0 \\
\hline & 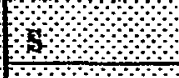 & 0,60 & 0,17 & 0,59 \\
\hline & 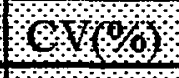 & 1,02 & 66,88 & 1,02 \\
\hline \multirow[t]{3}{*}{24} & $\mathrm{n}$ & 57,5 & 0,37 & 57,1 \\
\hline & 3 & 0.58 & 0,07 & 0,61 \\
\hline & $00(0)$ & 1.01 & 17.81 & 1,07 \\
\hline \multirow[t]{3}{*}{14} & $\mathrm{n}$ & 58,6 & 0.26 & 58,4 \\
\hline & 4 & 1,77 & 0,10 & 1,81 \\
\hline & Qn & 3,02 & 39,85 & 3,10 \\
\hline
\end{tabular}

m - média

s - desvio-padrão

$\mathrm{CV}$ - coeficiente de variação tratamento $16-0 \%$ de sulfidez tratamento 17 - $5 \%$ de sulfidez tratamento $18-10 \%$ de sulfidez tratamento $19-15 \%$ de sulfidez tratamento $20-20 \%$ de sulfidez tratamento $21-25 \%$ de sulfidez 
$\mathrm{Na}$ tabela 36 são apresentados os resultados das análises quimicas das celuloses obtidas nos tratamentos anteriores bem como algumas relações

Tabela 36. Número kappa, viscosidade, lignina residual e relações.

\begin{tabular}{|c|c|c|c|c|c|c|}
\hline \multicolumn{2}{|c|}{ tratamento } & \multirow{2}{*}{$\begin{array}{l}\frac{10 p+p}{30 p} \\
30,2\end{array}$} & \multirow{2}{*}{$\begin{array}{c}\text { w } \\
+ \\
10,1\end{array}$} & \multirow{2}{*}{$\frac{14 m}{1,5}$} & \multirow{2}{*}{$\begin{array}{c}\text { plopplo } \\
2,0\end{array}$} & \multirow{2}{*}{ 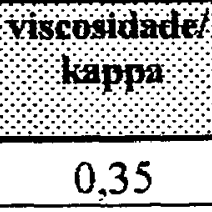 } \\
\hline 16 & $m$ & & & & & \\
\hline & 3 & 0,90 & 0,86 & 0,04 & 0,07 & 0.03 \\
\hline & $\theta \mathrm{u}(\alpha)$ & 2.96 & 8,20 & 2,71 & 3,37 & 7.92 \\
\hline \multirow[t]{3}{*}{17} & $\mathrm{~m}$ & 24,2 & 21,2 & 1,4 & 2,37 & 0.86 \\
\hline & 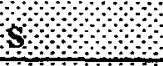 & 0,63 & 1,36 & 0,03 & 0,05 & 0.08 \\
\hline & $20(0)$ & 2.62 & 6,39 & 2,36 & 1,93 & 9,01 \\
\hline \multirow[t]{3}{*}{10} & 11 & 20,6 & 36,6 & 1,2 & 2,73 & 1,78 \\
\hline & 3 & 0.88 & 1.23 & 0,02 & 0,14 & 0,11 \\
\hline & $010 \%$ & 4,26 & 3,35 & 1,45 & 5,25 & 6.45 \\
\hline \multirow[t]{3}{*}{19} & $\mathrm{n}$ & 22,4 & 31,6 & 1,3 & 2,58 & 1,41 \\
\hline & 3 & 0,48 & 1,60 & 0,02 & 0,05 & 0.06 \\
\hline & $10 \%$ & 2,15 & 5,05 & 1,30 & 2,01 & 4,26 \\
\hline \multirow[t]{3}{*}{20} & $\mathrm{n}$ & 22.2 & 36,9 & 1,2 & 2,57 & 1,66 \\
\hline & 1 & 0.32 & 2,47 & 0.03 & 0.02 & 0.11 \\
\hline & $\theta(0)$ & 1.46 & 6.71 & 2,18 & 0.92 & 6.44 \\
\hline \multirow[t]{3}{*}{21} & $\mathrm{a}$ & 18,3 & 51,6 & 1,1 & 3,10 & 2.82 \\
\hline & 3 & 0,15 & 1,83 & 0,00 & 0,04 & 0,11 \\
\hline & 010,0 & 0,81 & 3,55 & -- & 1,42 & 4.08 \\
\hline
\end{tabular}

$\mathrm{m}$ - média

s - desvio-padrão

$\mathrm{CV}$ - coeficiente de variação tratamento $16-0 \%$ de sulfidez tratamento $17-5 \%$ de sulfidez tratamento $18 \cdot 10 \%$ de sulfidez tratamento $19-15 \%$ de sulfidez tratamento $20-20 \%$ de sulfidez tratamento $21-25 \%$ de sulfidez 
Na figura 57 estão representados os resultados de rendimento depurado, número kappa e viscosidade das celuloses obtidas nos tratamentos 16 , $17,18,19,20$ e 21 .

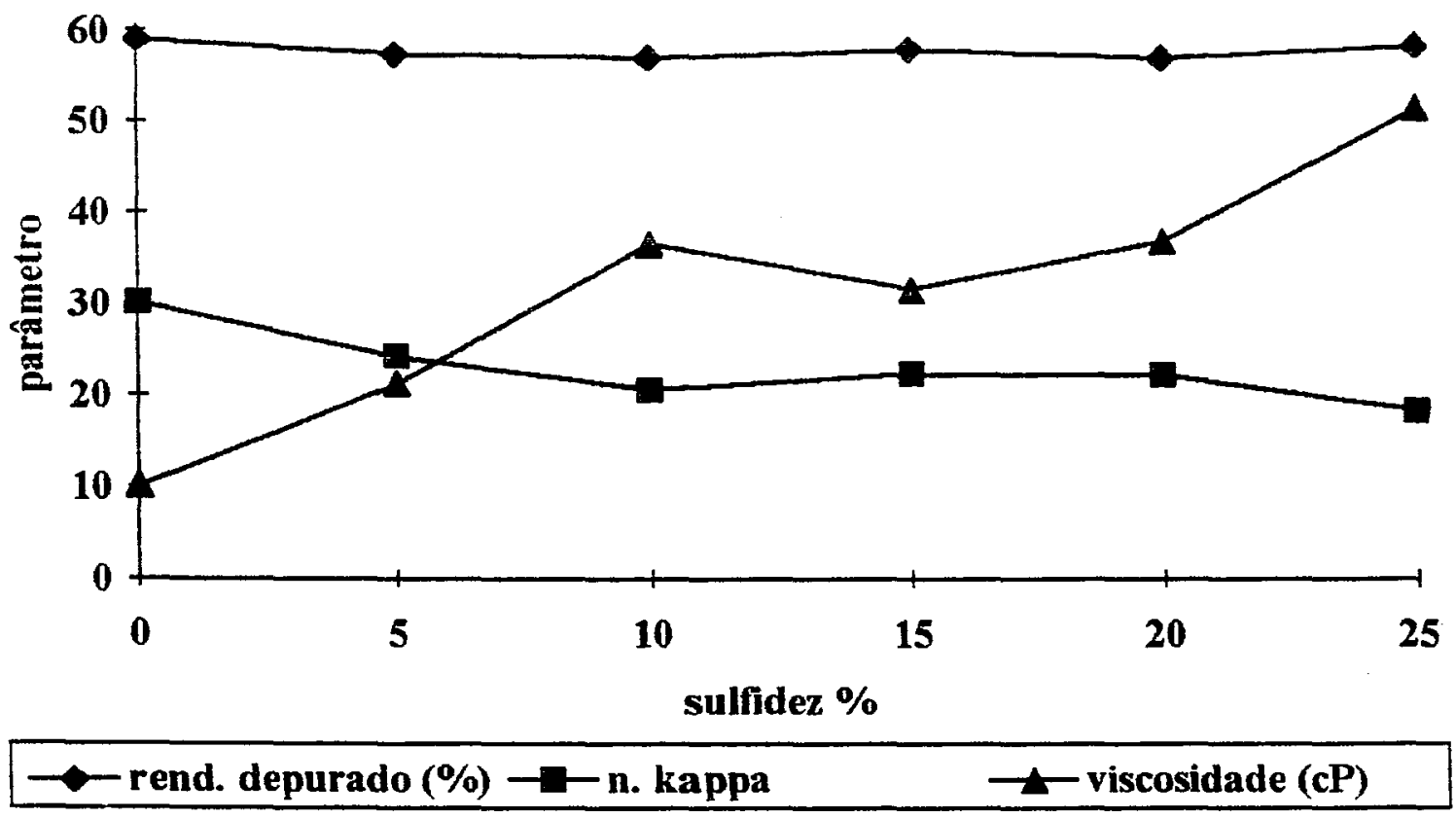

Figura 57. Número kappa, viscosidade e rendimento depurado das celuloses em função do nivel de sulfidez. 
$\mathrm{Na}$ figura 58 são apresentados a relação rendimento depurado/número kappa e viscosidade/número kappa em função do nível de sulfidez.

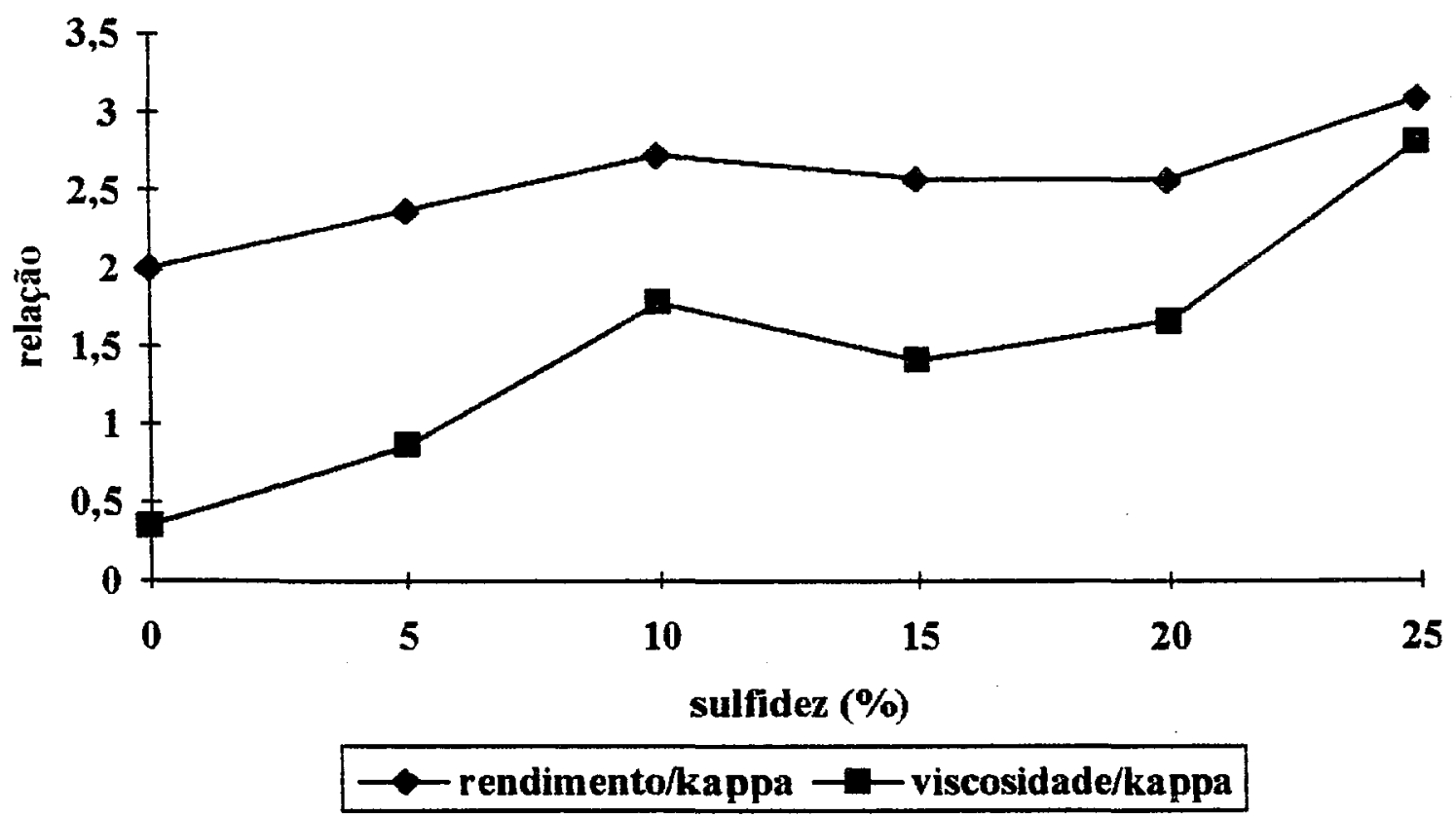

Figura 58. Relação rendimento depurado/número kappa e viscosidade/número kappa em função do nível de sulfidez. 
Na tabela 37 são apresentados os resultados das análises de teor de pentosanas e alfa, beta e gama celulose dos tratamentos $16,17,18,19,20$ e 21 .

Tabela 37. Teor de pentosanas e alfa, beta e gama celuloses dos tratamentos $16,17,18,19,20$ e 21 .

\begin{tabular}{|c|c|c|c|c|c|}
\hline \multicolumn{2}{|c|}{ thataturto } & 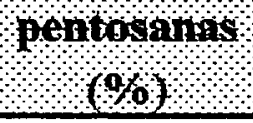 & 11 & bef & qumplot \\
\hline \multirow[t]{3}{*}{16} & 1 & 13.8 & 86,0 & 4,0 & 10,0 \\
\hline & 3 & 0,44 & 0,17 & 0,46 & 0,51 \\
\hline & 00 & 3,16 & 0.19 & 11.50 & 5,04 \\
\hline \multirow[t]{3}{*}{17} & $\mathrm{~m}$ & 15,0 & 85,9 & 4,4 & 9,74 \\
\hline & 5 & 0.60 & 0,20 & 0,31 & 0,41 \\
\hline & $010 \%$ & 3,98 & 0,23 & 7,11 & 4,21 \\
\hline \multirow[t]{3}{*}{18} & $1 \mathrm{~m}$ & 14,6 & 87,3 & 5,2 & 7,5 \\
\hline & 3 & 0.54 & 0,18 & 0,39 & 0,41 \\
\hline & 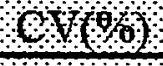 & 3,72 & 0,22 & 7,50 & 5,50 \\
\hline \multirow[t]{3}{*}{19} & $\mathrm{~m}$ & 15.6 & 83,7 & 7,9 & 8.4 \\
\hline & 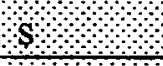 & 0,44 & 0,26 & 0,54 & 0,24 \\
\hline & $\alpha(\theta)$ & 2.79 & 0.31 & 6.84 & 2.83 \\
\hline \multirow[t]{3}{*}{20} & 1 & 14,9 & 87,1 & 3,1 & 9,8 \\
\hline & 3 & 0,36 & 0.22 & 0,35 & 0,36 \\
\hline & $\beta(\%)$ & 2,39 & 0,26 & 11,29 & 3.64 \\
\hline \multirow[t]{3}{*}{21} & $\mathrm{~m}$ & 16,4 & 82,4 & 3,5 & 14,1 \\
\hline & s & 0,69 & 0,18 & 0,14 & 0,15 \\
\hline & $\theta x(\%)$ & 4.22 & 0.21 & 4,00 & 1,08 \\
\hline
\end{tabular}

$\mathrm{m}$ - média

$\mathrm{s}$ - desvio-padrão

CV - coeficiente de variação tratamento $16-0 \%$ de sulfidez

tratamento $17-5 \%$ de sulfidez

tratamento 18 - $10 \%$ de sulfidez

tratamento $19-15 \%$ de sulfidez

tratamento $20-20 \%$ de sulfidez

tratamento $21-25 \%$ de sulfidez 
Nas tabelas $38,39,40,41,42$ e 43 são apresentados os resultados dos testes físicos e mecânicos realizados com as celuloses dos tratamentos 16,17 , $18,19,20,21$.

Tabela 38. Propriedades físicas e mecânicas da celulose do tratamento $16-0 \%$ de sulfidez.

\begin{tabular}{|c|c|c|c|c|}
\hline nevolucous & 0 & 2000 & 4000 & 6000 \\
\hline 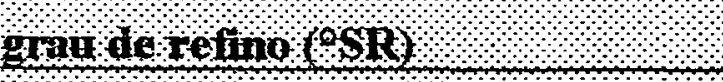 & 18,3 & 21,0 & 30,0 & 41,7 \\
\hline 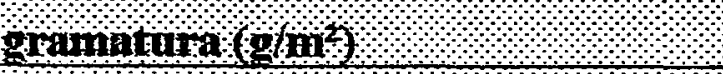 & 62,5 & 55,1 & 58,9 & 56,0 \\
\hline opposulan (1nn) & 0,150 & 0,120 & 0,114 & 0,108 \\
\hline 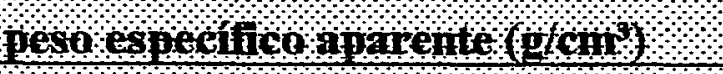 & 0,417 & 0,458 & 0,516 & 0,520 \\
\hline 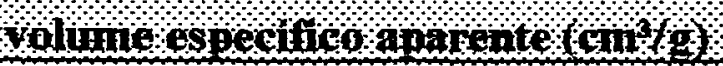 & 2,395 & 2,182 & 1,938 & 1,922 \\
\hline nd & 33.2 & 59,0 & 74,7 & 74.1 \\
\hline ostonthento $(\%)$ & 1,2 & 2,9 & 3,9 & 4.1 \\
\hline 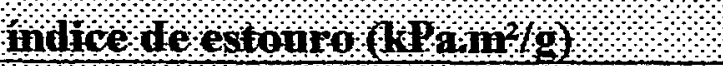 & 1,1 & 3,0 & 4.3 & 5.2 \\
\hline 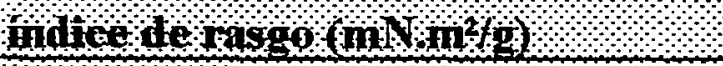 & 5,4 & 10,5 & 11,5 & 12,1 \\
\hline 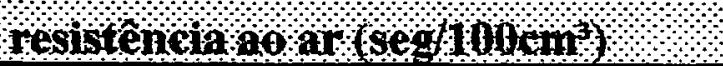 & 1,0 & 1,9 & 12,5 & 23,5 \\
\hline
\end{tabular}


Tabela 39. Propriedades físicas e mecânicas da celulose do tratamento $17-5 \%$ de sulfidez.

\begin{tabular}{|c|c|c|c|c|}
\hline 1enolugoes & 0 & 2000 & 4000 & 6000 \\
\hline 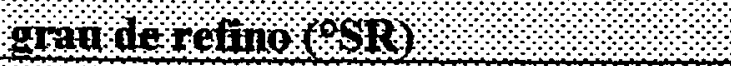 & 17,7 & 20,7 & 30,7 & 39,3 \\
\hline 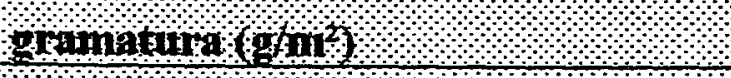 & 58,8 & 60,0 & 60,4 & 59.9 \\
\hline 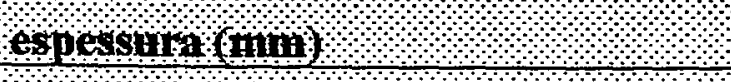 & 0,143 & 0.125 & 0.118 & 0.112 \\
\hline 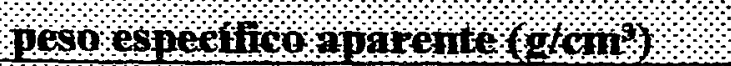 & 0,411 & 0,479 & 0,511 & 0.536 \\
\hline 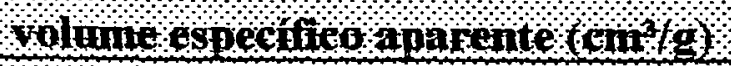 & 2.430 & 2,087 & 1,959 & 1,864 \\
\hline 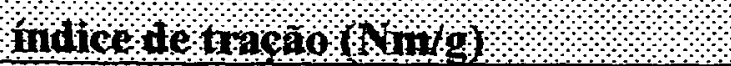 & 33,9 & 55,8 & 68.4 & 80.6 \\
\hline entwn, & 1,3 & 2,8 & 3,7 & 4.7 \\
\hline 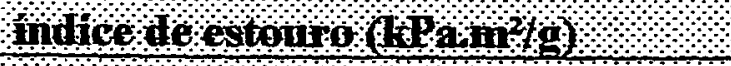 & 1,1 & 3,2 & 4,4 & 5,4 \\
\hline 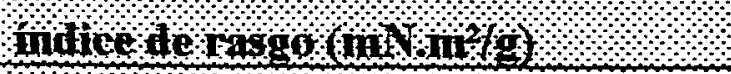 & 5,9 & 9,9 & 11,9 & 11,2 \\
\hline 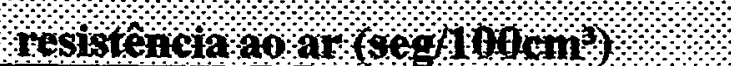 & 1,0 & 2,5 & 9,1 & 34,0 \\
\hline
\end{tabular}


Tabela 40. Propriedades fisicas e mecânicas da celulose do tratamento $18-10 \%$ de sulfidez.

\begin{tabular}{|c|c|c|c|c|}
\hline nevoluoss & 0 & 2000 & 1000 & 6000 \\
\hline 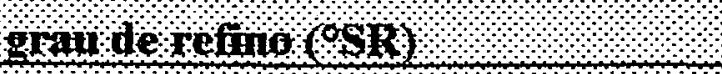 & 16,0 & 23,7 & 33,3 & 52,3 \\
\hline manaln $\left(0 / \mathrm{m}^{2}\right)$ & 62,3 & 52,3 & 60,0 & 59,1 \\
\hline espessun $(n \mathrm{nk})$ & 0,142 & 0,114 & 0,111 & 0,101 \\
\hline 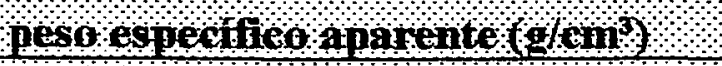 & 0,438 & 0,472 & 0,528 & 0,584 \\
\hline 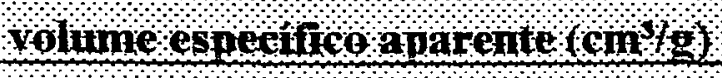 & 2.820 & 2.117 & 1.893 & 1.713 \\
\hline 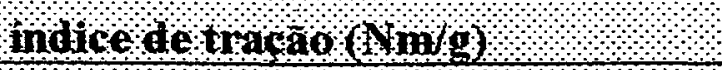 & 34,3 & 65,7 & 75,5 & 85.1 \\
\hline estranento $(0)$ & 1,4 & 3,3 & 3,9 & 4.6 \\
\hline 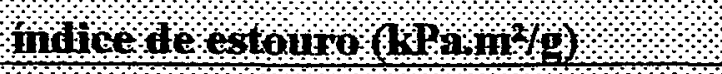 & 1,4 & 4,0 & 4,9 & 6,0 \\
\hline 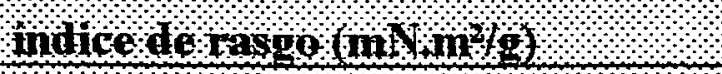 & 7,1 & 11,8 & 11,9 & 11,4 \\
\hline 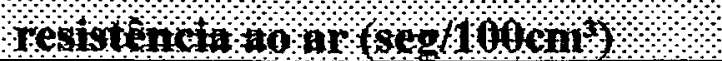 & 1,2 & 2,5 & 13,2 & 40,2 \\
\hline
\end{tabular}


Tabela 41. Propriedades físicas e mecânicas da celulose do tratamento $19-15 \%$ de sulfidez.

\begin{tabular}{|c|c|c|c|c|}
\hline $10 \times 01,000$ & 0 & 2000 & 0000 & 6000 \\
\hline 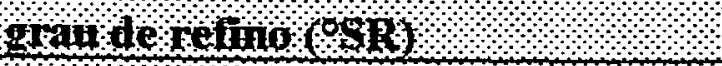 & 18,3 & 22,3 & 35,7 & 45,7 \\
\hline 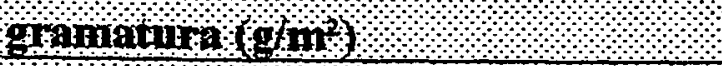 & 64,4 & 55,5 & 59,6 & 59,5 \\
\hline esestuth (nh) & 0,151 & 0,115 & 0,112 & 0,106 \\
\hline 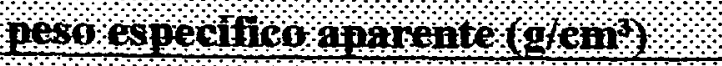 & 0,425 & 0,478 & 0,531 & 0.562 \\
\hline 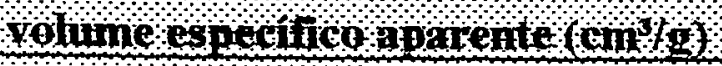 & 2,352 & 2.097 & 1,884 & 1,778 \\
\hline $11+0,1, a_{0}, 0(\mathrm{nn}, \mathrm{g})$ & 36,7 & 66,3 & 72,7 & 82,4 \\
\hline otphnohto $(\theta, 0)$ & 1,6 & 3,7 & 4,4 & 5,3 \\
\hline 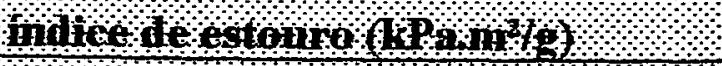 & 1,2 & 5,4 & 5,1 & 6,1 \\
\hline 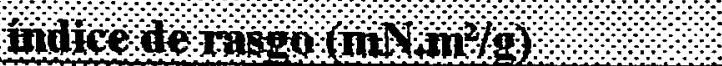 & 6,4 & 13,9 & 14,0 & 12,3 \\
\hline 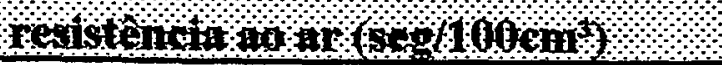 & 1,2 & 3,4 & 15,4 & 34,2 \\
\hline
\end{tabular}


Tabela 42. Propriedades físicas e mecânicas da celulose do tratamento $20-20 \%$ de sulfidez.

\begin{tabular}{|c|c|c|c|c|}
\hline 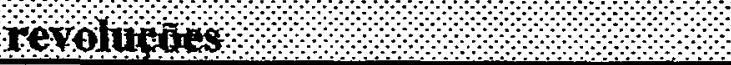 & 0 & 2000 & 1000 & 6000 \\
\hline 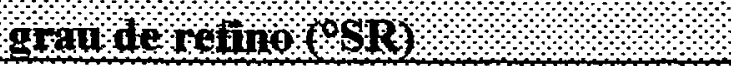 & 17.7 & 21,7 & 31,7 & 46,0 \\
\hline g & 59,3 & 60,9 & 59,3 & 60,7 \\
\hline 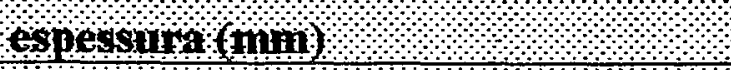 & 0,142 & 0,125 & 0,113 & 0,108 \\
\hline 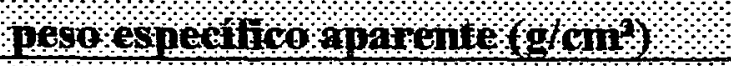 & 0,419 & 0,487 & 0,525 & 0.564 \\
\hline 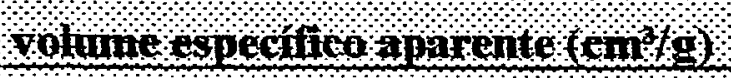 & 2,389 & 2.055 & 1,906 & 1.773 \\
\hline 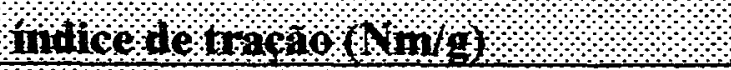 & 37,8 & 59,9 & 76,5 & 91.5 \\
\hline Sthnthlo $(\%)$ & 1,7 & 3,3 & 4,5 & 5,5 \\
\hline 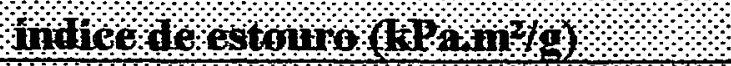 & 1,2 & 3,9 & 5,2 & 6,2 \\
\hline 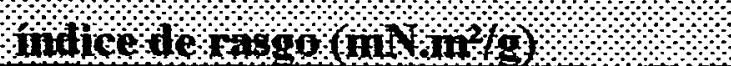 & 6,4 & 11,1 & 12,9 & 12,7 \\
\hline 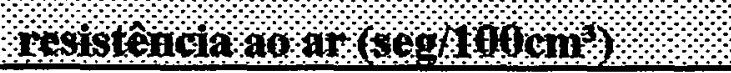 & 1,2 & 3,7 & 14,5 & 42,8 \\
\hline
\end{tabular}


Tabela 43. Propriedades físicas e mecânicas da celulose do tratamento $21-25 \%$ de sulfidez.

\begin{tabular}{|c|c|c|c|c|}
\hline revolugoes & 0 & 2000 & 4000 & 6000 \\
\hline 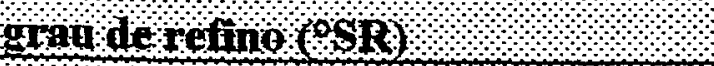 & 17,0 & 23,7 & 32,7 & 48,0 \\
\hline 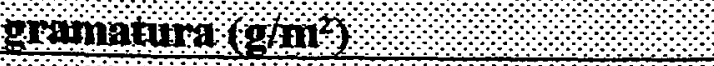 & 63,4 & 59,7 & 59,1 & 57,1 \\
\hline opposunam (n) & 0,148 & 0,120 & 0,109 & 0,104 \\
\hline 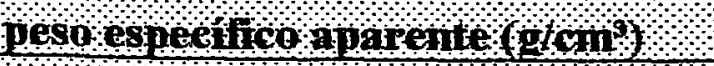 & 0,428 & 0,496 & 0,540 & 0.546 \\
\hline 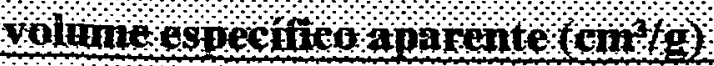 & 2,339 & 2,015 & 1,851 & 1.830 \\
\hline 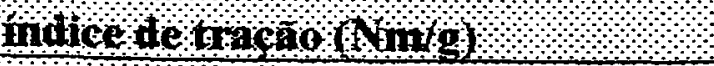 & 38,3 & 70,4 & 79.1 & 83.2 \\
\hline entanento $(\%)$ & 1,8 & 3,9 & 4.9 & 5,5 \\
\hline 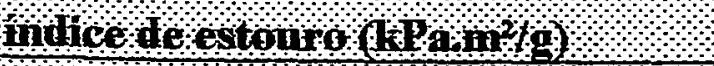 & 1,4 & 4,1 & 5,4 & 5,9 \\
\hline 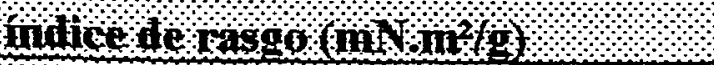 & 7,1 & 13,1 & 14,1 & 12,9 \\
\hline 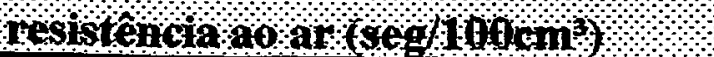 & 1,3 & 4,4 & 8,0 & 39,3 \\
\hline
\end{tabular}




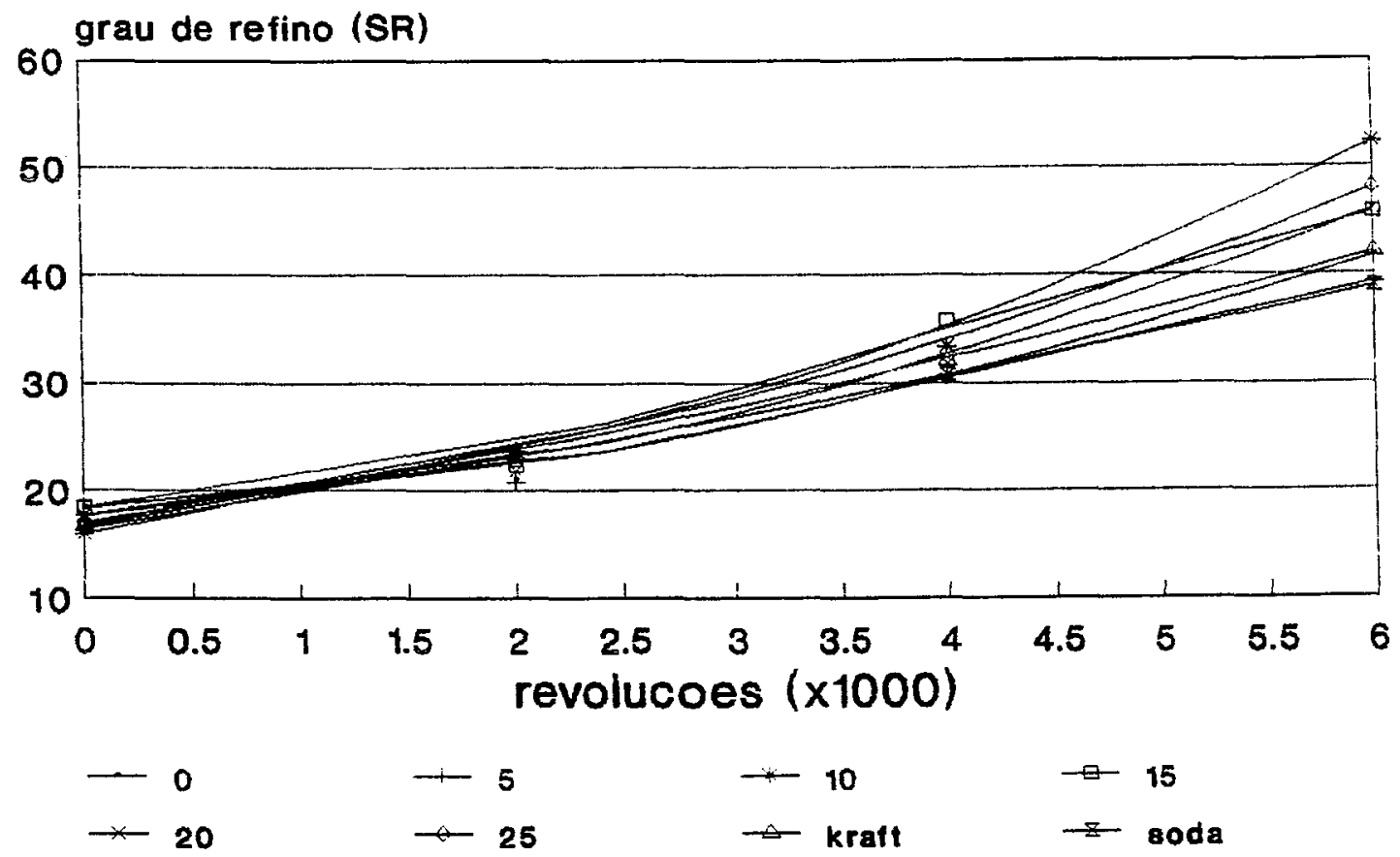

Figura 59. Grau de refino em função do número de revoluções (moinho PFI).

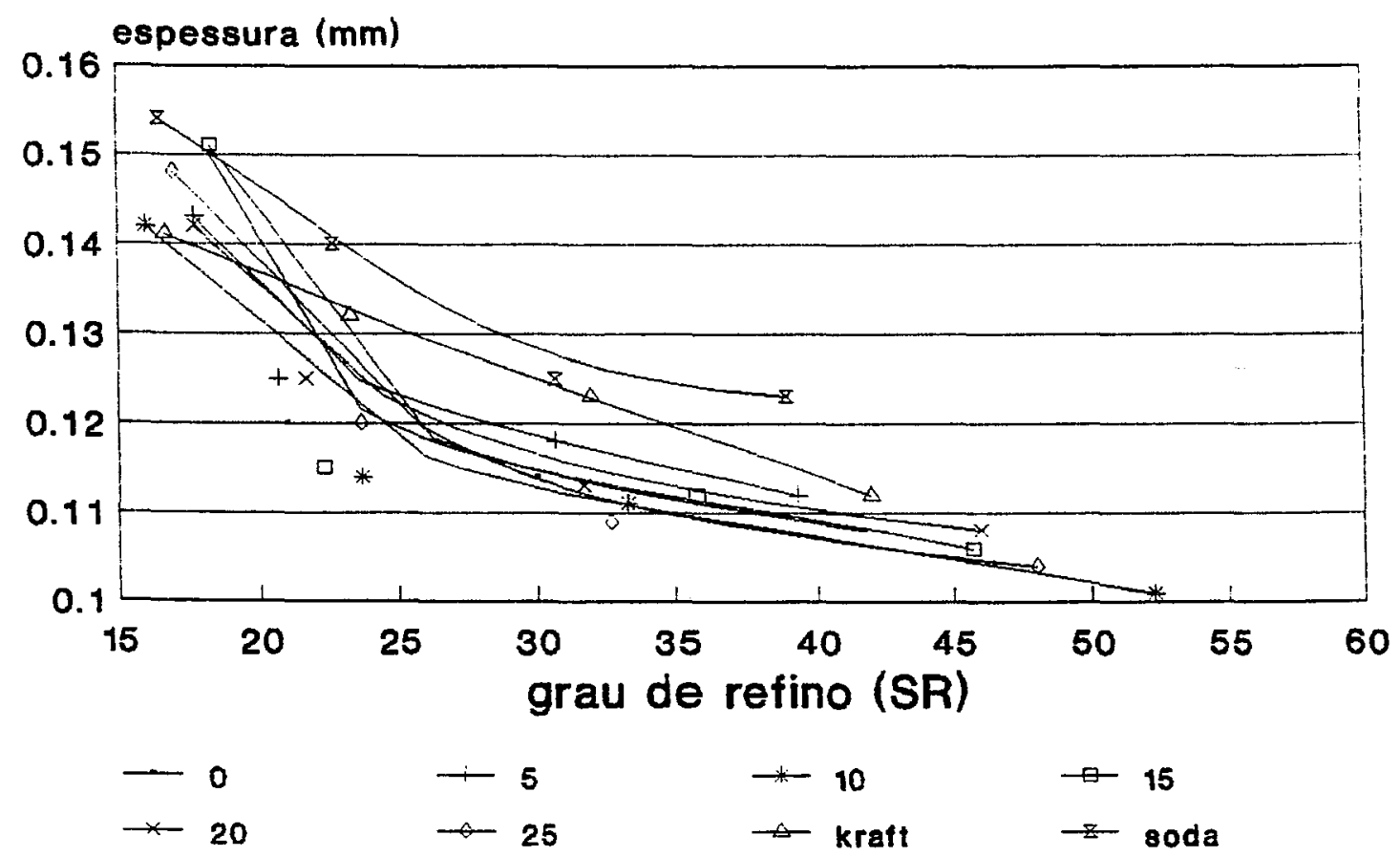

Figura 60. Espessura em função do grau de refino. 


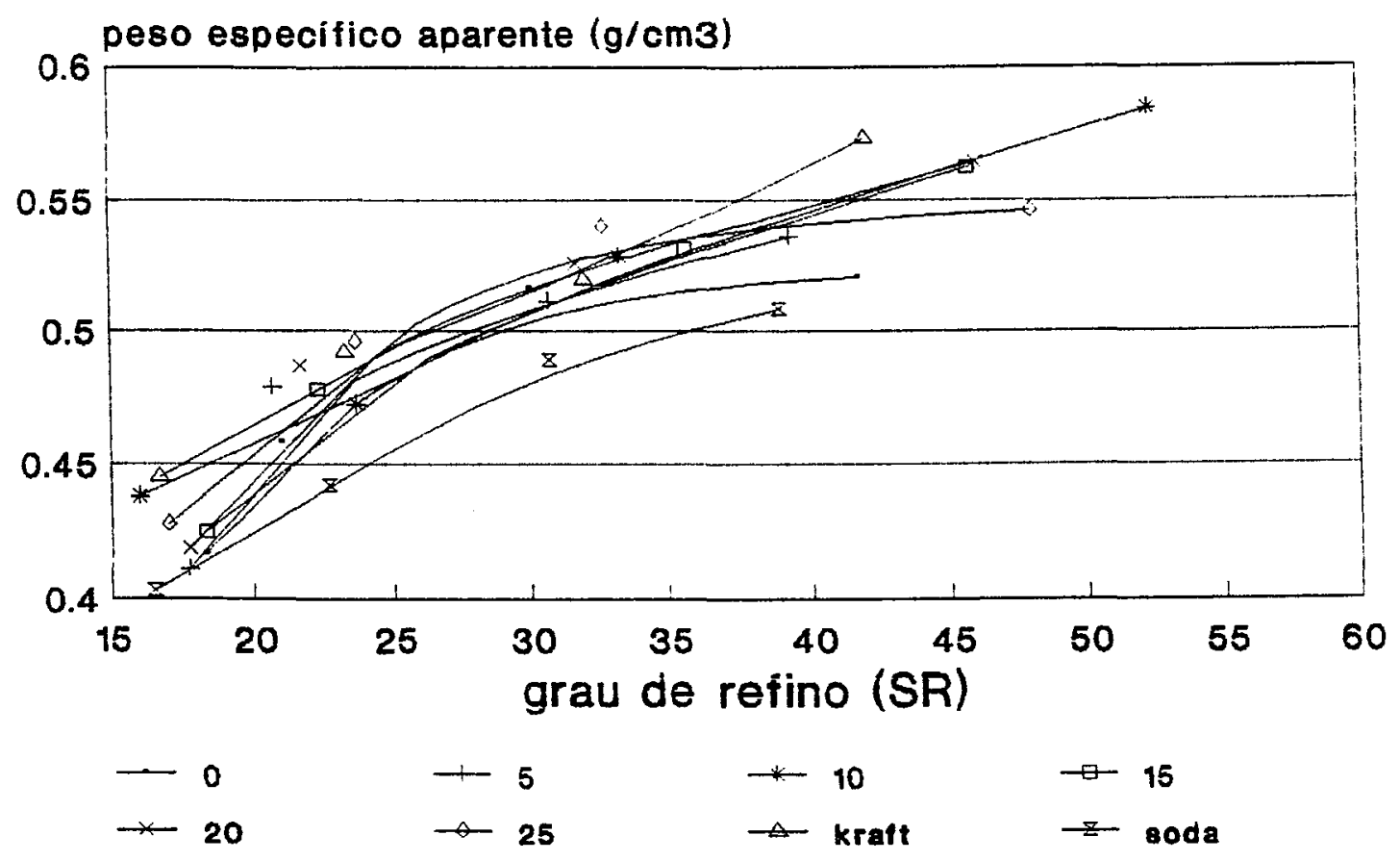

Figura 61. Peso especifico aparente em função do grau de refino.

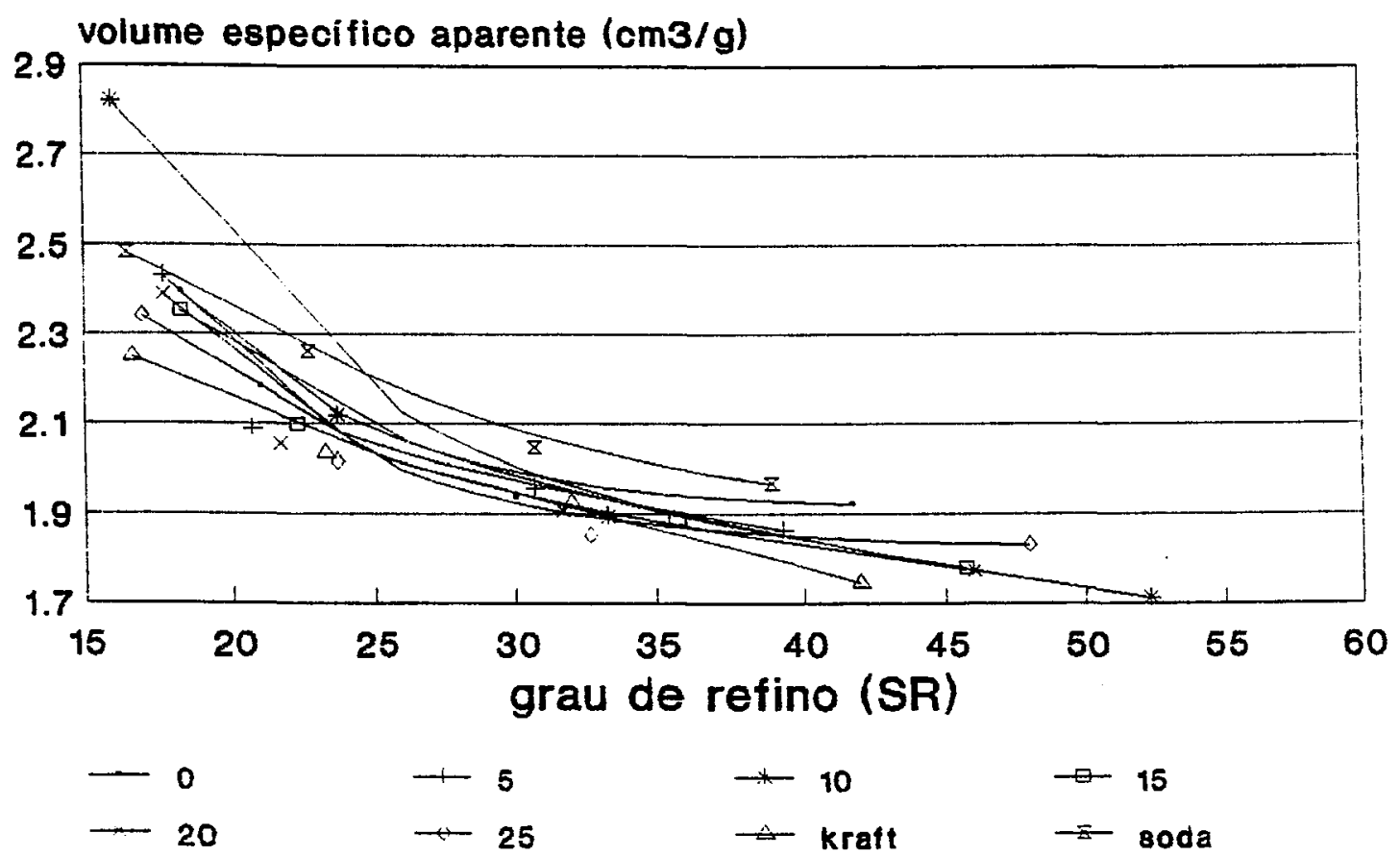

Figura 62. Volume específico aparente em função do grau de refino. 


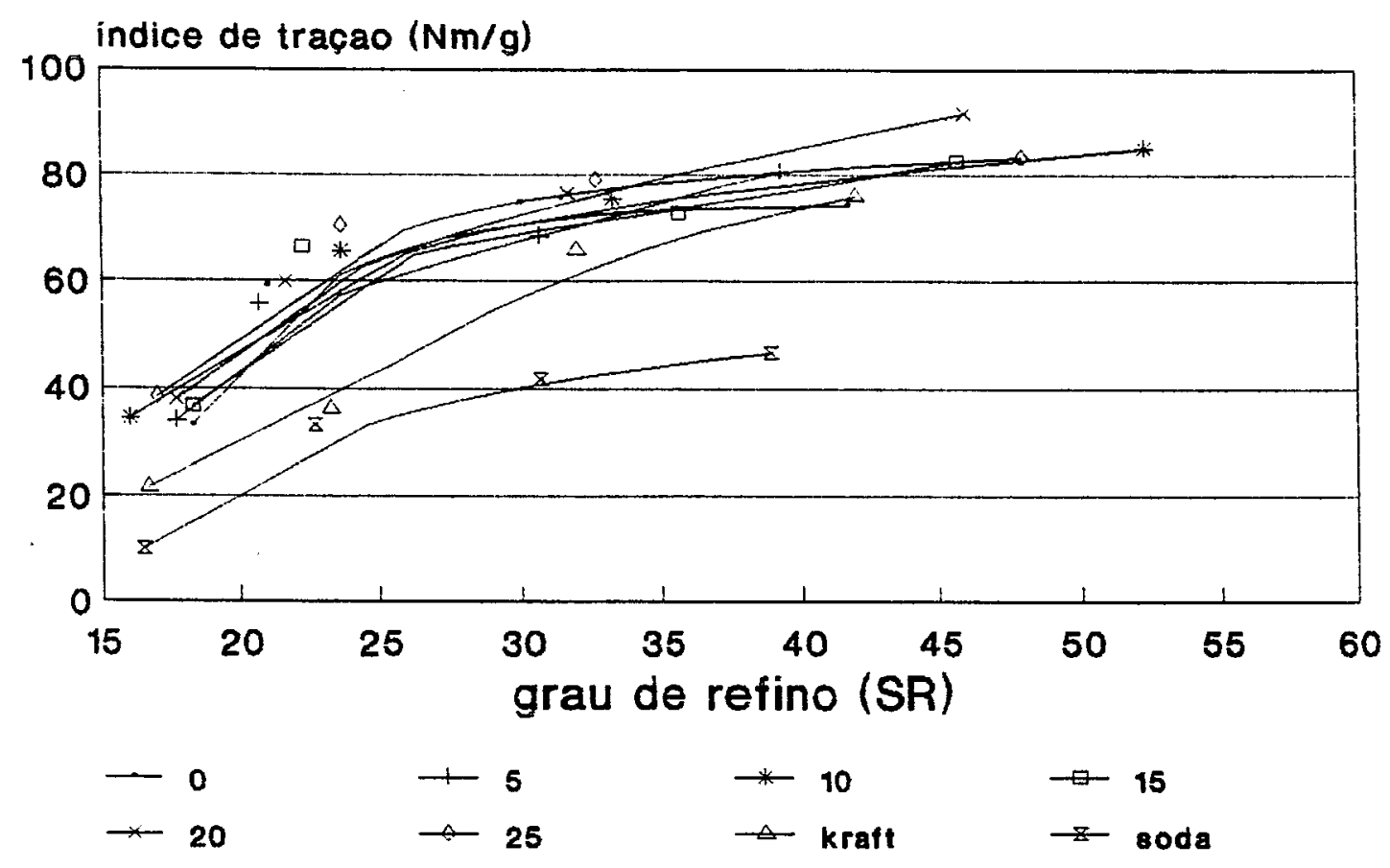

Figura 63. Índice de tração em função do grau de refino.

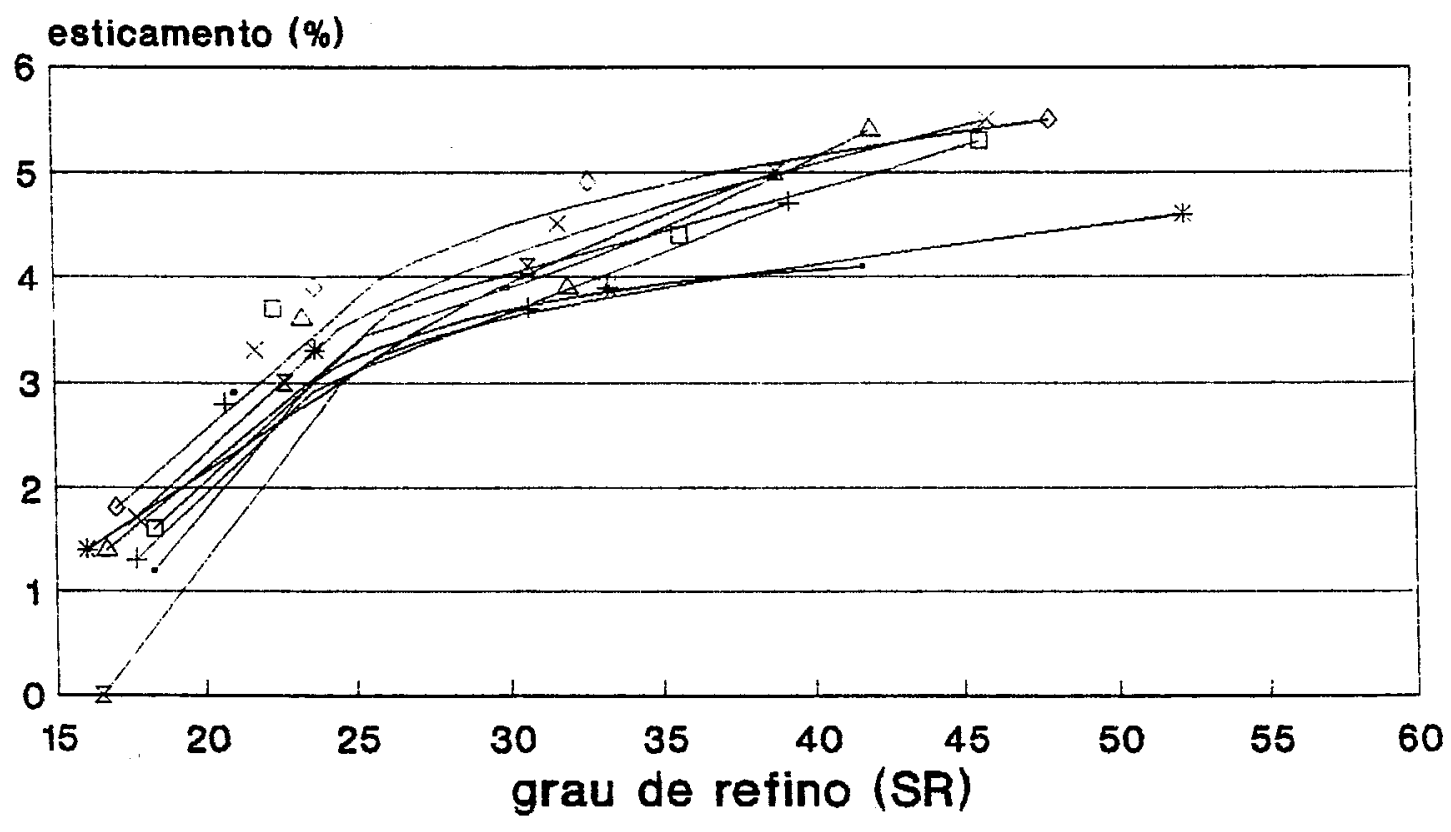

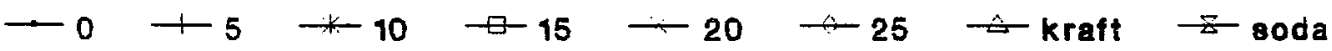

Figura 64. Esticamento em função do grau de refino. 


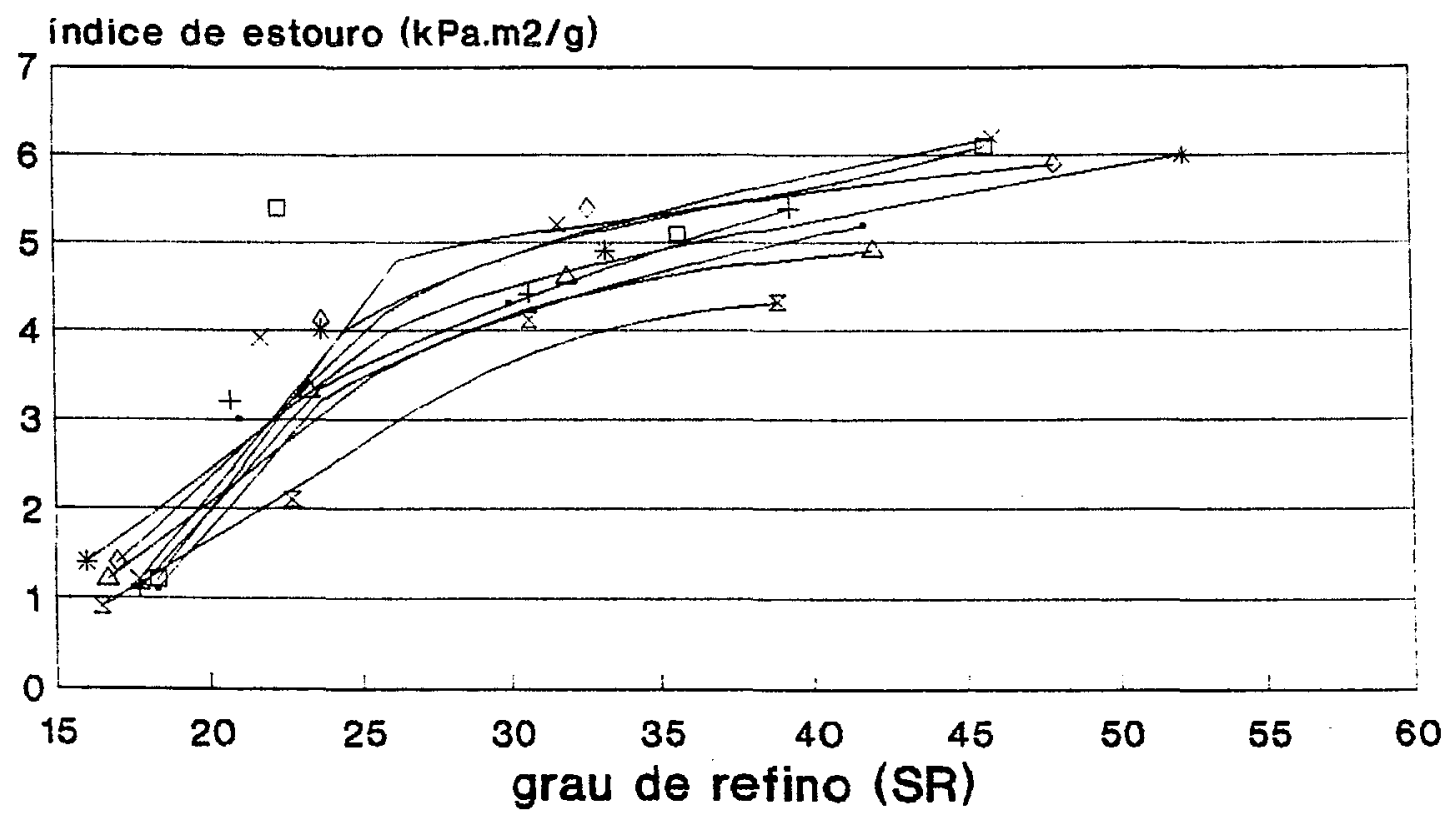

$\rightarrow 0 \rightarrow 5 \rightarrow 10 \rightarrow 15 \rightarrow 20 \multimap 25 \multimap$ kratt $\rightarrow$ soda

Figura 65. Indice de estouro em função do grau de refino.

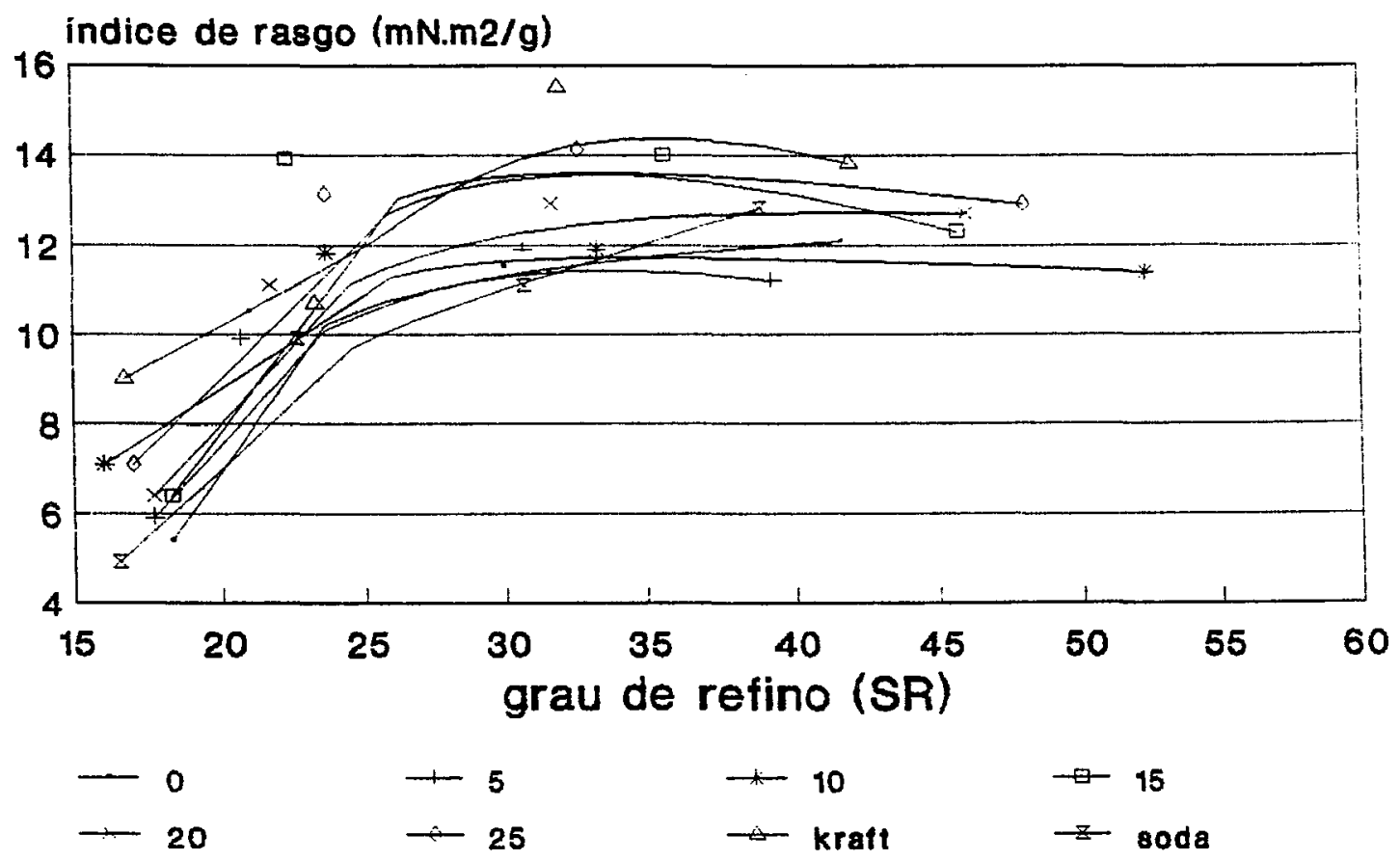

Figura 66. Índice de rasgo em função do grau de refino. 


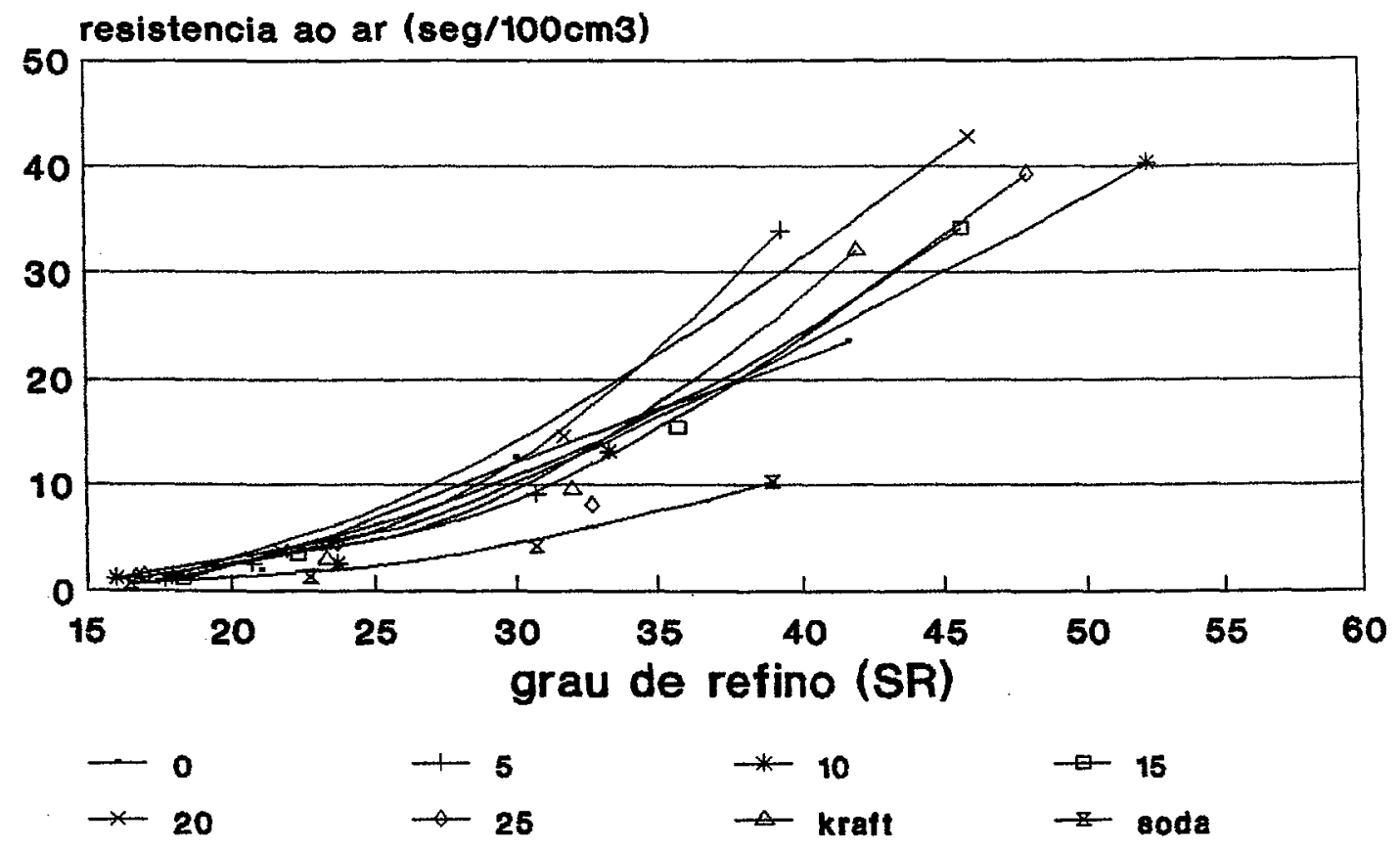

Figura 67. Resistência à passagem de ar em função do grau de refino. 
Na tabela 44 são apresentados os resultados das análises de licor negro.

Tabela 44. Análises de licor negro dos tratamentos $16,17,18,19$, 20 e 21 .

\begin{tabular}{|c|c|c|c|c|c|c|c|}
\hline tratuento & 44 & dentade & onote & natera & $\begin{array}{l}\text { roptra } \\
\text { woroquide }\end{array}$ & restonl $\%$ & vep \\
\hline 16 & 12,34 & 1.06 & 14.52 & 68,05 & 31,95 & 3,5 & 2.8 \\
\hline 17 & 12.52 & 1.06 & 14.37 & 63.19 & 33,93 & 3,9 & 2.81 \\
\hline 10 & 12,45 & 1,05 & 14.20 & 57,54 & 42,46 & 3.8 & 3,06 \\
\hline 19 & 12.50 & 1.05 & 14,48 & 60.60 & 39.40 & 4,0 & 2.65 \\
\hline 20 & 12,19 & 1,05 & 12.77 & 57,70 & 42,30 & 3,0 & 2,94 \\
\hline 21 & 11,85 & 1,06 & 13,64 & 57,09 & 42,91 & 2.4 & 2.49 \\
\hline
\end{tabular}

média de 2 determinações

tratamento $16-0 \%$ de sulfidez tratamento $17-5 \%$ de sulfidez tratamento $18-10 \%$ de sulfidez tratamento $19-15 \%$ de sulfidez tratamento $20-20 \%$ de sulfidez tratamento $21-25 \%$ de sulfidez

$\mathrm{Na}$ figura 68 , foram plotados os resultados das análises de teor de sólidos e álcali ativo residual no licor negro dos tratamentos 16, 17, 18, 19, 20 e 21. 


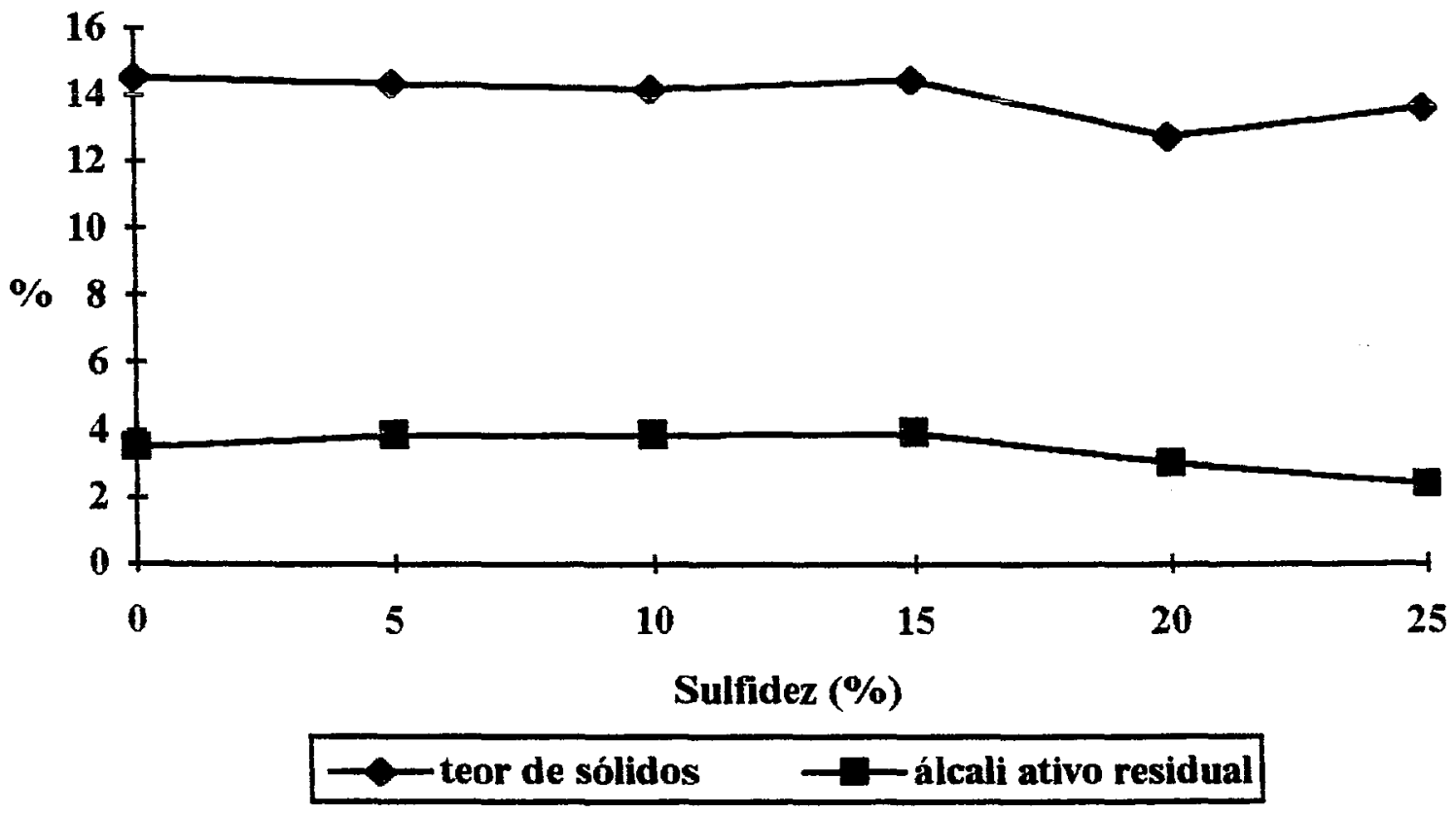

Figura 68. Teor de sólidos e álcali ativo residual em função do nivel de sulfidez. 


\section{5 - Discussão}

Os processos químicos de produção de celulose são relativamente simples do ponto de vista conceitual. Porém quando estes são analisados detalhadamente, verifica-se que existem variáveis que os afetam das mais diversas formas. Estas variáveis podem ser divididas em dois grupos:

- variáveis relacionadas à matéria-prima;

- variáveis relacionadas ao processo.

No que diz respeito às variáveis relacionadas à matéria-prima, pode-se destacar como principais:

- densidade básica

- composição quimica

- dimensões de fibras

- dimensões de cavacos

Neste trabalho, a título de caracterização do material, avaliou-se os parâmetros descritos acima para os cavacos de Eucalyptus grandis. A análise dos resultados apresentados na tabela 1 assim como nas figuras 6,7 e 8 mostra que para os cavacos, as dimensões apresentam distribuições relativamente normais com picos definidos sendo que para o comprimento, a maioria dos cavacos se concentram entre 14 e $18 \mathrm{~mm}$ com média de $15,8 \mathrm{~mm}$; para largura a maioria dos cavacos se 
concentram entre 6,5 e $13 \mathrm{~mm}$ com média de $10,2 \mathrm{~mm}$; e para espessura a maioria dos cavacos se concentram entre 1,5 e $3,0 \mathrm{~mm}$, com média de $2,2 \mathrm{~mm}$.

$\mathrm{Na}$ caracterização de matérias-primas destinadas ao processamento industrial a densidade básica é de fundamental importância. Pelas inúmeras facilidades que apresenta para sua determinação e pelas excelentes relações que mostra com as utilizações da madeira, a densidade básica tem-se constituído em um índice universal para avaliar a qualidade da mesma, que no entanto, deve ser analisado com critério para não se cometer erros e exageros (FOELKEL, 1990).

Na utilização de madeiras como matéria-prima para produção de celulose, à título de exemplificação, a densidade básica tem influência sobre parâmetros do processo tais como rendimento, teor de rejeitos, consumo de reagentes, entre outros, como consequência da sua relação com a composição química da madeira.

A análise dos resultados dos item 4.1.2. mostra que a densidade básica dos cavacos de E. grandis encontra-se dentro dos patamares considerados normais para a espécie, conforme BARRICHELO \& FOELKEL (1975a, 1975b), BARRICHELO \& BRITO (1977), FOELKEL (1978) e WEHR \& BARRICHELO (1993).

Os resultados apresentados na tabela 2 mostram que a composição química da madeira de E. grandis apresenta valores normais para a espécie. A mesma análise pode ser feita para os resultados obtidos na análise das dimensões de fibras, apresentados na tabela 3. Estes resultados são compatíveis com os obtidos por BARRICHELO \& FOELKEL (1975a. 1975b), BARRICHELO \& BRITO (1977) e FOELKEL (1978).

Com base no que foi discutido até este ponto pode-se perceber que os cavacos utilizados neste trabalho são amostras representativas da espécie de $E$. grandis utilizada para produção de celulose no Brasil. 
$\mathrm{Na}$ busca da substituição do processo kraft pelo processo soda-DDA faz-se necessário primeiramente avaliar-se os processos soda e kraft sem modificações. Neste sentido a primeira etapa deste trabalho consistiu na avaliação das características da celulose e dos licores obtidos após os processos de polpação.

Na comparação entre diferentes processos produtivos vários parâmetros devem ser considerados, entre eles: rendimento depurado, número kappa, viscosidade, teor de sólidos e álcali ativo residual do licor negro.

O rendimento depurado, número kappa e viscosidade da celulose são parâmetros que estão inter-relacionados; desta forma suas análises não devem ser feitas isoladamente, sendo interessante inclusive analisar-se índices como $o$ rendimento depurado $(R D) /$ kappa $(K)$ e viscosidade/ kappa.

A análise das tabelas 4 e 5 e figuras 9 e 10 mostra claramente a superioridade do processo kraft sobre o processo soda. O processo kraft caracterizou-se, conforme esperado, por um bom rendimento depurado $(56,1 \%)$, número kappa relativamente baixo $(19,3)$ e ainda uma elevada viscosidade $(52,3 \mathrm{cP})$ da celulose; consequentemente obteve-se altos valores para as relações $R D / K$ e viscosidade/kappa. No processo soda obteve-se um bom rendimento, no entanto o número kappa obtido foi bastante elevado $(48,7)$ e a viscosidade foi baixa $(13,6 \mathrm{cP})$, refletindo-se em baixos valores para as relações $\mathrm{RD} / \mathrm{K}$ e viscosidade/kappa. Deve-se ressaltar que pela estrita inter-relação entre número kappa e teor de lignina residual da polpa, este último apresentou o mesmo padrão de comportamento do número kappa para os tratamentos considerados.

As afirmações acima mostram a especificidade do ataque do sulfeto de sódio a lignina, sendo este reagente o diferencial entre o processo kraft e o processo soda, justificando dessa forma sua utilização.

A ação benéfica de compostos quinônicos, tais como a antraquinona, sobre o processo de produção de celulose tem sido relatada por vários autores. No 
Brasil a antraquinona tem sido utilizada por algumas indústrias que produzem celulose à partir da madeira de Eucalyptus spp. Neste trabalho, em um dos tratamentos testemunhas utilizou-se uma dosagem de $0,08 \%$ de antraquinona em cozimentos soda.

A adição da dosagem de $0,08 \%$ de antraquinona melhorou sobremaneira a qualidade da celulose soda especialmente no que diz respeito ao número kappa, reduzindo-o a patamar semelhante ao obtido para celulose kraft (redução de 55\%). No entanto não se observou melhoras no rendimento depurado nem na viscosidade. Como consequência destas observações, houve uma melhoria nas relações $\mathrm{RD} / \mathrm{K}$ e viscosidade/kappa quando comparados com os do processo soda tradicional. Estes fatos, por si só, mostram a eficiência da antraquinona como aditivo para cozimentos alcalinos. Conforme observado por GOMIDE \& OLIVEIRA (1979) a otimização das condições de cozimento do processo soda com auxílio de compostos quinônicos poderá vir a constituir alternativa viável para redução de problemas de poluição atmosférica do processo kraft.

Os resultados apresentados na tabela 6 mostram que do ponto de vista químico as celuloses kraft e soda-AQ são bastante semelhantes. A celulose soda apresenta menor teor de alfa e beta celulose, quando comparadas com as demais celuloses, indicando uma maior agressividade do processo sobre os carboidratos.

Com relação ao refino, as celuloses obtidas nos tratamentos 1,2 e 3 (kraft. soda-AQ e soda, respectivamente) apresentam praticamente o mesmo comportamento, com destaque para a celulose soda-AQ. A maior facilidade de refino desta celulose, conforme já observado por outros autores tais como GOMIDE et al. (1987) e DIAS (1979) entre outros, pode ser devida ao maior teor de hemiceluloses expresso como gama-celulose na tabela 6 , uma vez que o teor de lignina residual nas celuloses soda-AQ e kraft foram bastante semelhantes e inferiores ao da celulose soda. 
Segundo NEVES (1986) e CLARK (1985), no caso de celuloses kraft não branqueadas, a facilidade de refino é inversamente proporcional ao teor de lignina residual devido ao caráter hidrofóbico da lignina; celuloses que apresentam baixo teor de hemiceluloses são difíceis de se refinar pois o caráter hidrofilico das hemiceluloses auxiliam na absorção de água e consequente inchamento, tornando as fibras mais flexíveis e menos susceptiveis ao corte.

Com relação as características físicas das celuloses kraft, soda-AQ e soda (tratamentos 1, 2 e 3) - espessura, peso específico aparente e volume específico aparente - observa-se novamente a superioridade das celulose kraft seguida da celulose soda-AQ e da soda, sendo que as duas primeiras apresentam comportamento bastante semelhantes. As características em questão estão relacionadas com a morfologia da fibra, mais especificamente com a sua capacidade de colapso e ainda com as ligações interfibras. A capacidade de colapso da fibra por sua vez, pode ser prejudicada pelo teor de lignina residual que provavelmente confere maior rigidez a fibra colaborando para manter sua estrutura tubular, levando a um aumento da espessura da folha de celulose, reduzindo o peso específico aparente e aumentando o volume específico aparente.

As considerações acima são válidas para explicar os resultados para as resistências mecânicas apresentadas pelas celuloses dos tratamentos 1,2 e 3 . A lignina tende a manter a estrutura tubular da fibra e devido ao seu caráter aglutinante a manter unidas as fibrilas das fibras; estes dois fatores associados levam a uma redução das ligações inter-fibras o que tem como consequência uma redução das resistências mecânicas da celulose (CLARK, 1985). Nas figuras 15 a 19 observa-se que a celulose soda, como esperado, apresentou resistências inferiores a celulose kraft e soda- $\mathrm{AQ}$ especialmente para tração e rasgo. 
Os resultados obtidos nas análises dos licores negros dos tratamentos 1 , 2 e 3 refletem os resultados obtidos nos cozimentos relativos ao rendimento dos processos e qualidade da celulose.

$\mathrm{Na}$ tabela 10 observa-se que o $\mathrm{pH}$ não apresentou grandes alterações. A avaliação do $\mathrm{pH}$ do licor negro é da mais alta importância pois sua redução pode levar a precipitação e sorção de fragmentos de lignina pelas fibras, causando aumento do número kappa. No tratamento 1, devido à maior remoção de lignina, observa-se maior teor de sólidos no licor negro e de matéria orgânica, o que provoca, em termos relativos, a redução do teor de matéria inorgânica. Este comportamento observado para o teor de matéria inorgânica foi relatado por BUSNARDO (1981) no estudo da polpação kraft de Eucalyptus urophylla e pode ser explicado pelo aumento do teor de matéria orgânica no licor provocado pela dissolução dos constituintes da madeira, uma vez que não são incorporados ao licor, durante o cozimento, novas quantidades de material inorgânico, exceto parte dos minerais da madeira, cuja quantidade é praticamente desprezível.

As reações de deslignificação são responsáveis por um consumo elevado de reagentes; logo, o aumento da intensidade dessas reações, aumenta o consumo de álcali durante o cozimento, reduzindo o álcali ativo residual do licor negro. Este fato é observado nos resultados da tabela 10 onde o álcali ativo residual do licor negro soda foi superior (34\%) ao dos licores kraft e soda-AQ.

O teor de sólidos do licor negro tem correlação direta com a densidade e viscosidade do mesmo. Esta correlação pode ser observada nos resultados das análises de licor negro apresentados na tabela 10.

A segunda etapa na otimização do processo soda-DDA foi a avaliação do efeito deste aditivo sobre o processo soda.

Nas tabelas 11 e 12 são apresentados os resultados obtidos nos cozimentos com dosagens de DDA que variaram de $0,04 \%$ à $0,10 \%$. Da análise 
destes resultados observa-se que o DDA contribui para redução do teor de lignina residual e consequentemente do número kappa das celuloses. Com relação ao número kappa, quando se compara os tratamentos soda-DDA observa-se que a adição de $0,04 \%$ deste composto levou à uma redução da ordem de $50 \%$, tornando este processo semelhante ao kraft no que diz respeito a este parâmetro; no entanto a adição de doses maiores de DDA promoveu uma redução do número kappa porém com intensidade bem menor. A eficiência do DDA pode ser explicada, entre outros fatores, pela sua solubilidade no licor de cozimento e sua maior facilidade de penetração nos cavacos, estando mais prontamente nos sítios de reações de deslignificação.

A redução drástica do número kappa nos tratamentos em questão, levou a um aumento na mesma proporção da relação $\mathrm{RD} / \mathrm{K}$, uma vez que o efeito do DDA sobre o rendimento depurado foi reduzido quando comparado ao do número kappa. Este aumento foi bastante acentuado até a dosagem de 0,04\% de DDA, conforme pode ser observado nas figuras 21 e 22.

Nos tratamentos 4, 5, 6 e 7 (tratamento soda-DDA com dosagens de DDA de $0,04-0,06-0,08$ e $0,10 \%$ respectivamente) observou-se que a viscosidade foi bastante melhorada quando comparada com os tratamentos soda e soda- $\mathrm{AQ}$, mas ainda assim foi inferior ao cozimento kraft. Este fato mostra o efeito protetor do DDA sobre os carboidratos, no entanto este efeito é inferior ao do sulfeto de sódio. A associação deste dois componentes, DDA e sulfeto de sódio, pode conduzir à grandes ganhos em qualidade da polpa e em redução de poluição ambiental em relação ao processo tipicamente kraft.

O aumento da viscosidade e a redução do número kappa das celuloses em questão tiveram como consequência direta um aumento da relação viscosidade/kappa conforme pode ser observado na figura 22. 
Na tabela 13, observa-se que a adição de diferentes dosagens de DDA no processo soda teve pouco efeito sobre as características químicas da celulose. No entanto, quando se compara os resultados desta tabela com os da tabela 6 (tratamentos testemunhas) observa-se que a adição de DDA reduz substancialmente o ataque à celulose, conforme pode ser observado pelo teor de alfa-celulose, que apresenta valores semelhantes ao kraft e superiores ao soda e soda-AQ.

A adição de DDA ao cozimento soda, independentemente da dosagem, apresentou pouco efeito sobre as características de refino das celuloses (figura 23). Com relação ao refino a celulose kraft apresentou ligeira superioridade sobre as demais celuloses provavelmente devido ao maior teor de hemiceluloses .

As celuloses soda-DDA apresentaram características bastante semelhantes à celulose kraft e superior as celulose soda com relação a espessura, peso específico aparente e volume específico aparente.

A adição de DDA promoveu um aumento significativo das resistências mecânicas das celuloses quando comparadas às celuloses soda. Os resultados obtidos permitem afirmar que a celulose soda-DDA apresenta resistências mecânicas iguais ou superiores à celulose kraft, independentemente da dose de DDA utilizada.

O aumento da resistência à tração e rasgo é de grande importància, uma vez que influem diretamente na velocidade de operação das máquinas formadoras de papel.

A análise da tabela 18 mostra que a adição de DDA teve pouco efeito sobre o $\mathrm{pH}$ e teor de sólidos do licor negro, apresentando resultados semelhantes ao licor negro kraft. Esta fato é de grande importância do ponto de vista fabril, pois permite a obtenção de celulose de boa qualidade sem impor maior carga de sólidos à caldeira de recuperação, que na maioria das empresas brasileiras è o principal ponto de estrangulamento na produção de celulose. 
Continuando a análise da tabela 18 observa-se que houve uma redução do teor de matéria inorgânica. Este resultado, conforme discutido anteriormente, provavelmente tem sua explicação no aumento do teor de matéria orgânica do licor. Nos licores negros dos cozimentos 4, 5, 6 e 7, a matéria orgânica deve ser fundamentalmente composta de fragmentos de lignina, pois, conforme discutido anteriormente as reações de deslignificação foram significativamente aumentadas sem contudo aumentar a degradação de carboidratos da madeira. Estes resultados evidenciam a ação protetora do DDA sobre os carboidratos, pois houve uma aumento de viscosidade e pentosanas quando comparado com o processo soda (tabela 13).

A eficiência de deslignificação do DDA pode ser observada nas características da celulose bem como, de modo indireto, no álcali ativo residual. $\mathrm{Na}$ tabela 18 observa-se que, comparando-se com o licor negro kraft, o licor negro sodaDDA apresentou maior álcali ativo residual com relação direta com a dose de DDA aplicada. Esta observação, associada ao valor de $\mathrm{pH}$ dos licores obtidos, indica que a carga alcalina empregada é excessiva, podendo então ser reduzida. Este resultado aponta para uma possível economia de reagentes no processo de produção de celulose.

Com base nos resultado obtidos na etapa de otimização da dosagem de DDA, tanto no que diz respeito à qualidade da celulose, bem como ao rendimento depurado, características do licor e aspectos econòmicos envolvidos (custo do DDA), observa-se que, entre as dosagens estudadas, a mais recomendada para polpação soda-DDA de Eucalyptus grandis corresponde a 0,04\%. Acima desta dosagem, os ganhos obtidos são pequenos.

$\mathrm{Na}$ terceira etapa do trabalho buscou-se determinar a carga alcalina ideal para polpação soda-DDA da madeira de Eucalyptus grandis uma vez que, entre as dosagens consideradas, $0,04 \%$ de DDA sobre madeira seca foi a que apresentou os melhores resultados. 
$\mathrm{Na}$ tabela 19 estão apresentados os resultados obtidos para polpação soda-0,04\%DDA de cavacos de E. grandis, sendo que a carga alcalina variou de 13 à $15 \%$.

O aumento da carga alcalina tem como efeitos principais a redução dos rendimentos bruto e depurado e do teor de rejeito. Na tabela 19 observa-se claramente este padrão de comportamento. No tratamento 8 , onde aplicou-se $12 \%$ de álcali ativo o rendimento depurado foi de $58,1 \%$ e o teor de rejeitos de $2,3 \%$; no entanto quando a carga alcalina passou para $14 \%$, o rendimento depurado caiu para $54,5 \%$ não apresentando rejeitos.

A carga alcalina tem efeito marcante sobre a qualidade da celulose, notadamente no que diz respeito ao teor de lignina residual. Na tabela 20 observa-se que, em cozimentos soda- $0,04 \%$ de DDA de $E$. grandis, o aumento da carga alcalina reduz drasticamente o número kappa e por consequência o teor de lignina residual. Na tabela 20, observa-se, ao contrário do esperado, um aumento da viscosidade. Este resultado possivelmente é devido ao alto teor de lignina residual na polpa, que conforme o método TAPPI, pode mascarar o resultados obtidos; o tratamento com clorito de sódio foi realizado, mas acredita-se que este é bastante agressivo à celulose reduzindo ainda mais o seu grau de polimerização.

y Nos tratamentos 8 à 11 a redução do número kappa foi mais acentuada que a redução do rendimemto depurado; por esta razão observa-se na tabela 20 um aumento da relação $\mathrm{RD} / \mathrm{K}$ à medida que aumenta a carga alcalina.

O efeito do aumento do álcali ativo sobre a composição química da celulose pode ser observado na tabela 21 . Da análise dos resultados apresentados nesta tabela observa-se que o aumento da carga alcalina provoca redução no teor de hemiceluloses, expressa como gama-celulose. 
A variação da carga alcalina (12 a $15 \%$ ) em cozimentos soda- $0,04 \%$ DDA de cavacos de $E$. grandis não teve grande influência sobre o processo de refino das celuloses obtidas como pode ser observado na figura 35 .

Com relação às características físicas das celuloses obtidas nos tratamentos 8 à 11 , observa-se que as mesmas apresentam comportamento bastante semelhante entre si, indiferente à variação da carga alcalina .

Na figura 39 observa-se que com relação a resistência à tração, a redução da carga alcalina em cozimentos soda-DDA de E. grandis, levou a um aumento desta propriedade da celulose. Esta observação pode ter sua explicação no fato de que cozimentos com menor carga alcalina levam a um menor ataque dos carboidratos, especialmente às hemiceluloses, que favorecem as ligações interfibras. As celuloses obtidas apresentaram curvas para indice de tração com mesmo comportamento, sendo a distância entre elas proporcional à carga alcalina empregada.

Com relação ao esticamento, as celuloses apresentaram comportamento bastante semelhante sem apresentar correlação forte com a carga alcalina (figura 40).

$\mathrm{Na}$ figura 41, observa-se que a resistência ao estouro não foi influenciada pela variação da carga alcalina. As celuloses dos tratamentos 8 à 11 apresentaram resistências ao estouro bastante semelhantes entre si e semelhantes à celulose kraft.

$\mathrm{Na}$ figura 42 , observa-se claramente que em niveis altos de carga alcalina (15\%) houve redução da resistência ao rasgo.

$\mathrm{Na}$ figura 43 observa-se que a redução da carga alcalina em cozimentos soda-DDA levou a um ligeiro aumento da resistência à passagem do ar; contudo, a celulose kraft apresentou valores superiores para esta característica. 
Na tabela 26 são apresentados os resultados das análises de licor negro efetuadas nos licores dos tratamentos 8 à 11 . Nesta tabela observa-se uma tendència de aumento do teor de sólidos à medida que se aumenta a carga alcalina. Este resultado, conforme esperado, é devido a maior remoção de lignina e carboidratos durante a polpação da madeira. Esta tendência de aumento do teor de sólidos refletese no aumento da viscosidade do licor negro.

As análises de licor negro mostram um aumento do teor de matéria inorgânica e uma consequente diminuição do teor de matéria orgânica. Este resultado deve-se basicamente ao aumento da carga de reagentes (carga alcalina) que em termos relativos é maior que a remoção de lignina e carboidratos. Deve-se ressaltar que um aumento de $1 \%$ no álcali ativo de cozimentos soda-DDA corresponde a um aumento de aproximadamente $8 \%$ na carga de reagentes.

Dando continuidade a análise da tabela 26 observa-se uma redução do álcali ativo residual no licor negro à medida que se reduz a carga alcalina do licor branco de cozimento, sem contudo reduzir o $\mathrm{pH}$ do licor negro no final do cozimento, o que seria maléfico, conforme já discutido anteriormente.

Considerando-se as características do processo de produção de celulose, a qualidade da mesma e as implicações econômicas envolvidas, nesta etapa do trabalho, o ponto ótimo para carga alcalina foi definido como $13 \%$. No entanto, esta decisão foi baseada primordialmente na economia de reagentes que pode ser obtida. Desconsiderando-se todas as demais variáveis do processo, a carga alcalina ideal para este processo está entre 13 e 14\%, dependendo da qualidade da celulose que se deseja obter, especialmente no que diz respeito a alvura.

Dando sequência ao trabalho, foi avaliado a influência do fator $\mathrm{H}$ em cozimentos soda- $0,04 \%$ de DDA com álcali ativo de $13 \%$ para cavacos de $E$. grandis. 
Nos resultados da tabela 27 observa-se que o aumento do fator $\mathrm{H}$ levou a uma redução do rendimento bruto, rendimento depurado e teor de rejeitos. $O$ alto rendimento obtido nos tratamentos com fator $\mathrm{H}$ baixo é resultado da baixa intensidade das reações de deslignificação e degradação de carboidratos que ocorrem durante o processo de polpação.

$\mathrm{Na}$ tabela 28, conforme esperado, o aumento do fator $\mathrm{H}$ leva a uma redução do número kappa e consequente teor de lignina residual na polpa. A viscosidade também é aumentada, com o aumento do fator $H$. Neste ponto devem ser feitas algumas considerações: a celulose do tratamento 12 (fator H 215) apresenta caracteristicas de celulose obtida por processos semi-quimicos: alto rendimento, alto teor de rejeitos e elevado número kappa (indicativo de que as reações de deslignificação não foram intensas). Por estas razões a avaliação da viscosidade da celulose não apresenta significado, pois trata-se mais especificamente de uma celulose semi-química. Aliado a este fato, o alto teor de lignina residual influi negativamente no método de determinação da viscosidade.

Com o aumento do fator $\mathrm{H}$, observou-se também um aumento da relação $\mathrm{RD} / \mathrm{K}$. A avaliação da relação viscosidade/kappa, fica comprometida nesta etapa do trabalho devido aos fatores citados anteriormente.

Na tabela 29 , observa-se que a variação no fator $H$, teve pouca influência na composição química das celuloses, observando-se apenas uma redução do teor de gama-celulose na celulose do tratamento 15 (fator $\mathrm{H}$ 677).

As celuloses obtidas em cozimentos com diferentes fatores $\mathrm{H}$ apresentaram características diferentes com relação ao refino. Na figura 47 observase que o aumento do fator $\mathrm{H}$ apresenta correlação direta com a facilidade de refino. Este fato deve-se basicamente, ao teor de lignina residual na celulose, que diminui com o aumento do fator $\mathrm{H}$. Conforme discutido anteriormente a lignina apresenta caráner hidrofóbico, dificultando a operação de refino. 
De acordo com o que foi considerado nas etapas anteriores desta pesquisa, as características físicas das celuloses - espessura, peso específico aparente e volume especifico aparente - estão relacionadas com as características morfológicas da fibra, especialmente a capacidade das fibras em formarem fitas (colapso). Observa-se uma redução da espessura e volume específico aparente e ainda aumento do peso específico aparente à medida que se aumenta o fator $\mathrm{H}$. Deve-se ressaltar que a celulose soda- $0,04 \%$ DDA e $13 \%$ de álcali ativo de $E$. grandis, obtida com fator $\mathrm{H}$ de 522 apresentou caracteristicas físicas bastante semelhantes à celulose kraft.

A variação no fator $H$ apresentou pouca influência sobre resistência à tração e ao esticamento das celulose obtidas nos tratamentos 12 a 15 (fator $\mathrm{H}$ $217,369,522$ e 677 respectivamente) conforme pode ser observado nas figuras 51 e 52. Com relação à tração ressalta-se que as celuloses dos tratamentos em questão apresentaram características superiores à celulose kraft. $\mathrm{O}$ fator $\mathrm{H}$ teve pouca influência sobre a resistência ao estouro, conforme pode ser observado na figura 53. $O$ índice de rasgo foi a característica da celulose soda-DDA de E. grandis, que se apresentou mais influenciada pela variação do fator $\mathrm{H}$. Com o aumento do fator $\mathrm{H}$ houve uma tendência de aumento do índice de rasgo; no entanto a celulose kraft apresentou resultados ligeiramente superior aos das celuloses dos tratamentos 12 a 15 .

Nas análises de licor negro (tabela 34) observa-se um aumento do teor de sólidos à medida que se aumenta o fator $H$. Este resultado tem sua explicação no aumento da intensidade das reações de deslignificação e degradação de carboidratos, transferindo para a fase liquida do processo cozimento (licor negro) parte da massa da madeira; como consequência, observa-se comportamento semelhante para o teor de matéria orgànica e viscosidade do licor negro. 
O teor de matéria inorgânica reduz-se à medida que se aumenta o fator H. O teor de matéria inorgânica no licor negro, é oriundo da carga alcalina empregada no cozimento; como a carga alcalina nesta etapa foi a mesma para todos os tratamentos, a redução da teor de matéria inorgânica deve-se ao aumento do teor de matéria orgânica.

$\mathrm{Na}$ tabela 34 , observa-se que, o aumento do fator $\mathrm{H}$ leva a uma redução do álcali ativo residual. $\mathrm{O}$ aumento do fator $\mathrm{H}$, tanto pelo aumento do tempo como pelo aumento da temperatura de cozimento, ou aumento de ambos, intensifica as reações de deslignificação e degradação de carboidratos que consomem álcali.

Considerando-se os aspectos relativos à qualidade da celulose, especialmente as resistências mecânicas, observa-se que a redução do fator $\mathrm{H}$ para patamares em torno de 500 em cozimentos soda-0,04\% de DDA com carga alcalina de $13 \%$ de $E$. grandis, em pequenos níveis, tem pouca influência sobre a qualidade da mesma.

$\mathrm{Na}$ transição de uma etapa a outra, tem sido considerado, na decisão de otimização dos paràmetros em questão, a possibilidade de economia de reagentes e energia e ainda a possibilidade de tornar o processo mais rústico, testando dessa forma a eficiència do DDA em cozimentos em condições menos favoráveis.

Dentro da linha de raciocínio descrita acima e considerando-se os resultados obtidos na etapa de otimização do fator $\mathrm{H}$, para cozimentos soda com $0,04 \%$ de DDA e álcali ativo de $13 \%$ da madeira de $E$. grandis o fator $\mathrm{H}$ ótimo foi 522.

Na última etapa deste trabalho, com o objetivo de proporcionar ao mesmo, um caráter de pesquisa aplicada, avaliou-se o efeito da sulfidez sobre o processo soda-0,04\% de DDA (álcali ativo de $13 \%$ - fator $\mathrm{H} 522$ ) de E. grandis, uma vez que a remoção total do enxofre é muito dificil conforme exposto por LIMA 
et al.(1993) uma vez que o óleo combustivel que alimenta o forno de cal apresenta enxofre em sua composição.

Deve-se destacar também que em fábricas que utilizam o processo kraft tradicional, a redução da sulfidez pode levar à formação de gargalo no forno de cal. Esta situação tem sua explicação no fato de que com a redução do sulfeto de sódio, aumenta-se a proporção de hidróxido de sódio no licor de cozimento. O hidróxido de sódio é recuperado na etapa do ciclo de recuperação conhecida como caustificação que envolve a adição de óxido de cálcio $(\mathrm{CaO})$ ao licor verde para converter o carbonato de sódio $\left(\mathrm{Na}_{2} \mathrm{CO}_{3}\right)$ em hidróxido de sódio. Logo, o aumento da proporção de hidróxido de sódio no licor branco levará a maior formação de carbonato de sódio no licor verde, que por sua vez requererá maior quantidade de óxido de cálcio. A lama de cal resultante da caustificação, rica em carbonato de cálcio, alimenta o forno de cal onde obtem-se ao final do processo óxido de cálcio. Como consequência de um efeito em cascata, o aumento da quantidade relativa de hidróxido de sódio devido à redução da sulfidez do licor de cozimento, leva a formação de uma maior quantidade de lama de cal, podendo inclusive superar a capacidade de operação do forno de cal, formando-se então um gargalo.

Conforme pode ser observado nos resultados da tabela 35 , a adição de sulfeto de sódio não teve praticamente efeito sobre o rendimento bruto, teor de rejeitos e consequentemente, rendimento depurado da celulose soda-DDA de $E$. grandis.

$O$ efeito da sulfidez fica evidenciado nos resultados apresentados na tabela 36, através da redução do número kappa e teor de lignina residual e ainda aumento da viscosidade. Estes resultados mostram a especificidade de ataque do sulfeto de sódio sobre a lignina e que este composto associado ao DDA pode vir a constituir alternativa bastante interessante para produção de celulose de boa 
qualidade, com economia de reagentes e energia e ainda com redução de impacto ambiental.

Como consequència da redução do número kappa e aumento da viscosidade, observa-se, uma vez que não houve alteração significativa no rendimento depurado, aumento das relações $\mathrm{RD} / \mathrm{K}$ e viscosidade/kappa à medida que se aumenta a sulfidez.

O efeito da sulfidez sobre a composição química da celulose pode ser observado pela análise dos resultados apresentados na tabela $37 . \mathrm{O}$ aumento da sulfidez promove uma maior proteção dos carboidratos como pode ser visto através do aumento do teor de alfa-celulose e gama-celulose. Observa-se ainda que o aumento da sulfidez leva a um aumento do teor de pentosanas na polpa obtida.

A adição de sulfeto de sódio em cozimentos soda-DDA, com 13\% de álcali ativo e fator $\mathrm{H} 522$, de cavacos de E. grandis aumenta a facilidade de refino da celulose, apresentando inclusive valores superiores à celulose kraft tradicional, conforme pode ser observado na figura 59. Este fator é de grande importância pois o refino é uma operação caracterizada pelo elevado consumo de energia.

O aumento da sulfidez promove uma redução da espessura da folha de celulose. Este comportamento pode ter como explicação o aumento do índice de colapso por razões que já foram discutidas anteriormente. O mesmo comportamento se observa para a peso específico aparente e volume especifico aparente, sendo que as celuloses dos tratamentos 17 a 21 (cozimentos com $0,5,10,15,20$ e $25 \%$ de sulfidez) apresentaram resultados superiores aos da celulose soda e kraft.

Na resistência à tração o efeito benéfico do sulfeto de sódio aplicado em cozimentos soda-DDA é bastante evidente. A adição de qualquer dosagem de sulfeto de sódio melhora sobremaneira a resistência da celulose à tração com valores superiores ao das celuloses kraft e soda. Já com relação ao esticamento as celuloses apresentaram resultados semelhantes entre si e entre as celuloses kraft e soda. 
O mesmo comportamento pode ser evidenciado com relação a resistência ao estouro, sendo que houve uma tendência ao aumento desta resistência à medida que se aumenta a sulfidez. Os resultados obtidos com a adição de sulfeto de sódio à cozimentos soda-DDA com relação a resistência ao estouro foram superiores à celulose kraft e soda.

A resistência ao ar foi bastante influenciada pelo aumento da sulfidez, apresentado uma tendência de aumento com o aumento da sulfidez. Os resultados das celuloses dos tratamentos 17 a 21 foram, de uma forma geral, superiores ao das celuloses kraft e soda.

A adição de sulfeto de sódio aos cozimentos soda-DDA não apresentou modificações substanciais nas características analisadas nos licores negros. 


\section{6 - Conciusões}

A análise dos resultados obtidos no presente estudo sobre a conversão do processo kraft em processo soda-DDA usando-se cavacos de Eucalyptus grandis permite as seguintes conclusões:

a) a adição de DDA ao processo soda leva à obtenção de celulose de Eucalyptus grandis com qualidade semelhante à celulose kraft.

b) associando-se aspectos técnicos aos aspectos econômicos e considerando-se as dosagens de DDA testadas nesta pesquisa, para produção de celulose soda-DDA de Eucaluptus grandis, 0,04\% de DDA sobre o peso absolutamente seco de madeira é a dosagem ideal, comparando-se com as dosagens testadas.

c) o emprego de $0,04 \%$ de DDA em cozimentos soda de E. grandis permite a redução da carga alcalina. Associando-se aos aspectos técnicos os aspectos econômicos envolvidos na redução da carga alcalina, o álcali ativo ótimo para produção de celulose soda- $0,04 \%$ de DDA de Eucalyptus grandis é 13\%. O emprego de carga alcalina de $13 \%$ (como álcali ativo) representa uma economia da ordem de $8 \%$ nos gastos com reagentes, comparando-se com a carga alcalina tradicionalmente usada para produção de celulose de Eucalyptus grandis.

d) a utilização de $0,04 \%$ de DDA em cozimentos soda, com $13 \%$ de álcali ativo, de Eucalyptus grandis permite a redução do fator $\mathrm{H}$ em cerca de $23 \%$ 
sem afetar sobremaneira a qualidade da celulose, especialmente no que diz respeito as suas caracteristicas físico-mecânicas.

e) Para as condições avaliadas neste trabalho, o emprego de sulfeto de sódio em níveis de sulfidez entre 10 a $15 \%$ permite a obtenção de celulose com características químicas e físico-mecânicas semelhantes ou superiores a celulose kraft tradicional.

f) em cozimentos kraft, a adição de DDA permite uma redução da ordem de $50 \%$ da carga de enxofre, redução da carga alcalina e do consumo de energia sem prejudicar a qualidade da celulose nem os rendimentos do processo.

g) o efeito dos compostos quinônicos (antraquinona e 1,4-dihidro-9,10dihidroxi antraceno) sobre o aumento da velocidade de deslignificação e melhoria da qualidade da celulose soda faz com que o processo soda volte a ser atraente, especialmente pela menor poluição atmosférica.

h) a aplicação de DDA em cozimentos kraft significa um avanço significativo na redução do impacto ambiental causado por fábricas de celulose.

i) o DDA pode ser caracterizado como um agente que confere flexibilidade ao processo, pois apresenta vários efeitos que podem ser individuaimente explorados, tais como aumento da qualidade da celulose, aumento do rendimento, redução da carga alcalina, aumento de produção, entre outros. 


\section{Bibliografia}

ASSUMPÇÃO, R. M. V.; LIMA, A. F.; PARK, S. W.; JORDÃO, M. C. S. \& YOJO, L. M. Propriedades de engenharia do licor negro sulfato de Eucalyptus spp. In: CONGRESSO LATINOAMERICANO DE CELULOSE Y PAPEL, 3, São Paulo, 1983. Anais, São Paulo, ABCP, 1983. 1v., p. 643-659. Congresso Latino-Americano de Celulose y Papel - São Paulo 1983.

BARBADILLO, P. \& POTTI, J. J. Estado actual de los processos de cocción alcalinos en presencia de antraquinona. An. INIA/Ser. Florestal/ n. 6. Madrid. 1982.

BARRICHELO, L. E. G. \& FOELKEL, C. E. B. Estudos para produção de celulose sulfato de seis espécies de eucalipto. In: SEMINÁRIO DE INTEGRAÇÃO FLORESTAINDÚSTRIA, Piracicaba, 1975. Anais, Piracicaba, ESALQ/IPEF, 1975. p. 5-33. 
BARRICHELO, L. E. G. \& BRITO, J. O. Variações nas características da madeira de Eucalyptus grandis e suas correlações com a produção de celulose. In: CONGRESSO ANUAL DA ABCP 10. São Paulo, 1977. Anais, São Paulo, $\mathrm{ABCP}, 1977$. p.41-46.

BARRICHELO, L. E. G. \& FOELKEL, C. E. B. Estudos para produção de celulose sulfato de seis espécies de eucalipto. In: SEMINÁRIO DE INTEGRAÇÃO FLORESTAINDÚSTRIA, Piracicaba, 1975. Anais, Piracicaba, ESALQ/IPEF, 1975. p. 34-68.

BARRICHELO, L. E. G.; FOELKEL, C. E. B. \& BRASIL, M. A. M. Métodos para determinação da densidade básica de cavacos para coniferas e folhosas. IPEF, Piracicaba (2/3):65-74. 1977.

BENTVELZEN, J. M.; MCKEAN, W. T. \& GRATZL, J. S. Methyl mercaptan, dimethyl disulfide, and sodium sulfide reactions during black licor oxidation. TAPPI Journal, Atlanta, 59(1):130-133, 1976.

BIERMANN, C. J. \& DUTTA, T. Kraft pulping of Douglas-fir with 1,4-dihydro-9,10-dihydroxi antracene. TAPPI Journal, Atlanta, 72(2):175-177. 1989. 
BLAIN, T. J. \& HOLTON, H. H. Economics of AQ pulping: The net value of increased production. Pulp \& Paper Canada, 84(6):58-63, 1983.

BUGAJER, S.; CAHEN, R.; LIMA, A. F. \& PINHO, M. R. R. Fator $\mathrm{H}$ - parâmetro válido para polpação de eucalipto? $O$ Papel, São Paulo, 40(3):35-49, 1979.

BUGAJER, S. Cinética das Reações do Processo de Polpação Sulfato de Eucalipto. São Paulo, 1984.90 p. (Tese de Doutorado - Escola Politécnica/USP).

BURAZIN, M. A. \& MCDONOUGH, T. J. Building a mechanistic model of kraft-anthraquinone pulping kinetics, TAPPI Journal, Atlanta, 3:165-169, 1988.

CASEY, J. P. Pulp and Paper - Chemistry and Chemical Technology. Vol I .3. ed. John Wiley and Sons. New York. 1980 .

CLARK, J. D'A. Pulp Technology and Treatment for paper. 2. ed. Miller Freeman Publications Inc. San Francisco. 1985. 878 p.

CUERVO, J. J. P. Influência de la antrahidroquinona como aditivo en cocciones alcalinas. In: CONGRESSO LATINO- 
AMERICANO DE CELULOSE Y PAPEL, 3, São Paulo, 1983. Anais, São Paulo, ABCP, 1983. 1v., p. 983-998. Congresso Latino-Americano de Celulose y Papel - São Paulo 1983.

D'ALMEIDA, M. L. O. Formação de compostos malcheirosos durante o processo de polpação sulfato. O Papel, São Paulo, $8: 65-68,1985$.

DIAS, R. L. V. Antraquinona, polissulfeto, oxigênio e hipoclorito fatores para a redução do consumo de energia no refino das polpas de eucalipto. In: CONGRESSO ANUAL DE CELULOSE E PAPEL DA ABCP, São Paulo, 1979. Trabalhos Publicados. São Paulo, 1979. p. 133-140.

DIMMEL, D. R. Electron transfer reactions in pulping systems (I): Theory and applicability to anthraquinone pulping. Journal of Wood Chemistry and Technology, 5(1):1-14, 1983.

DIMMEL, D. R.; PERRY, L. F.; PALASZ, P. D. \& CUM, H. Electron transfer reactions in pulping systems (II): Electrochemistry of anthraquinone/lignin model quinonemethides. Journal of Wood Chemistry and Technology, 5(1):15-36, 1985. 
EACHUS, S. W. Effect of soda-anthraquinone pulping conditions on holocelulose fibers, TAPPI Journal, Atlanta, 66(2):85-88, 1983.

EVANS, R. HENDERSON, V. T., NELSON, P. F. \& VANDERHOEK§ . The soda-AQ semichemical pulping processe. APPITA, 37(1):60-64, 1983.

FALK, L. E.; SARKO, P.; BERGER, M. I. \& DENCE, C. W. The effect of anthraquinone and anthrahydroquinone penetration on delignification in the soda pulping of norway spruce. Journal of Wood Chemistry and Technology, 4(1):35-59, 1984.

FOELKEL, C. E. B. Análise de licores kraft e soda. Viçosa, UFV/CENIBRA, 1977. 5p.

FOELKEL, C. E. B. Análises em licores negros. Viçosa UFV/CENIBRA, 1977. 6p.

FOELKEL, C. E. B. \& MILANEZ, A. F. O uso do boridreto de sódio como aditivo no cozimento kraft. O Papel, São Paulo, 8:69-72, 1980. 
FOELKEL, C. E. B.; HERRERA, J.; VESZ, J. B.; MORA, E.; BORSSATO, M. F. B. \& BUSNARDO, C. A. Controle das emissões de $\mathrm{H}_{2} \mathrm{~S}$ no forno de cal através de suas variáveis operacionais. In: CONGRESSO LATINO-AMERICANO DE CELULOSE Y PAPEL, 3, São Paulo, 1983. Anais, São Paulo, ABCP, 1983. 1v., p. 959-970. Congresso Latino-Americano de Celulose y Papel - São Paulo - 1983.

FOELKEL, C. E. B.; MORA. E. \& MENOCHELLI, S. Densidade básica: sua verdadeira utilidade como indice de qualidade da madeira de eucalipto para produção de celulose. In: CONGRESSO FLORESTAL BRASILEIRO, 6, Campos do Jordão, 1990. Anais, Campos do Jordão. p. 719-728.

GHOSH. K. L.; VENKATESH, V,; CHIN, W. J. \& GRATZL, J. S. Quinone additives in soda puiping of hardwoods. TAPPI Journal, Atlanta, 60(11):127-131, 1977.

GOMIDE, J. L. Reação dos carboidratos e dissolução dos constituintes da madeira, durante polpação alcalina. O Papel, São Paulo, 11:119-128, 1979. 
GOMIDE, J. L. Antraquinona - Um eficiente aditivo para a polpação alcalina de madeiras. Boletim Técnico $n^{\circ} 6$, Viçosa, $1980,27 \mathrm{p}$.

GOMIDE, J. L. \& OLIVEIRA, R. C. Eficiência da antraquinona na polpação alcalina do eucalipto. O Papel, São Paulo, 41(1):67$72,1980$.

GOMIDE, J. L.; VIVONE. R. R. \& MARQUES, A. R. Utiiiização do processo soda/antraquinona para produção de celulose branqueável de Eucalyptus spp. In: CONGRESSO ANUAL DE CELULOSE E PAPEL DA ABCP, 20, São Paulo, 1987. Trabalhos Publicados. São Paulo, 1987. p. 35-42.

HALDAR, R. \& BHATTACHARYA, P. K. Studies on kraft and soda-anthraquinone pulping of Indian mixed hardwwods. TAPPI Journal, Atlanta. 7(6):129-132, 1987.

HOLTON, H. H. Better cooking with anthraquinone. Pulp \& Paper International, 8:49-52, 1978.

HOLTON, H. H. AQ: unconventional thinking triumphs. TAPPI Journal, Atlanta. 64(6)8:11. 1981. 
IPT, Tecnologia de Fabricação da pasta celulósica, São Paulo, SENAI/IPT. 2a Edição, 1988.

KAWASAKI KASEI CHEMICALS LTD. Technical bulletin of quinone compounds for non-pollution delignification process. Research \& Development Dept. 1979. 38 p.

KAWASAKI KASEI CHEMICALS LTD. Modern feature of cooking with quinone additive. Japan Pulp \& Paper, 24(1):59-68, 1986.

KAWASAKI KASEI CHEMICALS LTD. New trend of cooking with quinone additive. Research \& Development Dept. 1990. $51 \mathrm{p}$.

KETTUNEN. J.: RELLAMMA. I. \& RUHANEN, M. A case studyconverting a kraft mil into a NSAQ mill. TAPPI Journal, Atlanta, 65(12):63-67, 1982.

KUBES, G. \& FLEMING, B. I. Viscosities of unbleached alkaline pulps - III Wood species. Journal of Wood Chemistry and Technology, 4(4):459-464, 1984. 
LAI, Y. Z. \& HE, P. Influence of sulfite on the effectiveness of anthraquinone in soda pulping. TAPPI Journal, Atlanta, 69(12):89-90, 1986.

LANDUCCI, L. L. \& RALPH, J. Antraquinone losses during alkaline pulping. Journal of Wood Chemistry and Technology, 4(2):149-161, 1984.

LIEBERGOTT, N. \& VAN LIEROP, B. Ozone delignification of black spruce and hardwood kraft, kraft-anthraquinone and sodaanthraquinone pulps. TAPPI Journal, Atlanta, 64(6):95-99. 1981.

LIMA. A. F.; TURQUETTI, A; BARRETO, F.; VENTURA, J. W. \& SILVEIRA, P. R. P. Antraquinona para redução das emissões de TRS: a experiência da Riocell. In: Anais do XXVI Congresso Anual de Celulose e Papel da ABTCP. 777-783. São Paulo. 1993.

MACLEOD, J. M. et al. Soda-anthraquinone-ethylenediamine pulping. TAPPI Journal, 64(6):77-80. 1981.

MACLEOD, J. M. \& CYR, N. Soda-AQ pulps from hardwoods physical properties and bleachability. Pulp \& Paper Canada, 84(4):29-32, 1983. 
MACLEOD, J. M. \& FLEMING, B. I. Delignification rates of alkaline-AQ processes. TAPPI Journal, Atlanta, 66(12):81-82, 1983.

MALACHOWSKI, P. S.; PONIATOWSKI, S. E. \& WALKINSAW, J. W. The effects of anthraquinone on the reaction rate of the kraft pulping of Northeastern white pine. TAPPI Journal, Atlanta, 6:207-209, 1983.

MARQUES, A. R.; FOELKEL, C. E. B. \& OLIVEIRA, L. M. Otimização da relação tempo-temperatura na produção de celulose kraft de Eucalyptus urophylla de origem hibrida. $O$ Papel, São Paulo, 12:161-171, 1979.

MIGLIORINI, A. J. Variação da densidade básica da madeira de Eucalyptus grandis W. Hill ex Maiden em função de diferentes niveis de produtividade da floresta. Piracicaba, 1986. 80 p. (Dissertação de Mestrado - ESALQ/USP).

NELSON, P. J. \& IRVINE, G. M. Tearing resistance in soda-AQ and kraft pulps. TAPPI Journal, Atlanta, 1:163-166, 1992. 
NOMURA, Y. Quinone additive cooking-sulphate pulping with addition of 1.4-dihydro-9,10-dihyrodroxi anthracene. Central research Lab. Honshu Paper Co. Ltd. tokyo, 1974.

OBST, J .R.; LANDUCCI, L. L. \& SANYER, N. Quinones in alkaline pulping - $\beta$-ether cleavage of free phenolic units in lignin. TAPPI Journal, Atlanta, 62(1):55-59, 1979.

PAICE, M. G. ; JURASEK, L. \& DESROCHERS, M. Simplified analysis of wood sugars. TAPPI Journal, Atlanta, 65(7):103$106,1982$.

PARTHASARATHY, V. R., SINGH, B., CHANDRA, S., SAKSENA, U. L. \& CHOWDRARY, L. N. Low sulphidityAQ pulping of hardwood and softwood mixtures (Eucalyptus tereticornis: Pinus roxburghii [70:30]). APPITA, 37(1):7072. 1983.

PENALBER, A. M. C. Estudos tecnológicos de polpação de Eucalyptus grandis, pelo processo sulfito neutro, com e sem adição de antraquinona. Viçosa, 1983. 114p. (Tese - Mestrado - UFV).

REDKO, B. V. P. \& SILVA, O. F. S. Observações sobre a concentração da lixivia negra do eucalipto. O Papel 40(1):55$58,1979$. 
SIDAWAY, S. The availability and use of eucalyptus puips. TAPPI Journal, Atlanta, 71(12):47-51, 1988.

SJÖSTRÖM, F. The behavior of wood polysaccharides during alkaline pulping processes. TAPPI Journal, Atlanta, 60(9):151154, 1977.

TAPPI TEST METHODS, Atlanta, TAPPI PRESS, 1977.

VAN ALLEN, N. J.; HATTON, J. V. \& GEE, W. Y. Effect of suifidity in alkaline pulping of white spruce with anthraquinone. TAPPI Journal, Atlanta, 64(6):51-53. 1981.

VIRKOLA, N. E. Would anthraquinone be economical in your pulp mill? TAPPI Journal, Atlanta, 64(6):51-53. 1981

WEHR, T. R. \& BARRICHELO, L. E. G. Cozimentos kraft com madeira de Eucalyptus grandis de diferentes densidades básicas e dimensões de cavacos. O Papel, São Paulo, 5:33-41. São Paulo. 1993.

WERTHEMANN, D. P. Sulfide and anthraquinone-like catalysts delignify wood via different chemical mechanisms in alkaline pulping, TAPPI Journal, Atlanta, 66(7):98-101, 1983. 
WRIGHT, L. J. \& FULLERTON, T. J. Redox catalysis of alkaline pulping by organometalic complexes, Journal of Wood Chemistry and Technology, 4(1):61-74, 1984.

ZVINAKEVICIUS, C.; SANTOS, F. P. \& FOELKEL, C. E. B. Características de licores pretos de eucalipto. In: CONGRESSO ANUAL DE CELULOSE E PAPEL DA ABCP, São Paulo, 1979. Trabalhos Publicados. São Paulo. 1979. p. 35-39. 


\section{ANEXO I}

Determinação Simultânea de Extrativos Totais, Lignina e Holocelulose Setor de Química, Celulose e Energia

Departamento de Ciências Florestais

Escola Superior de Agricultura "Luiz de Queiroz"

Universidade de São Paulo 


\section{Determinação Simultânea de Extrativos Totais, Lignina e Holocelulose}

1. Pesar o equivalente a $1 \mathrm{~g}$ absolutamente seco (a. s.) de serragem e transferir para saquinho de papel de filtro.

2. Colocar a amostra no corpo do extrator

3. Fazer a extração com álcool-tolueno (1:2) e álcool $96^{\circ} \mathrm{GL}$, durante 8 horas em cada solvente, deixando secar ao ar após cada extração.

4. Ligar o banho-maria e mantê-lo em ebulição.

5. Transferir toda serragem do saquinho para erlenmeyer de $250 \mathrm{ml}$.

6. Adicionar $100 \mathrm{inl}$ de água destilada e colocar o erlenmeyer no banho-maria (que já deverá estar fervendo) e cobri-lo com um copo de $50 \mathrm{ml}$.

7. Agitar suavemente a cada 15 minutos.

8. Após 3 horas filtrar através de cadinho de vidro sinterizado tarado, transferindo toda a serragem do erlenmeyer para o cadinho.

9. Lavar (descontinuamente) o cadinho com $250 \mathrm{ml}$ de água quente (quase fervendo).

10. Mantê-lo na estufa até peso constante (normalmente deixa-se de um dia para outro).

11. Retirar o cadinho da estufa, esperar esfriar em dessecador e pesar.

12. Calcular a percentagem de "Extrativos Totais" através da expressão:

$\% \mathrm{ET}=(1-$ peso a. s. serragem $) \times 100$

13. Utilizando-se a mesma serragem do cadinho transferi-la para copo de 50 ou $100 \mathrm{ml}$.

14. Resfriar o $\mathrm{H}_{2} \mathrm{SO}_{4} 72 \%$ a $10-12^{\circ} \mathrm{C}$. 
15. Adicionar $15 \mathrm{ml} \mathrm{de} \mathrm{H}_{2} \mathrm{SO}_{4} 72 \%$ para o copo e mantê-lo no banho de água a $18-20^{\circ} \mathrm{C}$.

16. Agitar e manter no banho durante 2 horas. Homogeneizar periodicamente e manter o bastão dentro do copo.

17. Após 2 horas transferir para erlenmeyer de 1 litro usando $560 \mathrm{ml}$ de água destilada.

18. Ferver durante 4 horas mantendo constante o nivel do erlenmeyer por adição periódica de água destilada.

19. Após 4 horas deixar a lignina sedimentar totalmente (equivale a deixar de um dia para outro).

20. Filtrar através de cadinho de vidro sinterizado tarado, fazendo uma fundo com papel de filtro, e transferir toda a lignina do erlenmeyer para o cadinho.

21. Lavar o erlenmeyer com água quente (quase fervendo).

22. Larvar (descontinuamente) a lignina do cadinho com $250 \mathrm{ml}$ de água quente (quase fervendo).

23. Mantê-lo na estufa até peso constante (normaimente deixa-se de um dia para o outro).

24. Retirar o cadinho da estufa, esperar esfriar em dessecador e pesar

25. Calcular a porcentagem de lignina através da expressão:

$\% \mathrm{~L}=$ Peso a. $\mathrm{s}$. de resíduo $\times 100$

26. Calcular a porcentagem de holocelulose através da expressão :

$$
\% \mathrm{H}=100-(\% \mathrm{ET}-\% \mathrm{~L})
$$




\section{ANEXO II}

Determinação de Lignina Residual na Holocelulose

Setor de Química, Celulose e Energia

Departamento de Ciências Florestais

Escola Superior de Agricultura "Luiz de Queiroz" Universidade de São Paulo 


\section{DETERMINAÇÃO DE LIGNINA RESIDUAL NA HOLOCELULOSE}

ml.

1. Pesar $1 \mathrm{~g}$ de holocelulose saida da estufa e transferir para copo de 50

2. Adicionar $20 \mathrm{ml} \mathrm{de} \mathrm{H}_{2} \mathrm{SO}_{4} 72 \%$ e manter em banho a $20^{\circ} \mathrm{C}$ durante $2 \mathrm{~h}$.

3. Transferir para balão de $1000 \mathrm{ml}$, adicionar $50 \mathrm{ml}$ de $\mathrm{H}_{2} \mathrm{SO}_{4} 4 \mathrm{~N}$ e completar o volume

4. Pipetar $100 \mathrm{ml}$ e transferir para erlenmeyer de $500 \mathrm{ml}$ e manter em ebulição por $4 \mathrm{~h}$.

5. Esfriar e transferir para balão de $250 \mathrm{ml}$ e completar o volume.

6. Após diluição conveniente (1:20,1:10 ou 1:5) ler a absorbância a $205 \eta$ m. Usar solução de $\mathrm{H}_{2} \mathrm{SO}_{4}$ dil $( \pm 0,1 \mathrm{~N})$ como branco.

7. Havendo resíduos no balão de $250 \mathrm{ml}$, filtrar através de papel de filtro com tara conhecida (T), lavar, secar na estufa e pesar (PT).

8. Cálculos:

(1) $\mathrm{L}_{1}=\frac{\mathrm{A}}{110} \cdot 2,5 . \mathrm{D}$, onde:

$\mathrm{L}_{1}=$ teor de lignina na solução original ( $\mathrm{g} /$ litro)

$\mathrm{A}=$ absorbância

$\mathrm{D}=$ diluição

(2) $\mathrm{L}_{2}=(\mathrm{PT}-\mathrm{T}) \cdot 10$

, onde:

$\mathrm{L}_{2}=$ teor de lignina na solução original ( $\mathrm{g} /$ litro)

$\mathrm{PT}=$ peso papel filtro + lignina

$\mathrm{T}=$ tara do papel filtro

(3) $\mathrm{L}_{\mathrm{H}}=\left(\mathrm{L}_{1}+\mathrm{L}_{2}\right) \cdot 100$

, onde:

$\mathrm{L}_{1}=$ percentagem de lignina na holocelulose 
ANEXO III

Distribuição percentual em peso por classes de comprimento, largura e espessura de cavacos de $E$. grandis 
Tabela 1. Distribuição percentual em peso por classes de comprimento de cavacos de Eucalyptus grandis

\begin{tabular}{|c|c|c|c|}
\hline compln & ptos & Portentapent & Porefthtopth \\
\hline $7,0-8,0$ & 0,40 & 0,25 & 0,25 \\
\hline $8,0-9,0$ & 0,30 & 0,18 & 0,43 \\
\hline $9,0-10,0$ & 1,20 & 0,74 & 1,17 \\
\hline $10,0-11,0$ & 2,00 & 1.23 & 2,40 \\
\hline $11,0-12,0$ & 4.50 & 2,76 & 5,16 \\
\hline $12.0-13.0$ & 6,80 & 4,18 & 9,34 \\
\hline $13.0-14,0$ & 13,70 & 8,42 & 17,75 \\
\hline $14,0-15,0$ & 18,90 & 11,61 & 29,36 \\
\hline $15,0-16,0$ & 20,00 & 12,29 & 41,65 \\
\hline $16,0-17,0$ & 23,70 & 14,56 & 56,20 \\
\hline $17,0-18,0$ & 18,90 & 11,61 & 67,81 \\
\hline $18.0-19,0$ & 13,00 & 7,99 & 75,80 \\
\hline $19,0-20,0$ & 7,40 & 4,55 & 80,34 \\
\hline $20,0-21,0$ & 8,50 & 5,22 & 85,57 \\
\hline $21,0-22,0$ & 7,10 & 4,36 & 89.93 \\
\hline $22,0-23,0$ & 4,00 & 2,46 & 92,38 \\
\hline $23.0-24,0$ & 3.40 & 2,09 & 94.47 \\
\hline $24,0-25,0$ & 2,60 & 1,16 & 96,07 \\
\hline $25,0-26,0$ & 1,50 & 0.92 & 96.99 \\
\hline $26,0-27,0$ & 1,00 & 0,61 & 97,60 \\
\hline $27,0-28,0$ & 1,50 & 0,92 & 98,53 \\
\hline $28,0-29,0$ & 1,00 & 0,61 & 99,14 \\
\hline $29,0-30,0$ & 1,20 & 0.74 & 99,88 \\
\hline $30,0-31,0$ & 0,30 & 0,18 & 100,00 \\
\hline
\end{tabular}


Tabela 2. Distribuição percentual em peso por classes de largura de cavacos de Eucalyptus grandis

\begin{tabular}{|c|c|c|c|}
\hline Uassors & (t) & Poretertarent & Porcentagentou \\
\hline $4,5-5,0$ & 0,6 & 0,38 & 0,38 \\
\hline $5,0-5,5$ & 2,2 & 1,39 & 1,77 \\
\hline $5,5-6,0$ & 2,9 & 1,83 & 3,60 \\
\hline $6.0-6,5$ & 4,5 & 2.84 & 6,44 \\
\hline $6,5-7,0$ & 6.4 & 4,04 & 10,48 \\
\hline $7.0-7.5$ & 5.7 & 3,60 & 14,08 \\
\hline $7,5-8,0$ & 6,2 & 3,91 & 17,99 \\
\hline $8,0-8,5$ & 6,0 & 3.79 & 21.78 \\
\hline $8,5-9,0$ & 6,6 & 4,15 & 25,95 \\
\hline $9,0-9,5$ & 7,0 & 4,42 & 30,37 \\
\hline $9,5-10,0$ & 6.0 & 3,79 & 34,15 \\
\hline $10,0-10,5$ & 8,2 & 5,18 & 39,33 \\
\hline $10,5-11,0$ & 5.9 & 3,72 & 43.06 \\
\hline $11,5-12,0$ & 5,4 & 3,41 & 50,57 \\
\hline $12,0-12,5$ & 6,3 & 3,98 & 54,55 \\
\hline $12.5-13,0$ & 5,8 & 3.66 & 58,21 \\
\hline $13,0-13,5$ & 6.9 & 4,36 & 62,56 \\
\hline $14,0-14,5$ & 4.0 & 2,53 & 67.49 \\
\hline $14,5-15,0$ & 6.2 & 3,91 & 71,40 \\
\hline $15,0-15,5$ & 2,8 & 1.77 & 73,17 \\
\hline $15,5-16,0$ & 2.8 & 1,77 & 74,94 \\
\hline $16,0-16,5$ & 4,2 & 2,65 & 77,59 \\
\hline $16,5-17,0$ & 3,5 & 2.21 & 79,80 \\
\hline $17,0-17,5$ & 2,0 & 1,26 & 81,06 \\
\hline $17,5-18,0$ & 1,3 & 0.82 & 81,88 \\
\hline $18,0-18,5$ & 3,6 & 2,27 & 84,15 \\
\hline $18,5-19,0$ & 2.5 & 1,58 & 85,73 \\
\hline $19,0-19,5$ & 1,0 & 0,63 & 86,36 \\
\hline $19.5-20.0$ & 1.8 & 1,14 & 87,50 \\
\hline $20.0-20.5$ & 1,4 & 0.88 & 88,38 \\
\hline
\end{tabular}


Tabela 2. Continuação

\begin{tabular}{|c|c|c|c|}
\hline 'astert & (est & Porentopers & 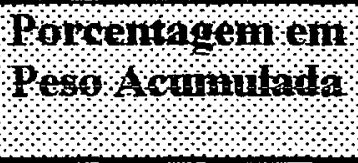 \\
\hline $20.5-21,0$ & 1.7 & 1,07 & 89.46 \\
\hline $21,0-21,5$ & 3.8 & 2,40 & 91,86 \\
\hline $21,5-22,0$ & 1,7 & 1,07 & 82,83 \\
\hline $22,0-22,5$ & 1,4 & 0,88 & 93.81 \\
\hline $22,5-23,0$ & 2,0 & 1,26 & 95,08 \\
\hline $23,0-23,5$ & 1,0 & 0,63 & 95,71 \\
\hline $23,5-24,0$ & 1,4 & 0.88 & 96.59 \\
\hline $24,0-24,5$ & 0,2 & 0,13 & 96,72 \\
\hline $24,5-25,0$ & 0.0 & 0,00 & 96.72 \\
\hline $25,0-25,5$ & 0.0 & 0,00 & 96.72 \\
\hline $25,5-26,0$ & 0,0 & 0,00 & 96,72 \\
\hline $26,0-26,5$ & 0,3 & 0.19 & 96,91 \\
\hline $26,5-27,0$ & 1,6 & 1,01 & 97,92 \\
\hline $27,0-27,5$ & 1,0 & 0,63 & 98,55 \\
\hline $27,5-28,0$ & 0,0 & 0,00 & 98,55 \\
\hline $28,0-28,5$ & 0,0 & 0,00 & 98,55 \\
\hline $28,5-29,0$ & 0,0 & 0,00 & 98,55 \\
\hline $29,0-29,5$ & 0,0 & 0,00 & 98.55 \\
\hline $29,5-30,0$ & 0,0 & 0,00 & 98,55 \\
\hline $30,0-30,5$ & 0,0 & 0,00 & 98,55 \\
\hline $30,5-31,0$ & 1.7 & 1,07 & 99.62 \\
\hline $31,0-31,5$ & 0,0 & 0.00 & 99.62 \\
\hline $31.5-32.0$ & 0.6 & 0,38 & 100,00 \\
\hline
\end{tabular}


Tabela 3. Distribuição percentual em peso por classes de espessura de cavacos de Eucalyptus grandis

\begin{tabular}{|c|c|c|c|}
\hline Hoppstop & pest & Porephtopt & Ponontathon an \\
\hline $1.5-2.0$ & 29.2 & 19.64 & 19.64 \\
\hline $2.0-2.5$ & 43.4 & 29.19 & 48.82 \\
\hline $2.5-3.0$ & 34.0 & 22.86 & 71.69 \\
\hline $3.0-3.5$ & 24.3 & 16.34 & 88.03 \\
\hline $3.5-4.0$ & 14.2 & 9.55 & 97.58 \\
\hline $4.0-4.5$ & 3.6 & 2.42 & 100.00 \\
\hline
\end{tabular}

